\title{
EFEITO DA EXPLORAÇÃO DA MADEIRA E DE DIFERENTES INTENSIDADES DE DESBASTES SOBRE A DINÂMICA DA VEGETAÇÃO DE UMA ÁREA DE 136ha NA FLORESTA NACIONAL DO TAPAJÓS
}

\author{
Lia CUNHA DE OLIVEIRA
}

Tese apresentada à Escola Superior de Agricultura "Luiz de Queiroz", Universidade de São Paulo, para obtenção do título de Doutor em Recursos Florestais, com opção em Silvicultura e Manejo. 


\title{
EFEITO DA EXPLORAÇÃO DA MADEIRA E DE DIFERENTES INTENSIDADES DE DESBASTES SOBRE A DINÂMICA DA VEGETAÇÃO DE UMA ÁREA DE 136ha NA FLORESTA NACIONAL DO TAPAJÓS
}

\author{
LIA CUNHA DE OLIVEIRA \\ Engenheiro Florestal
}

\author{
Orientador: Prof. Dr. HILTON THADEU ZARATE DO COUTO
}

\begin{abstract}
Tese apresentada à Escola Superior de Agricultura "Luiz de Queiroz", Universidade de São Paulo, para obtenção do título de Doutor em Recursos Florestais, com opção em Silvicultura e Manejo.
\end{abstract}

P I R A C I C A B A

Estado de São Paulo - Brasil

Fevereiro - 2005 
Dados Internacionais de Catalogação na Publicação (CIP) DIVISÃO DE BIBLIOTECA E DOCUMENTAÇÃO - ESALQ/USP

\section{Oliveira, Lia Cunha de}

Efeito da exploração da madeira e de diferentes intensidades de desbastes sobre a dinâmica da vegetação de uma área de 136 ha na floresta nacional do Tapajós / Lia Cunha de Oliveira. - - Piracicaba, 2005.

183 p. : il.

Tese (Doutorado) - - Escola Superior de Agricultura Luiz de Queiroz, 2005.

Bibliografia.

1. Comunidade vegetal 2. Crescimento vegetal 3. Dendrometria 4. Desbaste 5. Exploração florestal 6. Floresta 7. Madeira 8. Manejo florestal I. Título

CDD 634.98 
Dedico aos que cercam minha vida de amor e carinho: Ao meu esposo Marcelo Melo Ao meu filho Daniel Aos meus pais Lúcio Oliveira e Ocirema 


\section{AGRADECIMENTOS}

- Ao Prof. Dr. Hilton Thadeu Zarate do Couto pela orientação deste trabalho e pelo apoio e auxílio nas análises de dados;

- À Coordenação do Curso de Pós-Graduação em Recursos Florestais da Escola Superior de Agricultura “Luiz de Queiroz”, pela oportunidade concedida;

- À Coordenação de Aperfeiçoamento de Pessoal de Nível Superior (CAPES) pela concessão da bolsa de estudos durante o período do curso;

- A Embrapa Amazônia Oriental, através do projeto "Determinação de intensidades de exploração e avaliação de alternativas silviculturais para o manejo de florestas naturais da Amazônia", pelo apoio logístico e financeiro e por ceder o banco de dados;

- A Fundação de Amparo a Pesquisa do Estado de São Paulo (FAPESP) pelo auxílio financeiro durante as coletas de dados;

- A Universidade Federal Rural da Amazônia (UFRA) pelo apoio financeiro e institucional;

- Aos Pesquisadores José Natalino Macedo Silva, João Olegário P. de Carvalho e Paulo Contente de Barros pelas revisões no texto e comentários relevantes;

- Aos identificadores botânicos Erly e Nilson pelo precioso auxílio na identificação de material botânico em campo; e aos estagiários Breno, Sergio e Gustavo pela ajuda durante a coleta de dados no Tapajós;

- A todos os amigos de Piracicaba, que com seu apoio e amizade ajudaram a abrandar os momentos de solidão e saudade da família e do Pará. 


\section{SUMÁRIO}

RESUMO

Página

SUMMARY

xi

1 INTRODUÇÃO .

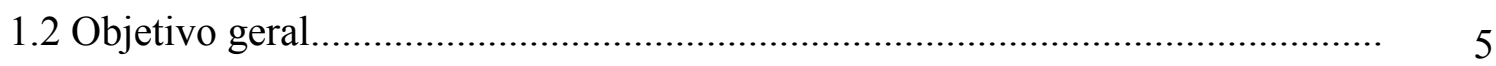

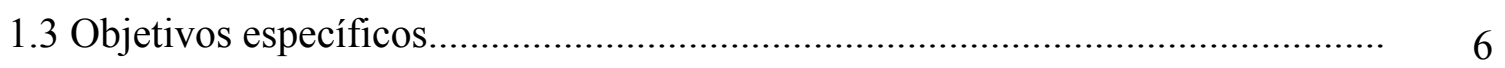

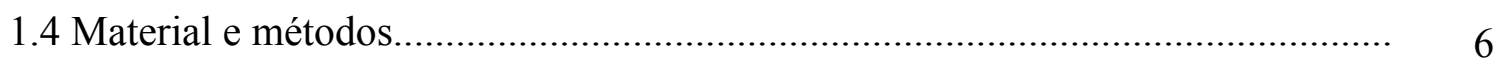

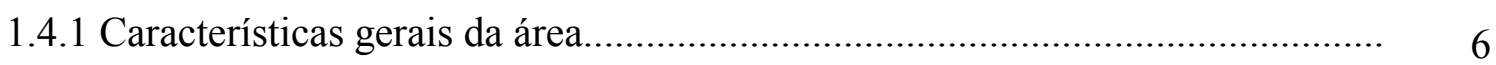

1.4.2 Histórico da área estudada................................................................... 8

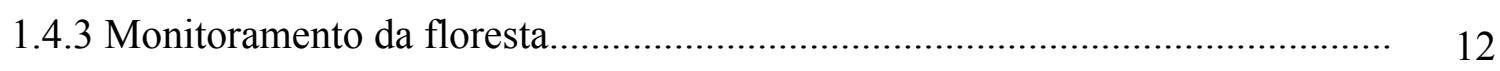

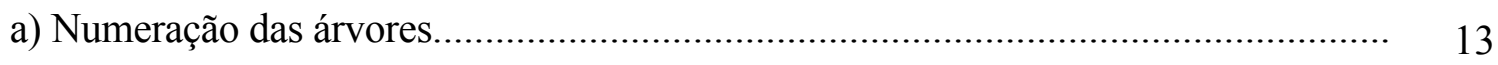

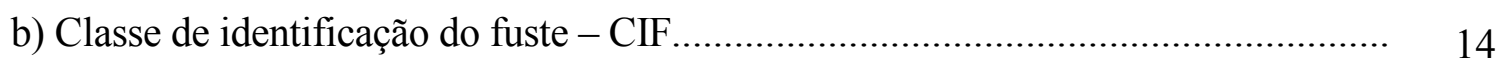

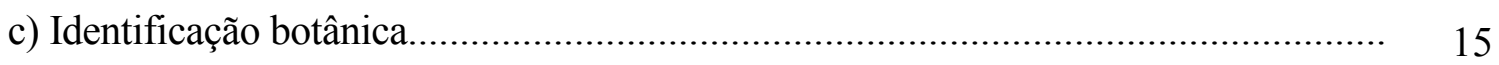

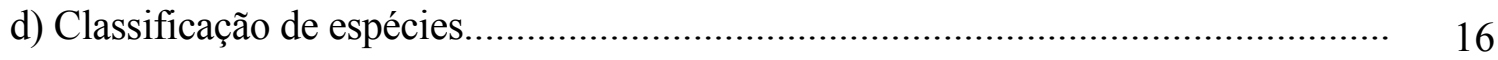

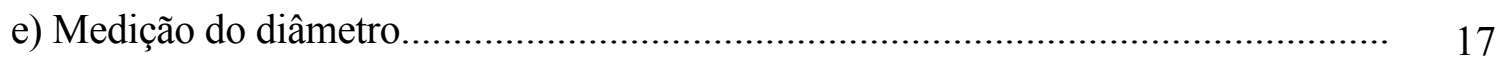

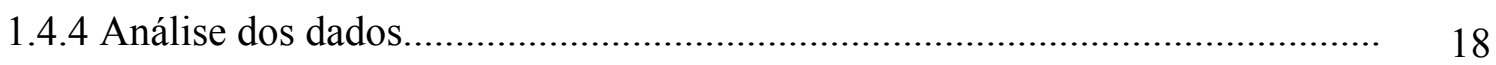

2 EXPLORAÇÃO FLORESTAL E EFICIÊNCIA DOS TRATAMENTOS SILVICULTURAIS REALIZADOS EM UMA ÁREA DE 136ha NA 20 FLORESTA NACIONAL DO TAPAJÓS, BELTERRA - PARÁ

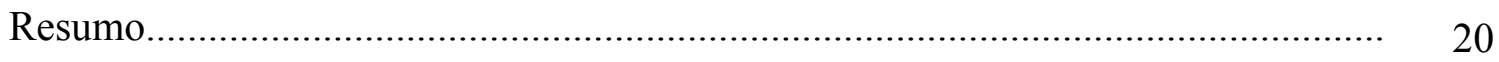

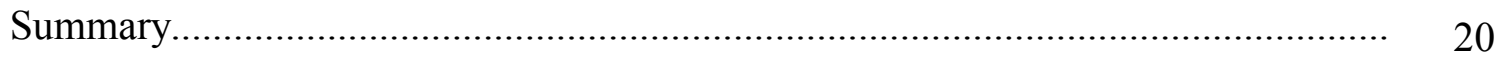

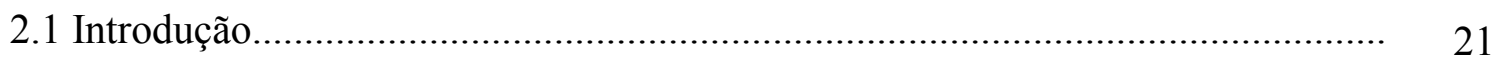

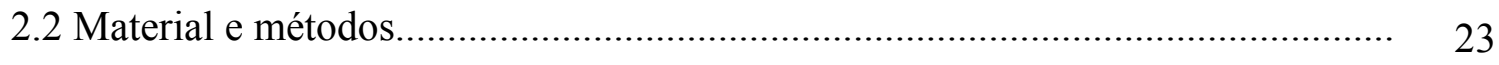

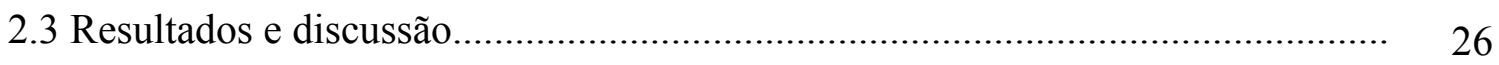

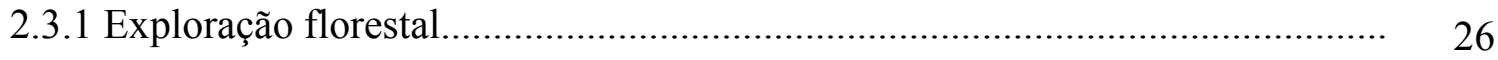

2.3.1.1 Danos causados a vegetação remanescente.............................................. 28

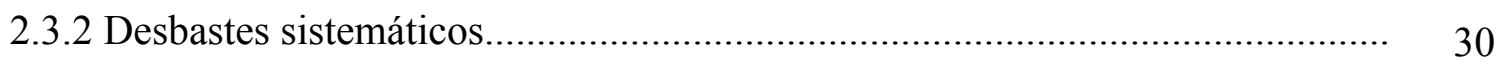

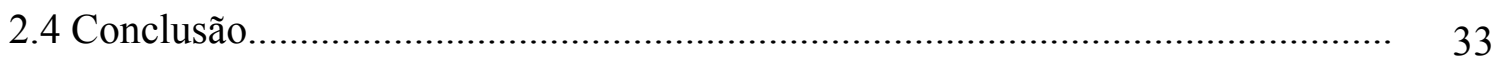


3 EFEITO DA EXPLORAÇÃO DE MADEIRA E TRATAMENTOS SILVICULTURAIS NA COMPOSIÇÃO FLORÍSTICA E DIVERSIDADE DE ESPÉCIES EM UMA ÁREA DE 136ha NA FLORESTA NACIONAL DO TAPAJÓS, BELTERRA-PARÁ

Resumo

Summary

3.1 Introdução.

3.2 Material e métodos.

3.3 Resultados.

3.3.1 Comparação da riqueza e diversidade florística entre os tratamentos aplicados.

3.3.1.1 Tratamento T1: Exploração de espécies comerciais madeireiras com DAP $\geq 45 \mathrm{~cm}(2,5 \mathrm{ha})$

3.3.1.2 Tratamento T2: Exploração de espécies comerciais madeireiras com DAP $\geq 55 \mathrm{~cm}+$ desbaste de espécies não comerciais totalizando $20 \%$ de redução da área basal original (1,75ha).

3.3.1.3 Tratamento T3: Exploração de espécies comerciais madeireiras com DAP $\geq 55 \mathrm{~cm}+$ desbaste de espécies não comerciais totalizando $40 \%$ de redução da área basal original (3,0ha).

3.3.1.4 Tratamento T4: Exploração de espécies comerciais madeireiras com DAP $\geq 55 \mathrm{~cm}+$ desbaste de espécies não comerciais totalizando $60 \%$ de redução da área basal original (1,5ha).

3.3.1.5 Tratamento T0: Testemunha, área sem intervenção (1,5ha).

3.4 Discussão

3.5 Conclusão

4 EFEITO DA EXPLORAÇÃO DE MADEIRA E TRATAMENTOS SILVICULTURAIS SOBRE A ESTRUTURA HORIZONTAL DE UMA ÁREA DE 136ha NA FLORESTA NACIONAL DO TAPAJÓS, BELTERRAPARÁ.

Resumo.

Summary.

4.1 Introdução.

4.2 Material e métodos.

4.3 Resultados 
4.3.1 Número de árvores/ha

4.3.1.1 Tratamento T1: Exploração de espécies comerciais madeireiras com DAP $\geq 45 \mathrm{~cm}(2,5 \mathrm{ha})$.

4.3.1.2 Tratamento T2: Exploração de espécies comerciais madeireiras com DAP $\geq 55 \mathrm{~cm}+$ desbaste de espécies não comerciais totalizando $20 \%$ de redução da área basal original (1,75ha)....

4.3.1.3 Tratamento T3: Exploração de espécies comerciais madeireiras com DAP $\geq 55 \mathrm{~cm}+$ desbaste de espécies não comerciais totalizando $40 \%$ de redução da área basal original (3,0ha).

4.3.1.4 Tratamento T4: Exploração de espécies comerciais madeireiras com DAP $\geq 55 \mathrm{~cm}+$ desbaste de espécies não comerciais totalizando $60 \%$ de redução da área basal original (1,5ha).

4.3.1.5 Tratamento T0: Testemunha, área sem intervenção (1,5ha)....

4.3.2 Área basal.

4.3.2.1 Tratamento T1: Exploração de espécies comerciais madeireiras com DAP $\geq 45 \mathrm{~cm}(2,5 \mathrm{ha})$

4.3.2.2 Tratamento T2: Exploração de espécies comerciais madeireiras com DAP $\geq 55 \mathrm{~cm}+$ desbastes de espécies não comerciais totalizando $20 \%$ de redução da área basal original (1,75ha)

4.3.2.3 Tratamento T3: Exploração de espécies comerciais madeireiras com DAP $\geq 55 \mathrm{~cm}+$ desbaste de espécies não comerciais totalizando $40 \%$ de redução da área basal original (3,0ha).

4.3.2.4 Tratamento T4: Exploração de espécies comerciais madeireiras com DAP $\geq 55 \mathrm{~cm}+$ desbaste de espécies não comerciais totalizando $60 \%$ de redução da área basal original (1,5ha).

4.3.2.5 Tratamento T0: Testemunha, área sem intervenção (1,5ha).

4.3.3 Volume.

4.4 Discussão.

4.5 Conclusão

5 FEITO DA EXPLORAÇÃO DE MADEIRA E TRATAMENTOS SILVICULTURAIS SOBRE A DINÂMICA DA VAGETAÇÃO DE UMA ÁREA DE 136 ha NA FLORESTA NACIONAL DO TAPAJÓS, BELTERRA-PARÁ

Resumo.

Summary 


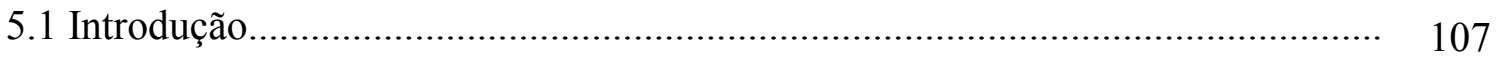

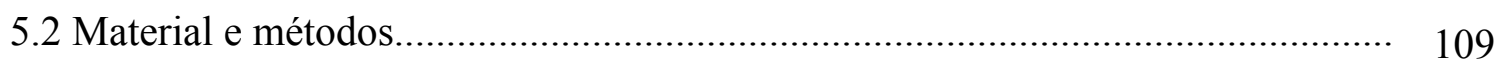

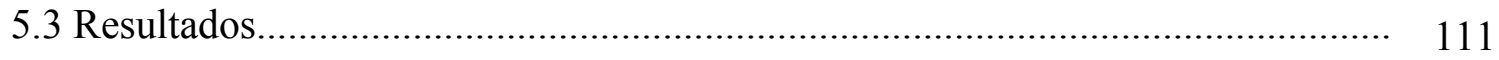

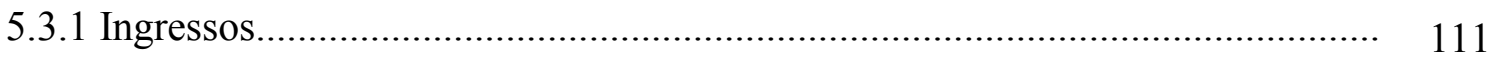

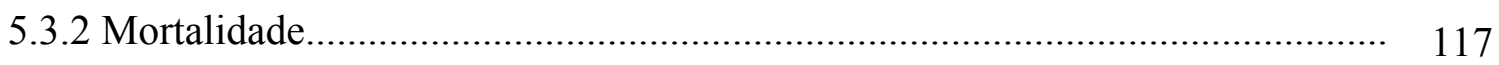

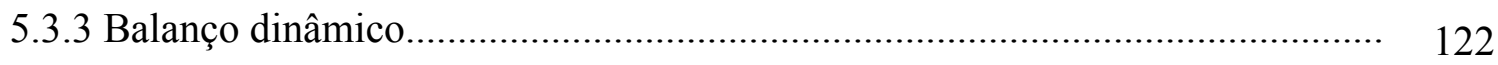

5.3.4 Crescimento em diâmetro......................................................................... 123

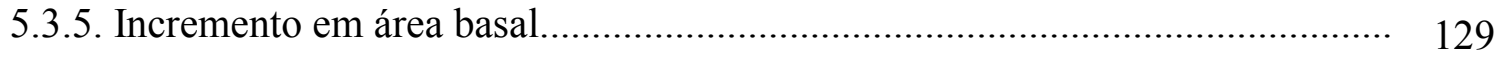

5.3.6. Incremento em volume............................................................................ 131

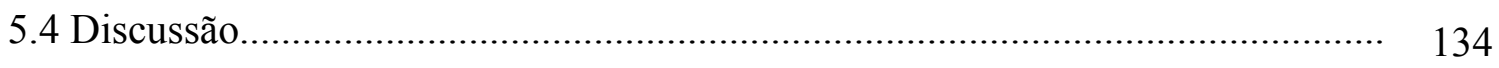

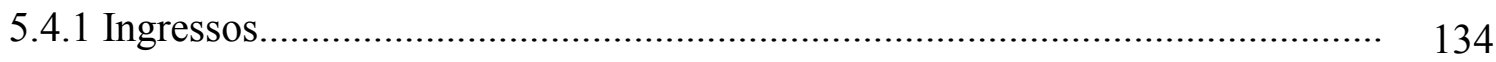

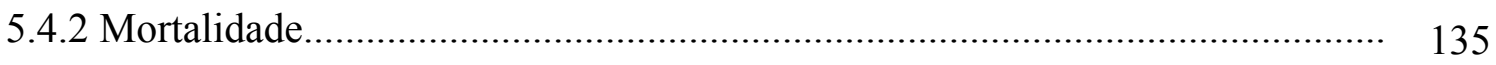

5.4.3 Balanço entre ingresso e mortalidade............................................................ 138

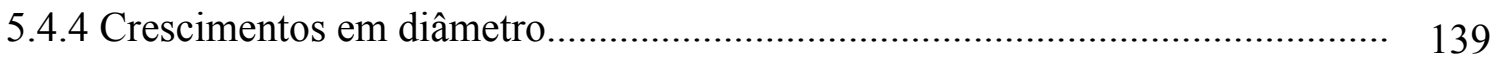

5.4.5 Crescimento em área basal e volume ............................................................ 141

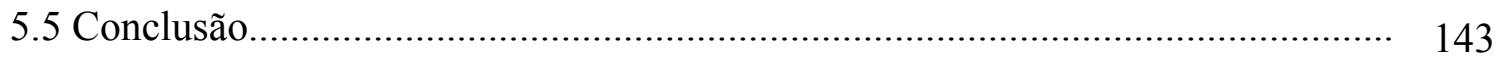

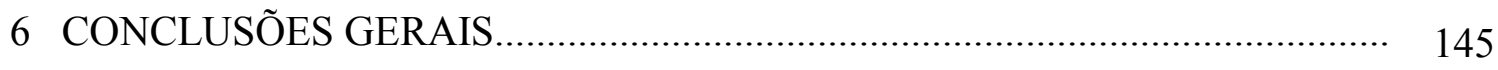

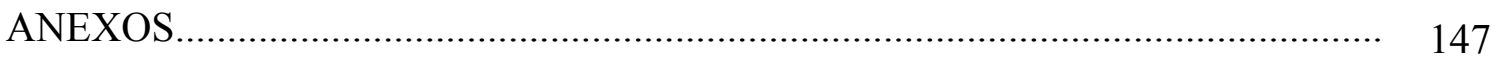

REFERÊNCIAS BIBLIOGRÁFICAS.......................................................... 174 


\title{
EFEITO DA EXPLORAÇÃO DA MADEIRA E DE DIFERENTES INTENSIDADES DE DESBASTES SOBRE A DINÂMICA DA VEGETAÇÃO DE UMA ÁREA DE 136ha NA FLORESTA NACIONAL DO TAPAJÓS
}

\author{
Autor: LIA CUNHA DE OLIVEIRA \\ Orientador: Prof. Dr. HILTON THADEU Z. DO COUTO
}

\section{RESUMO}

O objetivo deste trabalho foi analisar o efeito de quatro intensidades de redução da área basal, representadas pela exploração e desbastes sistemáticos, na composição florística, diversidade, estrutura e dinâmica do extrato arbóreo, durante um período de 22 anos. O experimento se localiza na Floresta Nacional do Tapajós, município de Belterra, Pará, a altura do km 114 da Rodovia Santarém-Cuiabá. O delineamento estatístico utilizado foi Blocos ao Acaso com 4 repetições onde foram testados os seguintes tratamentos: T0: controle, representado pela floresta não explorada; T1: Abate de árvores comerciais com DAP $\geq 45 \mathrm{~cm}$, sem nenhuma intervenção posterior; T2: Abate de árvores comerciais DAP $\geq 55 \mathrm{~cm}+$ desbaste de espécies não comerciais para reduzir a área basal em $20 \%$ da original; $\mathrm{T} 3$ : Abate de árvores comerciais DAP $\geq 55 \mathrm{~cm}+$ desbaste de espécies não comerciais para reduzir a área basal em $40 \%$ da original; T4: Abate de árvores comerciais DAP $\geq 55 \mathrm{~cm}+$ desbaste de espécies não comerciais para reduzir a área basal em $60 \%$ da original. Cada bloco possui uma área de 36ha, sendo 9ha por tratamento. Em cada tratamento foram instaladas ao acaso 12 parcelas permanentes (PP) de $0,25 \mathrm{ha}$, onde foram medidas todas árvores com diâmetro $\geq 5,0 \mathrm{~cm}$. A exploração de madeira foi realizada em 1982 e os desbastes foram iniciados em 1993 e concluídos em 
1994, com a finalidade de reduzir a área basal do povoamento e, com isso, propiciar a maior penetração de luz, favorecendo o desenvolvimento e estabelecimento das espécies comerciais. As medições das PP na área explorada foram realizadas 1 ano antes da exploração (1981), e após a exploração nos anos de 1983, 1987, 1989, 1995 e 2003 . Para a área testemunha foram realizadas 5 medições: 1983, 1987, 1989, 1995 e 2003. Os resultados mostraram que, 21 anos depois da exploração e nove após os desbastes, todos os tratamentos, exceto o testemunha, apresentaram aumento no número de espécies, o que indica o efeito positivo das intervenções. Cinco anos após a exploração, todos os tratamentos apresentaram número de árvores superior ao encontrado antes da intervenção, inclusive considerando somente as espécies de valor comercial. Porém, a área basal e o volume apresentaram recuperação mais lenta, ocorrendo de forma mais efetiva nas primeiras classes de diâmetro $(5-45 \mathrm{~cm})$. Nas classes acima de $45 \mathrm{~cm}$, que foram as mais afetadas pela extração de madeira, a área basal, 21 anos após a exploração, ainda está, em média, 30\% abaixo do valor original. As intervenções também alteraram a dinâmica da floresta, elevando as taxas de mortalidade, estimulando o aumento no número de ingressos e a aceleração nas taxas crescimento das árvores remanescentes. O tratamento $\mathrm{T} 3$ foi considerado o mais adequado porque induziu ao maior aumento na riqueza florística e favoreceu várias espécies de valor comercial madeireiro que aumentaram sua participação na abundância e área basal no povoamento. Esse tratamento também mostrou a maior taxa de recuperação da área basal comercial (aproximadamente 90\%), e as maiores taxas de incremento em AB e volume, no período após a aplicação do desbaste. 


\title{
EFEITO DA EXPLORAÇÃO DA MADEIRA E DE DIFERENTES INTENSIDADES DE DESBASTES SOBRE A DINÂMICA DA VEGETAÇÃO DE UMA ÁREA DE 136ha NA FLORESTA NACIONAL DO TAPAJÓS
}

\author{
Author: LIA CUNHA DE OLIVEIRA \\ Adviser: Prof. Dr. HILTON THADEU Z. DO COUTO
}

\section{SUMMARY}

The objective of this work was to analyze the effect of four intensities of basal area reduction, represented by systematic logging and liberation thinning, on the floristic composition, diversity, structure and dynamics of arboreal extract, over a period of 22 years. The experiment is located in the Tapajós National Forest, municipality of Belterra, Pará, at km 114 of the Santarém-Cuiabá Highway. The statistical delineation employed was Random Blocks with 4 repetitions, in which the following treatments were tested: T0: control, represented by unlogged forest; T1: Felling of commercial trees with $\mathrm{DBH} \geq 45 \mathrm{~cm}$, with no posterior intervention; T2: Felling of commercial trees DBH $\geq 55 \mathrm{~cm}+$ thinning of non-commercial species to reduce the original basal area by $20 \%$; T3: Felling of commercial trees $\mathrm{DBH} \geq 55 \mathrm{~cm}+$ thinning of non-commercial species to reduce the original basal area by $40 \%$; T4: Felling of commercial trees DBH $\geq 55 \mathrm{~cm}+$ thinning of non-commercial species to reduce the original basal area by $60 \%$. Each block measured 36ha, with 9ha for each treatment. In each treatment $120,25 \mathrm{ha}$ permanent parcels (PP) were randomly installed, in which all trees with diameter $\geq$ $5,0 \mathrm{~cm}$ were measured. Logging was carried out in 1982 and the thinning treatments were begun in 1993 and concluded in 1994, with the purpose of reducing the basal area of the. 
population and, so provide greater light penetration, favoring the development and establishment of commercial species The measurements of PP in the harvested area were carried out 1 year before logging (1981), and after logging in the years 1983, 1987, 1989, 1995 and 2003. For the unlogged area 5 measurements were done: 1983, 1987, 1989, 1995 and 2003. The results showed that, 21 years after logging nine after the thinnings, all of the treatments, except the witness, showed an increase in the number of species, which indicates the positive effect of the interventions. Five years after logging, all the treatments showed a greater number of trees than what was found before the intervention, including a count only of species with commercial value. However, the basal area and volume showed a lower recovery, occurring most effectively in the first diameter classes $(5-45 \mathrm{~cm})$. In the classes above $45 \mathrm{~cm}$, which were the ones most affected by timber harvesting, the basal area, 21 years after logging, is still on average $30 \%$ below the original value. The interventions also alter forest dynamics, increasing mortality rates, stimulating an increase in the number of ingresses and acceleration in growth of remaining trees. Treatment T3 was considered the most adequate one, because it induced a greater increase in floristic diversity and favored several species with commercially valuable timber, which increased their participation in terms of abundance and basal area in the population. This treatment also showed the highest recovery rate for the commercial basal area (approximately $90 \%$ ), and the greatest increments in $\mathrm{AB}$ and volume, in the period after application of the thinnings. 


\section{INTRODUÇÃO}

As florestas tropicais estão localizadas entre as latitudes $10^{\circ} \mathrm{N}$ e $10^{\circ} \mathrm{S}$ e representam aproximadamente $25 \%$ da superfície total de florestas do mundo, estando presentes em cerca de 70 países, sendo 23 nas Américas, 16 na Ásia e 31 na África (Ofosu-Asiedu, 1997). Estima-se que possuam cerca de 50\% da biodiversidade do planeta, numa área que cobre apenas 7\% das áreas continentais (Salati et al., 1998).

A América do Sul tem cerca de 885 milhões de hectares de florestas que correspondem a $54 \%$ das florestas tropicais úmidas do planeta (FAO, 2001). Dentro dela, a Amazônia é a região que possui a maior reserva contínua, cobrindo uma área de aproximadamente 250 milhões de hectares onde estão contidos mais de $50 \%$ do estoque de madeira dura tropical do mundo (Higuchi et al., 2000). Isso representa um volume estimado de 60 bilhões de metros cúbicos de madeira em tora, cujo valor econômico potencial pode alcançar 4 trilhões de reais em madeira serrada (Barros \& Veríssimo, 1996) .

A exploração comercial dessa riqueza começou ha aproximadamente três séculos, porém o volume de madeira extraído era pequeno e estava restrito às florestas de várzea ao longo dos principais rios da Amazônia. Com a abertura de estradas estratégicas de acesso (Belém-Brasília, Santarém-Cuiabá e Transamazônica) e o esgotamento dos estoques de madeira na região sul do Brasil, a exploração madeireira na Amazônia tornou-se uma atividade de grande importância sócio-econômica para a região.

No início dos anos 90, cerca de $75 \%$ da madeira consumida no Brasil provinha da floresta Amazônica (Barros \& Veríssimo, 1996). Em 1997, a produção de madeira em toras na Amazônia, foi de aproximadamente 28 milhões de metros cúbicos, o que 
equivale a $85 \%$ da produção do país (Smeraldi \& Veríssimo, 1999). No Pará, a exploração de madeira em 1990, estava em segundo lugar na geração de divisas para o Estado, sendo ultrapassada somente pelos minérios (Yared, 1990), e em 1997 o setor florestal contribuiu com 15\% do Produto Interno Bruto (PIB) com projeções de crescimento em torno de 10\% ao ano (Stone, 1997). Em 2001, as madeireiras instaladas no Pará extraíram 10,8 milhões de metros cúbicos de madeira em tora. O desdobro dessas toras resultou em uma produção de aproximadamente 4,0 milhões de metros cúbicos de madeira processada (Veríssimo et al., 2002)

Apesar de gerar todos esses dividendos, a exploração florestal na Amazônia brasileira se faz em bases tipicamente extrativistas. A retirada da madeira, tanto em terra firme como na várzea, é realizada em intensidades variáveis, que vão desde as bem leves (10-20 m3.ha $\left.{ }^{-1}\right)$ em áreas pouco povoadas, até extrações pesadas $\left(50-100 \mathrm{~m} 3 \cdot \mathrm{ha}^{-1}\right) \mathrm{em}$ regiões mais densamente habitadas (Veríssimo et al., 1992; Silva \& Uhl, 1992). De maneira geral, a exploração da madeira é feita de forma predatória, causando grandes impactos ambientais e econômicos às florestas remanescentes e sem qualquer preocupação com a sustentabilidade da produção futura.

No Pará, as madeireiras extraem de quatro a oito árvores por hectare (Holdswoth \& Uhl, 1997; Johns et al., 1996), reduzem a cobertura vegetal em 50\% ou mais (Uhl \& Vieira, 1989), afetam gravemente os solos (Johns et al., 1996; Holmes, et al., 2002) e danificam em torno de 25 árvores, com DAP maior que $10 \mathrm{~cm}$, para cada árvore extraída durante as operações de exploração (Johns et al., 1998).

Entretanto, a literatura nos mostra vários casos onde o planejamento das operações de exploração utilizando corte de cipós, mapeamento das árvores a serem extraídas, técnicas de derruba direcional, planejamento de trilhas de arraste e pátios de estocagem, entre outros, reduzem consideravelmente os danos causados pela extração madeireira (Vidal et al., 1997; Gerwing et al., 1996; Holmes, et al., 2002). Hendrison (1990), em pesquisas conduzidas na região de Mapane no Suriname, mostrou que a exploração controlada reduziu de $16,5 \%$ para $6,0 \%$ a área de clareiras abertas pela derruba quando comparada com a extração não controlada. Pinard \& Putz (1996) aplicando métodos de exploração de impacto reduzido em uma floresta de Dipterocarpáceas na Malásia 
conseguiram uma redução de $27 \%$ nos danos à floresta remanescente. Em outro estudo realizado na região de Paragominas, no Estado do Pará, Johns et al. (1998) encontraram uma redução de 32\% no número de árvores danificadas por árvore extraída, comparando a exploração com e sem planejamento.

No entanto, não basta apenas reduzir os danos durante a exploração. A produção de madeira em florestas tropicais, para ser sustentável, deve ser de tal intensidade que permita à floresta repor o volume retirado ao final do período de regeneração escolhido, isto é, "não se deve extrair mais do que a floresta pode produzir naturalmente ou com a ajuda da ciência", esse é o primeiro princípio do bom manejo. Para a FAO, Manejo Florestal Sustentável (MFS) é definido como "manejo e conservação da base dos recursos naturais e as orientações tecnológicas, que proporcionem a realização e a satisfação das necessidades humanas para a geração atual e futura”.

Projetos de manejo sustentado de florestas naturais com vistas à reposição obrigatória começaram a ser implantados no Estado do Pará a partir de 1981. Em fevereiro de 1992 haviam sido aprovados 267 projetos na Superintendência do IBAMA no Pará, segundo as instruções da Portaria 441. No início de 1992 entraram em vigor novas instruções para manejo, regulamentadas pela Instrução Normativa 080. No período 92-2000 foram aprovados 2.806 projetos de manejo. No entanto, pesquisas conduzidas pela Embrapa Amazônia Oriental em colaboração com o próprio IBAMA mostraram que a qualidade técnica desses projetos estava comprometida, uma vez que os madeireiros não cumpriam a maioria das atividades prometidas nos planos (Embrapa, 1997). Um relatório do IBAMA mostrou que apenas 14\% dos planos de manejo aprovados até 1998 estavam aptos, legal e tecnicamente. Do total de projetos cancelados, $61 \%$ foram suspensos exclusivamente por motivos técnicos (IBAMA, 2001).

Segundo Higuchi et al., (2000) as principais causas da ausência de sustentabilidade na produção incluem: a falta de políticas adequadas e sistemas de estímulo para o MFS; a ineficácia do sistema de controle da exploração madeireira; a oferta clandestina de madeira; e a abundância do recurso florestal.

De Graaf (1986) afirma que para encontrar o melhor sistema de manejo para as florestas tropicais deve-se observar três aspectos importantes: (1) a maneira eficiente 
com que as florestas conservam seus nutrientes, (2) a baixa intensidade de distúrbios normalmente encontrada em florestas sem interferência humana e (3) a grande diversidade de espécies encontrada. Qualquer sistema de manejo aplicado deve procurar obedecer a esses critérios para manter a sustentabilidade.

Dentre os sistemas de manejo conhecidos, o policíclico é o que melhor se encaixa nesses requisitos, embora existam alguns problemas inerentes ao método como: a exploração seletiva de poucas e valiosas espécies provoca grande pressão nas populações dessas espécies e permite que outras, menos desejáveis economicamente, dominem o povoamento após a extração. Para minimizar esse problema, De Graaf (1986) sugere duas opções que devem ser combinadas sempre que possível: a) ampliar a lista de espécies a ser explorada e extrair somente os indivíduos maduros dessas espécies e, b) aplicar tratamentos silviculturais que induzam a regeneração e o maior crescimento das espécies comercialmente valiosas, reduzindo a pressão seletiva nas populações das mesmas.

Entre os diversos métodos existentes, os refinamentos ou desbastes promovem a mortalidade das espécies mais abundantes e sem valor comercial do povoamento, reduzindo a competição sobre as espécies selecionadas para a próxima colheita. Métodos apropriados para a eliminação das espécies indesejáveis incluem anelamento mecânico, com ou sem a aplicação de arboricidas, que fazem com que a árvore morra em pé lentamente, perdendo folhas e galhos e diminuindo os danos a vegetação remanescente (Lamprecht, 1990; De Graaf, 1986).

Tratamentos silviculturais, aplicados periodicamente, podem resultar em uma floresta com predominância de espécies de valor econômico e em novas colheitas com ciclo de corte duas a três vezes menores que no caso de florestas não manejadas. Diversas técnicas têm sido aplicadas, em diferentes intensidades, em florestas tropicais. Os experimentos mais antigos foram realizados em florestas de Dipterocarpáceas na Malásia (Kammesheidt et al., 2003; Hutchinson, 1987) e na Indonésia (Kuusipalo et al., 1997); refinamentos pós-exploração foram testados em florestas no Suriname (Dekker \& De Graaf, 2003; De Graaf, 1986); na Bolívia (Pariona et al., 2001; Howard et al., 1996); no Paraguai (Zaneti, 2002); no México (Negreros-Castillo \& Mize, 1993); na Costa Rica 
(Finegan et al., 1999; Quiros \& Finegan, 1994; Delgado et al., 1997) e em Borneo (Kuusipalo et al., 1996).

Embora importantes dentro do contexto de um sistema silvicultural, essas técnicas tem sido pouco estudadas no Brasil. Na região de Linhares, ES, em floresta alta de tabuleiro, Jesus (2001) testou nove tratamentos de redução da área basal, que foram desde a área testemunha, sem interferência, até o corte raso, concluindo que o tratamento que causou os menores impactos com a extração foi o que reduziu a área basal em 15\%. Na Estação Experimental de Silvicultura do INPA, em Manaus, foram testados quatro tratamentos de redução da área basal comercial $(0 \%, 25 \%, 50 \%$ e $75 \%)$, e estudos têm sido realizados sobre o efeito dessas intervenções sobre o crescimento, ingressos e mortalidade da floresta remanescente (Higuchi et al., 1997) e sobre a regeneração natural de espécies comerciais (Jardim et al., 1990; Vieira \& Hosokawa, 1989).

No Estado do Pará, tem-se notícia de dois estudos, um realizado na região de Marabá, cujo objetivo foi avaliar o efeito de diferentes intensidades de exploração no comportamento da floresta tropical (Garcia, 1990), o outro, foi realizado em uma floresta secundaria na região de Belterra - PA, com o objetivo de testar a resposta da floresta a duas intensidades de desbaste de liberação. Todavia, devido o curto tempo de acompanhamento, ainda não há resultados conclusivos sobre esses experimentos. É necessário, portanto, estudar essas técnicas em longo prazo de modo a determinar sua viabilidade ecológica e econômica.

\subsection{Objetivo geral}

Analisar o efeito de quatro intensidades de redução da área basal, representadas pela exploração e desbastes sistemáticos na composição florística, diversidade, estrutura e crescimento do extrato arbóreo, durante um período de 22 anos, na Floresta Nacional do Tapajós. 


\subsection{Objetivos específicos}

1. Verificar se a exploração de madeira combinada com os desbastes atingiu a intensidade de redução da área basal planejada para cada tratamento;

2. Analisar se as diferentes intensidades de desbaste aplicadas resultaram em diferenças na composição florística, estrutura, e crescimento do extrato arbóreo remanescente;

3. Determinar qual(is) dentre os tratamentos testados, se mostrou mais eficiente quanto a recuperação do número de árvores, área basal e volume, no final do período monitorado;

4. Verificar se a extração de madeira combinada com os desbastes acelera o incremento (diâmetro, área basal e volume) das espécies com valor comercial madeireiro, em relação à floresta sem intervenção;

5. Determinar qual(is), dentre os tratamentos testados, é o mais adequado visando à produção sustentada de madeira, ou seja, produz as maiores taxas de crescimento os maiores ingressos e a menor mortalidade.

\section{Material e métodos}

\subsection{Características gerais da área}

O experimento se localiza na Floresta Nacional do Tapajós, município de Belterra, Pará, a altura do km 114 da Rodovia Santarém-Cuiabá entre as coordenadas $2^{\circ} 40^{\prime}-4^{\circ}$ 10’ de Latitude Sul e $54^{\circ} 45^{\prime}-55^{\circ} 30^{\prime}$ de Longitude Oeste (Figura 1).

A Floresta Nacional do Tapajós foi legalmente constituída pelo Congresso Nacional através do Decreto número 73.684 de 19 de fevereiro de 1974. Sua área total cobre aproximadamente $600.000 \mathrm{ha}(13 \mathrm{~km}-60 \mathrm{~km}$ de largura e $150 \mathrm{~km}$ de comprimento). É uma faixa de terra limitada a leste pela BR163 (Santarém - Cuiabá), estendendo-se do km 50 ao km 217 dessa rodovia, e a oeste pelo rio Tapajós, Estado do Pará. 


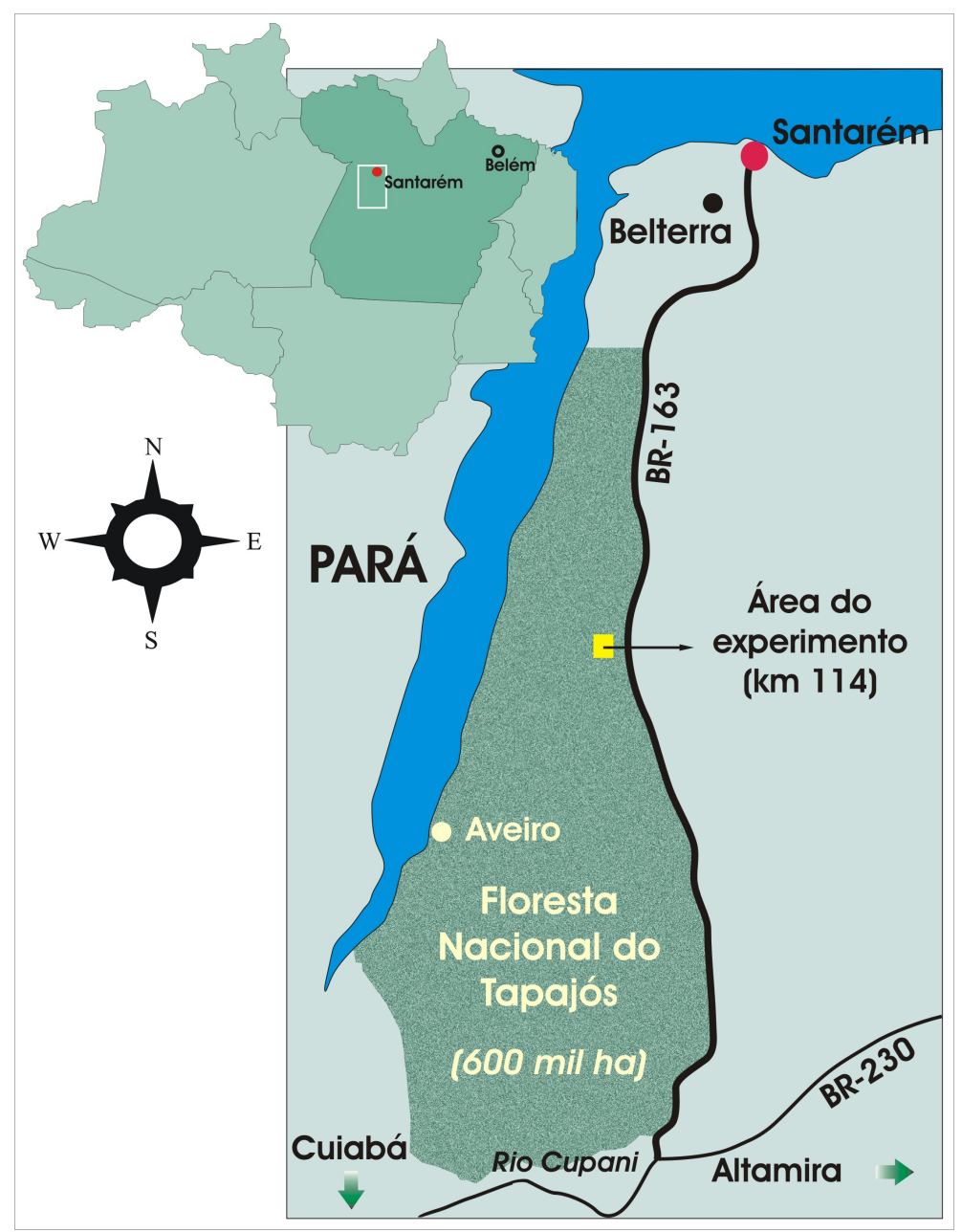

Figura 1 - Localização da Floresta Nacional do Tapajós, área de pesquisa do projeto

A altitude está em torno de $175 \mathrm{~m}$ acima do nível do mar sendo o relevo plano a levemente ondulado. A estação meteorológica mais próxima da área estudada fica na sede do município de Belterra, de onde foram obtidas as informações climáticas. $\mathrm{O}$ clima é do tipo Ami, segundo a classificação de Koppen, que é um clima tropical com uma estação seca de 2 a 3 meses por ano e precipitação anual acima de $2000 \mathrm{~mm}$. A média anual de temperatura gira em torno de $25^{\circ} \mathrm{C}$, com médias mínimas de $18,4^{\circ} \mathrm{C}$ e máximas de $32,6^{\circ} \mathrm{C}$. A umidade relativa é de aproximadamente $86 \%$ (76-93\%). A média anual de chuvas em Belterra está em torno de $2.110 \mathrm{~mm}$, com um período chuvoso de março a maio e período seco ou pouco chuvoso de agosto a novembro (Carvalho, 2001). 
O solo predominante é o latossolo amarelo moderado com textura pesada $(60 \%-$ 94\% de argila), com inclusão de latossolo amarelo concrescionário, derivado de argila pedregosa (Carvalho, 1992).

A Floresta Nacional do Tapajós é uma floresta de terra firme, classificada como Floresta Ombrófila Densa (Veloso et al., 1991). Dubois (1976), a classificou mais detalhadamente, em seis grandes tipos e diversos subtipos. Os tipos são: floresta alta com babaçu (Orbignya speciosa Burret); floresta alta sem babaçu; complexo de florestas baixas; complexo de florestas cipoálicas e cipoal; florestas inundadas; e capoeiras.

A área do experimento situa-se no tipo floresta alta sem babaçu, que, de acordo com Dubois (1976), ocorrem no planalto, em terrenos planos a levemente ondulados, onde não está presente a palmeira babaçu. Esta área foi selecionada por representar uma típica floresta densa de terra firme da região, sem interferência humana.

\subsubsection{Histórico da área estudada}

O experimento possuía 180ha e foi iniciado em 1981 pela equipe de manejo florestal da Embrapa Amazônia Oriental.

As atividades iniciais constaram de inventário por amostragem para determinação da área basal onde foram medidas todas as árvores com DAP (diâmetro a 1,30m do solo) maior ou igual a 5,0cm e inventário pré-exploratório de $100 \%$ de intensidade onde foram mensuradas todas as árvores com DAP $\geq 45,0 \mathrm{~cm}$.

No inventário por amostragem, a floresta apresentou área basal de $35,9 \mathrm{~m}^{2} \cdot \mathrm{ha}^{-1}$ (diâmetro $\geq 5,0 \mathrm{~cm}$ ), sendo $31 \%$ desse total composto por espécies de valor comercial. No inventário pré-exploratório foi obtido um volume bruto de $220 \mathrm{~m}^{3}$.ha ${ }^{-1}$ (diâmetro $\geq$ $45,0 \mathrm{~cm}$ ), sendo $113 \mathrm{~m}^{3} \cdot \mathrm{ha}^{-1}$ de espécies de valor comercial madeireiro (Silva et al., 1985). Foram encontradas mais de 300 espécies arbóreas, sendo as mais importantes comercialmente: andiroba (Carapa guianensis), angelim (Dinizia excelsa), aroeira (Astronium sp.) muiracatiara (Astronium gracile), faveira amargosa (Vataireopsis speciosa), freijó (Cordia goeldiana), jarana (Holopyxidium jarana), jutai-açu (Hymenaea courbaril), maçaranduba (Manilkara huberi), marupá (Simaruba amara), 
pau-d'arco (Tabebuia ochracea), quaruba (Vochysia máxima), sucupira (Diplotropis sp.) e tatajuba (Bagassa guianensis) (Silva et al., 1985).

Além dos inventários, foram realizados em 1981, o corte de cipós em toda a área e o estabelecimento e primeira medição das parcelas permanentes.

O delineamento estatístico utilizado foi o de Blocos ao Acaso com 4 repetições. Cada bloco possui uma área de 36ha, sendo 9ha por tratamento (Figura 2).

Os tratamentos silviculturais foram assim definidos:

- T0: controle, representado pela floresta não explorada;

- T1: Exploração tradicional - abate de árvores com DAP $\geq 45 \mathrm{~cm}$, sem nenhuma intervenção posterior;

- T2: Abate de árvores comerciais DAP $\geq 55 \mathrm{~cm}+$ anelamento com desvitalização de espécies não comerciais para reduzir a área basal em $20 \%$ da original;

- T3: Abate de árvores comerciais DAP $\geq 55 \mathrm{~cm}+$ anelamento com desvitalização de espécies não comerciais para reduzir a área basal em $40 \%$ da original;

- T4: Abate de árvores comerciais DAP $\geq 55 \mathrm{~cm}+$ anelamento com desvitalização de espécies não comerciais para reduzir a área basal em $60 \%$ da original

Em cada tratamento foram instaladas ao acaso três parcelas permanentes de 0,25ha, totalizando 12 parcelas por tratamento, perfazendo um total de 48 parcelas. $\mathrm{O}$ controle do experimento é realizado em 36ha de floresta primária não explorada, onde foram instaladas 12 parcelas de $0,25 \mathrm{ha}$. No total o experimento possui 60 parcelas permanentes de 0,25ha (Figura 2).

Do total de 180ha da área experimental, 144ha foram explorados em 1982 (36ha para cada tratamento) ficando uma área de 36ha como testemunha (tratamento T0). As operações iniciais da exploração experimental, realizadas na área compreenderam: corte de cipós, realizado um ano antes da exploração; mapeamento logístico das árvores que seriam exploradas; abertura de quatro pátios de estocagem de 0,7 ha cada e construção de oito ramais principais de arraste de $4 \mathrm{~m}$ de largura por $1.200 \mathrm{~m}$ de comprimento (Carvalho et al., 1984).

A derrubada foi efetuada em faixas de $100 \mathrm{~m} \times 1.200 \mathrm{~m}$ e a extração foi realizada com um "skidder" de rodas de $160 \mathrm{HP}$, operando em uma distância máxima de $1.200 \mathrm{~m}$. 


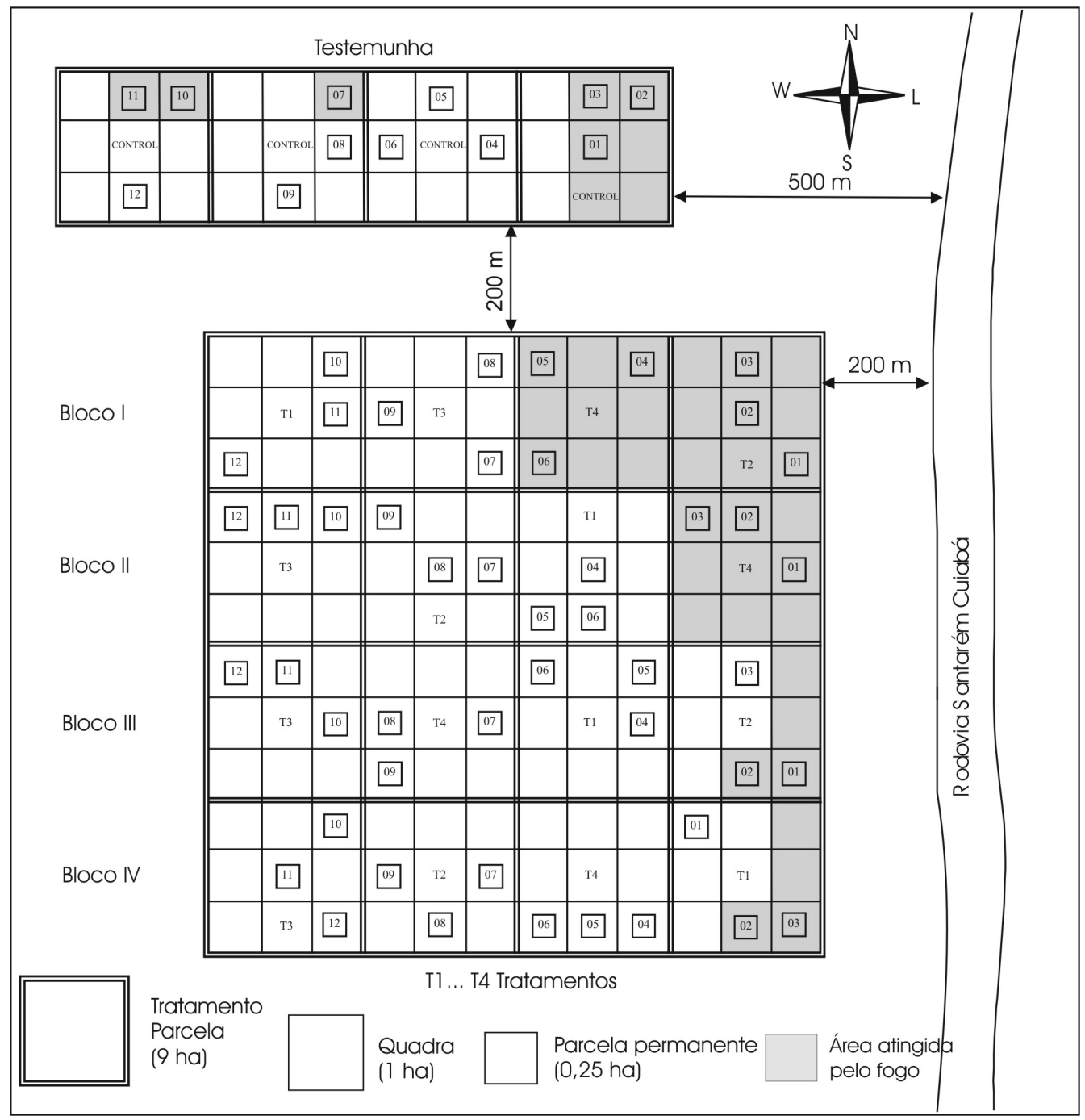

Figura 2 - Croqui da área experimental na Floresta Nacional do Tapajós (km 114 da BR 163)

No preparo dos pátios de estocagem e abertura dos ramais principais foi utilizado trator de esteira de 216HP. A derruba e o traçamento foram realizados com motosserra (Carvalho et al., 1984).

Foram exploradas 38 espécies comerciais. A escolha foi realizada com base na abundância e volume presentes na área e por serem comercializadas no mercado regional de Santarém (Carvalho, 1992).

Os tratamentos silviculturais foram iniciados em 1993 e concluídos em 1994, 12 anos após a exploração com a finalidade de eliminar árvores, preferencialmente de espécies consideradas não comerciais tanto do ponto de vista madeireiro como não 
madeireiro de modo a reduzir a área basal do povoamento e, com isso, propiciar a maior penetração de luz, favorecendo o desenvolvimento e estabelecimento das espécies comerciais.

No ano de 1997, após um grande período de estiagem, causada pelo El Niño, a área do experimento foi atingida por um incêndio acidental que afetou 44ha, atingindo severamente 19 das 60 parcelas permanentes instaladas. Com isso, a área experimental sofreu uma redução, passando de 180ha para 136ha e o número de parcelas por tratamento foi reduzido conforme a Tabela 1 (Figura 2).

Tabela 1 Distribuição dos tratamentos no experimento após o incêndio de 1997 ocorrido na Flona do Tapajós

\begin{tabular}{ccc}
\hline Tratamento & $\mathrm{N}^{\mathrm{o}}$ de parcelas após incêndio & Área amostral \\
\hline T0 & 6 & 1,50 ha \\
T1 & 10 & 2,50 ha \\
T2 & 7 & 1,75 ha \\
T3 & 12 & 3,00 ha \\
T4 & 6 & 1,50 ha \\
\hline
\end{tabular}

O Quadro 1 apresenta as principais eventos e atividades realizadas até o momento.

\begin{tabular}{|c|c|}
\hline Ano & Atividades Realizadas/Eventos \\
\hline 1981 & $\begin{array}{l}\text { Estabelecimento de uma quadra de } 144 \text { ha de área experimental a uma distância de } \\
\text { aproximadamente } 200 \mathrm{~m} \text { da rodovia BR } 163 \text { onde foram realizadas as seguintes atividades: } \\
\text { i. Inventário pré-exploratório a } 100 \% \text { em árvores com DAP } \geq 45,0 \mathrm{~cm} \text {; } \\
\text { ii. Inventário por amostragem da área basal em árvores com DAP } \geq 5,0 \mathrm{~cm} \text {; } \\
\text { iii. Corte de cipós; } \\
\text { iv. Instalação e primeira medição das } 48 \text { parcelas permanentes; }\end{array}$ \\
\hline 1982 & Exploração florestal na área experimental de 144ha, seguindo a prescrição dos tratamentos \\
\hline 1983 & $\begin{array}{l}2^{0} \text { Medição das } 48 \text { parcelas permanentes instaladas na área explorada; } \\
\text { Estabelecimento de uma quadra de } 36 \text { ha em floresta não explorada (área testemunha), a uma } \\
\text { distância de } 200 \mathrm{~m} \text { da área explorada e } 500 \mathrm{~m} \text { da rodovia; } \\
\text { Instalação e primeira medição de } 12 \text { parcelas permanentes na área testemunha. }\end{array}$ \\
\hline 1987 & $\begin{array}{l}3^{0} \text { Medição das } 48 \text { parcelas permanentes instaladas na área explorada; } \\
2^{\underline{0}} \text { Medição das } 12 \text { parcelas permanentes instaladas na área testemunha. }\end{array}$ \\
\hline 1989 & $\begin{array}{l}4^{0} \text { Medição das } 48 \text { parcelas permanentes instaladas na área explorada; } \\
3^{\circ} \text { Medição das } 12 \text { parcelas permanentes instaladas na área testemunha. }\end{array}$ \\
\hline 1993 & $\begin{array}{l}\text { Foi iniciada a aplicação dos tratamentos silviculturais, sendo interrompido pelo início da } \\
\text { estação chuvosa. }\end{array}$ \\
\hline 1994 & Foi concluído o tratamento silvicultural. \\
\hline 1995 & $\begin{array}{l}5^{0} \text { Medição das } 48 \text { parcelas permanentes instaladas na área explorada; } \\
4^{\mathrm{o}} \text { Medição das } 12 \text { parcelas permanentes instaladas na área testemunha. }\end{array}$ \\
\hline 1997 & Ocorrência de um incêndio acidental na área \\
\hline 2003 & $\begin{array}{l}6^{0} \text { Medição de } 35 \text { parcelas permanentes remanescentes na área explorada } \\
5^{-} \text {Medição de } 6 \text { parcelas permanentes remanescentes na área testemunha }\end{array}$ \\
\hline
\end{tabular}




\subsubsection{Monitoramento da floresta}

O inventário florestal contínuo, realizado através de parcelas permanentes, monitora as mudanças que ocorrem na floresta ao longo do tempo, de forma prática e econômica. Nestas parcelas foram medidas periodicamente todas árvores com diâmetro igual ou superior a 5,0cm. Assim, é possível estimar o crescimento, ingressos e mortalidade, determinando a produção volumétrica e o ciclo de corte. Além disso, permite avaliar a composição qualitativa e quantitativa da regeneração natural, informação básica para decidir sobre as necessidades de intervenções para induzir à regeneração ou para recomendar plantios de enriquecimento.

As parcelas permanentes possuem forma quadrada, com dimensões de 50m x 50m (0,25ha) e foram internamente subdivididas em 25 unidades de observações menores de $10 \mathrm{~m}$ x 10m (subparcelas ou quadrados) para facilitar a localização e o controle de cada árvore a ser medida e monitorada. As subparcelas foram numeradas de 1 a 25, iniciando sempre pelo canto sudoeste, conforme ilustra a Figura 3.

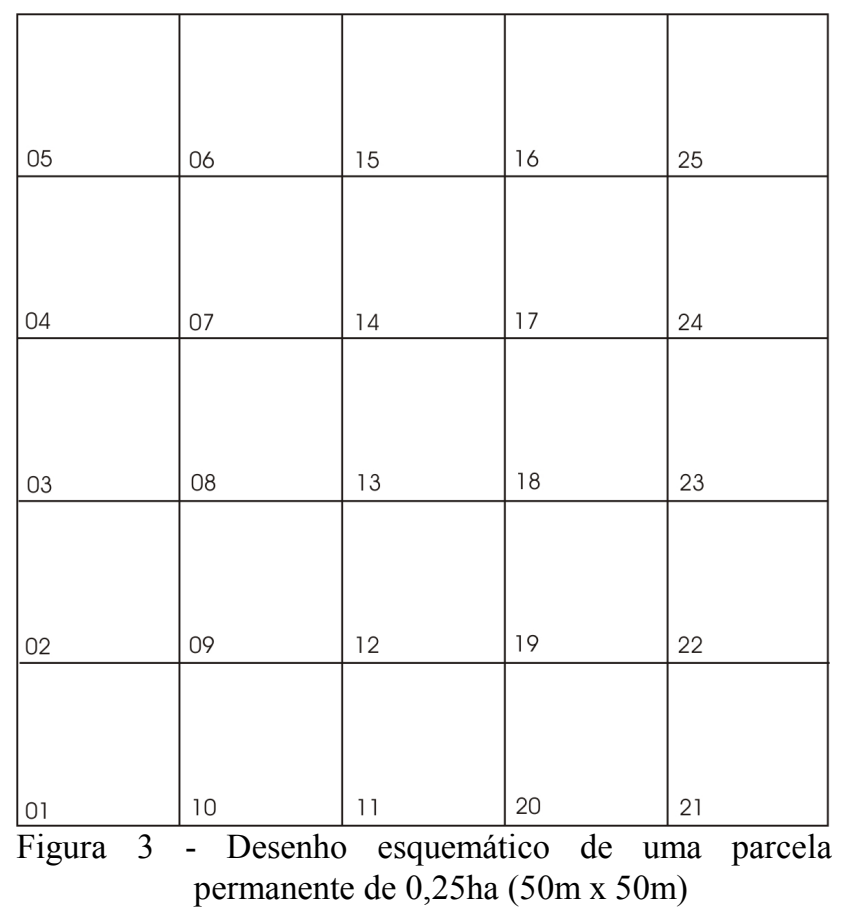


A metodologia utilizada para a medição das parcelas foi baseada em Silva \& Lopes, (1984). As variáveis observadas são descritas a seguir. Os números representam escores ou códigos usados para posterior processamento eletrônico.

\section{a) Numeração das árvores}

Cada árvore recebeu uma plaqueta de alumínio com um número que é composto por seis dígitos: os dois primeiros identificam a parcela, o terceiro e quarto dígitos referem-se à subparcela e os dois últimos identificam a árvore propriamente dita. Este procedimento facilita a reconstrução da parcela no caso do desaparecimento dos marcos (piquetes).

As plaquetas foram fabricadas a partir de folhas de alumínio com $3 \mathrm{~mm}$ de espessura e os números impressos com punção (Figura 4). Essas plaquetas foram pregadas aproximadamente 10 centímetros acima do ponto de medição do diâmetro. No caso de árvores com sapopemas muito altas, as plaquetas foram pregadas em local de fácil visibilidade e na mesma direção do ponto de medição.

O número da árvore não se repetiu dentro de uma subparcela. Cada subparcela teve sua seqüência própria de numeração.

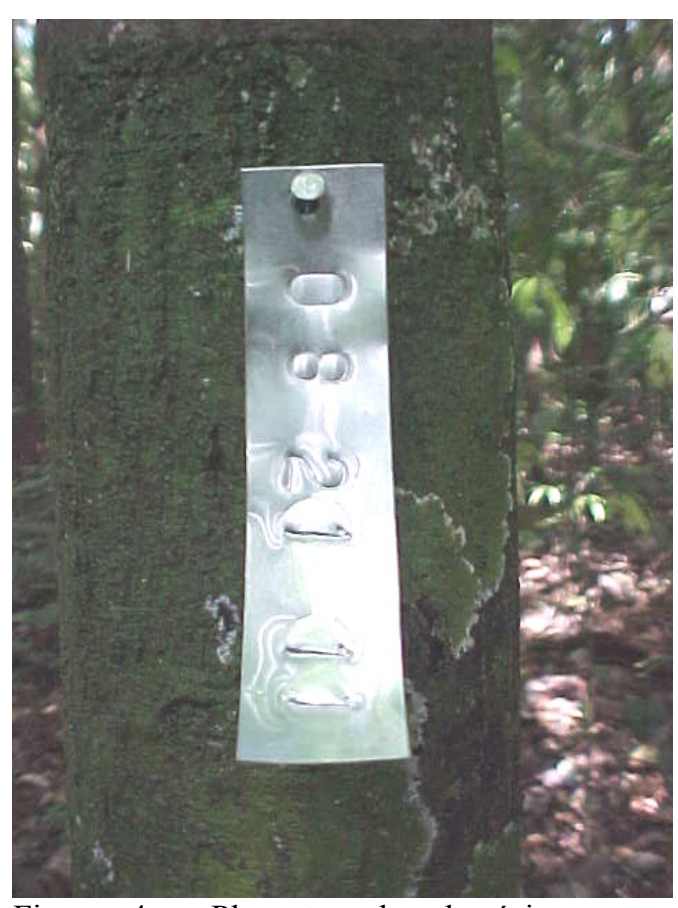

Figura 4 - Plaquetas de alumínio com a numeração das árvores. Flona Tapajós, Belterra-PA

Ex.: Subparcela 01: árvore 01......N1

Subparcela 02: árvore $01 \ldots . . . \mathrm{N} 2$ e assim sucessivamente 
Para árvores localizadas na linha divisória das subparcelas, convencionou-se que a árvore deve ser incluída na subparcela onde mais da metade de sua base estiver inserida. Da mesma forma, as árvores que estavam situadas nas linhas limítrofes (bordadura da parcela), foram incluídas na medição quando $50 \%$ ou mais de sua base estivesse dentro da parcela.

Os números das árvores que morreram não foram usados novamente em outra árvore. No caso de ingressos ${ }^{1}$ foi utilizado um novo número, o próximo da seqüência daquela subparcela.

\section{b) Classe de identificação do fuste - CIF}

Esta variável descreve os diversos estados em que podem ser encontradas as árvores em uma floresta. Esses estados são resultantes de seu próprio crescimento, ou de mudanças provocadas pelo homem ou pela natureza. Os códigos numéricos utilizados combinam a sanidade da árvore com o estado de seu fuste (Quadro 2).

\begin{tabular}{|c|c|c|c|c|c|}
\hline \multirow{2}{*}{ Árvore } & \multirow{2}{*}{ Completa } & \multicolumn{2}{|c|}{ Decapitada (sem copa) } & \multirow{2}{*}{$\begin{array}{c}\text { Toco de } \\
\text { Exploração }\end{array}$} & \multirow{2}{*}{$\begin{array}{c}\text { Não } \\
\text { Encontrada }\end{array}$} \\
\hline & & fuste $>4,0 \mathrm{~m}$ & fuste $<4,0 \mathrm{~m}$ & & \\
\hline Viva em pé & 111 & 112 & 113 & \multirow{5}{*}{134} & \multirow{5}{*}{139} \\
\hline Viva caída & \multicolumn{3}{|c|}{121} & & \\
\hline Morta natural & \multicolumn{3}{|c|}{131} & & \\
\hline Morta p/ exploração & \multicolumn{3}{|c|}{132} & & \\
\hline Morta $\mathrm{p} /$ tratamento & \multicolumn{3}{|c|}{133} & & \\
\hline
\end{tabular}

Quadro 2 - Códigos usados para as classes de identificação do fuste de árvores

As diferentes classes de identificação do fuste são ilustradas na Figura 5.

\footnotetext{
${ }^{1}$ Ingressos são indivíduos que atingem o diâmetro mínimo de medição (DAP $\geq 5,0 \mathrm{~cm}$ )
} 


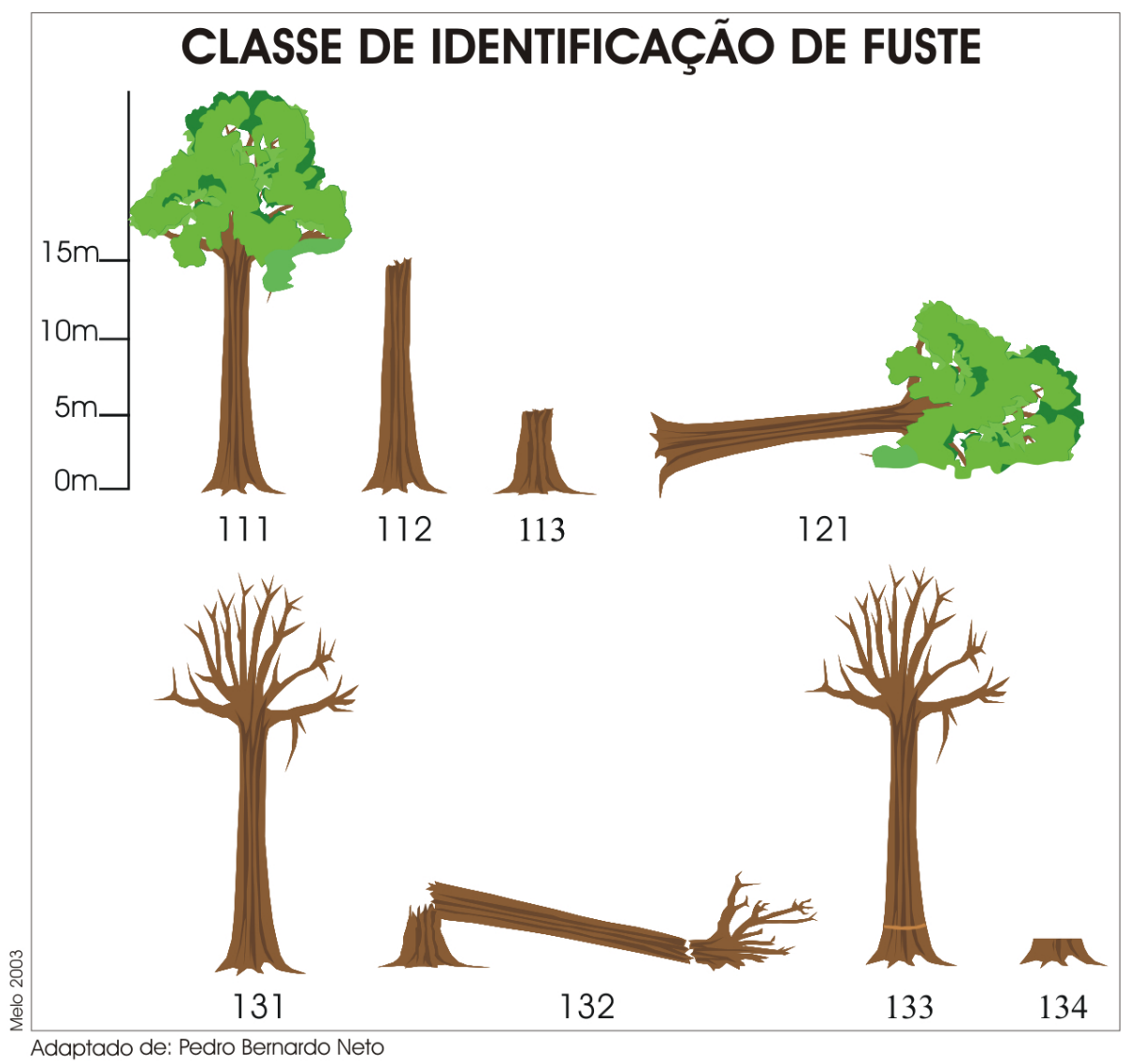

Figura 5 - Classes de identificação do fuste de árvores. Flona Tapajós, Belterra - PA

\section{c) Identificação botânica}

As árvores foram identificadas no campo pelo nome comum, pelos identificadores botânicos da Embrapa Amazônia Oriental. Após a primeira medição, foi preparada uma listagem contendo as espécies menos comuns e, durante a segunda coleta de dados, atenção especial foi dispensada para a coleta de material botânico para posterior identificação por comparação no Herbário IAN da Embrapa. Sempre que possível, a identificação foi feita até o nível de espécie. As espécies de difícil identificação, ou que eram confundidas com outras na floresta foram consideradas em grupos de gêneros ou famílias (Silva, 1989; Carvalho, 1992). Esses grupos estão listados no Quadro 3.

As poucas espécies que não puderam ser identificadas, nem ao nível de família, foram agrupadas em uma categoria especial de "espécies não identificadas". Uma lista 
com os nomes comuns e a correspondente identificação botânica das espécies encontradas na área, encontra-se no Anexo A.

\begin{tabular}{|l|l|}
\hline \multicolumn{1}{|c|}{ Grupos } & \multicolumn{1}{|c|}{ Espécies incluídas } \\
\hline Inga spp. & $\begin{array}{l}\text { Inga alba, I. capidata, I. edulis, I. fagifolia, I. falcistipula, I. gracilifolia, I. } \\
\text { marginata, I. rubiginosa, I. splendens e I. thibaugiana }\end{array}$ \\
\hline Lauraceae & $\begin{array}{l}\text { Aiouea sp., Aniba burchellii, Aniba williamsii, Licaria brasiliensis, Ocotea } \\
\text { acutangula, O. brachybotria, O. caudata, O. costulata e O. puberula }\end{array}$ \\
\hline Miconia spp & Miconia prasina, Miconia sp1 e Miconia sp2 \\
\hline Protium spp. & $\begin{array}{l}\text { Protium apiculatum, P. cordatum, P. decandrum, P. opacum, P. pallidum, P. } \\
\text { paraense, P. robustum e P. spruceana }\end{array}$ \\
\hline Saccoglottis spp. & Saccoglottis sp1 e Saccoglottis sp2 \\
\hline Sapotaceae & $\begin{array}{l}\text { Ecclinusa abbreviata, Micropholis ulei, Pouteria caimito, Pouteria } \\
\text { macrophylla, Prieurella cuneifólia, Prieurella prieurii, } \text { Radlkofella } \\
\text { macrocarpa, Sarcaulus brasiliensis e Syzygiopsis oppositifolia }\end{array}$ \\
\hline Sloanea spp. & $\begin{array}{l}\text { S. froesii, S. grandiflora e S. guianensis; } \text { e Talisia spp. que inclui T. carinata, } \\
\text { T. coriaceae e T. longifólia }\end{array}$ \\
\hline
\end{tabular}

Quadro 3 - Gêneros e famílias onde foram agrupadas as espécies de difícil identificação em uma área experimental na Floresta Nacional do Tapajós (Km114 da BR163)

Para o propósito de cálculos, cada grupo foi contado como uma espécie. Nas discussões, a palavra espécie inclui os grupos.

\section{d) Classificação de espécies}

Todas as espécies encontradas na área foram classificadas em relação ao potencial de aproveitamento no mercado madeireiro e em relação ao seu comportamento ecológico. Os grupos de qualidade da madeira foram:

- Espécies comerciais: aquelas que atualmente são comercializadas no mercado nacional e internacional;

- Espécies potenciais: aquelas que não são atualmente comercializadas, mas que apresentam características favoráveis de dimensões e qualidade da madeira para serem comercializadas em futuro próximo;

- Espécies não comerciais: são as que não tem características propícias para comercialização madeireira, ou cuja madeira não é suficientemente conhecida.

Quanto ao comportamento ecológico, as espécies foram classificadas em dois grupos principais: 
- Espécies tolerantes à sombra: espécies que toleram sombra nas etapas iniciais de seu desenvolvimento, mas que requerem ou apresentam alguns sinais de beneficiar-se com a existência de aberturas no dossel;

- Espécies pioneiras ou intolerantes à sombra: são espécies cuja regeneração não é encontrada sob o dossel, aparecendo somente depois da abertura de clareiras.

Essa classificação foi baseada na experiência de campo dos identificadores botânicos da Embrapa Amazônia Oriental.

\section{e) Medição do diâmetro}

A medição do diâmetro foi feita com fita diamétrica, com precisão de milímetros, em todas as árvores com DAP $\geq 5,0 \mathrm{~cm}$, incluindo as caídas, quebradas e danificadas.

Os diâmetros foram medidos em um ponto fixo chamado ponto de medição PDM. O PDM foi estabelecido sempre que possível a 1,30m do solo (DAP - diâmetro à altura do peito). O local era livre de cipós ou qualquer outra anomalia que levasse a erros de leitura. O PDM foi marcado com tinta a base de óleo, de cor vermelha, para evitar erros de leitura em medições subseqüentes (Figura 6).

Sempre que ocorreram sapopemas ou anormalidades como, danos ou deformações, o PDM era transferido para um ponto acima, livre desses impedimentos (Figura 7). Quando isso ocorria, uma observação era registrada na ficha de campo, informando o número da árvore e o motivo da alteração. 


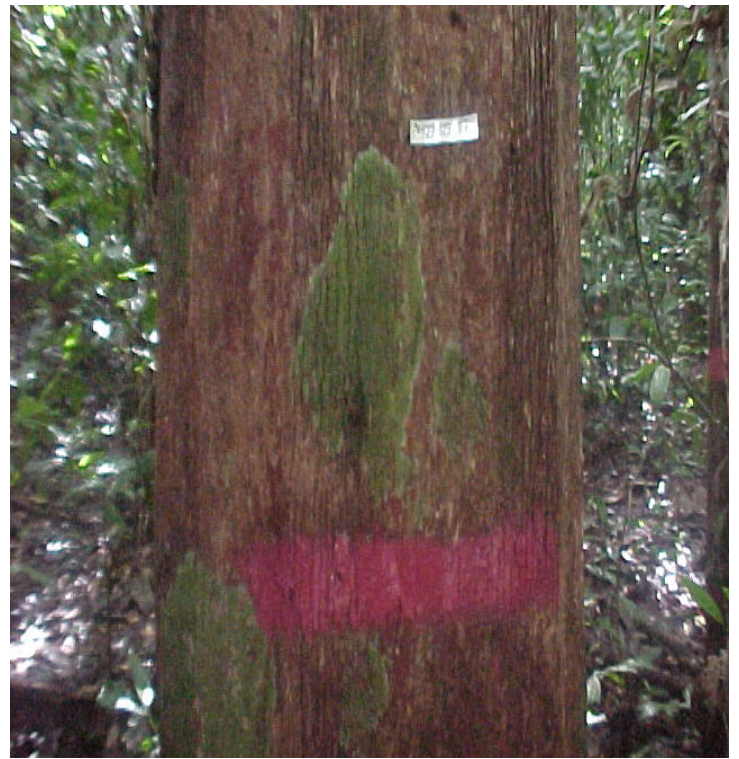

Figura 6 - Ponto de medição do diâmetro marcado com tinta óleo vermelha. Flona Tapajós, Belterra-PA

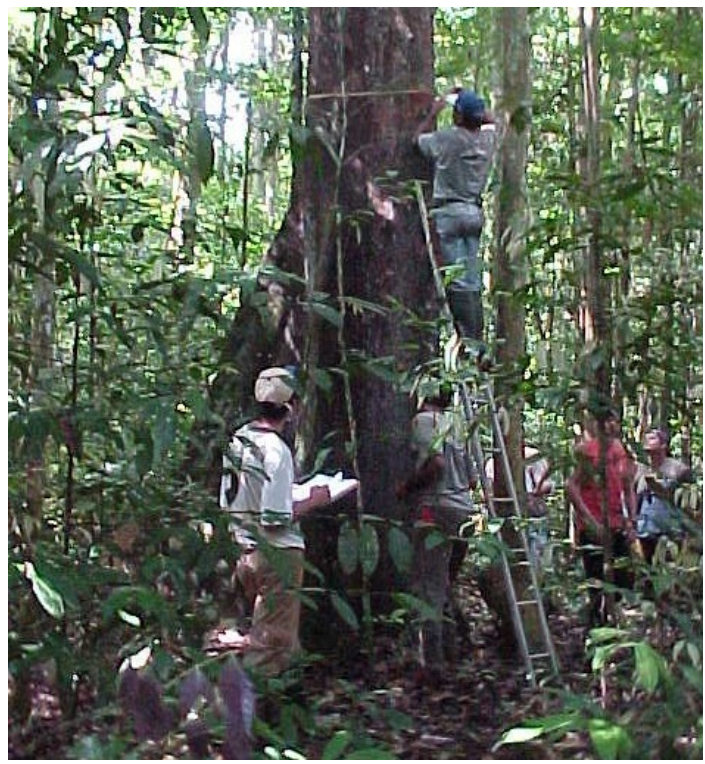

Figura 7 - Medição do diâmetro em árvores com presença de sapopemas. Flona Tapajós, Belterra - PA

\subsubsection{Análise dos dados}

Para estimar o volume das árvores do experimento foi utilizada uma equação de volume, desenvolvida para a região do Tapajós, pela equipe de pesquisadores da Embrapa Amazônia Oriental, a qual usa apenas o diâmetro como variável dependente. (Silva et al., 1984; Silva \& Araújo 1984; Silva, 1989) (Tabela 2).

Tabela 2 Equações de volume desenvolvidas para a área da Floresta Nacional do Tapajós

\begin{tabular}{lccc}
\hline \multicolumn{1}{c}{ Árvores } & Equação & $\boldsymbol{R}^{2}$ & Sy.x (\%) \\
\hline $15,0 \mathrm{~cm} \leq \mathrm{DAP}<44,9 \mathrm{~cm}$ & $V=0,0994+9,1941 \times 10^{-4} d^{2}$ & 0,96 & 12 \\
$\mathrm{DAP} \geq 45,0 \mathrm{~cm}$ & $\ln V=-7,6281+2,1809 \ln d$ & 0,84 & 16 \\
\hline
\end{tabular}

$V=$ Volume; $d=$ diâmetro; $R^{2}=$ coeficiente de determinação; $S y x=$ erro

As análises de dados presentes nos Capítulos III, IV e V foram realizadas com o auxílio do programa SFC (Sistema de Inventário Florestal Contínuo), desenvolvido pela equipe da Embrapa Amazônia Oriental para a entrada, correção, processamento e análise do banco de dados provenientes de parcelas permanentes. 
Foi utilizada, também, análise de variância e testes de comparação de médias visando identificar o(s) melhor(es) tratamentos.

Os métodos específicos de análise, utilizados para cada aspecto em particular, serão descritos separadamente em cada capítulo. 


\section{EXPLORAÇÃO FLORESTAL E EFICIÊNCIA DOS TRATAMENTOS SILVICULTURAIS REALIZADOS EM UMA ÁREA DE 136ha NA FLORESTA NACIONAL DO TAPAJÓS, BELTERRA - PARÁ.}

\section{Resumo}

Foram determinadas as quantidades de madeira extraídas, os danos ocasionados pela atividade de extração e a redução da área basal obtida após a aplicação de três intensidades de desbaste sistemático em uma área explorada na Floresta Nacional do Tapajós, município de Belterra, Pará. O monitoramento da floresta foi realizado através de parcelas permanentes medidas antes e após a exploração e a aplicação dos desbastes. A exploração florestal extraiu em média 11 árvores.ha ${ }^{-1}, 4,5 \mathrm{~m}^{2} \cdot \mathrm{ha}^{-1}$ de área basal e $61,0 \mathrm{~m}^{3} \cdot \mathrm{ha}^{-1}$ de volume, ocorrendo grande variação entre os tratamentos. Para cada árvore comercial explorada foram perdidos em média 4,3 indivíduos com DAP $\geq 10 \mathrm{~cm}$ e aproximadamente $0,5 \mathrm{~m}^{2}$ de área basal, afetada severamente pela exploração. A redução da área basal, obtida com a exploração de madeira e os desbastes, realizados através do anelamento e desvitalização de espécies sem valor comercial conhecido, foi aproximadamente $10 \%$ inferior ao planejado em todos os tratamentos devido a presença de grande número de espécies com reentrâncias no fuste e exudação de látex ou resina que dificultaram a execução do anelamento e a aplicação do arboricida.

\section{Summary}

The quantities of wood harvested, damages caused by logging and the reduction of basal area obtained after the application of three intensities of systematic thinning were 
obtained for an area logged in the Tapajós National Forest, municipality of Belterra, Pará. Monitoring of the forest was done through permanent plots measured before and after logging and application of the thinning. Logging extracted on average 11 trees.ha ${ }^{-1}$, $4.5 \mathrm{~m}^{2} \cdot \mathrm{ha}^{-1}$ of basal area and $61.0 \mathrm{~m}^{3} \cdot \mathrm{ha}^{-1}$ of volume, with a major variation occurring among the treatments. For each commercial tree harvested, on average 4.3 individuals with $\mathrm{DBH} \geq 10 \mathrm{~cm}$ were lost, and approximately $0.5 \mathrm{~m}^{2}$ of basal area were severely affected by logging. Reduction of the basal area, obtained through logging and thinning, carried out by means of girdling and devitalization of species without commercial value, were approximately $10 \%$ less than planned in all of the treatments due to the presence of a large number of species with recesses in the stem and exudation of latex and resin that complicated performance of girdling and application of arboricide.

\subsection{Introdução}

A extração de madeira em florestas tropicais é uma atividade que causa grandes impactos ao ecossistema, e por isso, constitui o momento mais crítico na aplicação de um sistema de manejo visando à produção sustentável. O planejamento adequado dessa atividade é a chave para se obter bons resultados, tanto do ponto de vista ambiental, como econômico (Silva et al., 2001).

A aplicação de técnicas que reduzem os impactos da atividade madeireira sobre a floresta residual tem sido intensificada recentemente, e constitui o primeiro passo para manter a produtividade das florestas tropicais (Hendrison, 1990; Gerwing et al., 1996; Pinard \& Putz, 1996; Johns et al., 1998; Holmes et al., 2002; Silva, 2004). Porém, somente a aplicação de técnicas de exploração florestal de impacto reduzido não é suficiente.

A ausência de uma adequada regeneração natural da maioria das espécies comerciais depois da colheita comercial de madeira e a elevada competição dos indivíduos remanescentes com espécies sem valor de mercado são algumas das causas que põem em risco a sustentabilidade do manejo de florestas tropicais. 
Para complementar a abertura ocasionada pela exploração florestal, incrementando os níveis de luz e incentivando a regeneração natural de espécies madeireiras mais valiosas, recomenda-se o tratamento de refinamento que elimina fustes defeituosos e sem valor econômico (Fredericksen, 1998). Além disso, essa técnica proporciona um maior espaço as árvores da futura colheita e permite o equilíbrio das espécies comerciais, diminuídas pela exploração, com a massa remanescente (Pariona et al., 2001). De acordo com Hutchinson (1988) esse tratamento é considerado como um primeiro passo para o aumento da qualidade e da produtividade das florestas após a exploração.

A redução da vegetação sem aproveitamento comercial pode ser feita por meio da aplicação de uma técnica conhecida como anelamento, que consiste na retirada da casca e da entrecasca formando um anel completo em torno do fuste da árvore, provocando uma descontinuidade nos elementos condutores. As árvores aneladas perdem, de forma lenta, primeiramente as folhas, depois os pequenos ramos e finalmente os galhos mais desenvolvidos (Jardim, 1995). Conseqüentemente quando a árvore está totalmente morta, sua queda diminui o impacto sobre a vegetação remanescente. Esse processo não implica em brusca admissão de luz sobre o solo florestal, reduzindo ao mínimo as possibilidades de sua dessecação pela ação do sol e do vento.

Dubois (1978) descreve três modalidades de anelagem: anelagem simples (retirada da casca em anel completo), anelagem com entalhes (anelagem simples e entalhes feitos com machadinha ou terçado no anel) e anelagem profunda (retirada da casca e camada superficial do alburno com espessura em torno de $2 \mathrm{~mm}$ ).

No entanto, a técnica de anelagem é pouco eficiente na eliminação de indivíduos de algumas espécies, principalmente aquelas com reentrâncias no fuste (Costa et al., 2001). Para melhorar a eficiência do anelamento e acelerar a morte das árvores pode-se aplicar arboricida no anel.

Pariona et al. (2001), estudando a efetividade de três tratamentos de anelamento na Bolívia, concluíram que o anelamento sem aplicação de arboricida somente causou a mortalidade de $10 \%$ das árvores tratadas, treze meses depois da aplicação. Os autores comentam que o principal motivo da baixa efetividade foi a cicatrização do anel em muitas das árvores tratadas sem arboricida que permitiu a rápida reconexão dos tecidos 
cortados. Além disso, muitas árvores que não receberam arboricida produziram rebrotos no fuste, abaixo do anel. Ainda que estes rebrotos não tenham efeito sobre as árvores liberadas, com o tempo se converterão em fustes mal formados de espécies não comerciais, que continuarão ocupando espaço e reduzindo a qualidade do povoamento.

O uso de anelagem com aplicação de arboricida vem sendo praticado em florestas tropicais desde 1930 (Sist \& Abdurachman, 1998). Um dos arboricidas mais utilizados atualmente tem sido o Tordon 2,4 D que é um fitormônio de ação seletiva que não afeta a fauna e possui baixa toxidez e rápida degradação (Lamprecht, 1990; Sist \& Abdurachman, 1998).

A exploração seletiva de madeira, realizada dentro dos critérios técnicos, aliada ao tratamento silvicultural de refinamento pós-exploração visando abrir dossel e induzir a regeneração e o crescimento de espécies de valor comercial, são importantes atividades para aumentar a qualidade e a produtividade das florestas após a exploração. Todavia, para que esse objetivo seja alcançado, os métodos utilizados devem ser eficientes para que os níveis de redução de área basal obtidos sejam equivalentes ao planejado.

Neste capítulo foram determinados as quantidades de madeira extraídas, os danos ocasionados pela atividade de extração e a redução da área basal obtida após a aplicação dos desbastes sistemáticos nas parcelas de cada tratamento, visando responder a seguinte questão: qual a intensidade de redução da área basal efetivamente alcançada em cada tratamento?

\subsection{Material e métodos}

Os dados referentes à colheita de madeira e aos tratamentos silviculturais foram obtidos em 35 parcelas permanentes de $50 \mathrm{~m}$ x 50m, estando incluídas todas as árvores com DAP $\geq 5,0 \mathrm{~cm}$, conforme descrito no Capítulo I.

A exploração comercial de madeira, realizada em 1982, extraiu 23 espécies comerciais, escolhidas com base na abundância e volume presentes na área e por serem comercializadas no mercado regional de Santarém. 
As medições das parcelas permanentes foram realizadas em seis ocasiões: 1 ano antes da exploração (1981), 1 ano após a exploração (1983) e 5, 7, 13 e 21 anos após a colheita de madeira, correspondendo aos anos de 1987, 1989, 1995 e 2003, respectivamente.

O acompanhamento de danos da exploração foi realizado dentro das parcelas permanentes de cada tratamento, por isso não foram considerados os danos ocorridos em áreas adjacentes, relativos à abertura de estradas e construção de pátios de estocagem. Para os cálculos dos danos, foram consideradas: a) árvores remanescentes, mortas em conseqüência das operações de exploração; b) árvores caídas; c) árvores descopadas a qualquer altura; d) árvores com mais de 50\% da copa quebrada, ainda que não haja danos no fuste; e) árvores com danos extensos no fuste $(>3,0 \mathrm{~m})$, ainda que a copa esteja sã.

Os tratamentos silviculturais foram iniciados em 1993 e concluídos em 1994, 12 anos após a exploração. $\mathrm{O}$ desbaste objetivou reduzir a competição entre árvores por espaço, luz e nutrientes, proporcionando aumento da sobrevivência, do crescimento e estabelecimento da regeneração natural das espécies de valor econômico.

A técnica utilizada foi o desbaste sistemático que consistiu em eliminar árvores de espécies não comerciais a partir de um diâmetro mínimo de $15 \mathrm{~cm}$, até atingir a redução de área basal planejada. A determinação das áreas basais a serem reduzidas foi feita com base nas tabelas de distribuição de $\mathrm{AB}$ por espécie antes da exploração. Nessa redução da área basal foi considerada aquela inicialmente provocada pela exploração florestal, ou seja, o impacto ocasionado pela exploração foi incluído (Costa et al., 2001).

A determinação do diâmetro mínimo das árvores a serem eliminadas em cada tratamento foi realizada da seguinte maneira: somou-se a área basal da maior para a menor classe de diâmetro até obter um valor aproximado ao da área basal a ser reduzida. Tomou-se o cuidado, durante o planejamento, de evitar a eliminação ou o risco de extinção de qualquer espécie, preservando com isso, a riqueza florística da comunidade. Cuidados especiais foram tomados para evitar o anelamento de árvores das espécies consideradas importantes para a fauna e para as atividades extrativistas. 
Os tratamentos silviculturais ficaram assim definidos:

- T0: controle, representado pela floresta sem nenhuma intervenção;

- T1: Exploração tradicional - abate de árvores com DAP $\geq 45 \mathrm{~cm}$, sem nenhuma intervenção posterior. O limite de $45 \mathrm{~cm}$ de diâmetro foi aplicado por ser $\mathrm{o}$ mínimo permitido pela legislação florestal para o corte de árvores em florestas naturais. A redução da área basal devida à exploração foi em torno de $24 \%$;

- T2: Abate de árvores comerciais com DAP $\geq 55 \mathrm{~cm}+$ anelamento com desvitalização para reduzir a área basal em $20 \%$ da original. Para atingir esse percentual foram aneladas todas as árvores de espécies não comerciais com DAP a partir de $45 \mathrm{~cm}$;

- T3: Abate de árvores comerciais com DAP $\geq 55 \mathrm{~cm}+$ anelamento com desvitalização para reduzir a área basal em $40 \%$ da original. Para atingir esse percentual foram aneladas todas as árvores de espécies não comerciais com DAP a partir de $15 \mathrm{~cm}$, mais espécies potenciais com DAP a partir de $65 \mathrm{~cm}$;

- T4: Abate de árvores comerciais com DAP $\geq 55 \mathrm{~cm}+$ anelamento com desvitalização para reduzir a área basal em $60 \%$ da original. Nesse caso, foram aneladas todas as árvores de espécies não comerciais e potenciais com DAP a partir de $15 \mathrm{~cm}$, com exceção do tauari (Couratari sp. e Cariniana sp.) e do paurosa (Aniba duckei).

A desvitalização foi realizada através da técnica de anelagem com entalhes, que consiste em um anel feito com golpes contínuos de machadinha em torno do fuste das árvores, sem a retirada da casca (Figura 1). O arboricida utilizado foi uma mistura de óleo diesel e 2,4 D (Tordon) a uma concentração de 95\% de óleo e 5\% do produto, aplicados com pulverizador costal nos anéis, na base das árvores (Costa et al., 2001). 


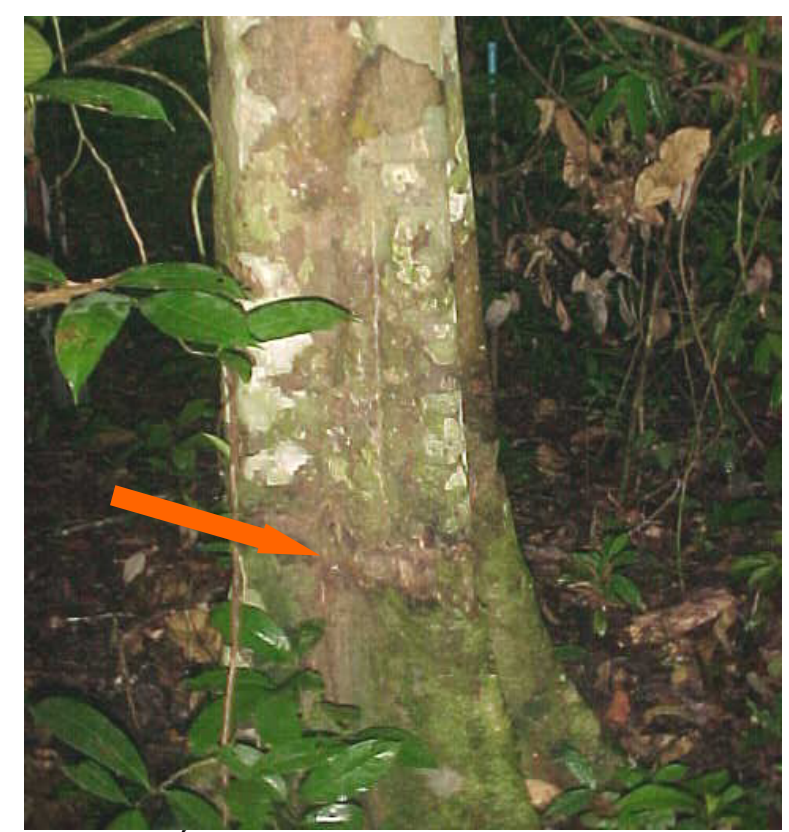

Figura 1 - Árvore anelada como parte dos tratamentos silviculturais aplicados em um experimento na Flona Tapajós, Belterra PA

\subsection{Resultados e discussão}

\subsubsection{Exploração florestal}

Os resultados referentes à colheita de madeira são estimativas baseadas na análise das parcelas permanentes, medidas antes e após a exploração, ou seja, não correspondem ao valor real extraído na época, o qual não foi possível resgatar devido à ausência de registros precisos dessa atividade.

A exploração florestal, realizada em 1982, extraiu em média 11 árvores.ha $^{-1}$, $4,5 \mathrm{~m}^{2} \cdot h \mathrm{~h}^{-1}$ de área basal e $61,0 \mathrm{~m}^{3} \cdot \mathrm{ha}^{-1}$ de volume. Esses valores variaram entre os tratamentos, devido a diferenças de intensidade (T1: exploração de árvores com DAP $\geq$ $45,0 \mathrm{~cm}$ e $\mathrm{T} 2=\mathrm{T} 3=\mathrm{T} 4$ : exploração com $\mathrm{DAP} \geq 55,0 \mathrm{~cm}$ ) e a variabilidade existente na distribuição de árvores de espécies comerciais aptas ao abate nas parcelas de cada tratamento (Tabela 1). 
No tratamento T1, onde a exploração foi mais intensa, foi retirado o maior número de arvores, aproximadamente $13,0 . \mathrm{ha}^{-1}$, porém em relação à área basal e volume, o tratamento T2 foi o que extraiu os maiores valores, $5,2 \mathrm{~m}^{2} \cdot \mathrm{ha}^{-1}$ e $72,3 \mathrm{~m}^{3}$.ha ${ }^{-1}$, isso porque várias árvores extraídas nas parcelas desse tratamento possuíam diâmetros elevados, acima de $85 \mathrm{~cm}$. Por outro lado, a maioria das árvores extraídas no tratamento T1 estava entre $45,0 \mathrm{~cm}$ e $70 \mathrm{~cm}$ de DAP (Tabela 1 ).

Tabela 1 Características da exploração de madeira realizada em cada tratamento em uma área experimental na Floresta Nacional do Tapajós (km 114 da BR 163)

\begin{tabular}{|c|c|c|c|c|c|}
\hline Variáveis & T1 & $\mathbf{T 2}$ & T3 & T4 & Média \\
\hline \multicolumn{6}{|l|}{ Características gerais } \\
\hline Tamanho da área de estudo (ha) & 2,5 & 1,75 & 3,0 & 1,5 & 2,2 \\
\hline $\mathrm{N}^{0}$ de árvores extraídas. $\mathrm{ha}^{-1}$ & 13,2 & 11,4 & 7,7 & 11,3 & 10,9 \\
\hline Área basal extraída $\left(\mathrm{m}^{2} \cdot \mathrm{ha}^{-1}\right)$ & 4,6 & 5,2 & 3,2 & 4,9 & 4,5 \\
\hline Volume extraído $\left(\mathrm{m}^{3} \cdot \mathrm{ha}^{-1}\right)$ & 61,6 & 72,3 & 43,5 & 66,8 & 61,1 \\
\hline $\mathrm{N}^{\mathrm{o}}$ de espécies extraídas & 11 & 11 & 11 & 9 & ? \\
\hline \multicolumn{6}{|c|}{$\begin{array}{l}\mathrm{N}^{0} \text { médio de árvores mortas e/ou } \\
\text { severamente danificadas pela exploração }\end{array}$} \\
\hline Árvores > 10cm DAP $\left(\mathrm{n}^{0} \cdot \mathrm{ha}^{-1}\right)$ & 41,6 & 32,6 & 41,0 & 66,7 & 55,35 \\
\hline Área basal $>10 \mathrm{~cm}$ DAP $\left(\mathrm{m}^{2} \cdot \mathrm{ha}^{-1}\right)$ & 2,95 & 1,04 & 1,75 & 2,48 & 2,05 \\
\hline Volume $>20 \mathrm{~cm}$ DAP $\left(\mathrm{m}^{3} \cdot \mathrm{ha}^{-1}\right)$ & 31,76 & 7,48 & 15,08 & 19,49 & 18,45 \\
\hline \multicolumn{6}{|l|}{ Índice de danos } \\
\hline Árvores danificadas/árvore extraída & 3,1 & 2,9 & 5,3 & 5,9 & 4,3 \\
\hline $\mathrm{m}^{2}$ danificado. $/ \mathrm{m}^{2}$ de $\mathrm{AB}$ extraída & 0,64 & 0,20 & 0,54 & 0,51 & 0,46 \\
\hline $\mathrm{m}^{3}$ danificado $/ \mathrm{m}^{3}$ extraído & 0,52 & 0,10 & 0,35 & 0,29 & 0,30 \\
\hline
\end{tabular}

Os valores médios de 11 árvores e $61 \mathrm{~m}^{3}$ extraídos por hectare neste experimento, são semelhantes aos reportados por Silva (1989), em outra área experimental da Flona Tapajós, onde foram exploradas 16 árvores.ha ${ }^{-1}$ e volume de $75 \mathrm{~m}^{3}$.ha ${ }^{-1}$. Porém são considerados bastante elevados em relação ao que é citado na literatura para outras áreas de florestas tropicais exploradas no Brasil. Silva et al. (2001) reporta que, na extração de madeira realizada no campo experimental da Embrapa, em Moju-PA, foram retirados 3,3 árvores.ha ${ }^{-1}$ e um volume geométrico romaneiado de $23 \mathrm{~m}^{3} \cdot \mathrm{ha}^{-1}$, equivalente a $66 \%$ do volume em pé planejado para a exploração que era de $35 \mathrm{~m}^{3} \cdot \mathrm{ha}^{-1}$. Na região de Paragominas-PA, Barreto et al. (1998) relatam que o volume extraído durante a exploração de madeira foi de $38,6 \mathrm{~m}^{3} \cdot \mathrm{ha}^{-1}$. Na Fazenda Cauaxi, a sudoeste de Paragominas, Holmes et al. (2002) extraíram aproximadamente 4 árvores.ha ${ }^{-1}$ com um 
volume de $25,3 \mathrm{~m}^{3} \cdot \mathrm{ha}^{-1}$. Em Tailândia, também no Estado do Pará, Veríssimo et al. (1996) reportam a exploração de 2 árvores e $16 \mathrm{~m}^{3}$ por hectare.

A redução da área basal original, considerando árvores extraídas, mortas e severamente danificadas pela exploração foi maior no tratamento T4, $(25,6 \%)$, seguido pelos tratamentos T1, T2 e T3 com valores de 23,6\%; 19,5\%; e 17,2\%, respectivamente.

O número total de espécies exploradas, considerando as quatro áreas estudadas, foi 23. Destas, apenas, Carapa guianensis, Manilkara huberi e Holopyxidium jarana estavam presentes em todos os tratamentos, totalizando 25,2 indivíduos.ha $^{-1}$ ou $58 \%$ do total das árvores extraídas.

A espécie mais explorada foi Carapa guianensis (andiroba) com uma densidade de 4,8 indivíduos por hectare no tratamento $\mathrm{T} 1 ; 2,3 \cdot \mathrm{ha}^{-1}$ no tratamento $\mathrm{T} 2 ; 1,0 . \mathrm{ha}^{-1}$ no T3 e $2,0 . \mathrm{ha}^{-1}$ no T4. Considerando as quatro áreas juntas, $23 \%$ de todas as árvores extraídas eram de andiroba.

A maioria das espécies exploradas (56\%) era exclusiva, ou seja, estava presente em apenas um dos tratamentos. A listagem contendo o número de árvores e área basal por espécie, extraídas em cada tratamento encontra-se no Anexo B.

\subsubsection{Danos causados a vegetação remanescente}

A quantidade de danos provocada pela extração de madeira depende principalmente do planejamento, da intensidade de exploração e do controle exercido durante a derrubada e extração das árvores. Todas as operações que envolveram a exploração florestal na área do presente estudo (corte de cipós; mapeamento logístico das árvores a serem exploradas; abertura de pátios de estocagem e ramais de arraste; derrubada; traçamento e extração) foram planejadas de modo a reduzir danos à floresta remanescente.

Considerando a média de todos os tratamentos, para cada árvore comercial explorada foram perdidos 4,3 indivíduos com DAP $\geq 10 \mathrm{~cm}$. Em termos de área basal, para cada metro quadrado extraído foram perdidos cerca de $0,5 \mathrm{~m}^{2}$, afetados severamente pela exploração. Em relação ao volume esse valor foi de $0,3 \mathrm{~m}^{3}$ (Tabela 1). 
Esses valores são considerados baixos se comparados aos obtidos por Veríssimo et al. (1996), para a exploração convencional na região de Tailândia-PA, onde foram destruídas 29 árvores com DAP $\geq 10 \mathrm{~cm}$ para cada árvore extraída e $1,2 \mathrm{~m}^{3}$ de madeira em tora foi danificado para cada $\mathrm{m}^{3}$ extraído. Em outro estudo, na região de Paragominas-PA, Johns et al. (1998) reportam que na exploração sem planejamento para cada árvore comercial derrubada foram danificadas 27 árvores com DAP $\geq 10 \mathrm{~cm}$. Por outro lado, utilizando técnicas de exploração de impacto reduzido, como as que foram utilizadas neste experimento, os danos às árvores remanescentes podem ser bem menores. No Mojú-PA, foi observado que para cada árvore extraída outras 19 foram danificadas, o que corresponde a $0,7 \mathrm{~m}^{3}$ por $\mathrm{m}^{3}$ retirado (Silva et al., 2001). Na região de Paragominas-PA, esses valores foram em torno de 12,2 árvores severamente danificadas por indivíduo extraído e $0,95 \mathrm{~m}^{3} / \mathrm{m}^{3}$ retirado (Johns et al., 1998).

Os danos às árvores remanescentes não foram proporcionais ao volume retirado. $\mathrm{O}$ tratamento T2, que extraiu o maior volume e área basal, foi o que causou os menores danos, afetando apenas $0,2 \mathrm{~m}^{2}$ de árvores remanescentes por $\mathrm{m}^{2}$ extraído e $0,1 \mathrm{~m}^{3}$ por $\mathrm{m}^{3}$ retirado durante as operações de colheita de madeira. Por outro lado, o tratamento T1, de exploração mais intensa (DAP $\geq 45,0 \mathrm{~cm}$ ) onde se extraiu o maior número de árvores.ha ${ }^{-}$ ${ }^{1}$, foi o que provocou maior perda em termos de área basal e volume devido aos danos ocasionados durante a exploração.

Para todos os tratamentos, de forma geral, o maior impacto em termos de danos devido à exploração (cerca de 60\%) foi observado entre as árvores pequenas $(10 \mathrm{~cm} \leq$ $\mathrm{DAP} \leq 20 \mathrm{~cm})$. O número médio de árvores comerciais impactadas foi 7,2 indivíduos por hectare $(17 \%)$ no tratamento $\mathrm{T} 1 ; 5,1 . \mathrm{ha}^{-1}(16 \%)$ no $\mathrm{T} 2 ; 3,6 . \mathrm{ha}^{-1}(9,0 \%)$ no $\mathrm{T} 3 \mathrm{e}$ $15,3 . \mathrm{ha}^{-1}(23 \%)$ no T4. Assim como na comunidade de maneira geral, mais de $50 \%$ das perdas entre as espécies comerciais ocorreu entre as árvores pequenas, com DAP < $20 \mathrm{~cm}$ (Figura 2). 

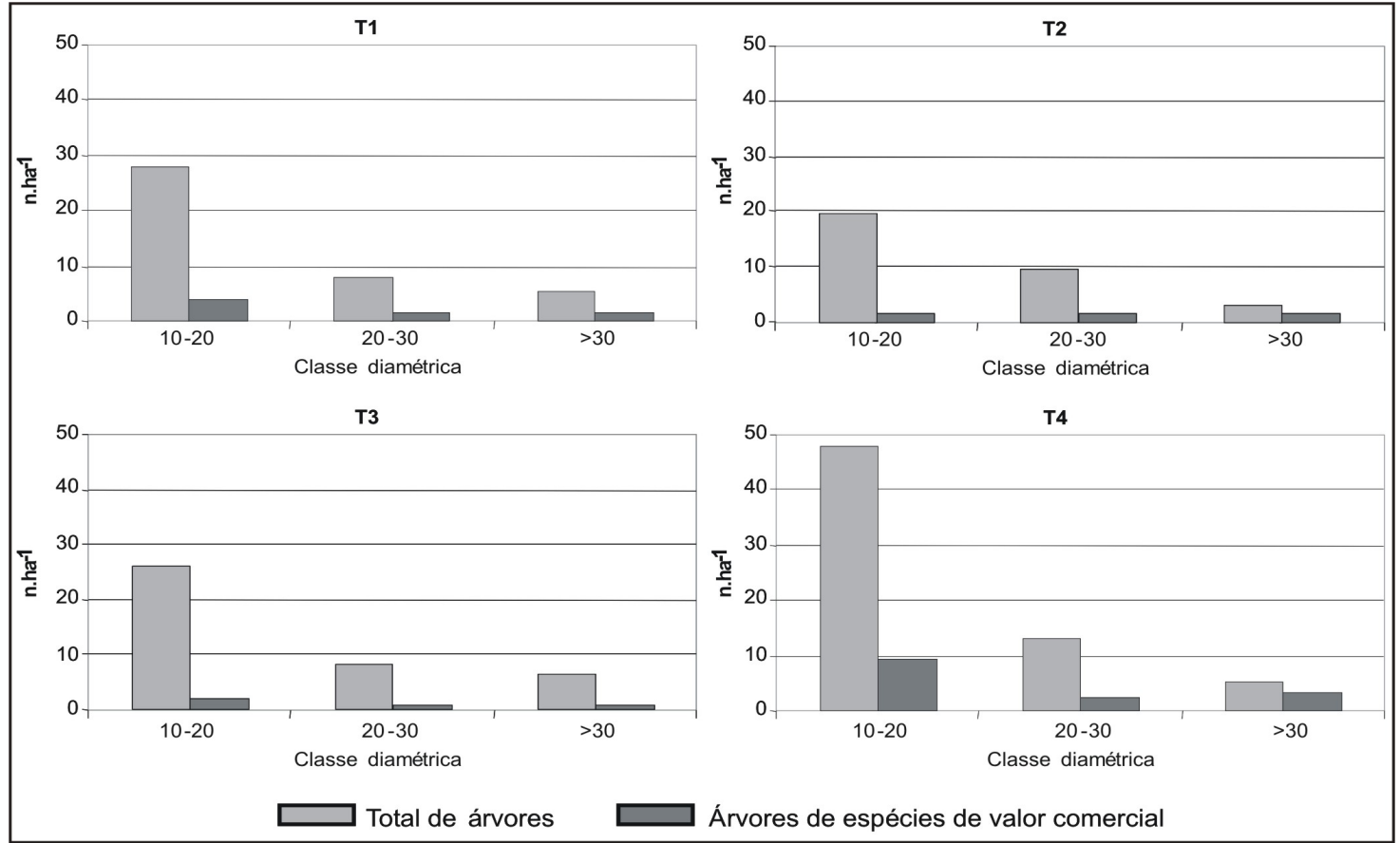

Figura 2 - Distribuição do número de árvores afetadas severamente pela exploração de madeira, por classe diamétrica, em cada tratamento. Floresta Nacional do Tapajós (Km 114 da BR 163)

\subsubsection{Desbastes Sistemáticos}

Pode-se observar na Tabela 2 que a quantidade de árvores mortas, em relação ao número de árvores aneladas, variou consideravelmente entre os tratamentos, mesmo após nove anos de sua aplicação, sendo as parcelas do T4 as que apresentaram a maior efetividade, com a mortalidade de aproximadamente $84 \%$ das árvores aneladas.

A baixa taxa de mortalidade observada no $\mathrm{T} 2$ se deve, em parte, às características morfológicas e dendrológicas da espécie Geissospermum sericeum (quinarana) e do grupo das sapotaceas (abius). A quinarana e os abius responderam por 55\% do total de árvores aneladas e apresentaram mortalidade de apenas 18\%. Geissospermum sericeum, da família Apocynaceae, possui o fuste bastante sulcado, o que dificultou a execução do anelamento e a aplicação do arboricida. As sapotaceas apresentam exsudação de látex, o que as torna relativamente resistentes à ação do arboricida. 
Tabela 2 Efetividade do anelamento com aplicação de arboricida, por tratamento, realizada na Floresta Nacional do Tapajós (Km114 da Br 163)

\begin{tabular}{|c|c|c|c|c|c|c|}
\hline \multirow{2}{*}{ Variáveis } & \multicolumn{2}{|c|}{ T2 } & \multicolumn{2}{|c|}{ T3 } & \multicolumn{2}{|c|}{ T4 } \\
\hline & n.hat ${ }^{-1}$ & $\%$ & n.hat ${ }^{-1}$ & $\%$ & n.hat ${ }^{-1}$ & $\%$ \\
\hline $\mathrm{N}^{0}$ de árvores aneladas & 11,4 & 100 & 163,7 & 100 & 242 & 100 \\
\hline $\mathrm{N}^{\mathrm{o}}$ de aneladas mortas após 1 ano & 1,7 & 14,9 & 75,3 & 46,0 & 118 & 48,8 \\
\hline \multirow[t]{2}{*}{$\mathrm{N}^{0}$ de aneladas mortas após 9 anos } & 4,0 & 35,1 & 129,3 & 79,0 & 204 & 84,3 \\
\hline & $\mathbf{m}^{2} \cdot \mathrm{ha}^{-1}$ & $\%$ & $\mathbf{m}^{2} \cdot \mathbf{h a}^{-1}$ & $\%$ & $\mathbf{m}^{2} \cdot \mathbf{h a}^{-1}$ & $\%$ \\
\hline Área basal original & 31,9 & 100 & 28,9 & 100 & 28,8 & 100 \\
\hline Redução da $\mathrm{AB}$ pela exploração & 5,2 & 16,3 & 3,2 & 11,1 & 4,9 & 17,0 \\
\hline Redução da AB pelo TS & 1,0 & 3,1 & 5,9 & 20,4 & 9,3 & 32,3 \\
\hline Redução total da $\mathrm{AB}$ & 6,2 & 19,4 & 9,1 & 31,5 & 14,2 & 49,3 \\
\hline
\end{tabular}

A resistência ao anelamento e ao arboricida demonstrados por árvores com fustes sulcados ou canelados e com exsudação tem sido observada por diversos autores. Pitt (1969) afirma que árvores de espécies com fustes sulcados somente são susceptíveis ao anelamento quando são pequenas (DAP em torno de $10 \mathrm{~cm}$ ) e que espécies que exsudam látex ou resina têm grande resistência à ação do arboricida. Jardim et al. (1990) também concluiu que o anelamento profundo com aplicação de óleo diesel tem efeito muito pequeno em árvores com essas características. Sandel \& Carvalho (2000) estudando diferentes métodos de anelamento na Floresta Nacional do Tapajós, em área adjacente a esta pesquisa, no km 69 da Rodovia Santarém-Cuiabá, concluíram que as espécies, Pouteria heterosepala e Hevea guianensis, pelo seu alto teor de látex, apresentaram-se resistentes à anelagem com baixas taxas de mortalidade, mesmo após cinco anos da aplicação.

Os resultados da efetividade do desbaste, por espécie tratada, considerando todos os tratamentos, podem ser observados no Anexo C. As espécies com maior número de indivíduos anelados foram Inga sp. (ingá), Pouteria sp. (abiu), Rinorea guianensis (acariquarana) e Cecropia sciadophylla (embaúba). Estas quatro espécies corresponderam a aproximadamente $45 \%$ do número total de árvores aneladas.

De modo geral, os gêneros Inga, Miconia, Brosimum, Cecropia e Pouroma que apresentam espécies pioneiras de madeira branca e rápido crescimento foram mais susceptíveis, enquanto que espécies com reentrâncias no fuste como Aspidosperma rigidum (carapanauba), Geissospermum senceum (quinarana) e Chimarrhis turbinata (pau de remo); que exsudam látex ou resina como Terminalia amazonica (cuiarana), 
Lacmellia sculenta (pau-de-colher) e as do gênero Pouteria (abius); e algumas Annonaceaes, chamadas "enviras", que possuem a casca com fibras longas que facilitam a cicatrização do anel como Guatteria ovalifolia (envira-cana) e Xylopia benthamiana (envira amarela) apresentaram maior resistência, com taxas abaixo de $40 \%$ de mortalidade (Anexo C).

Outro fator que pode ter reduzido a eficiência do desbaste, considerando todas as áreas, foi a utilização do anelamento com entalhes que é menos eficiente do que a anelagem completa. Segundo Sandel \& Carvalho (2000), a anelagem completa, apesar de maior demanda de tempo e conseqüentemente aumento dos custos, é mais indicada para tratamentos silviculturais, porque, além de dificultar a recuperação da incisão pela regeneração da casca, também mostra uma taxa de mortalidade maior que a anelagem com entalhes.

De maneira geral, o anelamento com a aplicação do arboricida mostrou maior efeito nas árvores com diâmetro inferior a $40 \mathrm{~cm}$, que apresentaram sobrevivência em torno de $14 \%$ a $29 \%$. Nas classes diamétricas superiores, apesar do número de árvores aneladas por hectare ter sido bem menor, a taxa média de sobrevivência foi em torno de 44\%, com um máximo de 73\% na classe de 50-60cm de DAP, mesmo após nove anos da aplicação (Figura 3).
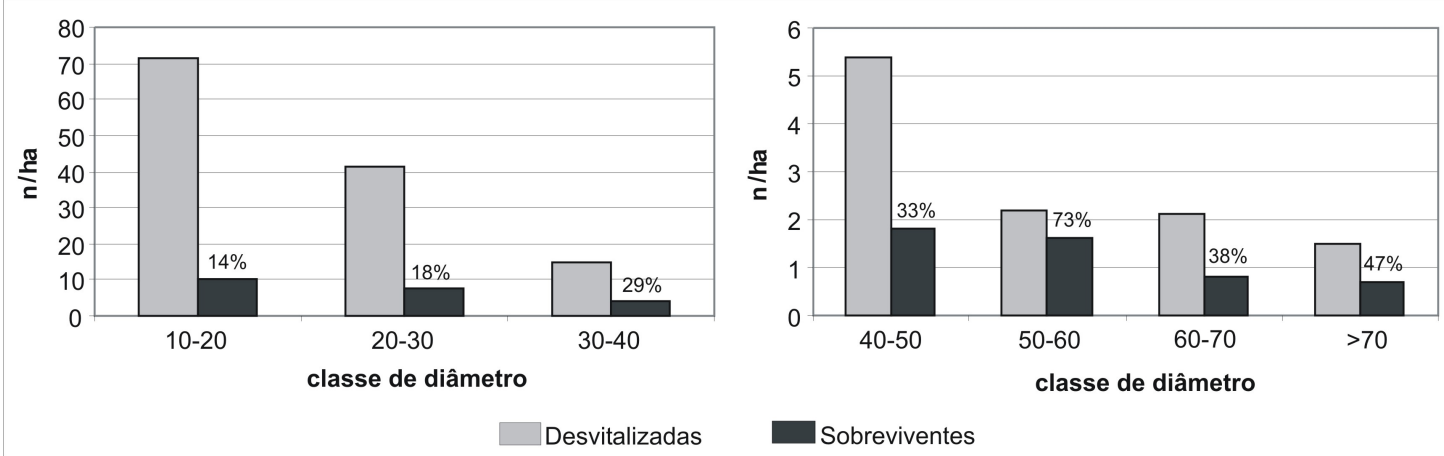

Figura 3 - Número de árvores desvitalizadas e sobreviventes, por classe diamétrica (Floresta Nacional do Tapajós)

Esses resultados são comparáveis aos encontrados por Jardim et al. (1990), que estudando diferentes intensidades de anelamento em uma floresta tropical próxima a Manaus - AM, observou que a percentagem de árvores vivas, dois anos após a 
aplicação do tratamento, estava entre 28\% e 33\% nas classes acima de $70 \mathrm{~cm}$ de diâmetro e entre $6 \%$ e 17\% nas classes inferiores. Costa et al. (2001), avaliando a efetividade de desbastes aplicados na região do Tapajós (PA) e Jarí (AP), verificaram que a sobrevivência nas classes acima de $45 \mathrm{~cm}$ de diâmetro ficou entre $40 \%$ e $60 \%$ enquanto que, entre as árvores menores, esses valores foram de 5\% a 30\%. Os dados obtidos nesta pesquisa concordam também com Dubois (1971), quando afirma que a anelagem perde eficácia com o aumento do diâmetro das árvores.

Pode-se observar também na Tabela 2 que a redução da área basal, somando-se o efeito da exploração e dos tratos silviculturais, ficou abaixo do esperado, sendo parcialmente alcançada no tratamento T2 $(19,4 \%)$ quando o planejado foi $20 \%$, no tratamento $\mathrm{T} 3$ que deveria ser de $40 \%$, foi obtida uma redução de $31,5 \%$ e no tratamento T4 a redução foi de aproximadamente 50\%, quando o esperado era de $60 \%$ da área basal.

\subsection{Conclusão}

- Houve grande variação na quantidade de madeira extraída nas parcelas dos tratamentos, mesmo considerando uma única lista de espécies a extrair e o mesmo diâmetro mínimo de corte. Isso era esperado devido a heterogeneidade natural existente entre as parcelas, uma vez que somente 13\% das espécies exploradas eram comuns a todos os tratamentos.

- A redução da área basal, obtida com a exploração e os desbastes, foi inferior ao planejado em todos os tratamentos. Isso pode levar a uma diminuição dos efeitos esperados no ingresso e crescimento das espécies de valor comercial reservadas para a futura colheita.

- Recomenda-se que outros desbastes, baseados no mesmo método e realizados em áreas com a presença de espécies com essas características dendrológicas (fuste com reentrâncias e exudação de latex ou resina), sejam executados com uma intensidade de aproximadamente $10 \%$ acima do planejado, para que sejam atingidos níveis satisfatórios de redução da área basal. Outra alternativa seria utilizar a técnica de 
anelagem completa que poderá apresentar maior eficiência que a anelagem com entalhes. 


\section{EFEITO DA EXPLORAÇÃO DE MADEIRA E TRATAMENTOS SILVICULTURAIS NA COMPOSIÇÃO FLORÍSTICA E DIVERSIDADE DE ESPÉCIES EM UMA ÁREA DE 136ha NA FLORESTA NACIONAL DO TAPAJÓS, BELTERRA-PARÁ}

\section{Resumo}

São discutidas as mudanças ocorridas na composição florística e na diversidade de espécies em uma área de 136ha, na Floresta Nacional do Tapajós, ao longo de 22 anos de monitoramento. São abordadas as influências da extração de madeira e das diferentes intensidades de desbastes aplicadas, visando induzir o aumento no número de espécies de valor comercial madeireiro. Foram incluídas todas as árvores com DAP $\geq 5,0 \mathrm{~cm}$ presentes em 41 parcelas permanentes de $0,25 \mathrm{ha}$, distribuídas entre os tratamentos. As medições da área explorada foram realizadas 1 ano antes da exploração (1981), e após a exploração nos anos de 1983, 1987, 1989, 1995 e 2003. Para a área testemunha foram realizadas 5 medições: 1983, 1987, 1989, 1995 e 2003. As duas intervenções provocaram a diminuição da riqueza florística logo após sua aplicação. Todavia com o passar do tempo a abertura no dossel estimulou a entrada de novas espécies no povoamento de tal forma que, 21 anos depois da exploração e nove após os desbastes, todos os tratamentos, apresentaram aumento no número de espécies em relação à primeira medição, o que indica o efeito positivo das intervenções. Na área testemunha, não houve aumento na riqueza florística durante o período avaliado. 


\section{Summary}

Changes occurring in floristic composition and species diversity in a 136ha area, in the Tapajós National Forest, during 22 years of monitoring are discussed. The influences of timber harvesting and of the different intensities of thinning applied, seeking to induce an increase in the number of commercially valuable timber species are considered. All trees with $\mathrm{DBH} \geq 5,0 \mathrm{~cm}$ present in 41 permanent plots measuring 0,25 ha were included, distributed among the treatments. Measurements of the logged area were carried out one year before harvest (1981), and after harvest in the years 1983, 1987, 1989, 1995 and 2003. For the control area, 5 measurements were carried out, 1987, 1989, 1995 and 2003. The two interventions led to a reduction in floristic diversity soon after their application. However, over time, opening of the canopy stimulated the entry of new species into the population, so that, 21 years after logging and nine after thinning, all the treatments presented an increase in the number of species in relation to the first measurement, which indicates the positive effect of the interventions. In the control area, there was no increase in floristic diversity during the period assessed.

\subsection{Introdução}

O conhecimento da composição florística e da diversidade de espécies em florestas tropicais é de suma importância para o planejamento da utilização racional desse recurso.

A grande maioria dos estudos florísticos em florestas manejadas na América Latina se concentra em inventários da vegetação arbórea, restringindo-se principalmente às espécies de interesse comercial atual ou potencial, ou na regeneração das mesmas pouco depois da extração madeireira. Conseqüentemente, pouca informação foi gerada sobre os efeitos da exploração florestal na composição florística e na diversidade de espécies a médio e longo prazo, ainda que esses conhecimentos formem a base da sustentabilidade do manejo florestal. Até o momento somente um número reduzido de 
pesquisas enfocou esse aspecto (Magnusson et al., 1999; Delgado et al., 1997; Carvalho, 1992; Wagner, 1997; Kammesheidt, 1997).

A diversidade vegetal em florestas tropicais está bastante relacionada ao processo de regeneração natural das espécies. Fatores que vão desde os de ordem natural até os de ação antrópica podem influenciar o processo de regeneração e a composição florística de uma floresta. A escala de tempo entre a perturbação do ecossistema e as fases de reconstrução também é um fator importante, que pode influenciar a riqueza e a diversidade de espécies (Bruenig, 1986).

A diversidade envolve a riqueza de espécies e sua uniformidade. De maneira geral os índices de diversidade podem variar entre um valor mínimo para comunidades monoespecíficas até um valor máximo em comunidades multiespecíficas.

A diversidade tem sido assunto de muitas discussões e gerado extensa literatura, principalmente porque o desejo de muitos pesquisadores é encontrar uma expressão matemática que melhor explique as suas definições biológicas. Muitos índices quantitativos têm sido propostos e usados em diversos estudos. Brower \& Zar (1977) propõem índices de diversidade e justificam que estes incorporam o número de espécies e o total de indivíduos em todas as espécies, Magurran (1988) examina detalhadamente 18 índices e Ludwig \& Reynolds (1988) discutem separadamente ou de forma combinada mais de dez índices de diversidade. Extensas revisões sobre o assunto também podem ser encontradas em Whittaker (1965) e McIntosh (1967).

Um ponto em comum entre a maioria dos autores sobre a definição e a medição dos índices de diversidade e a presença de dois elementos, a riqueza, também chamada de diversidade de espécies de uma comunidade, que é o número de espécies num determinado local e a uniformidade, também chamada de equabilidade, que é a forma como os indivíduos se distribuem entre as espécies de uma área ou amostra.

Entre os diversos índices encontrados na literatura, o índice de Shannon é um dos mais conhecidos e tem sido amplamente utilizado em estudos ecológicos por combinar a riqueza e a uniformidade de um dado habitat (Magurran, 1988).

O índice de Shannon (H') assume que os indivíduos foram amostrados ao acaso a partir de uma população infinitamente grande e que todas as espécies estão 
representadas na amostra. Seu valor será máximo quando cada indivíduo pertencer a uma espécie diferente, e mínimo quando todos pertencerem a mesma espécie. Segundo Felfili \& Ventuoli (2000) o uso desse índice induz a um resultado tendencioso, entretanto, na prática, este desvio raramente é significativo. Os autores citam como fonte de erro a falha de incluir todas as espécies na amostra, mas afirmam que apesar disso constitui um dos melhores índices usados em comparações, caso não haja interesse em separar abundância de raridade.

Neste capítulo são discutidas as mudanças ocorridas na composição florística e na diversidade de espécies em cada tratamento em uma área de 136ha, ao longo de 22 anos de acompanhamento. Serão abordadas as influências da atividade de extração de madeira e das diferentes intensidades de desbastes aplicadas, visando induzir o aumento no número de árvores de espécies de valor comercial madeireiro. Procura-se especificamente responder as seguintes perguntas:

1. As intervenções realizadas na área alteraram a riqueza florística e a diversidade de espécies arbóreas em relação à floresta testemunha?

2. Qual(is), dentre os tratamentos testados, é o mais adequado visando a produção sustentada de madeira, ou seja, favorece o aumento do número de espécies comerciais madeireiras na floresta?

\subsection{Material e métodos}

O número médio de famílias, gêneros e espécies foram determinados para as parcelas relativas aos cinco tratamentos aplicados:

- Tratamento T0: Testemunha, área sem intervenção (1,5ha).

- Tratamento T1: Exploração de espécies comerciais madeireiras com DAP $\geq$ $45 \mathrm{~cm}(2,5 \mathrm{ha})$

- Tratamento T2: Exploração de espécies comerciais madeireiras com DAP $\geq$ $55 \mathrm{~cm}+$ desbaste de espécies não comerciais totalizando aproximadamente $20 \%$ de redução da área basal original (1,75ha). 
- Tratamento T3: Exploração de espécies comerciais madeireiras com DAP $\geq$ $55 \mathrm{~cm}+$ desbaste de espécies não comerciais totalizando aproximadamente $30 \%$ de redução da área basal original (3,0ha).

- Tratamento T4: Exploração de espécies comerciais madeireiras com DAP $\geq$ $55 \mathrm{~cm}+$ desbaste de espécies não comerciais totalizando aproximadamente $50 \%$ de redução da área basal original (1,5ha).

Foram incluídas todas as árvores com DAP $\geq 5,0 \mathrm{~cm}$ presentes em 41 parcelas de $50 \mathrm{~m} \times 50 \mathrm{~m}$ distribuídas entre os tratamentos, conforme descrito no Capítulo I.

As medições da área explorada foram realizadas em seis ocasiões: 1 ano antes da exploração comercial de madeira (1981), 1 ano após a exploração (1983) e 5, 7, 13 e 21 anos após a colheita de madeira, correspondendo aos anos de 1987, 1989, 1995 e 2003, respectivamente. Para a área testemunha (tratamento T0) foram realizadas 5 medições: 1983, 1987, 1989, 1995 e 2003.

Considerando que esse estudo inclui somente árvores com o diâmetro igual ou superior a 5,0cm, a termo "aparecimento" ou "ingresso" de espécies, utilizado nas discussões, significa o surgimento, nas parcelas amostradas, de novas árvores nesta primeira classe de DAP, ou seja, o aumento no número de espécies, na maioria das vezes, se deve ao crescimento de indivíduos jovens já existentes na regeneração natural (ainda que algumas espécies pioneiras sejam capazes de crescer do estagio de sementes até $5,0 \mathrm{~cm}$ de DAP entre duas medições consecutivas). Da mesma forma, o termo “desaparecimento" de espécies significa a mortalidade, na área amostrada, somente dos indivíduos com DAP $\geq 5,0 \mathrm{~cm}$.

O índice de Shannon foi utilizado para determinar a diversidade de espécies em cada tratamento, através da seguinte equação:

$$
\begin{aligned}
& H^{\prime}=-\sum_{i=1}^{S} p i \cdot \ln p i \\
& P i=n i / N
\end{aligned}
$$

onde:

$$
n i=\text { número de indivíduos de indivíduos da espécie } \mathrm{i}
$$




$$
\begin{aligned}
& N=\text { número total de indivíduos amostrados } \\
& S=\text { número total de espécies na comunidade }
\end{aligned}
$$

A equabilidade foi calculada através da fórmula proposta por Pielou (1975).

$$
J=H^{\prime} / \ln S
$$

onde:

$$
\begin{aligned}
& H^{\prime}=\text { índice de diversidade de Shannon } \\
& S=\text { número total das espécies amostradas }
\end{aligned}
$$

$\mathrm{O}$ índice de equabilidade varia entre 0 e 1 , onde 1 representa a máxima uniformidade, isto é, todas as espécies são igualmente abundantes.

As áreas amostradas para cada tratamento possuem tamanhos diferentes, o que dificulta a comparação entre elas. Por isso, para a análise dos efeitos das intervenções sobre a composição florística e a diversidade foi utilizada a média, por parcela, do número de famílias, gêneros e espécies, encontrados a cada ano de medição.

A comparação entre os tratamentos foi realizada através da análise de variância, uma vez que as pressuposições básicas para o uso desse método (normalidade dos dados e homocedasticidade) foram obedecidas. A verificação da normalidade dos dados foi efetuada através do teste de Shapiro Wilks. As análises estatísticas foram efetuadas através do programa SAS System.

\subsection{Resultados}

\subsubsection{Comparação da riqueza e diversidade florística entre os tratamentos aplicados}

Na Tabela 1 encontram-se as médias do número de famílias, gêneros e espécies, obtidas por parcela, na área de cada tratamento, e a cada ano de medição.

Pode-se observar que, apesar de não ter sido captada diferenças estatísticas significativas (Tabela 2), havia certa heterogeneidade na riqueza florística dos tratamentos antes da realização das intervenções. As parcelas do tratamento T4 
apresentavam maior número de famílias, gêneros e espécies, seguidas do T3, T2 e T1 (Tabela 1).

Logo após a exploração, todos os tratamentos tiveram perdas no número médio de famílias, gêneros e espécies em conseqüência da mortalidade provocada pela extração de madeira. Todavia, essas perdas foram recuperadas nos anos posteriores através do ingresso de novas espécies na comunidade. Comparando-se a primeira com a última medição, verificou-se um balanço positivo, na riqueza florística de todos os tratamentos. O T3 foi o que obteve o maior aumento com aproximadamente 10 espécies a mais do que as presentes na primeira medição. Em seguida estão T1, T4 e T2 com ganhos de 6,5, 5,2 e 3,4 espécies.parcela ${ }^{-1}$, respectivamente.

Por outro lado, a floresta testemunha, onde nenhuma intervenção foi realizada, manteve-se praticamente estável em relação à riqueza florística durante todo o período de acompanhamento (Tabela 1 e Figura 1a).

Tabela 1 Número médio e respectivo desvio padrão relativo para famílias, gêneros e espécies por tratamento e por ano de medição em uma área de 10,25ha na Floresta Nacional do Tapajós (Km 114 da BR 163)

\begin{tabular}{cccccccc}
\hline \multirow{2}{*}{ Trat. } & Grupos & 1 ano antes & \multicolumn{6}{c}{ Anos após a exploração } \\
& Avaliados & da explor. & $\mathbf{1}$ & $\mathbf{5}$ & $\mathbf{7}$ & $\mathbf{1 3}$ & $\mathbf{2 1}$ \\
\hline \multirow{2}{*}{ T0 } & Fam & - & $36,0 \pm 1,4$ & $35,5 \pm 2,1$ & $35,0 \pm 1,4$ & $35,5 \pm 0,7$ & $34,5 \pm 0,7$ \\
& Gen & - & $66,2 \pm 6,2$ & $65,6 \pm 4,9$ & $65,6 \pm 4,4$ & $67,0 \pm 2,7$ & $67,2 \pm 1,9$ \\
& Esp & - & $79,0 \pm 5,3$ & $78,5 \pm 5,4$ & $78,5 \pm 4,1$ & $80,3 \pm 3,3$ & $79,5 \pm 5,4$ \\
T1 & Fam & $31,9 \pm 3,0$ & $31,4 \pm 3,1$ & $33,4 \pm 5,3$ & $34,7 \pm 3,3$ & $34,1 \pm 3,1$ & $34,5 \pm 3,4$ \\
& Gen & $62,6 \pm 5,2$ & $58,9 \pm 5,6$ & $64,6 \pm 6,1$ & $66,0 \pm 5,1$ & $65,1 \pm 4,8$ & $65,9 \pm 5,4$ \\
& Esp & $74,1 \pm 6,3$ & $67,6 \pm 8,0$ & $76,5 \pm 7,3$ & $78,9 \pm 6,7$ & $80,0 \pm 5,4$ & $80,6 \pm 5,7$ \\
T2 & Fam & $31,4 \pm 4,0$ & $30,1 \pm 4,1$ & $31,4 \pm 4,1$ & $32,4 \pm 1,8$ & $32,7 \pm 2,4$ & $32,1 \pm 3,0$ \\
& Gen & $64,0 \pm 8,9$ & $60,1 \pm 8,9$ & $62,9 \pm 6,0$ & $65,6 \pm 4,2$ & $64,6 \pm 5,5$ & $65,3 \pm 6,4$ \\
& Esp & $76,7 \pm 12,1$ & $71,6 \pm 11,1$ & $76,7 \pm 5,1$ & $78,4 \pm 6,1$ & $77,4 \pm 8,2$ & $80,1 \pm 10,6$ \\
T3 & Fam & $32,4 \pm 2,6$ & $31,7 \pm 2,7$ & $33,9 \pm 2,5$ & $35,1 \pm 4,4$ & $33,7 \pm 2,2$ & $34,7 \pm 2,5$ \\
& Gen & $65,7 \pm 6,1$ & $60,7 \pm 5,9$ & $66,7 \pm 5,3$ & $69,0 \pm 6,1$ & $68,1 \pm 6,6$ & $72,2 \pm 7,0$ \\
& Esp & $77,4 \pm 7,0$ & $71,0 \pm 7,5$ & $79,0 \pm 6,2$ & $81,7 \pm 7,0$ & $81,9 \pm 7,9$ & $87,3 \pm 9,0$ \\
T4 & Fam & $33,7 \pm 2,9$ & $30,8 \pm 4,3$ & $33,8 \pm 3,2$ & $34,2 \pm 2,5$ & $33,5 \pm 2,2$ & $33,8 \pm 2,7$ \\
& Gen & $67,5 \pm 7,7$ & $60,2 \pm 9,8$ & $66,7 \pm 8,5$ & $67,7 \pm 6,5$ & $68,0 \pm 7,2$ & $70,0 \pm 7,0$ \\
& Esp & $79,3 \pm 12,8$ & $71,0 \pm 13,6$ & $78,3 \pm 11,4$ & $80,2 \pm 9,8$ & $79,8 \pm 10,4$ & $84,5 \pm 8,2$ \\
\hline
\end{tabular}

O índice de Shannon apresentou pequena variação durante o período estudado, ficando entre 3,5 e 3,8. A área não explorada (testemunha) manteve os maiores valores, em torno de 3,8 durante todas as medições. A diversidade apresentou ligeira diminuição 
logo após a exploração em todos os tratamentos, exceto a testemunha, em conseqüência da extração de algumas espécies comerciais, em seguida voltou a crescer paulatinamente até o final do período (Figura 1b).

Apesar da variação ocorrida na riqueza florística entre os tratamentos ao longo do período avaliado, análises de variância e teste $\mathrm{F}$, realizados a cada ano de medição, não resultaram em diferenças significativas no número médio de espécies e na diversidade medida pelo índice de Shannon (Tabela 2 e 3).

Tabela 2 Valores dos testes de normalidade de Shapiro Wilks e do teste F da análise de variância obtidos para o número médio de espécies, em cada tratamento e a cada ano de medição, na Floresta Nacional do Tapajós (Km 114 da BR 163)

\begin{tabular}{|c|c|c|c|c|c|c|c|c|c|c|c|}
\hline \multirow{3}{*}{ Medições } & \multirow{3}{*}{ Ano } & \multicolumn{10}{|c|}{ Número de espécies } \\
\hline & & \multicolumn{5}{|c|}{ Médias dos tratamentos } & \multicolumn{2}{|c|}{ Normalidade } & \multicolumn{3}{|c|}{ Análise de variância } \\
\hline & & T0 & T1 & $\mathbf{T 2}$ & T3 & T4 & $\mathbf{W}$ & $\operatorname{Pr}>\mathbf{W}^{1}$ & $\mathbf{F}$ & $\operatorname{Pr}>F^{1}$ & CV \\
\hline $1 \mathbf{A E}$ & 1981 & $\begin{array}{ll}--- \\
--\end{array}$ & 74,1 & 76,7 & 77,4 & 79,3 & 0,97 & 0,40 & 0,46 & 0,71 & 12,1 \\
\hline $1 \mathrm{DE}$ & 1983 & 79,0 & 67,6 & 71,6 & 71,0 & 71,0 & 0,98 & 0,73 & 1,49 & 0,23 & 12,8 \\
\hline $5 \mathrm{DE}$ & 1987 & 78,5 & 76,5 & 76,7 & 79,0 & 78,3 & 0,97 & 0,29 & 0,23 & 0,92 & 9,5 \\
\hline $7 \mathrm{DE}$ & 1989 & 78,5 & 78,9 & 78,4 & 81,7 & 80,2 & 0,97 & 0,41 & 0,38 & 0,82 & 9,0 \\
\hline $13 \mathrm{DE}$ & 1995 & 80,3 & 80,0 & 77,4 & 81,9 & 79,8 & 0,98 & 0,77 & 0,42 & 0,79 & 9,3 \\
\hline $21 \mathrm{DE}$ & 2003 & 79,5 & 80,6 & 80,1 & 87,3 & 84,5 & 0,95 & 0,08 & 1,65 & 0,18 & 10,1 \\
\hline
\end{tabular}

Tabela 3 Valores dos testes de normalidade de Shapiro Wilks e do teste F da análise de variância obtidos para o índice de Shannon, em cada tratamento e a cada ano de medição, na Floresta Nacional do Tapajós (Km 114 da BR 163)

\begin{tabular}{|c|c|c|c|c|c|c|c|c|c|c|c|}
\hline \multirow{3}{*}{ Medições } & \multirow{3}{*}{ Ano } & \multicolumn{10}{|c|}{ Índice de Shannon } \\
\hline & & \multicolumn{5}{|c|}{ Médias dos tratamentos } & \multicolumn{2}{|c|}{ Normalidade } & \multicolumn{3}{|c|}{ Análise de variância } \\
\hline & & T0 & T1 & $\mathbf{T} 2$ & T3 & T4 & $\mathbf{W}$ & $\operatorname{Pr}>\mathbf{W}^{1}$ & $\mathbf{F}$ & $\operatorname{Pr}>F^{1}$ & $\mathbf{C V}$ \\
\hline $1 \mathbf{A E}$ & 1981 & 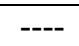 & 3,60 & 3,63 & 3,78 & 3,69 & 0,94 & 0,05 & 1,22 & 0,32 & 6,7 \\
\hline $1 \mathrm{DE}$ & 1983 & 3,81 & 3,55 & 3,56 & 3,67 & 3,64 & 0,94 & 0,05 & 1,33 & 0,28 & 6,8 \\
\hline 5 DE & 1987 & 3,81 & 3,63 & 3,66 & 3,78 & 3,70 & 0,97 & 0,47 & 1,62 & 0,19 & 4,8 \\
\hline 7 DE & 1989 & 3,81 & 3,66 & 3,69 & 3,79 & 3,72 & 0,97 & 0,24 & 1,23 & 0,31 & 4,6 \\
\hline $13 \mathrm{DE}$ & 1995 & 3,83 & 3,68 & 3,69 & 3,82 & 3,73 & 0,95 & 0,06 & 1,48 & 0,23 & 4,6 \\
\hline $21 \mathrm{DE}$ & 2003 & 3,82 & 3,73 & 3,74 & 3,85 & 3,75 & 0,97 & 0,35 & 1,49 & 0,22 & 3,8 \\
\hline
\end{tabular}

O índice de equabilidade também se manteve praticamente constante. Os tratamentos T2 e T3 apresentaram pequena queda, um ano após a exploração, mas 
recuperaram-se nos anos posteriores. A testemunha foi a área mais uniforme mantendose acima de 0,75 durante todo o período (Figura 1c).

A exploração madeireira e o tratamento silvicultural, realizados na área, independente da intensidade aplicada, não provocaram alterações significativas no número de espécies, diversidade e equabilidade. Algumas espécies madeireiras extraídas mais intensivamente durante a exploração estão, até o momento, ausentes na área de alguns tratamentos, todavia, houve o ingresso de outras espécies que não estavam presentes durante a primeira coleta de dados, o que contribuiu para manter constante a diversidade e a equabilidade. Nenhuma das espécies sem valor comercial conhecido, aneladas como parte dos tratamentos silviculturais, foram eliminadas da área, apenas as quantidades relativas dos indivíduos dessas espécies foram reduzidas visando beneficiar as de valor comercial madeireiro, preservando-se com isso a riqueza e a diversidade florística do povoamento.

Apesar de não terem sido encontradas diferenças estatísticas significativas entre o número de espécies e o índice de diversidade entre os tratamentos, as mudanças ocorridas ao longo do período de avaliação e o efeito das intervenções sobre a composição florística foram diferenciadas para cada área. Essas especificidades são discutidas separadamente para cada tratamento. 


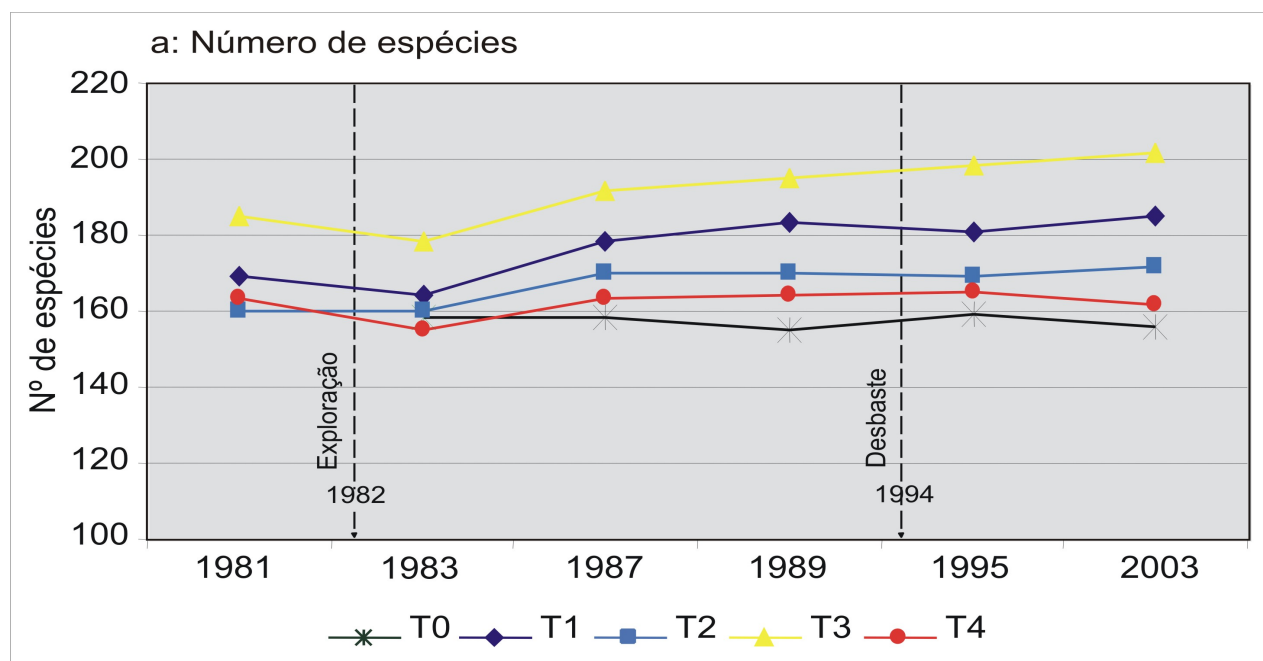

b: Índice de diversidade de Shannon

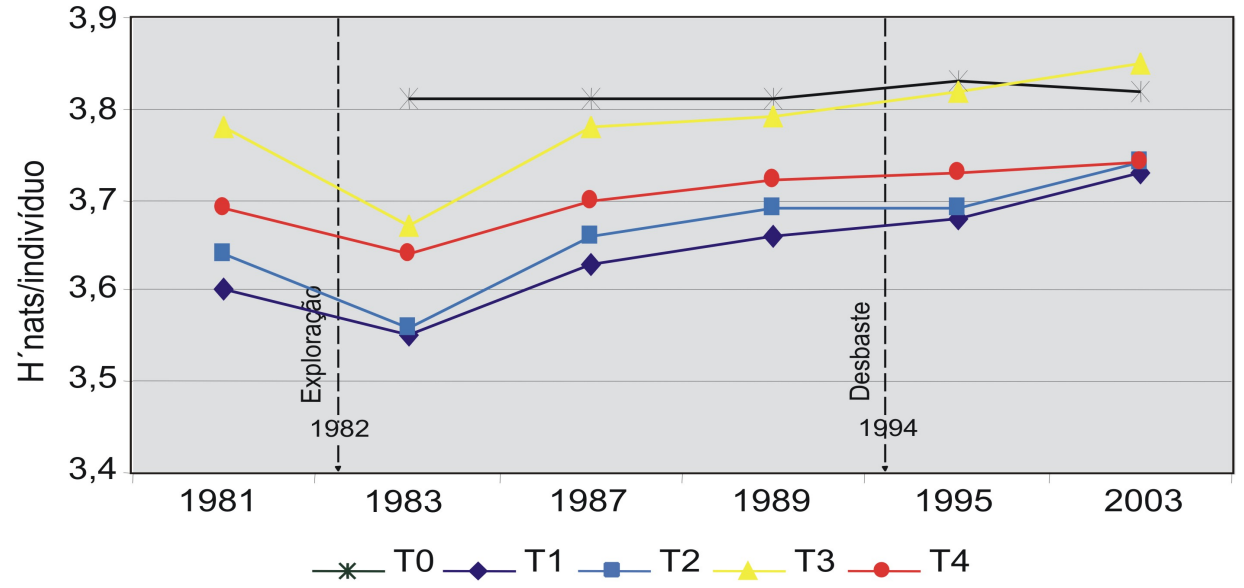

c: Índice de Equabilidade de Pielou

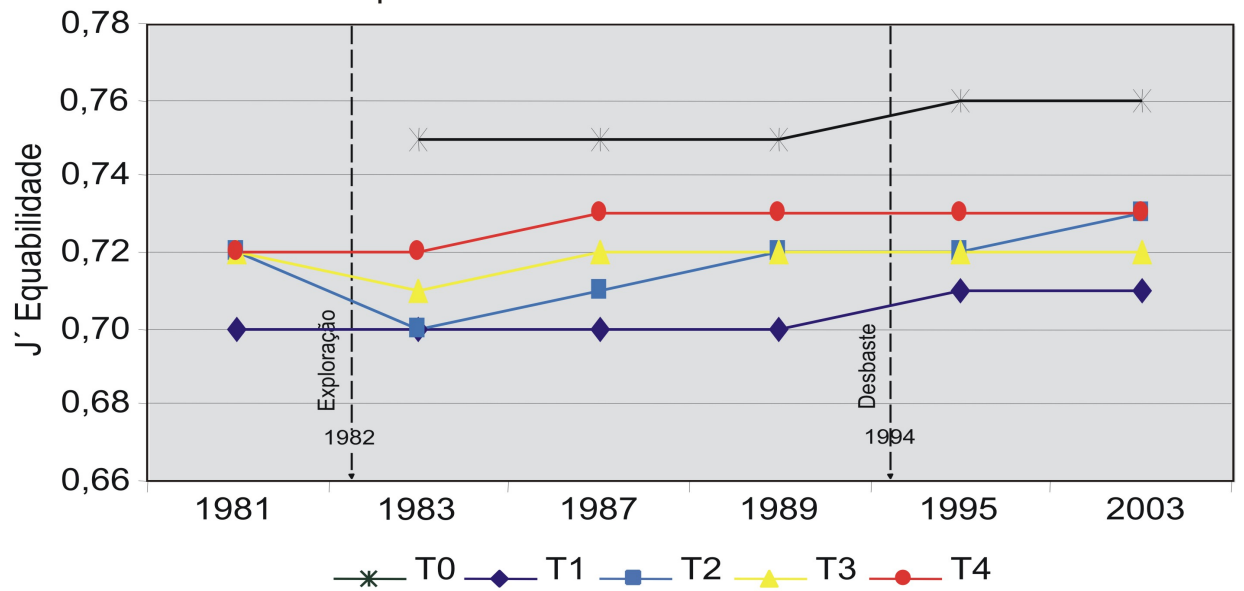

Figura 1 - Número de espécies.parcela ${ }^{-1}$ (a), índice de diversidade de Shannon (b) e índice de equabilidade de Pielou (c) por tratamento e ano de medição em uma área de 10,25ha na Floresta Nacional do Tapajós (Km 114 da BR 163) 


\subsubsection{Tratamento T1: Exploração de espécies comerciais madeireiras com $\mathrm{DAP} \geq$ $45 \mathrm{~cm}(2,5 \mathrm{ha})$}

As mudanças ocorridas na composição florística em relação à entrada e saída de espécies na área do tratamento T1, estão listadas na Tabela 4.

No primeiro período (1981-1983) houve o desaparecimento de 10 espécies, cinco delas de valor comercial, que foram extraídas durante as atividades de exploração em 1982. Nesse mesmo período surgiram na área cinco novas espécies, sendo três pioneiras (Hevea sp., Jacaranda copaia e Vochysia surinamensis) e duas tolerantes (Clarisia racemosa e Ocotea rubra). No segundo e terceiro períodos de acompanhamento (19831987 e 1987-1989) nenhuma espécie foi excluída e houve o aparecimento de 19, seis delas estavam reaparecendo na área, pois haviam desaparecido entre 1981-1983, em conseqüência da exploração. Os últimos dois períodos (1989-1995 e 1995-2003) foram equilibrados, com o desaparecimento de seis e o surgimento de oito novas espécies (Tabela 4).

Tabela 4 Mudanças na composição florística durante o período de 1981-2003 em 2,5ha no tratamento T1. Floresta Nacional do Tapajós (Km 114 da BR 163)

\begin{tabular}{|c|c|c|c|c|c|c|c|c|c|c|c|}
\hline \multirow[t]{2}{*}{ Espécies } & \multicolumn{2}{|c|}{$\begin{array}{c}1981- \\
1983\end{array}$} & \multicolumn{2}{|c|}{$\begin{array}{c}1983- \\
1987\end{array}$} & \multicolumn{2}{|c|}{$\begin{array}{c}1987- \\
1989\end{array}$} & \multicolumn{2}{|c|}{$\begin{array}{l}1989- \\
1995\end{array}$} & \multicolumn{2}{|c|}{$\begin{array}{l}1995- \\
2003\end{array}$} & \multirow[t]{2}{*}{$\begin{array}{c}\text { Grupo } \\
\text { Ecol. }\end{array}$} \\
\hline & D & I & D & I & D & $\mathbf{I}$ & D & I & D & $\mathbf{I}$ & \\
\hline Eperua schomburgkiana* & \# & & & + & & & & & & & Tol. \\
\hline Mouriria plasschaerti & $\#$ & & & + & & & & & & & Tol. \\
\hline Phyllanthus nobilis & $\#$ & & & + & & & & & & & Tol. \\
\hline Bagassa guianensis ${ }^{*}$ & $\#$ & & & & & + & & & & & Pio. \\
\hline Brosimum discolor & \# & & & & & + & & & & & Tol. \\
\hline Parkia pendula ${ }^{*}$ & \# & & & & & + & & & & & Pio. \\
\hline Ambelania sp. & \# & & & & & & & & & + & Tol. \\
\hline Bertholletia excelsa ${ }^{*}$ & \# & & & & & & & & & & Pio. \\
\hline Virola divergens ${ }^{*}$ & \# & & & & & & & & & & Tol. \\
\hline Cecropia sp. & $\#$ & & & & & & & & & & Pio. \\
\hline Clarisia racemosa & & + & & & & & & & & & Tol. \\
\hline Hevea sp. & & + & & & & & & & & & Pio. \\
\hline Jacaranda copaia ${ }^{*}$ & & + & & & & & & & & & Pio. \\
\hline Ocotea rubra ${ }^{*}$ & & + & & & & & & & & & Tol. \\
\hline Vochysia surinamensis ${ }^{*}$ & & + & & & & & & & & & Pio. \\
\hline Aegiphilla sp. & & & & + & & & & & & & Pio. \\
\hline
\end{tabular}


Tabela 4 Mudanças na composição florística durante o período de 1981-2003 em 2,5ha no tratamento T1. Floresta Nacional do Tapajós (Km 114 da BR 163)

\begin{tabular}{|c|c|c|c|c|c|c|c|c|c|c|c|}
\hline \multirow[t]{2}{*}{ Espécies } & \multicolumn{2}{|c|}{$\begin{array}{c}\text { 1981- } \\
1983\end{array}$} & \multicolumn{2}{|c|}{$\begin{array}{c}1983- \\
1987\end{array}$} & \multicolumn{2}{|c|}{$\begin{array}{c}1987- \\
1989\end{array}$} & \multicolumn{2}{|c|}{$\begin{array}{c}\text { 1989- } \\
1995\end{array}$} & \multicolumn{2}{|c|}{$\begin{array}{c}1995- \\
2003\end{array}$} & \multirow{2}{*}{$\begin{array}{c}\text { Grupo } \\
\text { Ecol. }\end{array}$} \\
\hline & D & $\mathbf{I}$ & D & I & D & $\mathbf{I}$ & D & $\mathbf{I}$ & D & $\mathbf{I}$ & \\
\hline Ambelania grandiflora & & & & + & & & & & & & Tol. \\
\hline Caryocar villosum ${ }^{*}$ & & & & + & & & & & & & Pio. \\
\hline Cecropia sciadophylla & & & & + & & & & & & & Pio. \\
\hline Dimorphandra gardneriana & & & & + & & & & & & & Pio. \\
\hline Ficus anthelminthica & & & & + & & & \# & & & & Tol. \\
\hline Parinarium barbatum & & & & + & & & & & & & Tol. \\
\hline Pithecelobium scandens & & & & + & & & & & & & Pio. \\
\hline Protium subserratum & & & & + & & & & & & & Tol. \\
\hline Siparuna decipiens & & & & + & & & & & & & Tol. \\
\hline Vismia japurensis & & & & + & & & & & & & Pio. \\
\hline Inga heterophylla & & & & & & & $\#$ & & & & Pio. \\
\hline Vatairea sericea $^{*}$ & & & & & & & \# & & & & Pio. \\
\hline Crudia sp. & & & & & & & & & \# & & Tol. \\
\hline Mezilaurus sp. & & & & & & & & & \# & & Tol. \\
\hline Guatteria sp. & & & & & & & & & \# & & Tol. \\
\hline Pithecelobium caulifloum & & & & & & + & & & & & Pio. \\
\hline Sapium marmieri & & & & & & + & & & & & Tol. \\
\hline Tachigali sp. & & & & & & & & + & & & Pio. \\
\hline Diplotropis purpúrea ${ }^{*}$ & & & & & & & & & & + & Tol. \\
\hline Mezilaurua itauba ${ }^{*}$ & & & & & & & & & & + & Tol. \\
\hline Poecilanthe effusa & & & & & & & & & & + & Tol. \\
\hline Saccoglottis amazonica & & & & & & & & & & + & Tol. \\
\hline Sclerolobium sp. & & & & & & & & & & + & Pio. \\
\hline Tabebuia impetiginosa ${ }^{*}$ & & & & & & & & & & + & Pio. \\
\hline
\end{tabular}

*Espécies de valor comercial, ${ }^{1} \mathrm{D}(\#)$ = espécies que desapareceram devido a mortalidade de todos os seus representantes com DAP $\geq 5,0 \mathrm{~cm},{ }^{2} \mathrm{I}(+)=$ espécies que ingressaram (atingiram $5,0 \mathrm{~cm}$ de diâmetro no período)

Considerando todo o período de avaliação, a área do T1 perdeu 16 espécies devido a mortalidade de todos os seus representantes dentro do limite de diâmetro considerado (DAP $\geq 5,0 \mathrm{~cm}$ ). Destas, sete reapareceram na área nos anos posteriores através do crescimento de indivíduos presentes na regeneração natural e apenas as espécies Bertholletia excelsa, Virola divergens, Cecropia sp., Ficus anthelminthica, Inga heterophylla, Vatairea sericea, Crudia sp., Mezilaurus sp., e Guatteria sp. ainda não reapareceram nas parcelas até o momento. Por outro lado, houve o surgimento de 24 espécies que não estavam presentes no primeiro levantamento, realizado antes da exploração o que gera um balanço positivo em termos de entrada e saída de espécies no período considerado (Tabela 4). 
O grupo de espécies com valor comercial madeireiro, que no primeiro levantamento constituía $32,5 \%$ do total de espécies da área, também teve um pequeno aumento, com o acréscimo de seis espécies, passando para 33\% do total. As espécies tolerantes a sombra dominaram o povoamento, mantendo-se com aproximadamente $70 \%$ do total de espécies durante todo o período.

As 10 espécies mais abundantes, considerando a última medição (2003), contribuíram com $45 \%$ do total de indivíduos.ha ${ }^{-1}$. Rinorea flavescens foi a mais abundante com 8,4\% do total, seguida de Inga sp. (7,6\%), Pouteria sp. (5,8\%) e Protium apiculatum (5,5\%) (Tabela 5). Essas espécies dominam o dossel inferior da floresta, tendo mais de $70 \%$ de seus indivíduos concentrados nas classes inferiores de diâmetro $(5,0 \mathrm{~cm} \leq \mathrm{DAP} \leq 15,0 \mathrm{~cm})$.

Tabela 5 Número de indivíduos por hectare (DAP $\geq 5,0 \mathrm{~cm}$ ) das espécies mais abundantes em 2,5ha no tratamento T1, ano de 2003. Floresta Nacional do Tapajós (Km 114 da BR 163)

\begin{tabular}{llcc}
\hline \multicolumn{1}{c}{ Espécies } & \multicolumn{1}{c}{ Família } & Grupo ecológico & Número de arv.ha $^{\mathbf{- 1}}$ \\
\hline Rinorea flavescens & Violaceae & Tolerante & 98,4 \\
Inga sp. & Fabaceae & Pioneira & 89,2 \\
Pouteria sp. & Sapotaceae & Tolerante & 68,0 \\
Protium apiculatum & Burseraceae & Tolerante & 63,6 \\
Rinorea guianensis & Violaceae & Tolerante & 48,0 \\
Bixa arborea & Bixaceae & Pioneira & 38,4 \\
Duguetia echinophora & Annonaceae & Tolerante & 37,2 \\
Cecropia sciadophylla & Moraceae & Pioneira & 31,6 \\
Ocotea sp. & Lauraceae & Tolerante & 27,2 \\
Neea sp. & Nyctaginaceae & Tolerante & 23,2 \\
Subtotal (10 espécies) & & & \\
Outras $(175$ espécies) & -- & -- & $524,8(45,0 \%)$ \\
Total (185 espécies) & -- & -- & $641,6(55,0 \%)$ \\
\hline
\end{tabular}

\subsubsection{Tratamento T2: Exploração de espécies comerciais madeireiras com $\mathrm{DAP} \geq$ $55 \mathrm{~cm}+$ desbaste de espécies não comerciais totalizando aproximadamente $20 \%$ de redução da área basal original (1,75ha).}

O balanço entre a entrada e a saída de espécies no tratamento T2, considerando todo o período, foi positivo, com o desaparecimento por mortalidade de 15 espécies e o ingresso de 22 que estavam ausentes no primeiro levantamento (Tabela 6). 
Tabela 6 Mudanças na composição florística durante o período de 1981-2003 em 1,75ha no tratamento T2. Floresta Nacional do Tapajós (Km 114 da BR 163)

\begin{tabular}{|c|c|c|c|c|c|c|c|c|c|c|c|}
\hline \multirow[t]{2}{*}{ Espécies } & \multicolumn{2}{|c|}{$\begin{array}{c}1981- \\
1983\end{array}$} & \multicolumn{2}{|c|}{$\begin{array}{l}1983- \\
1987\end{array}$} & \multicolumn{2}{|c|}{$\begin{array}{l}1987- \\
1989\end{array}$} & \multicolumn{2}{|c|}{$\begin{array}{c}1989- \\
1995\end{array}$} & \multicolumn{2}{|c|}{$\begin{array}{l}1995- \\
2003\end{array}$} & \multirow[t]{2}{*}{$\begin{array}{c}\text { Grupo } \\
\text { Ecol. }\end{array}$} \\
\hline & D & I & D & $\mathbf{I}$ & D & $\mathbf{I}$ & D & I & D & $\mathbf{I}$ & \\
\hline Didymopanax morototoni $i^{*}$ & $\#$ & & & + & & & & & & & Pio. \\
\hline Bertholletia excelsa ${ }^{*}$ & \# & & & + & & & & & & & Pio. \\
\hline Caryocar villosum ${ }^{*}$ & $\#$ & & & & & & & + & & & Pio. \\
\hline Calophyllum brasiliensis ${ }^{*}$ & \# & & & & & & & & & & Tol. \\
\hline Endopleura uchi ${ }^{*}$ & & + & & & & & & & & & Tol. \\
\hline Cecropia leucoma & & + & & & & & & & & & Pio. \\
\hline Sclerolobium guianensis & & + & & & & & & & & & Pio. \\
\hline Dipteryx odorata $^{*}$ & & & $\#$ & & & & & & & & Pio. \\
\hline Aegiphilla sp. & & & & + & & & & & & & Pio. \\
\hline Ambelania grandiflora & & & & + & & & & & & & Tol. \\
\hline Sapium marmieri & & & & + & & & & & & & Tol. \\
\hline Schyzolobium amazonicum $*$ & & & & + & & & & & & & Pio. \\
\hline Stryphnodendron pulcherrimum & & & & + & & & & & & & Pio. \\
\hline Castilla ulei & & & & + & & & & & & & Tol. \\
\hline Eugenia patrisii & & & & + & & & & & & & Tol. \\
\hline Jacaratia spinosa & & & & + & \# & & & & & & Pio. \\
\hline Solanum rugosum & & & & + & & & \# & & & & Pio. \\
\hline Dimorphandra gardneriana & & & & & & & \# & & & & Pio. \\
\hline Eugenia sp. & & & & & & & \# & & & & Tol. \\
\hline Myrcia sp. & & & & & & & \# & & & & Tol. \\
\hline Duroia macrophylla & & & & & & & \# & & & & Tol. \\
\hline Joannesia heveoides & & & & & & + & & & & & Tol. \\
\hline Cecropia sp. & & & & & & & & & \# & & Pio. \\
\hline Aspidosperma desmanthum ${ }^{*}$ & & & & & & & & & \# & & Tol. \\
\hline Maytenus pruinosa & & & & & & & & & \# & & Tol. \\
\hline Aniba sp. ${ }^{*}$ & & & & & & & & & \# & & Tol. \\
\hline Bellucia sp. & & & & & & & & + & & & Pio. \\
\hline Simaruba amara ${ }^{*}$ & & & & & & & & + & & & Pio. \\
\hline Siparuna decipiens & & & & & & & & + & & & Tol. \\
\hline Fagara pentandra & & & & & & & & + & & & Pio. \\
\hline Protium opacum & & & & & & & & & & + & Tol. \\
\hline Guatteria sp. & & & & & & & & & & + & Tol. \\
\hline Tachigali sp. & & & & & & & & & & + & Pio. \\
\hline Annona ambotay & & & & & & & & & & + & Tol. \\
\hline Bombax globosum ${ }^{*}$ & & & & & & & & & & + & Pio. \\
\hline Dinizia excelsa ${ }^{*}$ & & & & & & & & & & + & Pio. \\
\hline Pterocarpus amazonicus & & & & & & & & & & + & Tol. \\
\hline
\end{tabular}

${ }^{*}$ Espécies de valor comercial, ${ }^{1} \mathrm{D}(\#)$ = espécies que desapareceram devido a mortalidade de todos os seus representantes com DAP $\geq 5,0 \mathrm{~cm},{ }^{2} \mathrm{I}(+)=$ espécies que ingressaram (atingiram $5,0 \mathrm{~cm}$ de diâmetro no período)

Das 15 espécies que desapareceram, três reapareceram na área nos anos posteriores devido ao crescimento e ingresso de novos indivíduos. Duas (Jacaratia spinosa e Solanum rugosum) não estavam presentes no extrato arbóreo no primeiro levantamento, somente ingressaram e desapareceram da área em um curto período de 
tempo (dois e oito anos). As demais (10 espécies) ainda encontram-se ausentes nas parcelas amostradas para o tratamento. (Tabela 6).

Em relação ao grupo de valor comercial, a área do T2 perdeu sete espécies por mortalidade (quatro devido a extração de madeira pela exploração). Destas, três reingressaram na área nos anos posteriores e somente as espécies Calophyllum brasiliensis, Dipteryx odorata, Aspidosperma desmanthum e Aniba sp. ainda não reapareceram na área. Por outro lado, ingressaram no povoamento cinco novas espécies importantes do ponto de vista comercial madeireiro (Endopleura uchi, Schyzolobium amazonicum, Simaruba amara, Bombax globosum e Dinizia excelsa) que, se permanecerem na área, poderão fazer parte do conjunto de espécies para uma próxima colheita (Tabela 6).

O grupo de espécies tolerantes a sombra dominou o povoamento durante todo o período, mas sofreu redução em aproximadamente 3\%, mesma proporção do aumento no grupo das pioneiras.

As dez espécies mais importantes em termos de abundância, considerando a última medição (2003), contribuíram com $46 \%$ do número total de indivíduos.ha ${ }^{-1}$. Dentre elas destaca-se Rinorea flavescens com aproximadamente 12\%. Esta espécie é amplamente distribuída na área e domina o sub-bosque da floresta possuindo 85\% de seus indivíduos com diâmetro inferior a $10 \mathrm{~cm}$ (Tabela 7).

Tabela 7 Número de indivíduos por hectare (DAP $\geq 5,0 \mathrm{~cm}$ ) das espécies mais abundantes em 1,75ha no tratamento T2, ano de 2003. Floresta Nacional do Tapajós (Km 114 da BR 163)

\begin{tabular}{|c|c|c|c|}
\hline Espécies & Família & Grupo ecológico & Número de arv.ha ${ }^{-1}$ \\
\hline Rinorea flavescens & Violaceae & Tolerante & 141,1 \\
\hline Inga $\mathrm{sp}$. & Fabaceae & Pioneira & 74,9 \\
\hline Protium apiculatum & Burseraceae & Tolerante & 69,1 \\
\hline Pouteria sp. & Sapotaceae & Tolerante & 68,0 \\
\hline Rinorea guianensis & Violaceae & Tolerante & 51,4 \\
\hline Jacaranda copaia $^{*}$ & Bignoniaceae & Pioneira & 33,7 \\
\hline Guarea kunthiana & Meliaceae & Tolerante & 23,4 \\
\hline Eschweilera odora & Lecythidaceae & Tolerante & 22,9 \\
\hline Eschweilera blanchetiana & Lecythidaceae & Tolerante & 20,6 \\
\hline \multirow[t]{2}{*}{ Neea sp. } & Nyctaginaceae & Tolerante & 20,6 \\
\hline & -- & -- & \\
\hline Subtotal (10 espécies) & & & $525,7(46 \%)$ \\
\hline Outras (162 espécies) & -- & -- & $617,3(54 \%)$ \\
\hline Total (172 espécies) & -- & -- & $1143,4(100 \%)$ \\
\hline
\end{tabular}




\subsubsection{Tratamento T3: Exploração de espécies comerciais madeireiras com $\mathrm{DAP} \geq$ $55 \mathrm{~cm}+$ desbaste de espécies não comerciais totalizando aproximadamente $30 \%$ de redução da área basal original (3,0ha).}

A área do tratamento $\mathrm{T} 3$ foi bastante dinâmica em termos de entrada e saída de espécies ao longo do período de acompanhamento, com o desaparecimento de 24, devido à mortalidade de todos os seus representantes, e o ingresso de 41 espécies (Tabela 8).

Das 24 espécies que desapareceram, sete reingressaram na área nos anos posteriores devido ao crescimento, até o limite mínimo de DAP considerado $(\geq 5,0 \mathrm{~cm})$, de indivíduos presentes na regeneração natural. Dimorphandra gardneriana, Dinizia excelsa, Licaria armeniaca e Peltogyne paradoxa não estavam presentes nem no primeiro nem no último levantamento. Elas mantiveram-se na comunidade por curto período de tempo, ingressando e morrendo durante os inventários intermediários (Tabela $8)$.

Entre as 41 espécies que ingressaram nas parcelas do T3, 30 não estavam presentes na primeira medição em 1981 e mantiveram-se até o último levantamento em 2003, o

que representa um acréscimo de aproximadamente 16\% no número de espécies. A abertura de dossel provocada pela colheita de madeira e pelo desbaste teve um efeito positivo à entrada de novas espécies no povoamento.

Em termos de valor comercial madeireiro o tratamento T3 perdeu cinco espécies. Entre elas, Ocotea rubra foi totalmente extraída durante a exploração e até o momento não reapareceu na área experimental. As demais, Roupala sp., Cordia goeldiana, Enterolobium schomburgkii e Parkia gigantocarpa desapareceram por mortalidade natural ou por danos em conseqüência das atividades de exploração. Por outro lado, ingressaram no povoamento 11 espécies comercializadas no mercado madeireiro, sendo 9 pioneiras de rápido crescimento que se beneficiaram da maior entrada de luz na floresta (Tabela 8). 
Tabela 8 Mudanças na composição florística durante o período de 1981-2003 em 3,0ha no tratamento T3. Floresta Nacional do Tapajós (Km 114 da BR 163)

\begin{tabular}{|c|c|c|c|c|c|c|c|c|c|c|c|}
\hline \multirow[t]{2}{*}{ Espécies } & \multicolumn{2}{|c|}{$\begin{array}{c}1981- \\
1983\end{array}$} & \multicolumn{2}{|c|}{$\begin{array}{c}1983- \\
1987\end{array}$} & \multicolumn{2}{|c|}{$\begin{array}{c}1987- \\
1989\end{array}$} & \multicolumn{2}{|c|}{$\begin{array}{c}1989- \\
1995\end{array}$} & \multicolumn{2}{|c|}{$\begin{array}{l}1995- \\
2003\end{array}$} & \multirow{2}{*}{$\begin{array}{c}\text { Grupo } \\
\text { Ecol. }\end{array}$} \\
\hline & D & I & D & I & D & I & D & $\mathbf{I}$ & D & $\mathbf{I}$ & \\
\hline Protium sagotianum & \# & & & + & & & & & & & Tol. \\
\hline Vismia japurensis & \# & & & & & + & & & & & Pio. \\
\hline Stryphnodendron pulcherrimum & \# & & & & & & & + & & & Pio. \\
\hline Erisma uncinatum $^{*}$ & \# & & & & & & & + & & & Pio. \\
\hline Ambelania grandiflora & \# & & & & & & & + & & & Tol. \\
\hline Ocotea rubra ${ }^{*}$ & \# & & & & & & & & & & Tol. \\
\hline Gustavia augusta & \# & & & & & & & & & & Tol. \\
\hline Roupala sp. ${ }^{*}$ & \# & & & & & & & & & & Tol. \\
\hline Eugenia patrisii & & + & & & & & & & & & Tol. \\
\hline Aegiphilla sp. & & & & + & & & & & & & Pio. \\
\hline Bellucia sp. & & & & + & & & & & & & Pio. \\
\hline Caryocar villosum ${ }^{*}$ & & & & + & & & & & & & Pio. \\
\hline Cecropia sciadophylla & & & & + & & & & & & & Pio. \\
\hline Didymopanax morototoni ${ }^{*}$ & & & & + & & & & & & & Pio. \\
\hline Pterocarpus rohrii & & & & + & & & & & & & Tol. \\
\hline Eschweilera amazonica & & & & + & & & & & & & Tol. \\
\hline Cassia letandra & & & & + & & & & & & & Pio. \\
\hline Diplotropis purpurea* & & & & + & & & & & & & Tol. \\
\hline Capiona huberiana & & & & + & & & & & & & Tol. \\
\hline Dimorphandra gardneriana & & & & + & & & & & \# & & Pio. \\
\hline Dinizia excelsa* & & & & + & & & \# & & & & Pio. \\
\hline Annona ambotay & & & & + & & & \# & & & + & Tol. \\
\hline Cecropia sp. & & & & & & & \# & & & & Pio. \\
\hline Fícus anthelminthica & & & & & & & \# & & & & Tol. \\
\hline Emmotum fagifolium & & & & & & & \# & & & + & Tol. \\
\hline Crudia sp. & & & & & & & \# & & & & Tol. \\
\hline Licaria armeniaca & & & & & & + & \# & & & & Tol. \\
\hline Rinorea macrocarpa & & & & & & + & & & & & Tol. \\
\hline Peltogyne paradoxa* & & & & & & + & & & \# & & Tol. \\
\hline Fagara pentandra & & & & & & & & & \# & & Pio. \\
\hline Cordia goeldiana* & & & & & \# & & & & & & Pio. \\
\hline Dipteryx odorata ${ }^{*}$ & & & & & & & & + & & & Pio. \\
\hline Eugenia paraensis & & & & & & & & + & & & Tol. \\
\hline Sapium marmieri & & & & & & & & + & & & Tol. \\
\hline Parinarium barbatum & & & & & & & & + & & & Tol. \\
\hline Vatairea sericea $^{*}$ & & & & & & & & + & & & Pio. \\
\hline Abarema sp. ${ }^{*}$ & & & & & & & & + & & & Pio. \\
\hline Vochysia máxima* & & & & & & & & + & & & Pio. \\
\hline Bombax sp. & & & & & & & & & \# & & Pio. \\
\hline Vismia sp. & & & & & & & & & \# & & Pio. \\
\hline Enterolobium schomburgkii ${ }^{*}$ & & & & & & & & & \# & & Pio. \\
\hline Enterolobium sp. & & & & & & & & & \# & & Pio. \\
\hline Parkia gigantocapa ${ }^{*}$ & & & & & & & & & \# & & Pio. \\
\hline Protium opacum & & & & & & & & & & + & Tol. \\
\hline
\end{tabular}


Tabela 8 Mudanças na composição florística durante o período de 1981-2003 em 3,0ha no tratamento T3. Floresta Nacional do Tapajós (Km 114 da BR 163)

\begin{tabular}{|c|c|c|c|c|c|c|c|c|c|c|c|}
\hline \multirow[t]{2}{*}{ Espécies } & \multicolumn{2}{|c|}{$\begin{array}{c}1981- \\
1983\end{array}$} & \multicolumn{2}{|c|}{$\begin{array}{l}1983- \\
1987\end{array}$} & \multicolumn{2}{|c|}{$\begin{array}{c}1987- \\
1989\end{array}$} & \multicolumn{2}{|c|}{$\begin{array}{c}1989- \\
1995\end{array}$} & \multicolumn{2}{|c|}{$\begin{array}{l}1995- \\
2003\end{array}$} & \multirow{2}{*}{$\begin{array}{c}\text { Grupo } \\
\text { Ecol. }\end{array}$} \\
\hline & D & I & D & I & D & I & D & I & D & I & \\
\hline Inga alba & & & & & & & & & & + & Pio. \\
\hline Pithecelobium scandens & & & & & & & & & & + & Pio. \\
\hline Poecilante effusa & & & & & & & & & & + & Tol. \\
\hline Cedrela huberi ${ }^{*}$ & & & & & & & & & & + & Pio. \\
\hline Cedrela odorata* & & & & & & & & & & + & Pio. \\
\hline Bagassa guianensis ${ }^{*}$ & & & & & & & & & & + & Pio. \\
\hline Pourouma paraensis & & & & & & & & & & + & Pio. \\
\hline Virola sp. ${ }^{* 2}$ & & & & & & & & & & + & Tol. \\
\hline Coccoloba latifolia & & & & & & & & & & + & Pio. \\
\hline
\end{tabular}

Espécies de valor comercial, ${ }^{1} \mathrm{D}(\#)$ = espécies que desapareceram devido a mortalidade de todos os seus representantes com DAP $\geq 5,0 \mathrm{~cm},{ }^{2} \mathrm{I}(+)=$ espécies que ingressaram (atingiram $5,0 \mathrm{~cm}$ de diâmetro no período)

Comparando-se a primeira com a última medição, o grupo das espécies pioneiras, que constituía aproximadamente $30 \%$ do total de espécies da área, teve um acréscimo de 9 espécies, passando para $32 \%$.

As 10 espécies mais abundantes, considerando a última medição (2003), contribuíram com $42 \%$ do número total de indivíduos.ha ${ }^{-1}$. Inga sp. foi a mais abundante com 10,5\% do total, seguida de Protium apiculatum (8,0\%), Pouteria sp. $(4,2 \%)$ e Neea sp. $(3,9 \%)$ (Tabela 9$)$.

Tabela 9 Número de indivíduos por hectare das espécies mais abundantes em 3,0ha no tratamento T3, ano 2003. Floresta Nacional do Tapajós (Km 114 da BR 163)

\begin{tabular}{llcc}
\hline \multicolumn{1}{c}{ Espécies } & \multicolumn{1}{c}{ Família } & Grupo ecológico & Número de arv.ha $^{-1}$ \\
\hline Inga sp. & Fabaceae & Pioneira & 137,7 \\
Protium apiculatum & Burseraceae & Tolerante & 105,3 \\
Pouteria sp. & Sapotaceae & Tolerante & 55,3 \\
Neea sp. & Nyctaginaceae & Tolerante & 51,3 \\
Duguetia echinophora & Annonaceae & Tolerante & 50,7 \\
Jacaranda copaia & Bignoniaceae & Pioneira & 37,3 \\
Rinorea flavescens & Violaceae & Tolerante & 31,0 \\
Ocotea sp. & Lauraceae & Tolerante & 29,7 \\
Rinorea guianensis & Violaceae & Tolerante & 28,3 \\
Perebea guianenis & Moraceae & Tolerante & 25,7 \\
& & & $552,3(42,0 \%)$ \\
Subtotal (10 espécies) & -- & -- & $761,7(58,0 \%)$ \\
Outras (192 espécies) & -- & -- & $1314,0(100 \%)$ \\
Total (202 espécies) & -- & -- &
\end{tabular}


Estas espécies estão bem distribuídas em toda a área experimental, porém possuem em torno de $85 \%$ de seus indivíduos concentrados nas classes inferiores de diâmetro $(5,0 \mathrm{~cm} \leq \mathrm{DAP} \leq 15,0 \mathrm{~cm})$.

\subsubsection{Tratamento T4: Exploração de espécies comerciais madeireiras com DAP $\geq$ $55 \mathrm{~cm}+$ desbaste de espécies não comerciais totalizando aproximadamente $50 \%$ de redução da área basal original (1,5ha).}

A área do tratamento T4 também apresentou grande dinâmica em termos de entrada e saída de espécies durante os 22 anos de acompanhamento, com o desaparecimento de 35 , devido à mortalidade de todos os seus representantes dentro do limite de diâmetro considerado, e o ingresso de 34 espécies (Tabela 10).

No primeiro período (1981-1983), 13 espécies presentes no levantamento realizado antes da exploração não foram encontradas na área, em conseqüência das atividades de extração de madeira realizada em 1982. Destas, seis reapareceram nos anos posteriores (Tabela 10).

Logo após a extração madeireira e no período seguinte (1983-1987), observou-se o ingresso de 14 novas espécies, sendo 11 pioneiras (Tabela 10).

Tabela 10 Mudanças na composição florística durante o período de 1981-2003 em 1,5ha no tratamento T4. Floresta Nacional do Tapajós (Km 114 da BR 163)

\begin{tabular}{|c|c|c|c|c|c|c|c|c|c|c|c|}
\hline \multirow[t]{2}{*}{ Espécies } & \multicolumn{2}{|c|}{$\begin{array}{l}1981- \\
1983\end{array}$} & \multicolumn{2}{|c|}{$\begin{array}{c}1983- \\
1987\end{array}$} & \multicolumn{2}{|c|}{$\begin{array}{c}1987- \\
1989\end{array}$} & \multicolumn{2}{|c|}{$\begin{array}{c}1989- \\
1995\end{array}$} & \multicolumn{2}{|c|}{$\begin{array}{l}1995- \\
2003\end{array}$} & \multirow[t]{2}{*}{$\begin{array}{c}\text { Grupo } \\
\text { Ecol. }\end{array}$} \\
\hline & D & I & D & I & D & I & D & I & D & I & \\
\hline Byrsonima crispa & \# & & & + & & & \# & & & + & Pio. \\
\hline Didymopanax morototoni ${ }^{*}$ & \# & & & + & & & & & & & Pio. \\
\hline Dimorphandra gardneriana & \# & & & + & & & & & & & Pio. \\
\hline Emmotum fagifolim & \# & & & & & & & + & & & Tol. \\
\hline Dinizia excelsa* & \# & & & & & & & & & + & Pio. \\
\hline Goupia glabra* & \# & & & & & & & & & + & Pio. \\
\hline Calophyllum brasiliensis ${ }^{*}$ & \# & & & & & & & & & & Tol. \\
\hline Cariniana sp. ${ }^{*}$ & \# & & & & & & & & & & Tol. \\
\hline Manilkara paraensis ${ }^{*}$ & \# & & & & & & & & & & Tol. \\
\hline Aniba sp. ${ }^{*}$ & \# & & & & & & & & & & Tol. \\
\hline Eperua bijuga & \# & & & & & & & & & & Tol. \\
\hline Gustavia augusta & \# & & & & & & & & & & Tol. \\
\hline Mezilaurus sp. & \# & & & & & & & & & & Tol. \\
\hline Pourouma cecropiaefolia & & + & & & \# & & & & & & Pio. \\
\hline Cecropia sciadophylla & & + & & & & & & & & & Pio. \\
\hline Jacaratia spinosa & & + & & & & & & & \# & & Pio. \\
\hline
\end{tabular}


Tabela 10 Mudanças na composição florística durante o período de 1981-2003 em 1,5ha no tratamento T4. Floresta Nacional do Tapajós (Km 114 da BR 163)

\begin{tabular}{|c|c|c|c|c|c|c|c|c|c|c|c|}
\hline \multirow[t]{2}{*}{ Espécies } & \multicolumn{2}{|c|}{$\begin{array}{c}1981- \\
1983\end{array}$} & \multicolumn{2}{|c|}{$\begin{array}{c}1983- \\
1987\end{array}$} & \multicolumn{2}{|c|}{$\begin{array}{c}1987- \\
1989\end{array}$} & \multicolumn{2}{|c|}{$\begin{array}{c}1989- \\
1995\end{array}$} & \multicolumn{2}{|c|}{$\begin{array}{c}1995- \\
2003\end{array}$} & \multirow{2}{*}{$\begin{array}{c}\text { Grupo } \\
\text { Ecol. }\end{array}$} \\
\hline & D & I & D & I & D & I & D & I & D & I & \\
\hline Symphonia globulifera* & & + & & & & & & & & & Pio. \\
\hline Tabebuia impetiginosa ${ }^{*}$ & & + & & & & & & & & & Pio. \\
\hline Cecropia sp. & & & \# & & & & & & & & Pio. \\
\hline Phyllanthus nobilis & & & $\#$ & & & & & & & & Tol. \\
\hline Theobroma subincanum & & & \# & & & & & & & & Pio. \\
\hline Aegiphilla sp. & & & & + & & & & & & & Pio. \\
\hline Bagassa guianensis ${ }^{*}$ & & & & + & & & & & & & Pio. \\
\hline Bellucia sp. & & & & + & & & & & & & Pio. \\
\hline Ficus anthelminthica & & & & + & & & & & & & Tol. \\
\hline Jacaranda copaia $^{*}$ & & & & + & & & & & & & Pio. \\
\hline Miconia sp. & & & & + & & & & & & & Pio. \\
\hline Pouteria sp. & & & & + & & & & & & & Tol. \\
\hline Vismia japurensis & & & & + & & & & & & & Pio. \\
\hline Aniba canelila* & & & & & \# & & & & & & Tol. \\
\hline Licaria armeniaca & & & & & & + & & & & & Tol. \\
\hline Mabea sp. & & & & & & + & & & \# & & Tol. \\
\hline Parkia sp. & & & & & & + & & & & & Pio. \\
\hline Brosimum lactescens & & & & & & & \# & & & & Tol. \\
\hline Hymenolobium excelsum ${ }^{*}$ & & & & & & & \# & & & & Pio. \\
\hline Luehea speciosa & & & & & & & \# & & & & Tol. \\
\hline Annona sp. & & & & & & & \# & & & & Tol. \\
\hline Ouratea aquatica & & & & & & & \# & & & & Tol. \\
\hline Stryphnodendron barbatimam & & & & & & & \# & & & + & Pio. \\
\hline Ambelania sp. & & & & & & & & + & & & Tol. \\
\hline Dipteryx odorata $^{*}$ & & & & & & & & + & & & Pio. \\
\hline Fagara pentandra & & & & & & & & + & & & Pio. \\
\hline Pourouma paraensis & & & & & & & & + & & & Pio. \\
\hline Simaruba amara* & & & & & & & & + & & & Pio. \\
\hline Tachigali sp. & & & & & & & & + & & & Pio. \\
\hline Vismia sp. & & & & & & & & + & & & Pio. \\
\hline Aniba duckei & & & & & & & & & \# & & Tol. \\
\hline Brosimum obovata & & & & & & & & & \# & & Tol. \\
\hline Couepia bracteosa & & & & & & & & & \# & & Tol. \\
\hline Endopleura uchi ${ }^{*}$ & & & & & & & & & \# & & Tol. \\
\hline Lindackeria paraensis & & & & & & & & & \# & & Tol. \\
\hline Eugenia sp. & & & & & & & & & \# & & Tol. \\
\hline Ocotea caniculata & & & & & & & & & \# & & Tol. \\
\hline Swartzia stipulifera & & & & & & & & & \# & & Tol. \\
\hline Virola divergens ${ }^{*}$ & & & & & & & & & \# & & Tol. \\
\hline Inga alba & & & & & & & & & & + & Pio. \\
\hline Ormosia discolor & & & & & & & & & & + & Pio. \\
\hline Protium opacum & & & & & & & & & & + & Tol. \\
\hline Sclerolobium guianenis & & & & & & & & & & + & Pio. \\
\hline
\end{tabular}

${ }^{*}$ Espécies de valor comercial, ${ }^{1} \mathrm{D}(\#)$ = espécies que desapareceram devido a mortalidade de todos os seus representantes com DAP $\geq 5,0 \mathrm{~cm},{ }^{2} \mathrm{I}(+)=$ espécies que ingressaram (atingiram $5,0 \mathrm{~cm}$ de diâmetro no período) 
Nos dois últimos períodos (1989-1995 e 1995-2003) a aplicação do tratamento silvicultural, realizada em 1994, provocou nova aceleração na dinâmica da comunidade, com o desaparecimento de 17 espécies e o ingresso de 16, sendo 12 delas pioneiras (Tabela 10).

Comparando-se o primeiro e o último levantamento, verificou-se que a maior abertura no dossel, ocasionada pelas intervenções, favoreceram as espécies pioneiras, que se beneficiaram da maior entrada de luz na floresta e aumentaram em torno de $10 \%$ sua participação na comunidade. O grupo com valor comercial madeireiro sofreu redução de duas espécies $(0,4 \%)$.

As dez espécies mais abundantes na área, considerando a última medição (2003), contribuíram com $45 \%$ do número total de indivíduos. Inga sp. foi a mais abundante com 13\% do total, seguida de Rinorea flavescens com 8\% e Protium apiculatum com 6\% (Tabela 11). Entre as mais abundantes merece destaque Jacaranda copaia, uma heliófila atualmente comercializada no mercado madeireiro. Esta espécie não estava presente na comunidade (DAP $\geq 5,0 \mathrm{~cm}$ ) no primeiro levantamento e foi beneficiada pela abertura de dossel promovida durante a extração madeireira de tal forma que, cinco anos após a exploração, em 1997, ela já estava entre as mais abundantes com aproximadamente 41 indivíduos por hectare.

Tabela 11 Número de indivíduos por hectare das espécies mais abundantes 1,5ha no tratamento T4, ano 2003. Floresta Nacional do Tapajós (Km 114 da BR 163)

\begin{tabular}{llcc}
\hline \multicolumn{1}{c}{ Espécies } & \multicolumn{1}{c}{ Família } & Grupo ecológico & Número de arv.ha $^{-1}$ \\
\hline Inga sp. & Fabaceae & Pioneira & 180,7 \\
Rinorea flavescens & Violaceae & Tolerante & 111,3 \\
Protium apiculatum & Burseraceae & Tolerante & 84,0 \\
Pouteria sp. & Sapotaceae & Tolerante & 54,0 \\
Jacaranda copaia ${ }^{*}$ & Bignoniaceae & Pioneira & 52,0 \\
Rinorea guianensis & Violaceae & Tolerante & 38,7 \\
Ocotea sp. & Lauraceae & Tolerante & 31,3 \\
Neea sp. & Nyctaginaceae & Tolerante & 30,0 \\
Duguetia echinophora & Annonaceae & Tolerante & 28,7 \\
Bixa arborea & Moraceae & Tolerante & 23,3 \\
Subtotal $(10$ espécies) & & & $634,0(46 \%)$ \\
Outras $(152$ espécies) & -- & -- & $744,7(54 \%)$ \\
Total $(162$ espécies) & -- & -- & $1378,7(100 \%)$ \\
${ }^{*}$ Espécies de valor comercial & -- & - &
\end{tabular}




\subsubsection{Tratamento T0: Testemunha, área sem intervenção (1,5ha).}

A área controle (T0), apresentou uma discreta dinâmica durante o período de acompanhamento, pois houve a saída de 12 espécies e o ingresso de 10 (Tabela 12).

A espécie Parinarium barbatum que desapareceu entre o primeiro e o segundo levantamento voltou a ser encontrada nas parcelas, oito anos depois, no inventário realizado em 1995. Outras espécies como Didymopanax morototoni, Cecropia sciadophylla, Cecropia leucoma e Jacaratia spinosa, que necessitam de grande intensidade luminosa para seu desenvolvimento, estavam restritas a áreas de clareiras e desapareceram provavelmente devido ao fechamento do dossel dessas áreas, dando lugar a espécies de estágios seriais posteriores (Tabela 12).

Tabela 12 Mudanças na composição florística durante o período de 1983-2003 em 1,5ha no tratamento T0. Floresta Nacional do Tapajós (Km 114 da BR 163)

\begin{tabular}{|c|c|c|c|c|c|c|c|c|c|}
\hline \multirow[t]{2}{*}{ Espécies } & \multicolumn{2}{|c|}{$\begin{array}{c}1983- \\
1987\end{array}$} & \multicolumn{2}{|c|}{$\begin{array}{c}1987- \\
1989\end{array}$} & \multicolumn{2}{|c|}{$\begin{array}{c}1989- \\
1995\end{array}$} & \multicolumn{2}{|c|}{$\begin{array}{c}1995- \\
2003\end{array}$} & \multirow[t]{2}{*}{$\begin{array}{c}\text { Grupo } \\
\text { Ecol. }\end{array}$} \\
\hline & D & I & D & I & D & I & D & I & \\
\hline Parinarium barbatum & \# & & & & & + & & & Tol. \\
\hline Apuleia molaris ${ }^{*}$ & \# & & & & & & & & Pio. \\
\hline Protium subserratum & & + & & & & & & & Tol. \\
\hline Enterolobium sp. & & + & & & & & & & Pio. \\
\hline Annona ambotay & & & $\#$ & & & & & & Tol. \\
\hline Didymopanax morototoni ${ }^{*}$ & & & $\#$ & & & & & & Pio. \\
\hline Guatteria ovalifolia & & & $\#$ & & & & & & Tol. \\
\hline Diplotropis purpurea ${ }^{*}$ & & & $\#$ & & & & & & Tol. \\
\hline Protium sagotianum & & & & + & & & & & Tol. \\
\hline Dimorphandra gardneriana & & & & & & + & & & Pio. \\
\hline Aspidosperma duckei & & & & & & + & & & Tol. \\
\hline Pterocarpus amazonicus & & & & & & + & & & Tol. \\
\hline Cecropia sciadophylla & & & & & & & $\#$ & & Pio. \\
\hline Cecropia leucoma & & & & & & & $\#$ & & Pio. \\
\hline Emmotum fagifolim & & & & & & & $\#$ & & Tol. \\
\hline Jacaratia spinosa & & & & & & & \# & & Pio. \\
\hline Miconia sp. & & & & & & & \# & & Pio. \\
\hline Vismia japurensis & & & & & & & $\#$ & & Pio. \\
\hline Protium opacum & & & & & & & & + & Tol. \\
\hline Tachigali sp. & & & & & & & & + & Pio. \\
\hline Vochysia maxima $^{*}$ & & & & & & & & + & Pio. \\
\hline
\end{tabular}

Espécies de valor comercial, ${ }^{\mathrm{I}} \mathrm{D}(\#)=$ espécies que desapareceram devido a mortalidade de todos os seus representantes com DAP $\geq 5,0 \mathrm{~cm},{ }^{2} \mathrm{I}(+)=$ espécies que ingressaram (atingiram 5,0cm de diâmetro no período) 
Em termos de valor comercial madeireiro a área testemunha perdeu as espécies Apuleia molaris, Didymopanax morototoni e Diplotropis purpurea e ocorreu o ingresso de Vochysia maxima. O grupo ecológico das espécies tolerantes a sombra dominou o povoamento, mantendo-se acima de $70 \%$ do numero total de espécies durante todo o período.

As dez espécies mais importantes em termos de abundância, considerando a última medição (2003), contribuíram com aproximadamente $45 \%$ do número total de indivíduos.ha-1 ${ }^{-1}$ Estas espécies dominam o sub-bosque da floresta e estão bem distribuídas em toda a área, estando presentes em grande número durante todo o período de acompanhamento. Dentre elas destacam-se Rinorea guianensis com 86,0 indivíduos.ha ${ }^{-1}$, seguida de Protium apiculatum com 81,3.ha ${ }^{-1}$ e Duguetia echinophora com 72, $0 . \mathrm{ha}^{-1}$ (Tabela 13).

Tabela 13 Número de indivíduos por hectare das espécies mais abundantes 1,5ha no tratamento T0, ano 2003. Floresta Nacional do Tapajós (Km 114 da BR 163)

\begin{tabular}{llcc}
\hline \multicolumn{1}{c}{ Espécies } & \multicolumn{1}{c}{ Família } & Grupo ecológico & Número de arv.ha $^{-1}$ \\
\hline Rinorea guianensis & Violaceae & Tolerante & 86,0 \\
Protium apiculatum & Burseraceae & Tolerante & 81,3 \\
Duguetia echinophora & Annonaceae & Tolerante & 72,0 \\
Pouteria sp. & Sapotaceae & Tolerante & 56,7 \\
Inga sp. & Fabaceae & Pioneira & 44,0 \\
Eperua bijuga & Fabaceae & Tolerante & 30,0 \\
Eschweilera blanchetiana & Lecythidaceae & Tolerante & 28,7 \\
Eschweilera odora & Lecythidaceae & Tolerante & 28,7 \\
Guarea kunhtiana & Meliaceae & Tolerante & 25,3 \\
Perebea guianensis & Moraceae & Tolerante & 24,0 \\
Subtotal (10 espécies) & & & $476,7(44,7 \%)$ \\
Outras (146 espécies) & -- & -- & $589,3(55,3 \%)$ \\
Total (156 espécies) & -- & -- & $1066,0(100 \%)$ \\
\hline
\end{tabular}

\subsection{Discussão}

Os distúrbios são fortes agentes de modificação na composição florística e estrutura das florestas tropicais por causar diferentes graus de abertura no dossel (Clark, 1990; Denslow, 1995) e constituem importante fator a ser considerado no manejo sustentável dessas florestas. 
Como resultado da extração de madeira e dos tratamentos silviculturais aplicados, ocorreram mudanças na composição florística, sendo a dinâmica dessas mudanças diretamente relacionada com a intensidade do tratamento e a conseqüente abertura no dossel da floresta.

De maneira geral as duas intervenções realizadas provocaram a diminuição da riqueza florística logo após sua aplicação. Todavia com o passar do tempo a abertura no dossel estimulou a entrada de novas espécies no povoamento de tal forma que, 21 anos depois da exploração e nove após os desbastes, todos os tratamentos, apresentaram aumento no número de espécies em relação à primeira medição, realizada antes de qualquer intervenção. Por outro lado, na área testemunha, apesar de ter ocorrido discreta dinâmica entre a entrada e saída de espécies, não houve aumento na riqueza florística durante o período avaliado.

A diminuição no número de espécies logo após a exploração e posterior recuperação e aumento na diversidade florística também foi observado por Silva (2004) em Paragominas-PA, onde a redução na diversidade logo após a intervenção foi de $8 \%$ para a área explorada convencionalmente e 6\% para a área explorada com técnicas de manejo de impacto reduzido. Sete anos após, houve o aumento no número de espécies, principalmente na área da exploração convencional. A mesma tendência foi observada por Nicholson et al. (1988) em Queensland na Austrália e Carvalho (1992) na Flona Tapajós, Brasil.

O aumento na riqueza de espécies arbóreas após a intervenção tem sido reportado por diversos autores em florestas tropicais. Magnusson et al. (1999), estudando uma floresta ao norte de Manaus no Amazonas, verificou que nas parcelas onde ocorreu extração de madeira houve um aumento significativo na riqueza de espécies em relação às parcelas testemunha. Plumptre (1996) realizando pesquisas na reserva florestal de Budongo, na Uganda, observou que áreas exploradas e tratadas com arboricida tiveram aumento no número de espécies em relação à floresta primária sem intervenção.

Alguns resultados encontrados na literatura apontam, todavia, em outra direção. Johns (1988) menciona que as atividades de exploração, em área de pesquisa no Oeste da Malásia, não afetaram as proporções relativas de diferentes famílias, havendo uma 
alta correlação entre a abundância destas antes e após a exploração. Okali \& Ola-Adams (1987), estudando uma área onde foi realizada exploração, corte de cipós e envenenamento de espécies não comercias na Reserva Florestal de Omo, na Nigéria, concluiu que, 28 anos após a intervenção, o número de espécies e famílias permaneceu similar e o tratamento não conseguiu induzir um estoque desejável de espécies econômicas como era o esperado. Wagner (1997), observou que a exploração reduziu em 15\% o número de espécies no extrato arbóreo (DAP > 10) mesmo após 14 anos, em uma floresta primária na Costa Rica.

A extração de madeira e os desbastes, realizados no presente estudo, provocaram o aumento na quantidade de espécies pioneiras, alterando o balanço entre os grupos ecológicos. Porém essa alteração só foi expressiva no tratamento T4 (50\% de redução da área basal) onde o aumento no número de espécies pioneiras foi de $10 \%$. Nos demais tratamentos esse valor ficou em torno de $2 \%$ a $3 \%$.

A mesma tendência foi observada por Silva et al. (1995), 13 anos após a exploração, na região do Tapajós, onde a extração de madeira alterou a composição florística, reduzindo o número das espécies tolerantes e estimulando o aumento das pioneiras.

\subsection{Conclusão}

- A composição florística na área do presente estudo mostrou-se bastante dinâmica em relação à entrada e saída de espécies em todos os tratamentos, exceto no T0.

- A extração de madeira e os desbastes induziram o aumento na riqueza florística de todos os tratamentos, principalmente no $\mathrm{T} 3$, onde houve o acréscimo de aproximadamente 10 espécies, seis gêneros e duas famílias. Apesar disso, não foram constatadas diferenças estatísticas significativas no número de espécies e na diversidade, medida pelo índice de Shannon, entre os tratamentos em nenhum período de medição. 
- Em relação ao grupo de valor comercial madeireiro, os tratamentos T1 e T3 mostraram-se mais eficientes, com o aumento de seis espécies, embora isso represente apenas $0,5 \%$ em relação ao número total. 


\section{EFEITO DA EXPLORAÇÃO DE MADEIRA E TRATAMENTOS SILVICULTURAIS SOBRE A ESTRUTURA HORIZONTAL DE UMA ÁREA DE 136ha NA FLORESTA NACIONAL DO TAPAJÓS, BELTERRA-PARÁ.}

\section{Resumo}

O objetivo deste trabalho foi analisar o efeito de quatro intensidades de redução da área basal, representadas pela exploração e desbastes sistemáticos, na estrutura do extrato arbóreo, durante um período de 22 anos. O experimento se localiza na Floresta Nacional do Tapajós, município de Belterra, Pará, a altura do km 114 da Rodovia SantarémCuiabá. O delineamento estatístico utilizado foi Blocos ao Acaso com 4 repetições onde foram testados os seguintes tratamentos: T0: controle, representado pela floresta não explorada; T1: Abate de árvores comerciais com DAP $\geq 45 \mathrm{~cm}$, sem nenhuma intervenção posterior; T2: Abate de árvores comerciais DAP $\geq 55 \mathrm{~cm}+$ desbaste de espécies não comerciais para reduzir a área basal em $20 \%$ da original; T3: Abate de árvores comerciais DAP $\geq 55 \mathrm{~cm}+$ desbaste de espécies não comerciais para reduzir a área basal em $40 \%$ da original; T4: Abate de árvores comerciais DAP $\geq 55 \mathrm{~cm}+$ desbaste de espécies não comerciais para reduzir a área basal em $60 \%$ da original. Em cada tratamento foram instaladas ao acaso 12 parcelas permanentes (PP) de 0,25ha, onde foram medidas todas árvores com diâmetro $\geq 5,0 \mathrm{~cm}$. A exploração de madeira foi realizada em 1982 e os desbastes em 1994. As medições das PP foram realizadas em 1981, 1983, 1987, 1989, 1995 e 2003. Os resultados mostraram que cinco anos após a exploração todos os tratamentos apresentaram número de árvores superior, ao 
encontrado antes da intervenção, inclusive considerando somente as espécies de valor comercial. Porém, a área basal e o volume apresentaram recuperação mais lenta, ocorrendo de forma mais efetiva nas primeiras classes de diâmetro $(5-45 \mathrm{~cm})$. Nas classes acima de $45 \mathrm{~cm}$, que foram as mais afetadas pela extração de madeira, a área basal, 21 anos após a exploração, ainda está, em média, 30\% abaixo do valor original. O tratamento T3 foi considerado o mais adequado porque favoreceu várias espécies de valor comercial madeireiro que aumentaram sua participação na abundância e área basal no povoamento. Esse tratamento também mostrou a maior taxa de recuperação da área basal comercial (aproximadamente 90\%).

\section{Summary}

The objective of this work was to analyze the effect of four intensities of basal area reduction, represented by logging and systematic liberation thinning, on the structure of arboreal extract, over a period of 22 years. The experiment is located in the Tapajós National Forest, municipality of Belterra, Pará, at km 114 of the Santarém-Cuiabá Highway. The statistical delineation employed was Random Blocks with 4 repetitions, in which the following treatments were tested: T0: control, represented by unlogged forest; $\mathrm{T} 1$ : Felling of commercial trees with $\mathrm{DBH} \geq 45 \mathrm{~cm}$, with no posterior intervention; $\mathrm{T} 2$ : Felling of commercial trees $\mathrm{DBH} \geq 55 \mathrm{~cm}+$ thinning of non-commercial species to reduce the original basal area by 20\%; T3: Felling of commercial trees DBH $\geq 55 \mathrm{~cm}+$ thinning of non-commercial species to reduce the original basal area by $40 \%$; T4: Felling of commercial trees $\mathrm{DBH} \geq 55 \mathrm{~cm}+$ thinning of non-commercial species to reduce the original basal area by $60 \%$. In each treatment 12 ,25ha permanent parcels (PP) were randomly installed, in which all trees with diameter $\geq 5,0 \mathrm{~cm}$ were measured. Logging was carried out in 1982 and the thinning treatments in 1994. The measurements of PP were carried in 1981, 1983, 1987, 1989, 1995 and 2003. The results showed that, five years after logging, all the treatments showed a greater number of trees than what was found before the intervention, including a count only of species with commercial value. 
However, the basal area and volume showed a lower recovery, occurring most effectively in the first diameter classes $(5-45 \mathrm{~cm})$. In the classes above $45 \mathrm{~cm}$, which were the ones most affected by timber harvesting, the basal area, 21 years after logging, is still on average $30 \%$ below the original value. Treatment T3 was considered the most adequate one, because it favored several species with commercially valuable timber, which increased their participation in terms of abundance and basal area in the population. This treatment also showed the highest recovery rate for the commercial basal area (approximately 90\%).

\subsection{Introdução}

A análise estrutural de uma floresta diz respeito a quantificação da abundância, freqüência, valor de cobertura das espécies, características sociológicas e dinâmica da população (Hosokawa, 1982).

Estudos buscando a caracterização da estrutura são fundamentais, porque permitem um melhor entendimento das florestas, contribuindo assim para a melhor eficiência do manejo com o emprego de tratamentos silviculturais mais adequados. A busca desse conhecimento torna-se essencial, principalmente quando se visa a sustentabilidade da produção das florestas, ou seja, o fluxo contínuo de produtos e serviços florestais, minimizando os efeitos indesejáveis sobre o ambiente (Jardim \& Silva, 2003).

Segundo Leal Filho (2000), um dos grandes obstáculos operacionais para o sucesso do manejo florestal é a regeneração lenta e imprevisível das espécies de valor comercial após a exploração. Kammesheidt et al. (2001), complementam, afirmando que a maioria das espécies de alto valor comercial regenera insuficientemente em áreas exploradas e somente poucas espécies de baixo valor potencial se beneficiam dos distúrbios causados pelas atividades de exploração.

Estudos realizados na região de Moju (PA) têm mostrado que a estrutura da floresta tropical se modifica expressivamente após a exploração florestal seletiva, devido a dois fatores principais: a redução dos parâmetros estruturais das espécies comerciais 
(abundância, dominância e posição sociológica) e o ingresso de indivíduos de espécies heliófilas, cuja regeneração natural é estimulada pela abertura das clareiras da exploração (Jardim \& Silva, 2003).

Carvalho (2001) comenta que a recuperação da estrutura da floresta após a colheita de madeira é lenta, principalmente quando a área é submetida a exploração pesada. Todavia, De Graaf (1986) sugere que, para induzir a regeneração e o crescimento de espécies comerciais valiosas após a exploração, devem-se aplicar tratamentos silviculturais periódicos que reduzam a competição por luz e nutrientes com as espécies mais abundantes e sem valor comercial.

Diversas técnicas de tratamentos silviculturais baseadas em refinamentos têm sido aplicadas, em diferentes intensidades, em florestas tropicais em nível internacional (Kammesheidt et al., 2003; Hutchinson, 1987; Kuusipalo et al., 1997; Dekker \& De Graaf, 2003; De Graaf, 1986; Pariona et al., 2001; Howard et al., 1996; Zaneti, 2002; Negreros-Castillo \& Mize, 1993; Finegan et al., 1999; Quiros \& Finegan, 1994; Delgado et al., 1997; Kuusipalo et al., 1996). No Brasil, existem experimentos na região de Linhares, ES (Jesus, 2001); na Estação Experimental de Silvicultura do INPA, em Manaus (Higuchi et al., 1997; Jardim et al., 1990; Vieira \& Hosokawa, 1989); na região de Marabá, PA (Garcia, 1990) e na região de Belterra, PA (Oliveira, 1995).

Apesar deste volume de trabalhos, ainda existe carência de conhecimentos sobre os efeitos em longo prazo das operações de manejo em florestas tropicais. Devido a problemas de ordem técnica, operacional e/ou financeira, somente um número reduzido de parcelas tem sido mantido e acompanhado por tempo suficiente para medir o impacto das operações de exploração sobre a vegetação remanescente.

Como parte da contribuição deste trabalho ao conhecimento dos efeitos das atividades de manejo em florestas tropicais, serão analisadas neste capítulo, as mudanças no número de árvores, área basal e volume provocadas pela exploração de madeira e desbastes para a redução da área basal, relativos a 22 anos de acompanhamento em 136ha da Floresta Nacional do Tapajós, localizada no Município de Belterra-Pará. Para isso, pretende-se responder as seguintes questões: 
1. Quais as principais alterações na distribuição do número de árvores, área basal e volume, após as intervenções, nos diferentes tratamentos testados?

2. Qual(is), dentre os tratamentos testados, mostrou-se mais eficiente quanto a recuperação do número de árvores, área basal e volume, no final do período monitorado?

\subsection{Material e métodos}

O número de árvores, área basal e volume por hectare foi determinado para todos os indivíduos arbóreos com DAP $\geq 5,0 \mathrm{~cm}$, presentes em 41 parcelas permanentes de 50m x 50m distribuídas entre os seguintes tratamentos:

- Tratamento T0: Testemunha, área sem intervenção (6 parcelas - 1,5ha amostrado).

- Tratamento T1: Exploração de espécies comerciais madeireiras com DAP $\geq$ $45 \mathrm{~cm}$ (10 parcelas - 2,5ha amostrados)

- Tratamento T2: Exploração de espécies comerciais madeireiras com DAP $\geq$ $55 \mathrm{~cm}+$ desbaste de espécies não comerciais totalizando aproximadamente $20 \%$ de redução da área basal original (7 parcelas - 1,75ha amostrado).

- Tratamento T3: Exploração de espécies comerciais madeireiras com DAP $\geq$ $55 \mathrm{~cm}+$ desbaste de espécies não comerciais totalizando aproximadamente $30 \%$ de redução da área basal original (12 parcelas - 3,0ha amostrados).

- Tratamento T4: Exploração de espécies comerciais madeireiras com DAP $\geq$ $55 \mathrm{~cm}+$ desbaste de espécies não comerciais totalizando aproximadamente $50 \%$ de redução da área basal original (6 parcelas - 1,5ha amostrado).

As medições das parcelas permanentes foram realizadas conforme metodologia descrita no Capítulo I. Na área explorada foram realizados levantamentos em seis ocasiões: 1 ano antes da exploração comercial de madeira (1981), 1 ano após a exploração (1983) e 5, 7, 13 e 21 anos após a colheita de madeira, correspondendo aos 
anos de 1987, 1989, 1995 e 2003, respectivamente. Para a área testemunha (T0) foram realizadas 5 medições: 1983, 1987, 1989, 1995 e 2003.

As mudanças na estrutura horizontal da floresta, em relação às diferentes intervenções ao longo dos anos, foram determinadas em termos de número de árvores.ha` , área basal $\left(\mathrm{m}^{2} \cdot \mathrm{ha}^{-1}\right)$ e volume $\left(\mathrm{m}^{3} \cdot \mathrm{ha}^{-1}\right)$.

Para o estudo da variação entre os tratamentos, foi utilizada a análise de variância e o teste Tukey para a comparação das médias, sempre que as pressuposições básicas de normalidade e homocedasticidade foram obedecidas. A verificação da normalidade dos dados foi realizada através do teste de Shapiro Wilks e a análise de variância através do Proc GLM, ambos com auxílio do programa estatístico "SAS-system (Statistical Analysis System)”. Quando não foi possível obedecer as pressuposições da análise, procedeu-se a transformação dos dados. As médias de número de árvores comerciais para os anos 5, 7 e 21 após a exploração foram transformadas através do log para obter a normalidade dos valores.

\subsection{Resultados}

\subsubsection{Número de árvores por hectare}

Pode-se observar na Tabela 1 que, apesar das parcelas dos tratamentos estarem aleatorizadas dentro de uma mesma área de floresta, havia certa heterogeneidade em relação ao número de árvores, antes da exploração de madeira. $\mathrm{O}$ tratamento com maior densidade (T4) apresentou em torno de 40 árvores.ha $^{-1}$ a mais que a área menos densa (T3).

O número de árvores considerando a comunidade total e somente as espécies de valor comercial madeireiro foi reduzido entre o primeiro (1981) e o segundo ano de medição (1983), em todos os tratamentos. Para o número total de árvores, essa redução foi maior no tratamento T4 (16\%), seguida do T1, T3 e T2, com reduções de 14,7\%; $12,6 \%$ e $9,3 \%$, respectivamente. Para as espécies comerciais, o tratamento que sofreu a maior redução foi o T3 (18\%), seguido pelo T4, T1 e T2 com diminuição de 15,8\%; 
15,2\% e 12,9\% (Tabela 1). O motivo principal dessa diminuição foi a colheita de madeira, realizada na área em 1982, que extraiu em média 11 árvores.ha ${ }^{-1}$ (ver Capítulo II). Além disso, os danos causados pela exploração e o fenômeno climático El Niño ocorrido no período 1982-1983, que provocou estiagem prolongada na região do Tapajós e provavelmente aumentou as taxas de mortalidade, contribuíram para essa redução.

Tabela 1 Número de árvores total e número de árvores das espécies comerciais em cada tratamento e a cada ano de medição, em uma amostra de 10,25ha na Floresta Nacional do Tapajós, considerando todas as árvores com DAP $\geq 5,0 \mathrm{~cm}$

\begin{tabular}{|c|c|c|c|c|c|c|c|c|c|c|}
\hline \multirow{2}{*}{ Anos } & \multicolumn{5}{|c|}{ Número de árvores total.ha ${ }^{-1}$} & \multicolumn{5}{|c|}{$\mathrm{N}^{0}$ arv. espécies comerciais.ha ${ }^{-1}$} \\
\hline & TO & T1 & $\mathbf{T 2}$ & T3 & T4 & T0 & T1 & $\mathbf{T 2}$ & T3 & $\mathbf{T 4}$ \\
\hline $1981(1 \mathrm{AE})$ & - & 1122,4 & 1121,1 & 1097,0 & 1138,7 & - & 168,4 & 194,8 & 213,0 & 193,3 \\
\hline $1983(1 \mathrm{DE})$ & 1056,7 & 957,2 & 1017,1 & 958,7 & 957,3 & 208,6 & 142,8 & 169,7 & 174,7 & 162,7 \\
\hline $1987(5 \mathrm{DE})$ & 1056,0 & 1219,2 & 1153,1 & 1201,3 & 1242,0 & 208,6 & 193,2 & 218,2 & 234,0 & 238,7 \\
\hline 1989 (7 DE) & 1062,0 & 1227,6 & 1186,9 & 1264,7 & 1312,7 & 205,3 & 212,4 & 233,1 & 251,3 & 263,4 \\
\hline 1995 (13DE, 1DT) & 1068,7 & 1238,8 & 1140,0 & 1209,7 & 1203,3 & 206,0 & 217,6 & 234,2 & 275,7 & 268,7 \\
\hline 2003 (21DE 9DT) & 1066,0 & 1166,4 & 1143,4 & 1314,0 & 1378,7 & 207,3 & 220,0 & 240,0 & 314,0 & 333,3 \\
\hline
\end{tabular}

Cinco anos após a exploração, todos os tratamentos apresentaram aumento no número de árvores total e comercial por hectare, superando os valores encontrados na floresta antes da intervenção (Tabela 1 e Figura 1).

Observa-se que a abertura do dossel causada pela extração de madeira favoreceu o ingresso de novas árvores no povoamento e conseqüentemente o aumento do número de indivíduos. Todavia, esse efeito positivo diminuiu ao longo dos anos, de acordo com o gradual fechamento do dossel, que reduziu a disponibilidade de luz e desacelerou o crescimento e a entrada de novos indivíduos nas primeiras classes de DAP. No período de 1983 a 1987 (1 a 5 anos após a exploração) as taxas de aumento no número de árvores foram $27,4 \%$ no T1, $13,3 \%$ no T2, $25,3 \%$ no $\mathrm{T} 3$ e $29,7 \%$ no $\mathrm{T} 4$ (3,3\% a $7,4 \%$ ao ano). No período seguinte (1987-1989), as taxas diminuíram para 0,7\% no T1, 3\% no T2, $5,3 \%$ no $\mathrm{T} 3$ e $5,7 \%$ no T4 (0,3\% a $2,8 \%$ ao ano).

$\mathrm{Na}$ medição de 1995, realizada 13 anos após a exploração e um ano após a aplicação do tratamento silvicultural, ocorreu redução no número de árvores total.ha ${ }^{-1}$ nas áreas onde essa intervenção foi aplicada (T2, T3 e T4). $\mathrm{Na}$ área do $\mathrm{T} 4$, onde o 
desbaste foi aplicado com maior intensidade, ocorreu uma diminuição de $8,3 \%$ em relação ao número de árvores encontrado na medição imediatamente anterior. Para o T2 e T3 essa redução foi de 4,0\% e 4,3\%, respectivamente (Tabela 1 e Figura 1).

No último levantamento, realizado em 2003, 21 anos após a exploração e 9 anos após os desbastes, houve um novo crescimento em número de indivíduos.ha ${ }^{-1}$ em relação a medição anterior (1995). Na área do T2, de intensidade mais leve (20\% de redução da área basal), esse aumento foi pequeno, apenas 3 indivíduos.ha ${ }^{-1}(0,30 \%)$. Na área do T3 (30\% de redução da $\mathrm{AB})$ e $\mathrm{T} 4(50 \%$ de redução da $\mathrm{AB})$, o aumento no número de árvores.ha ${ }^{-1}$ foi de $104(8,6 \%)$ e $175(14,6 \%)$, respectivamente. $\mathrm{Na}$ área do $\mathrm{T} 1$, onde não foi realizada intervenção após a exploração de madeira, ocorreu diminuição de 5,8\% no número de árvores, neste último período (Tabela 1 e Figura 1). Os motivos dessa redução serão discutidos no item 4.3.1.1 onde as mudanças em relação às espécies presentes em cada tratamento são detalhadas.

Analisando todo o período de acompanhamento, observa-se que a exploração, aliada à redução da área basal, favoreceu a recuperação do número de árvores.ha ${ }^{-1} \mathrm{em}$ todos os tratamentos onde foram aplicadas, principalmente no T3 e no T4, que ultrapassaram o número de árvores original em 20\% e 21\%, respectivamente, 21 anos após a exploração. Considerando somente as espécies de valor comercial, esses valores sobem para $47,4 \%$ e $72,3 \%$ (Tabela 1 e Figura 1 ).

A área do tratamento $\mathrm{T} 0$, onde não houve intervenções, permaneceu com os valores do número de árvores total e comercial praticamente constantes durante todo o período de acompanhamento (Figura 1). 


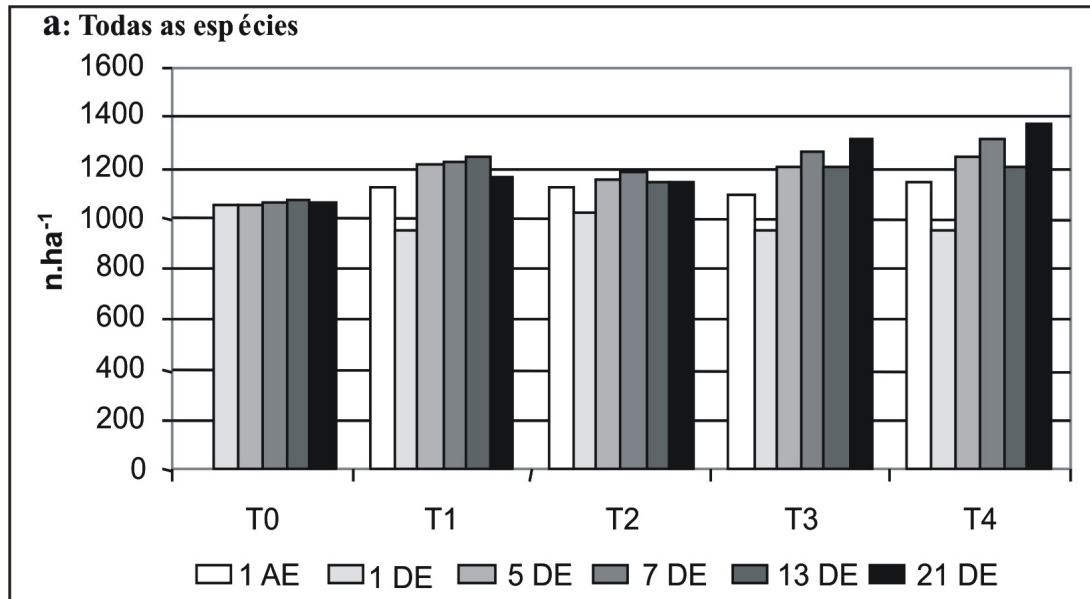

b: Espécies comerciais

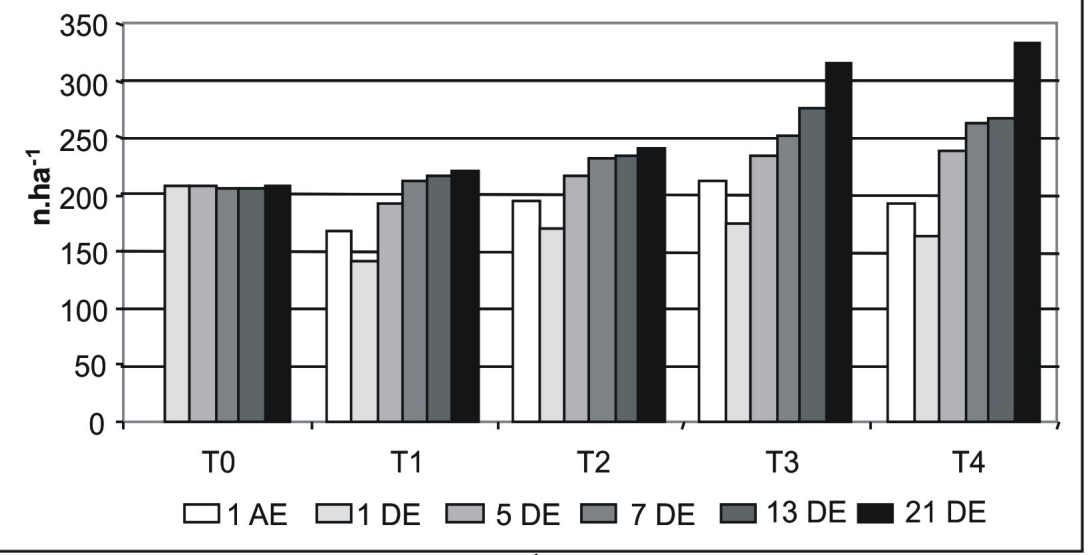

Figura 1 - Número de indivíduos.ha ${ }^{-1}$ para todas as espécies (a) e para as espécies comerciais (b) em cada tratamento e a cada ano de medição em uma amostra de 10,25ha na Floresta Nacional dos Tapajós, considerando todas as árvores com DAP $\geq 5,0 \mathrm{~cm}$. AE: número de anos antes da exploração, DE: número de anos após a exploração

Não foram encontradas diferenças estatísticas significativas entre os tratamentos onde houve intervenções, para as variáveis número de árvores total.ha ${ }^{-1}$ e o número de árvores comercial.ha ${ }^{-1}$, antes da exploração e durante as medições intermediárias. Diferenças significativas para essas duas variáveis só foram observadas no último levantamento, realizado em 2003, vinte e um anos após a exploração, quando as médias do T3 e T4 foram iguais entre si e, estatisticamente, superiores aos demais tratamentos (Anexo D). 
As mudanças ocorridas ao longo do período de avaliação e o efeito das intervenções sobre o número de árvores.ha ${ }^{-1}$ são discutidos separadamente para cada tratamento.

\subsubsection{Tratamento T1: Exploração de espécies comerciais madeireiras com $\mathrm{DAP} \geq$ $45 \mathrm{~cm}(2,5 \mathrm{ha})$}

$\mathrm{Na}$ área do tratamento $\mathrm{T} 1$, havia 1.222,4 indivíduos por hectare com $\mathrm{DAP} \geq 5,0 \mathrm{~cm}$ antes da exploração. Em relação aos grupos ecológicos, 86\% dos indivíduos pertenciam a espécies tolerantes à sombra e 14\% eram indivíduos de espécies pioneiras. Rinorea flavescens foi a espécie mais abundante com 148 árvores.ha $^{-1}$ (12,1\% do total), seguida do grupo das sapotaceas com 75,2.ha ${ }^{-1}(6,2 \%)$, Rinorea guianensis com 68,0.ha ${ }^{-1}(5,6 \%)$, Duguetia echinophora com 58,0.ha ${ }^{-1}(4,7 \%)$ e Protium apiculatum com 55,2.ha ${ }^{-1}$ (4,5\%). Rinorea flavescens e Duguetia echinophora são espécies tolerantes à sombra, com madeira sem valor comercial conhecido, que dominam o sub-bosque da floresta tendo a maioria de seus indivíduos concentrados entre os diâmetros de $5,0 \mathrm{~cm}$ e $15,0 \mathrm{~cm}$. O grupo das sapotaceas e Rinorea guianensis também são tolerantes à sombra e sem uso comercial conhecido, porém apresentaram-se melhor distribuídas entre as classes de diâmetro, chegando a atingir 70,0cm de DAP. As 40 espécies mais abundantes no T1, a cada ano de medição, encontram-se no Anexo E.

Um ano após a exploração, o número total de árvores foi reduzido em aproximadamente $22 \%$ caindo para 957,2 por hectare. As espécies mais abundantes foram as mesmas encontradas na floresta original, porém com menor número de indivíduos. Algumas espécies sofreram reduções severas no número de árvores, principalmente as que foram extraídas durante a exploração madeireira, tais como Didymopanax morototoni (redução de 67\%), Holopyxidium jarana (53\%), Hymenaea courbaril (50\%) e Carapa guianensis (47\%). Outras, apesar de não terem sido exploradas, foram reduzidas devido aos danos causados pelas operações de colheita, entre elas estão: Eugenia sp. (57\% de redução), Tachigali sp. (45,5\%), Myrcia cf, m paivae $(42,8 \%)$ e Lacunaria jenmani (41\%). As classes diamétricas mais elevadas foram 
as mais afetadas pela redução no número de árvores em relação a abundância inicial. As classes acima de $75 \mathrm{~cm}$ passaram de 10,0 para 4,8 árvores.ha ${ }^{-1}$ (52\% de redução).

Cinco anos após a exploração foram quantificadas 1.219,2 árvores por hectare. Esse valor foi $8,6 \%$ superior ao encontrado na floresta original e $27,4 \%$ maior em relação à medição realizada um ano após a intervenção. As espécies mais abundantes da medição anterior permaneceram em posição de destaque, porém algumas espécies pioneiras tais como Cecropia leucoma, Jacaranda copaia, Cecropia sciadophylla e Bixa arbórea, que não estavam presentes no primeiro levantamento, ou eram representadas por poucos indivíduos, surgem agora entre as mais abundantes (Anexo E). A entrada de um grande número de espécies pioneiras fez com que esse grupo ecológico aumentasse sua participação de $14 \%$ para $31,5 \%$ do número total de árvores.

Na medição seguinte, sete anos após a exploração, o número total de árvores subiu para $1.227,6 . \mathrm{ha}^{-1}$, representando um aumento de $0,7 \%$ em relação à medição imediatamente anterior, $28 \%$ em relação ao valor obtido no primeiro ano após a exploração e de 9,4\% em relação à floresta original. Inga sp. e Bixa arborea foram as espécies que apresentaram maior aumento no número de árvores em relação à medição anterior com 28\% e 21\%, respectivamente. As espécies pioneiras continuaram aumentando seu percentual de participação no povoamento, passando para $34 \%$.

Treze anos após a exploração o numero de árvores total aumentou para 1.238,8.ha ${ }^{-}$ 1 , que representa 10,4\% a mais do que a floresta original. Algumas espécies pioneiras, que foram favorecidas pela abertura do dossel e tornaram-se abundantes cinco anos após a exploração, diminuíram em relação ao número de árvores durante este período, são elas: Cecropia leucoma (redução de 49\%), Sloanea froesii (redução de 30\%), Cecropia sciadophylla (19\%) e Jacaranda copaia (14\%).

No último levantamento, 21 anos após a exploração o número total de árvores diminuiu para $1.166,4 . \mathrm{ha}^{-1}$, que representa uma redução de 5,8\% em relação ao período anterior. Essa redução se deve principalmente à grande mortalidade das espécies Cecropia leucoma (42,4\% de redução), Cecropia sciadophylla (27\%), Sloanea froesii (25\%), Jacaranda copaia (20,6\%) e Inga sp. (20\%). Essas pioneiras, que necessitam de 
luz direta para crescer e se desenvolver, foram prejudicadas pelo fechamento das clareiras abertas pela exploração e juntas foram responsáveis pela diminuição de 48 indivíduos.ha ${ }^{-1}$, somente nestes últimos 8 anos. A grande mortalidade das pioneiras, observada nas duas últimas medições, fez com que esse grupo diminuísse sua participação para $30 \%$ do total de árvores.

Um outro fator que pode ter ocasionado a diminuição no número de árvores no período (1995-2003) foi a ocorrência, entre julho de 1997 e março de 1998, do El Niño que segundo o INPE/CPTEC (Instituto Nacional de Pesquisas Espaciais/Centro de Previsão do Tempo e Estudos Climáticos) foi o mais intenso dos últimos 50 anos, e provocou aumento de temperatura e estiagem prolongada nas regiões Norte e Nordeste do Brasil (Grimm, 2003), com isso, houve menos chuvas na região do Tapajós e muitas árvores provavelmente sucumbiram à seca prolongada.

Considerando o período total de acompanhamento, o número de árvores observado na última medição foi aproximadamente $4 \%$ superior ao da primeira, o que demonstra um aumento de $0,2 \%$ ao ano ou, em termos absolutos, 2 árvores.ha ${ }^{-1} \cdot$ ano $^{-1}$.

\subsubsection{Tratamento T2: Exploração de espécies comerciais madeireiras com DAP $\geq$ $55 \mathrm{~cm}+$ desbaste de espécies não comerciais totalizando aproximadamente $20 \%$ de redução da área basal original (1,75ha).}

$\mathrm{Na}$ área do tratamento T2 havia 1.121,0 árvores.ha ${ }^{-1}$ antes da exploração. As espécies mais abundantes eram Rinorea flavescens, grupo das Sapotaceas (9 esp.), Protium apiculatum, Rinorea guianensis e Inga sp., que representaram 36\% do total de indivíduos. Essas espécies mantiveram-se como as mais importantes em número de árvores.ha ${ }^{-1}$ durante todo o período de acompanhamento, com pequenas oscilações nos seus valores absolutos ao longo do tempo. As espécies tolerantes à sombra perfaziam $85 \%$ do número total de árvores e as pioneiras, os $15 \%$ restantes. No Anexo $\mathrm{F}$ estão listadas as 40 espécies mais abundantes em cada medição na área do T2.

Um ano após a exploração o número total de árvores foi reduzido para 1.017,0.ha ${ }^{-1}$ (diminuição de 9,3\%). Nesse período, 68 espécies tiveram sua abundância reduzida, 
destacando-se Holopyxidium jarana (38,5\%), Carapa guianensis (25\%), Hymenaea courbaril (25,3\%), Maquira sclerophylla (38,5\%), Miconia sp. (50\%) e Neea sp. (21\%). As três primeiras foram exploradas e as demais tiveram seus números reduzidos em conseqüência dos danos causados pela extração de madeira ou por mortalidade natural. As classes acima de $75 \mathrm{~cm}$ de DAP foram as mais afetadas pela exploração, passando de 5,2 para 2,3 árvores.ha ${ }^{-1}$ (redução de 56\%).

No levantamento seguinte, realizado em 1987, cinco anos após a exploração, o número total de árvores subiu para 1.153,0.ha ${ }^{-1}$, representando um aumento de 13,4\% em relação à medição anterior e $2,8 \%$ em relação à floresta original. A maior entrada de luz na floresta, em conseqüência da exploração madeireira, favoreceu algumas espécies pioneiras que se tornaram abundantes, tais como Jacaranda copaia (de 3,4 ind.ha ${ }^{-1} \mathrm{em}$ 1983 para 38,3.ha ${ }^{-1}$ em 1987, aumento de 1026\%), Cecropia sciadophylla (de 0,6.ha ${ }^{-1}$ para $\left.11,4 . \mathrm{ha}^{-1}, 1800 \%\right)$, Bixa arborea (de 0,6.ha ${ }^{-1}$ para 10,9.ha $\left.{ }^{-1}, 1717 \%\right)$, Cecropia leucoma (de 0,6.ha $\mathrm{h}^{-1}$ para 8,0.ha ${ }^{-1}, 1233 \%$ ) e Sloanea froesii (de 8,0.ha $\mathrm{h}^{-1}$ para 20,3.ha $\mathrm{h}^{-1}$, $154 \%$ ). O grupo ecológico das pioneiras passou a compor $22,3 \%$ do total de árvores da área.

Sete anos após a exploração o número total de árvores aumentou para 1.187,0.ha ${ }^{-1}$ que representa $2,9 \%$ em relação ao levantamento anterior e $6 \%$ a mais que a floresta original. Algumas espécies comerciais pioneiras tiveram um aumento considerável em abundância em relação ao período anterior, entre elas estão Laetia procera (de 4,6.ha ${ }^{-1}$ para 9,7.ha ${ }^{-1}$, aumento de 110\%), Cordia bicolor (de 9,1.ha $\mathrm{a}^{-1}$ para 11,4.ha $\mathrm{a}^{-1}, 25,3 \%$ ), Jacaranda copaia (de 38,3.ha ${ }^{-1}$ para 45,1.ha ${ }^{-1}, 18 \%$ ) e Sclerolobium chrysophyllum (de 8,0.ha ${ }^{-1}$ para 9,1.ha ${ }^{-1}, 14 \%$ ).

No levantamento realizado treze anos após a exploração, o número de árvores diminuiu em aproximadamente $4 \%$ em relação ao período anterior, passando para $1.140,0 . \mathrm{ha}^{-1}$. As principais espécies responsáveis por essa diminuição foram Duguetia echinophora (30\% de redução), Cecropia leucoma (29\%), grupo das lauraceas (12\%), Neea sp. (12\%), grupo das sapotaceas (7,7\%) e Rinorea flavescens (4,5\%). Estas espécies, entre outras, que estavam entre as mais abundantes e sem uso econômico 
conhecido, foram reduzidas em conseqüência do desbaste, via anelamento, aplicado na área no ano anterior.

Vinte e um anos após a exploração e nove após o refinamento, o número de árvores manteve-se praticamente estável com um aumento de apenas 0,3\%, em relação ao levantamento anterior, passando para $1.143,4$ árvores.ha $^{-1}$. As espécies com maiores perdas em número de árvores foram Cecropia leucoma (58\%), Jacaranda copaia $(21,4 \%)$ e Guarea kunthiana (14,6\%). Por outro lado, algumas espécies comerciais tiveram aumento em sua abundância, destacando-se Virola melinonii (39,2\%), Licaria canella $(26,7 \%)$ e Laetia procera (20,2\%). Em relação aos grupos ecológicos, as espécies pioneiras continuaram aumentando sua participação, passando a compor $26 \%$ do número total de árvores.

Considerando o período total de acompanhamento, o número de árvores observado na última medição foi $2 \%$ superior ao da primeira, o que demonstra um aumento de aproximadamente $0,1 \%$ ao ano, durante todo o período ou, em termos absolutos, uma árvore.ha- ${ }^{-1} \cdot$ ano $^{-1}$.

\subsubsection{Tratamento T3: Exploração de espécies comerciais madeireiras com $\mathrm{DAP} \geq$ $55 \mathrm{~cm}+$ desbaste de espécies não comerciais totalizando aproximadamente $30 \%$ de redução da área basal original (3,0ha).}

No primeiro ano de medição foram encontradas $1.097,0$ árvores.ha ${ }^{-1}$ na área do T3. Em relação aos grupos ecológicos, 82,5\% dos indivíduos pertenciam a espécies tolerantes à sombra e 17,5\% eram indivíduos de espécies pioneiras. O grupo das sapotaceas foi o mais abundante com 79,7 indivíduos.ha ${ }^{-1}$, seguido de Inga sp. com 73,7.ha ${ }^{-1}$, Protium apiculatum com 68,0.ha ${ }^{-1}$, Rinorea guianensis com 62,7.ha ${ }^{-1}$ e Neea sp. com 52,0.ha ${ }^{-1}$. Estas cinco espécies representaram 30,6\% do número total de árvores antes da exploração e mantiveram-se como as mais abundantes durante todo o período de acompanhamento. No Anexo G estão listadas as 40 espécies que se destacaram em número.ha ${ }^{-1}$, ao longo dos anos de medição, no T3. Estas espécies representam juntas em torno de $70 \%$ do número total de árvores encontradas na área em cada medição. 
Um ano após a exploração, o número de árvores foi reduzido em 12,6\% caindo para $958,7 \cdot \mathrm{ha}^{-1}$. No período entre o primeiro e o segundo levantamento 105 espécies tiveram sua abundância reduzida, entre elas destacaram-se Simaruba amara $(66,5 \%)$, Goupia glabra (66,5\%), Manilkara huberi (45\%) e Carapa guianensis (12,8\%), que foram extraídas durante a exploração de madeira, e as espécies Swartzia brachyrachis (57\%), Iryanthera juruensis (29\%), Perebea guianensis (26,3\%) e Talisia longifolia $(21,6 \%)$, que foram reduzidas em conseqüência dos danos causados pela colheita ou por mortalidade natural. A classe de diâmetro mais afetada pela exploração foi $55 \mathrm{~cm}$ a $65 \mathrm{~cm}$ que passou de 9,3 para 5,7 árvores.ha ${ }^{-1}$ (redução de 38,7\%).

Cinco anos após a exploração o número total de árvores passou para 1.201,3.ha ${ }^{-1}$, que representa um aumento de $25,2 \%$ em relação à medição anterior e 9,5\% em relação à floresta original. A abertura do dossel devida à exploração e à conseqüente maior entrada de luz na floresta, beneficiou algumas espécies pioneiras que eram representadas por poucos indivíduos na medição anterior, entre elas destacaram-se Laetia procera (de 0,3.ha ${ }^{-1}$ em 1983 para 8,0.ha ${ }^{-1}$ em 1987, aumento de 2567\%), Cecropia leucoma (de 1,7.ha ${ }^{-1}$ para $22,7 . \mathrm{ha}^{-1}, 1235 \%$ ) e Jacaranda copaia (de 2,3.ha ${ }^{-1}$ para $36,3 . \mathrm{ha}^{-1}, 1478 \%$ ). Além disso, a maior incidência de luz favoreceu o surgimento de outras quatro espécies pioneiras que não estavam presentes no primeiro levantamento, entre elas as mais abundantes foram Cecropia sciadophylla (23 indivíduos.ha ${ }^{-1}$ ) e Aegiphilla sp. (11 indivíduos.ha ${ }^{-1}$ ). O grupo de pioneiras passou a compor aproximadamente $30 \%$ do número total de árvores do povoamento.

Na medição seguinte, sete anos após a exploração, o número total de árvores subiu para 1.264,7.ha $\mathrm{a}^{-1}$, representando um aumento de 5,3\% em relação à medição imediatamente anterior, $32 \%$ em relação ao valor obtido no primeiro ano após a exploração e de 15,3\% em relação à floresta original. Neste período, a maioria das espécies permaneceu estável (sem grandes alterações na abundância), apenas Pouteria bilocularis teve redução acentuada, perdendo 10 indivíduos.ha $^{-1}$ (73\%) e Inga sp. mostrou um aumento de 18,7 árvores.ha ${ }^{-1}(17 \%)$. 
Treze anos após a exploração o número de árvores diminuiu em 4,3\% em relação ao período anterior, passando para $1.209,7 \cdot \mathrm{ha}^{-1}$. A causa principal dessa redução foi o desbaste aplicado na área um ano antes. As espécies com maior redução na abundância foram Cecropia sciadophylla, redução de 21,6 indivíduos.ha ${ }^{-1}$ (79\%), Cecropia leucoma, 15,3.ha $\mathrm{h}^{-1}(64 \%)$, Inga sp., 11,7.ha ${ }^{-1}(9,2 \%)$ e o grupo das Sapotaceas 10,0.ha ${ }^{-1}(13,3 \%)$.

No último levantamento, realizado 21 anos após a exploração e 9 após o refinamento, o número de árvores observado foi $1.314,0 . \mathrm{ha}^{-1}$, o que representa um aumento de $8,6 \%$ em relação ao levantamento anterior e aproximadamente $20 \%$ a mais que a floresta original (antes da exploração). Sagotia racemosa, Duguetia echinophora, Inga sp. e Protium apiculatum foram as espécies que tiveram maior aumento no número de árvores, contribuindo juntas com 61 indivíduos.ha $^{-1}$ a mais do que na medição anterior. Além disso, observou-se o aumento na abundância de espécies comerciais, importantes no mercado madeireiro, como Couratari oblongifolia (de 12,0.ha ${ }^{-1}$ em 1995 para $16 . \mathrm{ha}^{-1}$ em 2003, aumento de 33\%), Virola melinonii (de 10,3.ha ${ }^{-1}$ para 14,7.ha ${ }^{-1}$, $43 \%$ ) e Licaria canella (de $19,7 \cdot \mathrm{ha}^{-1}$ para $25,3 \cdot \mathrm{ha}^{-1}, 28,4 \%$ ). O grupo das pioneiras continuou aumentando sua participação na área, porém em um ritmo menos acelerado, passando para $32,3 \%$.

Considerando o período total de acompanhamento, o número de árvores observado na última medição foi $20 \%$ superior ao da primeira, o que demonstra um aumento de $0,9 \%$ ao ano durante todo o período ou, em termos absolutos, aproximadamente 10 árvores.ha ${ }^{-1} \cdot$ ano $^{-1}$.

\subsubsection{Tratamento T4: Exploração de espécies comerciais madeireiras com $\mathrm{DAP} \geq$ $55 \mathrm{~cm}+$ desbaste de espécies não comerciais totalizando aproximadamente $50 \%$ de redução da área basal original (1,5ha).}

No T4 foram inventariadas $1.138,7$ árvores com DAP $\geq 5,0 \mathrm{~cm}$ por hectare, antes da exploração. As espécies tolerantes à sombra perfaziam $84 \%$ do número total de árvores e as pioneiras os $16 \%$ restantes. Rinorea flavescens foi a mais abundante com 119,3 indivíduos.ha ${ }^{-1}$ (10,5\% do total), seguida de Protium apiculatum com 83,3.ha ${ }^{-1}$ 
(7,3\%), do grupo das sapotaceas com 76,7.ha ${ }^{-1}(6,7 \%)$, Rinorea guianensis com 60,7.ha ${ }^{-1}$ $(5,3 \%)$ e Inga sp. com 60,7.ha ${ }^{-1}$ (5,3\%). Estas cinco espécies representaram 35\% do total de árvores no primeiro levantamento e permaneceram como as mais abundantes durante todo o período de acompanhamento. As 40 espécies mais importantes em número de árvores por hectare, ao longo dos anos de medição, no T4, estão listadas no Anexo H.

Um ano após a exploração o número total de árvores foi 957,3.ha ${ }^{-1}$, o que representa uma redução de aproximadamente $16 \%$. Entre a primeira e a segunda medição, 85 espécies sofreram redução na abundância e 66 não tiveram alteração. Algumas foram severamente reduzidas por terem sido extraídas durante a exploração, entre elas destacaram-se Bertholletia excelsa (redução de 66,5\%), Manilkara huberi (50\%), Holopyxidium jarana (50\%), e Hymenolobium excelsum (49,6\%). Outras como Protium apiculatum (24\% de redução), Inga sp. (28,6\%), Guatteria poeppigiana $(31,2 \%)$ e Coussarea paniculata $(30 \%)$, foram reduzidas devido aos danos causados pelas operações de colheita ou devido a mortalidade natural.

A classe de diâmetro mais afetada pela exploração foi $55 \mathrm{~cm}$ a $65 \mathrm{~cm}$ que passou de 10 para 0,4 árvore.ha ${ }^{-1}$, apresentando redução de $96 \%$.

Cinco anos após a exploração, foram quantificadas 1.242,0 árvores por hectare. Esse valor foi $9,1 \%$ superior ao encontrado na floresta original e $29,7 \%$ maior em relação à medição realizada um ano após a intervenção. Assim como nos demais tratamentos, a abertura do dossel devida à exploração beneficiou espécies pioneiras, que eram representadas por poucos indivíduos na medição anterior, tais como Cecropia sciadophylla (de 0,7.ha ${ }^{-1}$ em 1983 para 40,7.ha ${ }^{-1}$ em 1987, aumento de 5614\%), Cecropia leucoma $\left(2,7 . \mathrm{ha}^{-1}\right.$ para $\left.38,0 . \mathrm{ha}^{-1}, 1307 \%\right)$, Laetia procera $\left(0,7 . \mathrm{ha}^{-1}\right.$ para $7,3 . \mathrm{ha}^{-}$ 1, 942\%) e Sloanea froesii (de 9,3.ha ${ }^{-1}$ para 21,3.ha ${ }^{-1}, 129 \%$ ), além de favorecer o surgimento de outras pioneiras que não estavam presentes na floresta original, como Aegiphylla sp. com 12,7 indivíduos.ha ${ }^{-1}$ e Jacaranda copaia com 41,3.ha ${ }^{-1}$. O aumento no número de indivíduos de espécies pioneiras fez com que esse grupo dobrasse sua participação no povoamento, passando a compor $32,3 \%$ do total. 
$\mathrm{Na}$ medição seguinte, sete anos após a exploração, o número total de árvores subiu para 1.312,7.ha ${ }^{-1}$, representando um aumento de 5,7\% em relação à medição imediatamente anterior e 15,3\% em relação à floresta original. As espécies Laetia procera, Aegiphylla sp., Sloanea froesii e Jacaranda copaia foram as que apresentaram maior aumento na abundância neste período.

Treze anos após a exploração, o número de árvores diminuiu em 8,3\% em relação ao período anterior, passando para $1.203,3 \cdot \mathrm{ha}^{-1}$. O anelamento aplicado um ano antes desse levantamento foi a principal causa dessa redução. As espécies mais afetadas foram: Cecropia sciadophylla, que perdeu 40,0 indivíduos.ha ${ }^{-1}$ (90\%), Cecropia leucoma perdeu $22,0 . \mathrm{ha}^{-1}(60 \%)$, Inga sp. perdeu $13,3 \cdot \mathrm{ha}^{-1}(12 \%)$ e o grupo das sapotaceas que perdeu $12,0 . \mathrm{ha}^{-1}(18 \%)$.

No último levantamento, 21 anos após a exploração e 9 após o desbaste, o número de árvores aumentou para $1.378,7 . \mathrm{ha}^{-1}$, que representa $14,6 \%$ a mais que a medição anterior e $21 \%$ superior à floresta original. As espécies com maior aumento na abundância nesse período foram Bixa arborea (de 12,7.ha ${ }^{-1}$ em 1995 para 23,3.ha ${ }^{-1}$ em 2003, aumento de 83,5\%), Inga sp. (de $100 . \mathrm{ha}^{-1}$ para $180,7 . \mathrm{ha}^{-1}$, 80\%) e Talisia longifolia (de 7,3.ha ${ }^{-1}$ para $12,7 . \mathrm{ha}^{-1}, 74 \%$ ). Assim como no tratamento $\mathrm{T} 3$, ocorreu também aumento na abundância de espécies comerciais como Virola melinonii (de 7,3.ha ${ }^{-1}$ para 19,3.ha ${ }^{-1}, 164 \%$ ), Sclerolobium chrysophyllum (de 6,7.ha ${ }^{-1}$ para 14,0.ha ${ }^{-1}$, 109\%), Cordia alliodora (de 8,7.ha ${ }^{-1}$ para 12,7.ha ${ }^{-1}, 46 \%$ ), Cordia bicolor (de 12,7.ha ${ }^{-1}$ para $17,3 . \mathrm{ha}^{-1}, 36 \%$ ) e Licaria canella (de $16,7 . \mathrm{ha}^{-1}$ para $20,7 \cdot \mathrm{ha}^{-1}, 24 \%$ ). A intensidade do desbaste provocou grandes aberturas no dossel, beneficiando as espécies pioneiras, que passaram a compor $38 \%$ do número total de árvores.ha ${ }^{-1}$, além de favorecer a infestação de cipós nas maiores clareiras, dificultando sua regeneração (Figura 2).

Considerando o período total de acompanhamento, o número de árvores observado na última medição foi $21 \%$ superior ao da primeira, o que demonstra um aumento de aproximadamente $1,0 \%$ ao ano durante todo o período ou, em termos absolutos, aproximadamente 11 árvores.ha ${ }^{-1} \cdot$ ano $^{-1}$. 

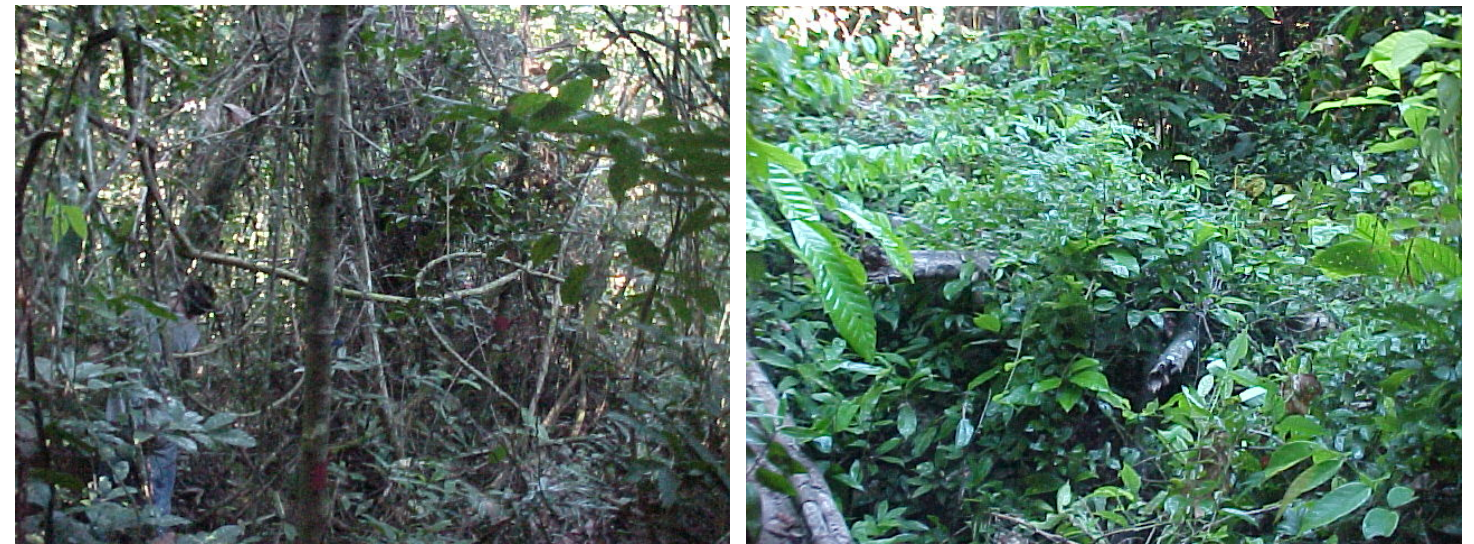

Figura 2 - Infestação por cipós e grandes clareiras abertas na área do tratamento T4, observadas nove anos após o desbaste, devido à intensidade de abertura do dossel

\subsubsection{Tratamento T0: Testemunha, área sem intervenção (1,5ha).}

$\mathrm{Na}$ área sem intervenção foram inventariadas 1.056,7 árvores por hectare no primeiro levantamento (1983). As espécies mais abundantes foram Rinorea guianensis, Protium apiculatum, Duguetia echinophora, o grupo das Sapotaceae e Inga sp. Somente estas cinco espécies contribuíram com aproximadamente $31 \%$ do número total de árvores.ha ${ }^{-1}$ na floresta testemunha, e permaneceram como as mais abundantes durante todo o período de acompanhamento. As 40 espécies mais importantes em termos de número de árvores por hectare, durante o período de medição, no T0 estão listadas no Anexo I.

No segundo levantamento, realizado em 1987, o número de árvores manteve-se praticamente a mesmo $\left(1.056,0 . \mathrm{ha}^{-1}\right)$. Dois anos depois, em 1989, houve um pequeno aumento de $0,6 \%$ em relação ao período anterior $\left(1.062,0 . \mathrm{ha}^{-1}\right)$. No inventário seguinte, em 1995, foram encontradas 1.068,7.ha ${ }^{-1}$ (aumento de 0,63\%), e no último levantamento, em 2003, foram observadas 1.066,0 árvores.ha ${ }^{-1}$ (redução de 0,25\%).

Pode-se observar que as alterações no número de árvores na área testemunha foram muito pequenas. Entre a primeira e a última medição, realizada 20 anos depois, houve um aumento de apenas $0,9 \%$. As espécies que mais diminuíram em abundância foram Eperua bijuga e Licaria canella, que foram reduzidas em 5,3 indivíduos.ha ${ }^{-1}(15 \%)$ e 
2,7.ha ${ }^{-1}$ (22,5\%), respectivamente. Rinorea flavescens e Protium apiculatum foram as que apresentaram maior acréscimo no número de árvores, com aumentos de 6,6.ha ${ }^{-1}$ $(62 \%)$ e $12,6 \cdot \mathrm{ha}^{-1}(18 \%)$.

\subsection{2 Área basal}

Entre os anos de 1981 e 1983 houve redução da área basal em todos os tratamentos, exceto a testemunha. Para o total de espécies, essa redução foi maior no T4 (27,5\%), seguida pelo T1, T3 e T2, com reduções de 24,0\%, 20,1\% e 19,4\%, respectivamente. Para as espécies comerciais, o tratamento que sofreu a maior redução também foi o T4 (42,5\%), seguido do T1, T2 e T3, com diminuição de 36,6\%, 35,4\% e 30,7\% (Tabela 2 e Figura 3). A principal causa dessa diminuição foi a colheita de

madeira, realizada em 1982, que extraiu em média 4,5 $\mathrm{m}^{2}$.ha ${ }^{-1}$ (ver Capítulo II). Outras causas menores foram os danos ocasionados pela exploração e o El Niño, ocorrido no período de 1982-1983 que provocou seca prolongada na região do Tapajós.

Nos levantamentos seguintes, realizados 5 e 7 anos após a exploração, a área basal total e comercial cresceu progressivamente em todos os tratamentos. Esse aumento foi estimulado pela maior entrada de luz na floresta, resultado da abertura do dossel devido a exploração, que acelerou o crescimento das árvores remanescentes e a entrada de novos indivíduos na comunidade (Tabela 2 e Figura 3).

Imediatamente após os desbastes, na medição de 1995, ocorreu nova redução na área basal considerando todas as espécies, porém apenas para os tratamentos T3 e T4, nos quais o desbaste foi realizado nas intensidades de 30\% e 50\%. A área basal do T3 foi reduzida em 8,7\% em relação a medição anterior (1989). Para o T4 esse valor foi de aproximadamente $15 \%$. No T2 (20\% de redução da área basal) não ocorreu diminuição, a área basal continuou a crescer, assim como no $\mathrm{T} 1$, onde não foi realizado o desbaste (Tabela 2 e Figura 3). 
Tabela 2 Área basal de todas as espécies e área basal das espécies comerciais em cada tratamento e a cada ano de medição, em uma amostra de 10,25ha na Floresta Nacional do Tapajós, considerando todas as árvores com DAP $\geq 5,0 \mathrm{~cm}$

\begin{tabular}{|c|c|c|c|c|c|c|c|c|c|c|}
\hline \multirow[t]{2}{*}{ Anos } & \multicolumn{5}{|c|}{ Área basal total $\left(\mathrm{m}^{2} \cdot \mathrm{ha}^{-1}\right)$} & \multicolumn{5}{|c|}{ Área basal comercial $\left(\mathrm{m}^{2} \cdot \mathrm{ha}^{-1}\right)$} \\
\hline & TO & $\mathrm{T} 1$ & $\mathrm{~T} 2$ & $\mathrm{~T} 3$ & $\mathrm{~T} 4$ & T0 & $\mathrm{T} 1$ & $\mathrm{~T} 2$ & $\mathrm{~T} 3$ & $\mathrm{~T} 4$ \\
\hline 1981 (1 AE) & & 31,95 & 31,87 & 29,20 & 28,81 & & 13,68 & 15,23 & 13,61 & 13,58 \\
\hline 1983 (1 DE) & 30,51 & 24,31 & 25,68 & 23,34 & 20,90 & 15,59 & 8,67 & 9,83 & 9,43 & 7,81 \\
\hline 1987 (5 DE) & 31,33 & 26,49 & 27,77 & 25,46 & 23,51 & 16,06 & 9,60 & 10,54 & 9,69 & 8,30 \\
\hline 1989 (7 DE) & 31,16 & 28,49 & 28,95 & 26,66 & 25,12 & 15,70 & 10,18 & 11,08 & 10,02 & 8,69 \\
\hline 1995 (13DE, 1DT) & 30,50 & 30,14 & 29,94 & 24,35 & 21,34 & 14,94 & 10,77 & 11,84 & 10,68 & 8,35 \\
\hline 2003 (21DE 9DT) & 31,71 & 30,70 & 31,76 & 25,40 & 22,22 & 15,30 & 11,11 & 12,97 & 12,17 & 9,53 \\
\hline
\end{tabular}

No último levantamento, realizado em 2003, nove anos após os desbastes, todos os tratamentos apresentaram aumento nos valores de área basal, com destaque para a área basal das espécies comerciais nos tratamentos T3 e T4 que tiveram elevações percentuais de $14 \%$ e 14,1\%, respectivamente, em relação à medição anterior (Figura 3).

Não foram encontradas diferenças estatísticas significativas entre os tratamentos onde houve intervenção (T1, T2, T3 e T4) para a variável área basal de espécies comerciais, durante todo o período de acompanhamento. Para a área basal de todas as espécies só foram detectadas diferenças significativas nos dois últimos períodos (13 e 21 anos após a exploração), que correspondem a um e nove anos após a aplicação dos desbastes, quando as médias dos tratamentos T3 e T4 foram iguais entre si e estatisticamente inferiores aos demais (Anexo J). Essa diferença pode ser explicada porque os tratamentos T3 e T4 foram os que sofreram as maiores reduções na área basal, com a aplicação dos tratos silviculturais, 30\% e 50\%, respectivamente, e essa redução não atingiu as espécies de valor comercial, ou seja, a área basal comercial não foi afetada. 
A área testemunha, tratamento T0, permaneceu com os valores de área basal total praticamente constantes, em torno de $30 \mathrm{~m}^{2} \cdot \mathrm{ha}^{-1}$, durante todo o período de acompanhamento. Nas espécies comerciais houve redução de 1,9\% em relação ao valor obtido na primeira medição (Figura 3).

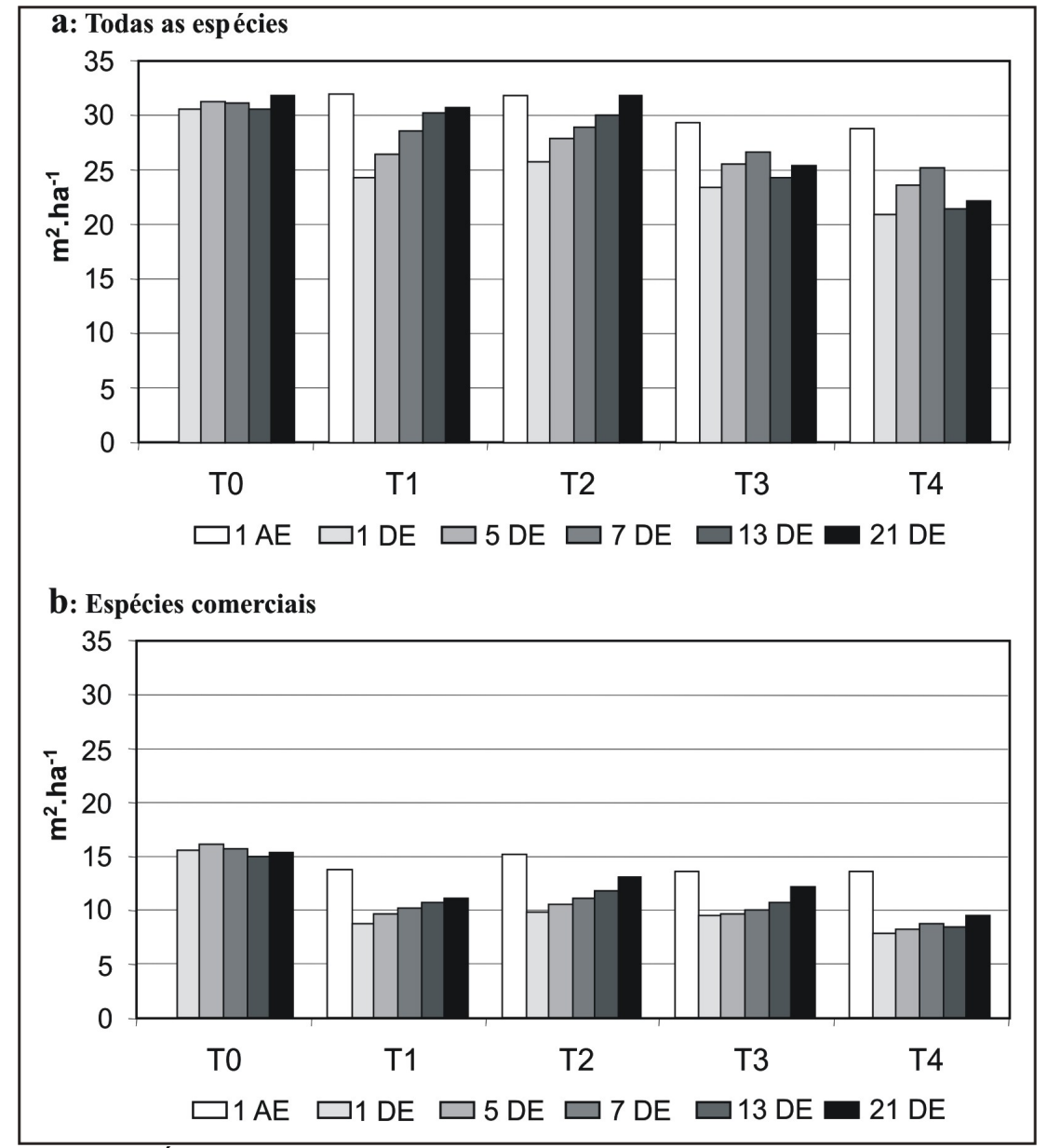

Figura 3 - Área basal de todas as espécies (a) e das espécies comerciais (b) em cada tratamento e a cada ano de medição em uma amostra de 10,25ha na Floresta Nacional dos Tapajós, considerando todas as árvores com DAP $\geq 5,0 \mathrm{~cm}$. AE: número de anos antes da exploração DE: número de anos após a exploração

Analisando todo o período de acompanhamento, observa-se que a recuperação da área basal total, entre os tratamentos onde houve intervenção, foi maior para o T2, que recuperou $99,7 \%$ do valor obtido no levantamento antes da extração de madeira. Para os tratamentos T1, T3 e T4 esses valores são 96\%, 87\% e 77\%, respectivamente. Em relação a recuperação da área basal das espécies de valor comercial, o tratamento que 
mais se destacou foi o T3 (89,5\%), seguido do T2, T1 e T4 com 85,2\%, 81,2\% e 70,1\%, respectivamente (Figura 3 ).

As mudanças ocorridas ao longo do período de avaliação e o efeito das intervenções sobre a área basal das espécies são discutidos separadamente para cada tratamento.

\subsubsection{Tratamento T1: Exploração de espécies comerciais madeireiras com $\mathrm{DAP} \geq$ $45 \mathrm{~cm}(2,5 \mathrm{ha})$}

No primeiro levantamento, antes da exploração, a área basal média do tratamento $\mathrm{T} 1$ era $31,9 \mathrm{~m}^{2} \cdot \mathrm{ha}^{-1}$. Em relação aos grupos ecológicos, 79\% dos indivíduos pertenciam a espécies tolerantes à sombra e $21 \%$ a espécies pioneiras. As espécies dominantes eram: grupo das sapotaceas com $1,90 \mathrm{~m}^{2} \cdot \mathrm{ha}^{-1}$, Rinorea guianensis com $1,75 \mathrm{~m}^{2} \cdot \mathrm{ha}^{-1}$, Carapa guianensis com $1,73 \mathrm{~m}^{2} \cdot \mathrm{ha}^{-1}$ e Minquartia guianensis com $1,13 \mathrm{~m}^{2} \cdot \mathrm{ha}^{-1}$, todas tolerantes à sombra. As 40 espécies mais dominantes, ao longo dos anos de medição, no T1, estão listadas no Anexo K.

Um ano após a exploração a área basal total foi reduzida para $24,3 \mathrm{~m}^{2} \cdot \mathrm{ha}^{-1}(24 \%)$. As espécies extraídas durante a exploração tiveram as maiores reduções na área basal, entre elas destacaram-se: Bagassa guianensis (redução de $0,4 \mathrm{~m}^{2} \cdot \mathrm{ha}^{-1}, 100 \%$ ), Hymenaea courbaril $\left(0,5 \mathrm{~m}^{2} \cdot \mathrm{ha}^{-1}, 99,5 \%\right)$, Caryocar glabrum $\left(0,28 \mathrm{~m}^{2} \cdot \mathrm{ha}^{-1}, 96 \%\right)$, Carapa guianensis $\left(1,3 \mathrm{~m}^{2} \cdot \mathrm{ha}^{-1}, 80,6 \%\right)$, Holopyxidium jarana $\left(0,9 \mathrm{~m}^{2} \cdot \mathrm{ha}^{-1}, 80 \%\right)$ e Manilkara huberi $\left(0,7 \mathrm{~m}^{2} \cdot \mathrm{ha}^{-1}, 72 \%\right)$.

Cinco anos após a exploração foi registrada uma área basal de $26,5 \mathrm{~m}^{2} \cdot \mathrm{ha}^{-1}$, o que representa um aumento de $9 \%$ em relação ao levantamento anterior. Nesse período, as espécies com maior aumento na área basal foram as pioneiras beneficiadas pela abertura do dossel, que aumentaram seu percentual de participação no povoamento passando de $21 \%$ (antes da exploração) para 26\%. Entre elas destacaram-se Cecropia leucoma (de $0,02 \mathrm{~m}^{2} \cdot \mathrm{ha}^{-1}$ em 1983, para $0,19 \mathrm{~m}^{2} \cdot \mathrm{ha}^{-1}$ em 1987, aumento de 850\%), Bixa arborea $\left(0,20 \mathrm{~m}^{2} \cdot \mathrm{ha}^{-1}\right.$ para $\left.0,37 \mathrm{~m}^{2} \cdot \mathrm{ha}^{-1}, 85 \%\right)$, Inga sp. (de $0,62 \mathrm{~m}^{2} \cdot \mathrm{ha}^{-1}$ para $\left.0,84 \mathrm{~m}^{2} \cdot \mathrm{ha}^{-1}, 35,5 \%\right)$ e Sclerolobium chrysophyllum $\left(0,67 \mathrm{~m}^{2} \cdot \mathrm{ha}^{-1}\right.$ para $\left.0,80 \mathrm{~m}^{2} \cdot \mathrm{ha}^{-1}, 19,4 \%\right)$. Além disso, 
Jacaranda copaia e Cecropia sciadophylla, que não estavam presentes no povoamento antes da exploração, surgiram entre as mais dominantes com $0,15 \mathrm{~m}^{2} \cdot \mathrm{ha}^{-1} \mathrm{e} 0,56 \mathrm{~m}^{2} \cdot \mathrm{ha}^{-1}$, respectivamente.

Sete anos após a exploração, a área basal média passou para $28,5 \mathrm{~m}^{2} \cdot \mathrm{ha}^{-1}$ (aumento de 7,5\%). As espécies pioneiras, citadas anteriormente, permaneceram com as maiores taxas de aumento na área basal.

No levantamento seguinte, realizado 13 anos após a exploração, a área basal foi $30,14 \mathrm{~m}^{2} \cdot \mathrm{ha}^{-1}$ (aumento de 5,8\% em relação ao período anterior). O grupo das pioneiras continuou aumentando sua participação no povoamento, passando a compor aproximadamente $34 \%$ da área basal total. Algumas espécies comerciais importantes no mercado madeireiro tiveram grandes aumentos em área basal nesse período. Entre elas, destacaram-se Tachigali myrmecophyla (de $0,11 \mathrm{~m}^{2} \cdot \mathrm{ha}^{-1} \mathrm{em} 1987$ para $0,21 \mathrm{~m}^{2} \cdot \mathrm{ha}^{-1} \mathrm{em}$ 1995, aumento de 91\%), Jacaranda copaia (de $0,20 \mathrm{~m}^{2} \cdot \mathrm{ha}^{-1}$ para $0,28 \mathrm{~m}^{2} \cdot \mathrm{ha}^{-1}, 40 \%$ ), Virola melinonii (de $0,26 \mathrm{~m}^{2} \cdot \mathrm{ha}^{-1}$ para $0,32 \mathrm{~m}^{2} \cdot \mathrm{ha}^{-1}, 23 \%$ ), Parkia multijuga (de $0,23 \mathrm{~m}^{2} \cdot h \mathrm{ha}^{-1}$ para $0,28 \mathrm{~m}^{2} \cdot \mathrm{ha}^{-1}, 21,7 \%$ ) e Manilkara huberi (de $0,33 \mathrm{~m}^{2} \cdot \mathrm{ha}^{-1}$ para $\left.0,39 \mathrm{~m}^{2} \cdot \mathrm{ha}^{-1}, 18,2 \%\right)$.

No último inventário, 21 anos após a exploração, observou-se um aumento na área basal de apenas $1,9 \%$ em relação à medição anterior, passando para $30,7 \mathrm{~m}^{2} \cdot \mathrm{ha}^{-1}$. As espécies pioneiras representaram 35,6\% da área basal total (aumento de 14,6\% em relação a floresta original). As espécies dominantes foram Cecropia sciadophylla com $2,4 \mathrm{~m}^{2} \cdot \mathrm{ha}^{-1}$, o grupo das sapotaceas com $2,1 \mathrm{~m}^{2} \cdot \mathrm{ha}^{-1}$, Inga sp. com $1,6 \mathrm{~m}^{2} \cdot \mathrm{ha}^{-1}$, Rinorea

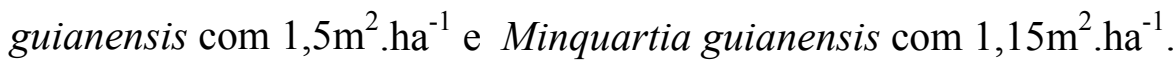

Analisando todo o período de acompanhamento, verificou-se que, 21 anos após a exploração, a área do T1 recuperou $96 \%$ da área basal total da floresta original. Porém esta recuperação não foi bem distribuída entre as classes de diâmetro. Nas classes que vão de $5,0 \mathrm{~cm}$ a $45,0 \mathrm{~cm}$ (estoque para as próximas colheitas) a área basal passou de $16,5 \mathrm{~m}^{2} \cdot h \mathrm{a}^{-1}$ (primeiro levantamento) para $19,7 \mathrm{~m}^{2} \cdot \mathrm{ha}^{-1}$ (21 anos após exploração), ultrapassando em $20 \%$ o valor inicial. Nas classes de diâmetro superiores a $45 \mathrm{~cm}$ a recuperação da área basal não foi suficiente para repor o valor original, ficando 
aproximadamente $29 \%$ abaixo, ou seja, estas classes precisarão de $4,5 \mathrm{~m}^{2} \cdot \mathrm{ha}^{-1}$ a mais do que o valor atual para atingir os mesmos níveis anteriores à exploração (Figura 4a).

O mesmo se deu entre as espécies de valor comercial, onde as classes inferiores a $45 \mathrm{~cm}$ de DAP ultrapassaram em 18,4\% o valor da área basal anterior à exploração, passando de $3,5 \mathrm{~m}^{2} \cdot \mathrm{ha}^{-1}$ para $4,2 \mathrm{~m}^{2} \cdot \mathrm{ha}^{-1}$. Nas classes de diâmetro superiores a $45 \mathrm{~cm}$ esse valor ficou aproximadamente $32 \%$ abaixo e estas classes precisarão de $3,2 \mathrm{~m}^{2} \cdot \mathrm{ha}^{-1}$ a mais para atingir os níveis anteriores à exploração (Figura 4b).

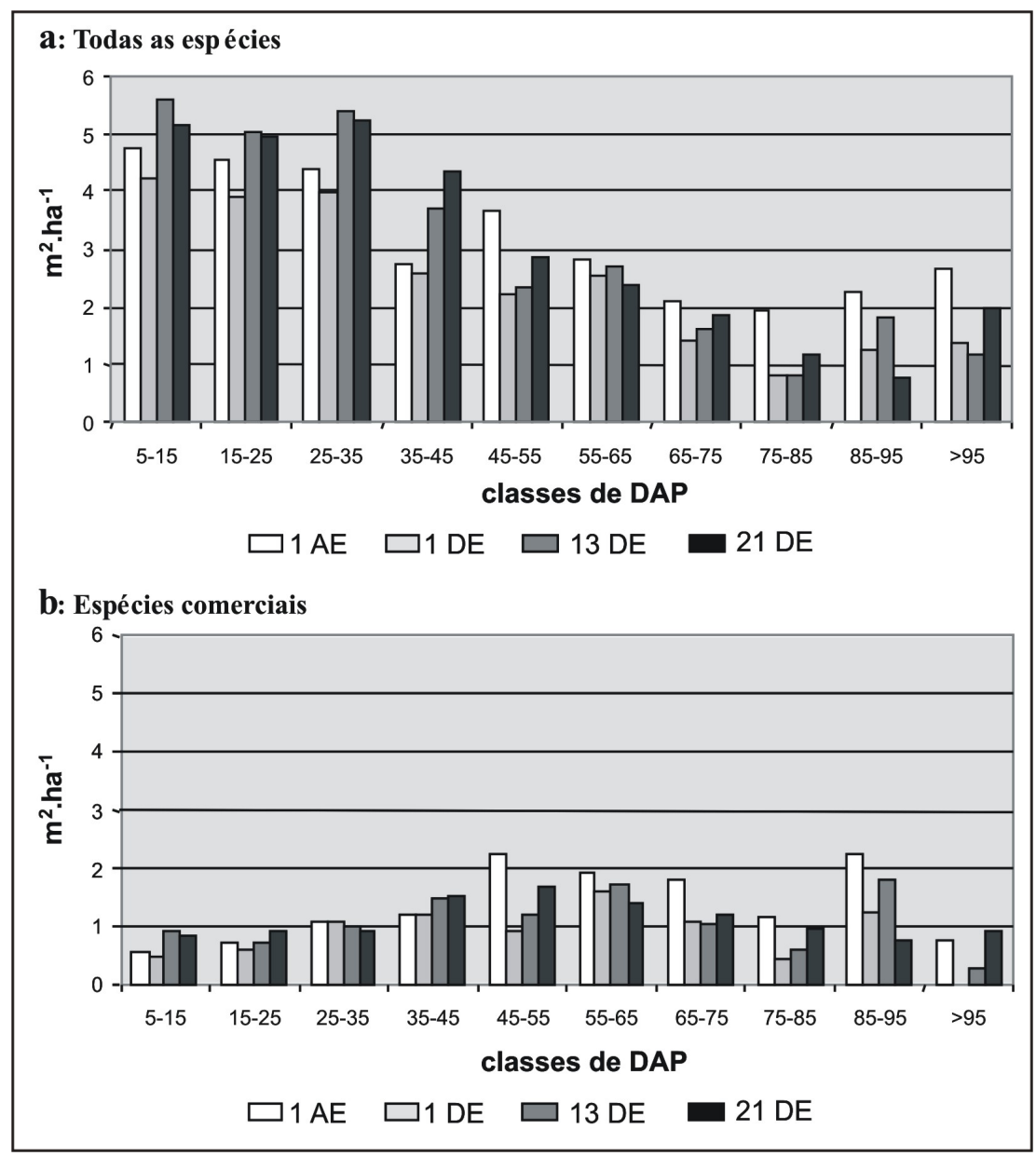

Figura 4 - Distribuição da área basal por classe diamétrica no tratamento T1, considerando todas as árvores (a) e somente árvores de espécies com valor comercial (b), em uma amostra de 2,5ha na Floresta Nacional do Tapajós, em 4 períodos de medição: $1 \mathrm{AE}$ (um ano antes da exploração), 1DE (um ano depois da exploração), 13DE (13 anos depois da exploração), 21DE (21 anos depois da exploração) 


\subsubsection{Tratamento T2: Exploração de espécies comerciais madeireiras com $\mathrm{DAP} \geq$ $55 \mathrm{~cm}+$ desbastes de espécies não comerciais totalizando $20 \%$ de redução da área basal original (1,75ha).}

A área basal média no T2, antes da exploração, era $31,9 \mathrm{~m}^{2} \cdot \mathrm{ha}^{-1}$. Deste total, $79 \%$ era formado por espécies tolerantes à sombra e 21\% por pioneiras. As espécies dominantes eram: Minquartia guianensis com 2,23 $\mathrm{m}^{2} \cdot \mathrm{ha}^{-1}$, o grupo das sapotaceas com $1,82 \mathrm{~m}^{2} \cdot \mathrm{ha}^{-1}$, Carapa guianensis com $1,53 \mathrm{~m}^{2} \cdot \mathrm{ha}^{-1}$, Rinorea guianensis com $1,51 \mathrm{~m}^{2} \cdot \mathrm{ha}^{-1} \mathrm{e}$ Holopyxidium jarana com $1,29 \mathrm{~m}^{2} \cdot \mathrm{ha}^{-1}$. No Anexo L estão listadas as 40 espécies mais dominantes, ao longo dos anos de medição, no tratamento T2.

Um ano após a exploração a área basal passou para $25,7 \mathrm{~m}^{2} \cdot \mathrm{ha}^{-1}$ (diminuição de 19,4\%). Algumas espécies extraídas durante a colheita de madeira foram severamente reduzidas, entre elas pode-se citar: Bertholletia excelsa (redução de 1,62 $\mathrm{m}^{2} \cdot \mathrm{ha}^{-1}, 100 \%$ ), Didymopanax morototoni $\left(0,20 \mathrm{~m}^{2} \cdot \mathrm{ha}^{-1}, 100 \%\right)$, Caryocar villosum $\left(0,31 \mathrm{~m}^{2} \cdot \mathrm{ha}^{-1}, 100 \%\right)$, Tabebuia serratifolia $\left(0,16 \mathrm{~m}^{2} \cdot \mathrm{ha}^{-1}, 90,7 \%\right)$, Astronium gracile $\left(0,38 \mathrm{~m}^{2} \cdot \mathrm{ha}^{-1}, 95,4 \%\right)$, Holopyxidium jarana $\left(1,12 \mathrm{~m}^{2} \cdot \mathrm{ha}^{-1}, 86,6 \%\right)$, Swartzia stipulifera $\left(0,16 \mathrm{~m}^{2} \cdot \mathrm{ha}^{-1}, 74,2 \%\right)$, e Vatairea sericea $\left(0,26 \mathrm{~m}^{2} \cdot \mathrm{ha}^{-1}, 73,5 \%\right)$. A retirada de várias espécies comerciais pioneiras diminuiu a participação deste grupo ecológico de $21 \%$ para $14,8 \%$.

Cinco anos após a exploração foram encontrados $27,8 \mathrm{~m}^{2} \cdot \mathrm{ha}^{-1}(8,2 \%$ a mais do que o período anterior). As espécies com maior aumento na área basal foram Cecropia sciadophylla (de $0,06 \mathrm{~m}^{2} \cdot \mathrm{ha}^{-1}$ em 1983 para $0,14 \mathrm{~m}^{2} \cdot \mathrm{ha}^{-1}$ em 1987 , aumento de $133 \%$ ), Jacaranda copaia (de $0,19 \mathrm{~m}^{2} \cdot \mathrm{ha}^{-1}$ para $0,39 \mathrm{~m}^{2} \cdot \mathrm{ha}^{-1}, 105 \%$ ), Sclerolobium chrysophyllum (de $0,33 \mathrm{~m}^{2} \cdot \mathrm{ha}^{-1}$ para $0,49 \mathrm{~m}^{2} \cdot \mathrm{ha}^{-1}, 48,5 \%$ ) e Inga sp. (de $0,69 \mathrm{~m}^{2} \cdot \mathrm{ha}^{-1}$ para $0,92 \mathrm{~m}^{2} \cdot \mathrm{ha}^{-1}$, $33,3 \%$ ), todas pioneiras beneficiadas pela maior entrada de luz na floresta após a exploração.

No levantamento seguinte, sete anos após a exploração, a área basal subiu para $28,9 \mathrm{~m}^{2} \cdot \mathrm{ha}^{-1}$ (aumento de 4,2\%). As espécies pioneiras que vinham apresentando elevadas taxas de aumento em área basal, no período anterior, permaneceram com a mesma tendência nesse período, o que fez com que este grupo ecológico passasse a representar $20 \%$ da área basal total. 
Treze anos após a exploração a área basal média foi $29,9 \mathrm{~m}^{2} \cdot$.ha ${ }^{-1}$ (aumento de 3,4\% em relação ao período anterior). As espécies Rinorea guianensis, Chimarrhis turbinata, Pouteria bilocularis, Iryanthera juruensis e Eschweilera amara apresentaram grandes perdas em área basal por terem sido aneladas como parte do tratamento silvicultural, aplicado um ano antes.

No último período de acompanhamento, 21 anos após a exploração, observou-se um aumento de $6 \%$ na área basal, em relação à medição anterior, passando para $31,8 \mathrm{~m}^{2} \cdot \mathrm{ha}^{-1}$. Os indivíduos de espécies pioneiras representaram $26 \%$ da área basal total (aumento de $5 \%$ em relação à floresta original). As espécies dominantes foram Minquartia guianensis, o grupo das sapotaceas, Rinorea guianensis, Protium apiculatum e Couratari oblongifolia. As três primeiras estavam entre as mais dominantes na primeira medição e mantiveram-se com elevada área basal durante os 22 anos de acompanhamento.

Analisando todo o período, verificou-se que aos 21 anos após a exploração, o povoamento recuperou praticamente toda a área basal subtraída pela exploração e tratamento silvicultural (99,6\% do total presente na floresta original). Porém, assim como no T1, esta recuperação não foi bem distribuída entre as classes diamétricas. Nas menores classes $(5,0 \mathrm{~cm}$ a $45,0 \mathrm{~cm})$ a área basal acumulada passou de $17,8 \mathrm{~m}^{2} \cdot \mathrm{ha}^{-1}$, no primeiro levantamento para $20,2 \mathrm{~m}^{2} \cdot \mathrm{ha}^{-1}$, no último (13,2\% maior) (Figura $5 \mathrm{a}$ ).

Nas classes de diâmetro superiores a $45 \mathrm{~cm}$ a recuperação da área basal não foi suficiente para repor o valor original, ficando aproximadamente 17,6\% abaixo. Apenas a classe de $55-65 \mathrm{~cm}$ apresentou recuperação expressiva, superando os valores originais em 10,7\% (Figura 5a).

Entre as espécies de valor comercial observou-se a mesma tendência. A área basal acumulada nas classes inferiores a $45 \mathrm{~cm}$ de diâmetro ultrapassaram em $18 \%$ o valor anterior à exploração. Entre as classes superiores a $45 \mathrm{~cm}$, apenas duas, $55-65 \mathrm{~cm}$ e 85 $95 \mathrm{~cm}$, recuperaram a área basal, superando os valores originais em $1,1 \%$ e 3,4\%, respectivamente. Apesar disso, o valor acumulado nestas classes ainda ficou 30,4\% 
abaixo do obtido no primeiro levantamento e estas classes precisarão de $3,1 \mathrm{~m}^{2} \cdot \mathrm{ha}^{-1}$ a mais para atingir os níveis anteriores à exploração (Figura 5b).

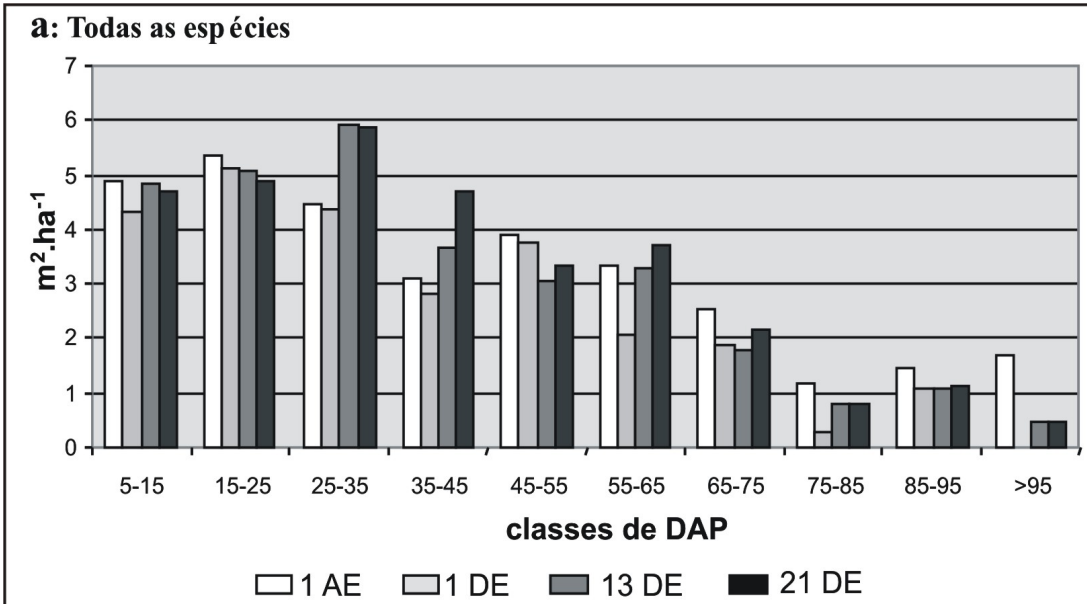

b: Espécies comerciais

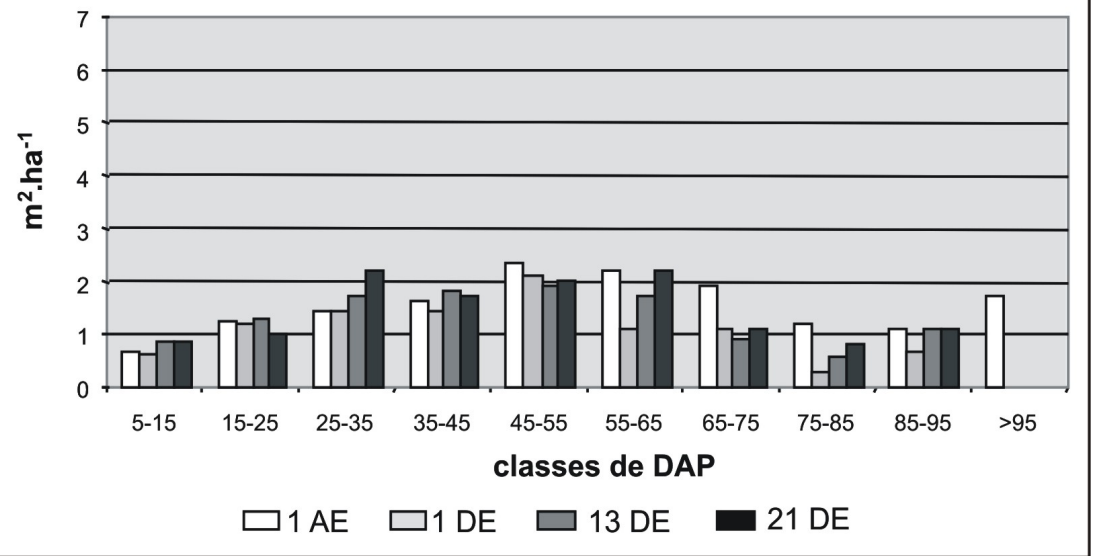

Figura 5 Distribuição da área basal por classe diamétrica no tratamento T2, considerando todas as árvores (a) e somente árvores de espécies com valor comercial (b), em uma amostra de 1,75ha na Floresta Nacional do Tapajós, em 4 períodos de medição: 1AE (um ano antes da exploração), 1DE (um ano depois da exploração), 13DE (13 anos depois da exploração), 21DE (21 anos depois da exploração) 


\subsubsection{Tratamento T3: Exploração de espécies comerciais madeireiras com $\mathrm{DAP} \geq$ $55 \mathrm{~cm}+$ desbaste de espécies não comerciais totalizando aproximadamente $30 \%$ de redução da área basal original (3,0ha).}

No primeiro levantamento a área basal média do T3 foi $29,20 \mathrm{~m}^{2} \cdot \mathrm{ha}^{-1}$. Em relação aos grupos ecológicos, $78,4 \%$ era composto por tolerantes à sombra e $21,6 \%$ composto por pioneiras. As espécies dominantes eram: grupo das sapotaceas com $2,71 \mathrm{~m}^{2} \cdot \mathrm{ha}^{-1}$, Manilkara huberi com $1,31 \mathrm{~m}^{2} \cdot \mathrm{ha}^{-1}$, Rinorea guianensis com $1,28 \mathrm{~m}^{2} \cdot \mathrm{ha}^{-1}$, Pouteria bilocularis com $1,14 \mathrm{~m}^{2} \cdot \mathrm{ha}^{-1}$ e Couratari oblongifolia com $1,13 \mathrm{~m}^{2} \cdot \mathrm{ha}^{-1}$, todas tolerantes a sombra. As 40 espécies mais dominantes, ao longo dos anos de medição, no T3, estão listadas no Anexo M.

Um ano após a exploração a área basal total diminuiu para $23,3 \mathrm{~m}^{2} \cdot \mathrm{ha}^{-1}(20 \%)$. Algumas espécies, extraídas durante a exploração, tiveram sua área basal severamente reduzida, entre elas destacaram-se: Ocotea rubra (redução de $0,14 \mathrm{~m}^{2} \cdot \mathrm{ha}^{-1}, 100 \%$ ), Goupia glabra $\left(0,63 \mathrm{~m}^{2} \cdot \mathrm{ha}^{-1}, 97,7 \%\right)$, Simaruba amara $\left(0,31 \mathrm{~m}^{2} \cdot \mathrm{ha}^{-1}, 93,3 \%\right)$, Hymenaea courbaril $\left(0,25 \mathrm{~m}^{2} \cdot \mathrm{ha}^{-1}, 93,2 \%\right)$, Manilkara huberi $\left(0,98 \mathrm{~m}^{2} \cdot \mathrm{ha}^{-1}, 74,6 \%\right)$, Holopyxidium jarana $\left(0,46 \mathrm{~m}^{2} \cdot \mathrm{ha}^{-1}, 70,8 \%\right)$ e Carapa guianensis $\left(0,36 \mathrm{~m}^{2} \cdot \mathrm{ha}^{-1}, 42 \%\right)$.

Cinco anos após a exploração foram encontrados $25,5 \mathrm{~m}^{2} \cdot \mathrm{ha}^{-1}$, esse valor representa um aumento de 9,4\% em relação ao período anterior. As espécies com maior acréscimo na área basal foram Jacaranda copaia (de $0,05 \mathrm{~m}^{2} \cdot \mathrm{ha}^{-1}$ em 1983 para 0,24m $\mathrm{m}^{2} \cdot \mathrm{ha}^{-1} \mathrm{em}$ 1987, aumento de 308\%) Brosimum lactescens (de 0,15 $\mathrm{m}^{2} \cdot \mathrm{ha}^{-1}$ para $0,31 \mathrm{~m}^{2} \cdot \mathrm{ha}^{-1}, 107 \%$ ), Maquira sclerophylla (de $0,16 \mathrm{~m}^{2} \cdot \mathrm{ha}^{-1}$ para $0,28 \mathrm{~m}^{2} \cdot \mathrm{ha}^{-1}, 75 \%$ ), e Inga sp. (de $1,14 \mathrm{~m}^{2} \cdot \mathrm{ha}^{-1}$ para $\left.1,42 \mathrm{~m}^{2} \cdot \mathrm{ha}^{-1}, 24,6 \%\right)$.

No levantamento seguinte, realizado sete anos após a exploração, a área basal média passou para $26,7 \mathrm{~m}^{2} \cdot \mathrm{ha}^{-1}$ (aumento de 4,7\%). Dentre as 40 espécies mais dominantes, apenas seis tiveram redução na área basal, sete permaneceram estáveis (sem alterações na dominância) e 27 tiveram aumento, entre elas destacaram-se Jacaranda copaia $(29,2 \%)$ e Inga sp. (18,3\%).

Treze anos após a exploração e um ano após a aplicação do refinamento, a área basal média caiu para $24,3 \mathrm{~m}^{2} \cdot \mathrm{ha}^{-1}$ (diminuição de $8,7 \%$ em relação ao período anterior). 
Algumas espécies aneladas como parte do tratamento silvicultural apresentaram grandes perdas em área basal, entre elas destacaram-se Inga sp. (49,4\%), o grupo das sapotaceas (32,7\%), Sclerolobium chrysophyllum (33,3\%), Piptadenia suaveolens (72\%) e Saccoglottis sp. (38\%).

Na última medição, realizada 21 anos após a exploração e nove após o tratamento silvicultural, observou-se um aumento de 4,3\% na área basal em relação ao período anterior, subindo para $25,4 \mathrm{~m}^{2} \cdot \mathrm{ha}^{-1}$. As espécies pioneiras, que na floresta original representavam 21,6\%, passaram a compor 28,4\% da área basal total. Esse aumento, de aproximadamente sete pontos percentuais, se deu devido à exploração e ao desbaste que promoveram a abertura do dossel e a maior entrada de luz na floresta. Nesse período, observou-se também o aumento pronunciado na área basal de espécies comerciais importantes no mercado madeireiro, tais como Jacaranda copaia (78,7\%), Licaria canella (28,6\%), Trattinickia rhoifolia (27,8\%), Carapa guianensis (23,5\%), Manilkara huberi (19\%) e Pouteria bilocularis $(15,4 \%)$.

Analisando todo o período, verificou-se que após 22 anos, o povoamento recuperou $87 \%$ da área basal total existente da floresta original. Essa baixa recuperação se deve à exploração de madeira aliada ao desbaste, que reduziu a área basal original da floresta em 31,5\% (conforme descrito no Capítulo II). Apenas duas classes de diâmetro apresentaram valores de área basal maiores que os encontrados na primeira medição: a primeira $(5-15 \mathrm{~cm})$ que passou de $4,9 \mathrm{~m}^{2} \cdot \mathrm{ha}^{-1}$, no primeiro levantamento para $6,3 \mathrm{~m}^{2} \cdot \mathrm{ha}^{-1}$, no último $\left(28,4 \%\right.$ maior) e a classe $55-65 \mathrm{~cm}$ que passou de $2,5 \mathrm{~m}^{2} \cdot \mathrm{ha}^{-1}$ para $2,6 \mathrm{~m}^{2} \cdot \mathrm{ha}^{-1}$ (aumento de 4\%). Nas demais, a área basal observada 21 anos após a exploração, fícou abaixo do encontrado na floresta original, principalmente nas classes $35-45 \mathrm{~cm}, 65-75 \mathrm{~cm}$ e $75-85 \mathrm{~cm}$ (Figura 6a).

Entre as espécies de valor comercial, a área basal encontrada no último levantamento foi superior a do primeiro em quatro classes de diâmetro $(5-15 \mathrm{~cm}, 15$ $25 \mathrm{~cm}, 25-35 \mathrm{~cm}$ e $55-65 \mathrm{~cm})$. O valor acumulado, em 2003, nas classes abaixo de $45,0 \mathrm{~cm}$ de DAP $\left(5,7 \mathrm{~m}^{2} \cdot \mathrm{ha}^{-1}\right)$ ultrapassou em aproximadamente $24,0 \%$ o valor existente na primeira medição $\left(4,6 \mathrm{~m}^{2} \cdot \mathrm{ha}^{-1}\right)$. As classes a partir de $45 \mathrm{~cm}$ apresentaram valores de área 
basal acumulada em torno de $28 \%$ inferiores aos originais e precisarão de $2,5 \mathrm{~m}^{2} \cdot \mathrm{ha}^{-1}$ a mais para atingir os níveis anteriores à exploração (Figura 6b).

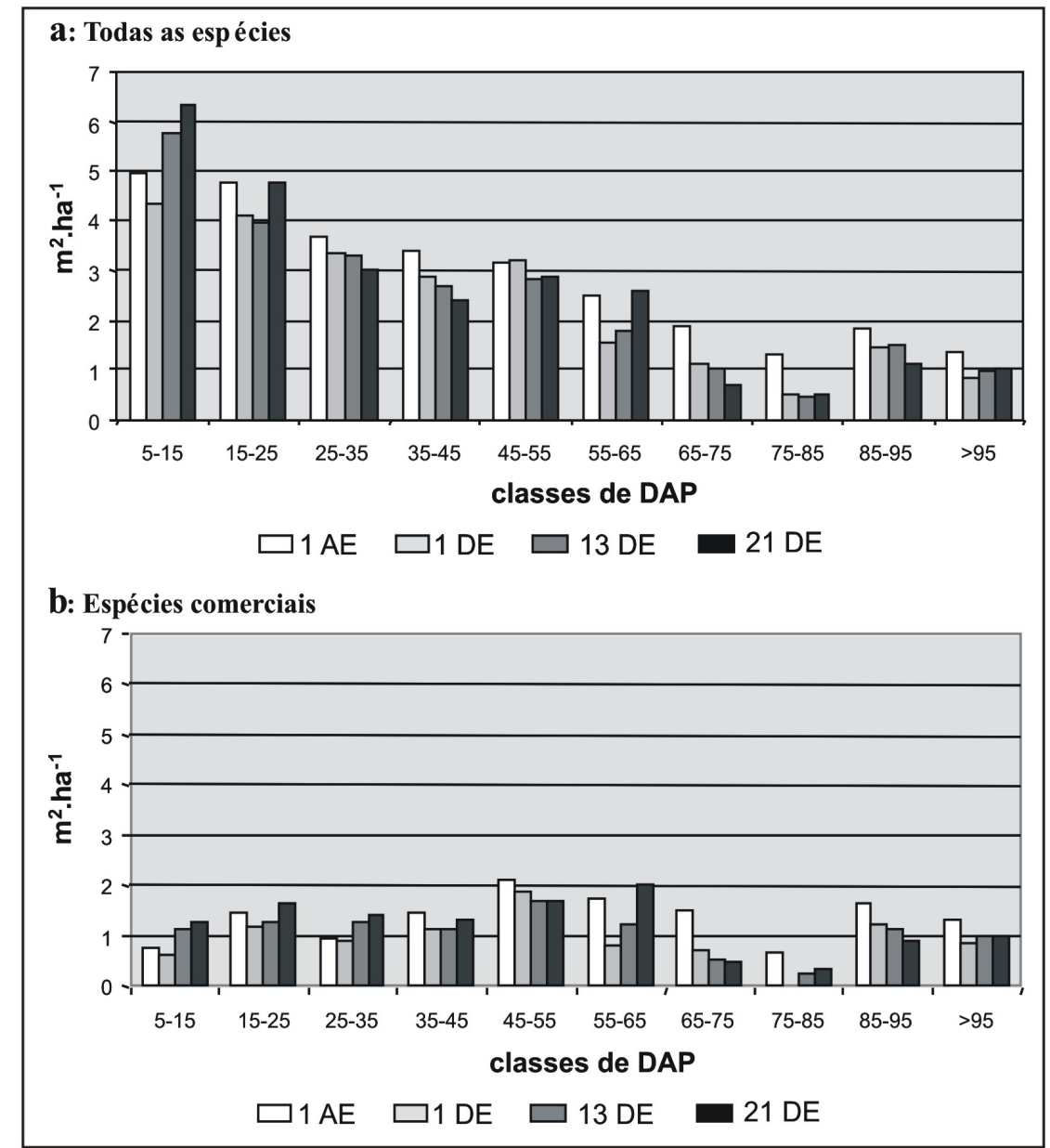

Figura 6 - Distribuição da área basal por classe diamétrica no tratamento T3, considerando todas as árvores (a) e somente árvores de espécies com valor comercial (b), em uma amostra de 3,0ha na Floresta Nacional do Tapajós, em 4 períodos de medição: $1 \mathrm{AE}$ (um ano antes da exploração), 1DE (um ano depois da exploração), 13DE (13 anos depois da exploração), 21DE (21 anos depois da exploração)

\subsubsection{Tratamento T4: Exploração de espécies comerciais madeireiras com $\mathrm{DAP} \geq$ $55 \mathrm{~cm}+$ desbaste de espécies não comerciais totalizando aproximadamente $50 \%$ de redução da área basal original (1,5ha).}

A área basal encontrada no primeiro levantamento para o $\mathrm{T} 4$ foi $28,8 \mathrm{~m}^{2} \cdot \mathrm{ha}^{-1}$. Deste total, $73,7 \%$ era formado por espécies tolerantes e $26,3 \%$ por pioneiras. As espécies que 
mais se destacavam em termos de dominância eram: grupo das sapotaceas com $1,78 \mathrm{~m}^{2} \cdot \mathrm{ha}^{-1}$, Rinorea guianensis com $1,49 \mathrm{~m}^{2} \cdot \mathrm{ha}^{-1}$, Manilkara huberi com $1,40 \mathrm{~m}^{2} \cdot \mathrm{ha}^{-1} \mathrm{e}$ Carapa guianensis com $1,22 \mathrm{~m}^{2} \cdot \mathrm{ha}^{-1}$. No Anexo N estão listadas as 40 espécies mais dominantes, ao longo dos anos de medição.

$\mathrm{Na}$ segunda medição, um ano após a exploração, a área basal diminuiu para $20,9 \mathrm{~m}^{2} \cdot \mathrm{ha}^{-1}(27,4 \%)$. As espécies com maiores perdas em área basal foram: Goupia glabra (redução de $\left.1,12 \mathrm{~m}^{2} \cdot \mathrm{ha}^{-1}, 100 \%\right)$, Bertholletia excelsa $\left(0,80 \mathrm{~m}^{2} \cdot \mathrm{ha}^{-1}, 99 \%\right)$, Hymenaea courbaril $\left(0,39 \mathrm{~m}^{2} \cdot \mathrm{ha}^{-1}, 93 \%\right)$, Holopyxidium jarana $\left(0,36 \mathrm{~m}^{2} \cdot \mathrm{ha}^{-1}, 91 \%\right)$, Hymenolobium excelsum $\left(0,37 \mathrm{~m}^{2} \cdot \mathrm{ha}^{-1}, 91 \%\right)$ e Manilkara huberi $\left(1,14 \mathrm{~m}^{2} \cdot \mathrm{ha}^{-1}, 82 \%\right)$, todas extraídas durante a exploração de madeira.

Cinco anos após a exploração foram encontrados $23,5 \mathrm{~m}^{2} \cdot \mathrm{ha}^{-1}$, o que representa um aumento de 12,4\% em relação ao período anterior. As espécies pioneiras, beneficiadas pela maior entrada de luz na floresta após a exploração, foram as que apresentaram maior aumento na área basal, entre elas destacaram-se Cecropia leucoma $\left(\mathrm{de} 0,11 \mathrm{~m}^{2} \cdot \mathrm{ha}^{-1}\right.$ em 1983 para 0,27 $\mathrm{m}^{2} \cdot \mathrm{ha}^{-1}$ em 1987, aumento de 145\%), Schyzolobium amazonicum (de $0,24 \mathrm{~m}^{2} \cdot \mathrm{ha}^{-1}$ para $\left.0,40 \mathrm{~m}^{2} \cdot \mathrm{ha}^{-1}, 66,7 \%\right)$, Inga sp. (de $0,58 \mathrm{~m}^{2} \cdot \mathrm{ha}^{-1}$ para $0,83 \mathrm{~m}^{2} \cdot \mathrm{ha}^{-1}, 43 \%$ ) e Sclerolobium chrysophyllum $\left(0,36 \mathrm{~m}^{2} \cdot \mathrm{ha}^{-1}\right.$ para $\left.0,51 \mathrm{~m}^{2} \cdot \mathrm{ha}^{-1}, 41,6 \%\right)$.

Sete anos após a exploração a área basal subiu para $25,1 \mathrm{~m}^{2} \cdot \mathrm{ha}^{-1}(6,8 \%$ a mais que o levantamento anterior). As espécies pioneiras que vinham apresentando elevadas taxas de aumento em área basal no período anterior permaneceram com a mesma tendência nesse período, aumentando seu percentual de participação no povoamento para 29,3\%,

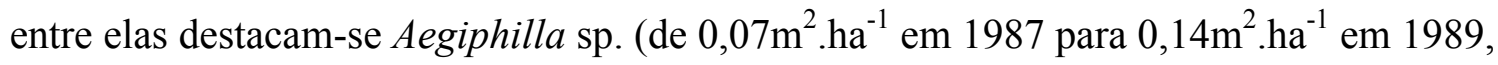
aumento de $100 \%$ ), Cecropia sciadophylla (de $0,54 \mathrm{~m}^{2} \cdot \mathrm{ha}^{-1}$ para $1,03 \mathrm{~m}^{2} \cdot \mathrm{ha}^{-1}, 90,7 \%$ ) e Cecropia leucoma (de 0,27 $\mathrm{m}^{2} \cdot \mathrm{ha}^{-1}$ para $\left.0,43 \mathrm{~m}^{2} \cdot \mathrm{ha}^{-1}, 59,2 \%\right)$.

Treze anos após a exploração a área basal média foi reduzida em 15\%, passando para $21,3 \mathrm{~m}^{2} \cdot \mathrm{ha}^{-1}$. O desbaste, aplicado no ano anterior, em maior intensidade na área do T4, foi o principal responsável por essa diminuição. As espécies não comerciais aneladas apresentaram grandes perdas em área basal, entre elas destacaram-se Cecropia 
sciadophylla (89,3\%), Bixa arborea (67,8\%), Cecropia leucoma (58\%) e Apeiba albiflora $(56,6 \%)$.

Na última medição, realizada 21 anos após a exploração e nove após o tratamento silvicultural, a área basal média foi $22,2 \mathrm{~m}^{2} \cdot h \mathrm{~h}^{-1}$ (aumento de $4,2 \%$ em relação ao período anterior). Algumas espécies sem valor comercial conhecido, que haviam sido aneladas, continuaram apresentando reduções na área basal, tais como: Guatteria poeppigiana (68,4\%), Maquira sclerophylla (76,5\%) e Rinorea guianensis (58\%). Por outro lado, devido a intensidade do refinamento, algumas espécies pioneiras foram beneficiadas pela abertura do dossel e apresentaram grandes aumentos em dominância, entre elas destacaram-se Bixa arborea (de 0,09 $\mathrm{m}^{2} \cdot \mathrm{ha}^{-1}$ em 1995 para $0,36 \mathrm{~m}^{2} \cdot \mathrm{ha}^{-1}$ em 2003, aumento de $300 \%$ ), Sclerolobium chrysophyllum (de $0,04 \mathrm{~m}^{2} \cdot \mathrm{ha}^{-1}$ para $0,15 \mathrm{~m}^{2} \cdot \mathrm{ha}^{-1}$, $275 \%$ ), Inga sp. (de $0,73 \mathrm{~m}^{2} \cdot \mathrm{ha}^{-1}$ para $2,0 \mathrm{~m}^{2} \cdot \mathrm{ha}^{-1}, 174 \%$ ), Schyzolobium amazonicum (de $0,18 \mathrm{~m}^{2} \cdot \mathrm{ha}^{-1}$ para $\left.0,44 \mathrm{~m}^{2} \cdot \mathrm{ha}^{-1}, 144 \%\right)$ e Jacaranda copaia $\left(0,56 \mathrm{~m}^{2} \cdot \mathrm{ha}^{-1}\right.$ para $1,12 \mathrm{~m}^{2} \cdot \mathrm{ha}^{-1}$, $100 \%$ ). O grupo das pioneiras, que no primeiro levantamento representava $26 \%$, aumentou sua participação para $38,5 \%$.

Analisando todo o período de acompanhamento, verificou-se que após 22 anos, a área do tratamento $\mathrm{T} 4$ recuperou $77 \%$ da área basal total existente na floresta original. Somente a primeira classe de diâmetro apresentou valores de área basal maiores que os encontrados na primeira medição. Nas demais, a área basal, ficou abaixo do encontrado na floresta antes da exploração, principalmente nas classes acima de $55 \mathrm{~cm}$ de diâmetro, alvo da extração comercial de madeira. Além da exploração, o desbaste realizado em 1994, contribuiu para essa baixa recuperação. As duas intervenções reduziram a área basal original em 49,3\% (conforme descrito no Capítulo II). (Figura 7a).

Entre as espécies de valor comercial, o povoamento recuperou $70 \%$ da área basal existente na floresta antes da exploração. No último levantamento, três classes de diâmetro apresentaram área basal superior a encontrada na primeira medição $(5-15 \mathrm{~cm}$, $15-25 \mathrm{~cm}$ e $45-55 \mathrm{~cm})$. O valor acumulado, em 2003 , nas classes abaixo de $45,0 \mathrm{~cm}$ de DAP $\left(5,8 \mathrm{~m}^{2} \cdot \mathrm{ha}^{-1}\right)$ ultrapassou em $23,4 \%$ o valor existente na primeira medição $\left(4,7 \mathrm{~m}^{2} \cdot \mathrm{ha}^{-1}\right)$. As classes a partir de $45 \mathrm{~cm}$ apresentaram valores de área basal acumulada 
$58,4 \%$ inferiores aos originais e precisarão de aproximadamente $5,0 \mathrm{~m}^{2} \cdot \mathrm{ha}^{-1}$ a mais para atingir os níveis anteriores à exploração (Figura 7b).

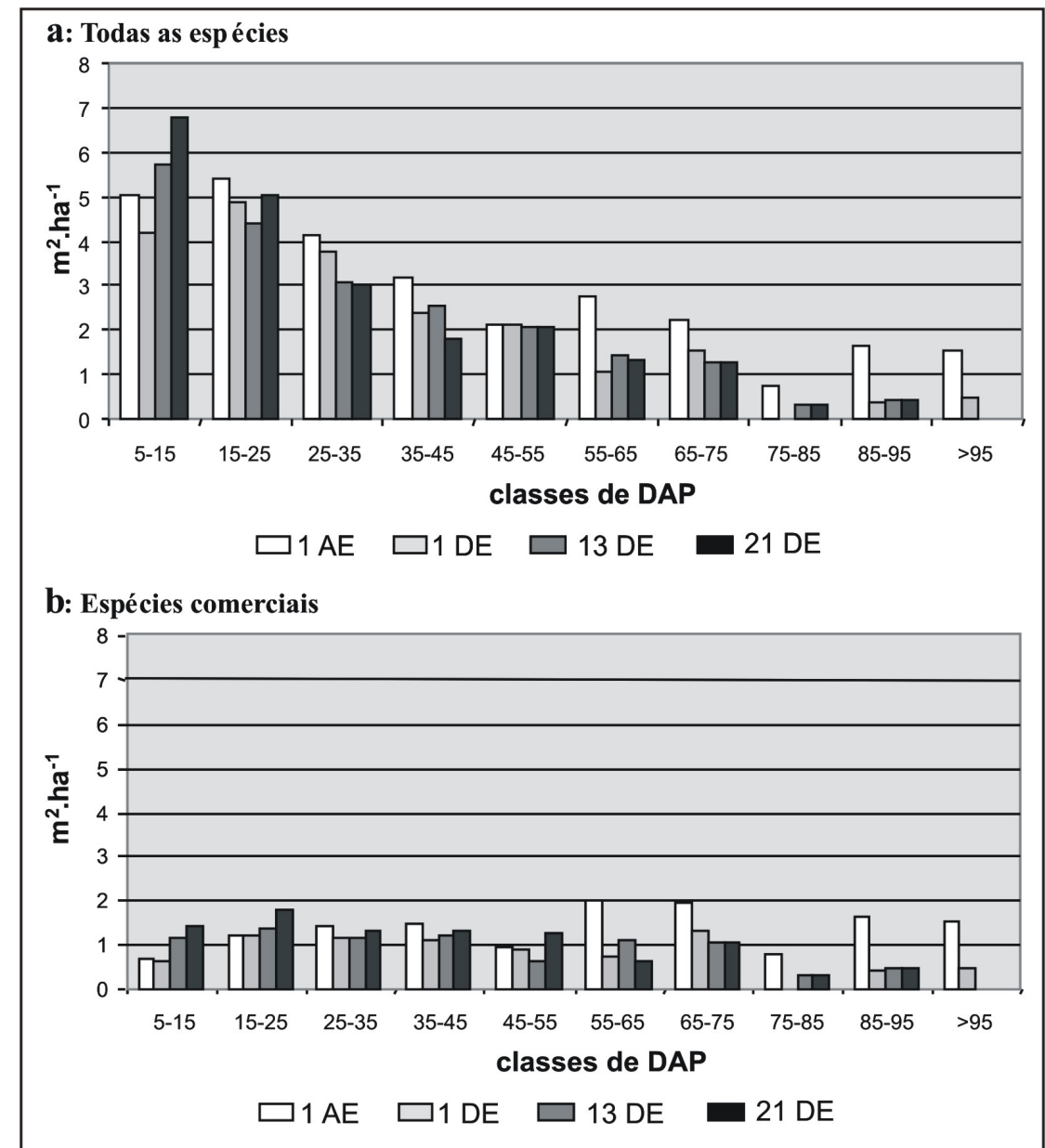

Figura 7 - Distribuição da área basal por classe diamétrica no tratamento T4, considerando todas as árvores (a) e somente árvores de espécies com valor comercial (b), em uma amostra de 1,5ha na Floresta Nacional do Tapajós, em 4 períodos de medição: 1AE (um ano antes da exploração), 1DE (um ano depois da exploração), 13DE (13 anos depois da exploração), 21DE (21 anos depois da exploração)

\subsubsection{Tratamento T0: Testemunha, área sem intervenção (1,5ha).}

$\mathrm{Na}$ floresta testemunha a área basal obtida no primeiro levantamento, em 1983, foi $30,5 \mathrm{~m}^{2} \cdot \mathrm{ha}^{-1}$. As espécies mais importantes em termos de dominância foram Manilkara 
huberi, o grupo das Sapotaceae, Rinorea guianensis, Sclerolobium chrysophyllum e Couratari oblongifolia. Somente estas cinco espécies contribuíram com aproximadamente $27 \%$ da área basal total, e permaneceram como as mais dominantes durante todo o período de acompanhamento. As 40 espécies mais importantes em termos de área basal, ao longo dos anos de medição, no T0, estão listadas no Anexo O.

No segundo levantamento, realizado em 1987, a área basal teve um pequeno aumento de 2,6\%, passando para $31,3 \mathrm{~m}^{2} \cdot \mathrm{ha}^{-1}$. Dois anos depois, em 1989, manteve-se praticamente a mesma $\left(31,2 \mathrm{~m}^{2} \cdot \mathrm{ha}^{-1}\right)$. No inventário seguinte, em 1995, a área basal teve uma pequena redução $2,2 \%$ em relação ao período anterior, passando para $30,5 \mathrm{~m}^{2} \cdot \mathrm{ha}^{-1} \mathrm{e}$ no último levantamento, em 2003, foi $31,7 \mathrm{~m}^{2}$.ha ${ }^{-1}$ (aumento de 3,9\%).

Pode-se observar que as alterações na dominância na área testemunha foram muito pequenas. Entre a primeira e a última medição, realizada 20 anos depois, houve um aumento de apenas 3,9\% (0,2\% ao ano). As espécies que mais diminuíram em área basal ao longo do período foram Tachigali myrmecophyla (de $0,69 \mathrm{~m}^{2} \cdot \mathrm{ha}^{-1}$ em 1983 para $0,11 \mathrm{~m}^{2} \cdot \mathrm{ha}^{-1}$ em 2003, redução de $84 \%$ ), Pouteria bilocularis (de $0,94 \mathrm{~m}^{2} \cdot \mathrm{ha}^{-1}$ para $\left.0,49 \mathrm{~m}^{2} \cdot \mathrm{ha}^{-1}, 47,8 \%\right)$, Maquira sclerophylla (de $0,28 \mathrm{~m}^{2} \cdot \mathrm{ha}^{-1}$ para $0,18 \mathrm{~m}^{2} \cdot \mathrm{ha}^{-1}, 35,7 \%$ ) e Holopyxidium jarana (de $0,85 \mathrm{~m}^{2} \cdot \mathrm{ha}^{-1}$ para $0,68 \mathrm{~m}^{2} \cdot \mathrm{ha}^{-1}, 20 \%$ ). As que tiveram maior aumento foram Inga sp. (de $0,50 \mathrm{~m}^{2} \cdot \mathrm{ha}^{-1}$ para $0,84 \mathrm{~m}^{2} \cdot \mathrm{ha}^{-1}$, aumento de $68 \%$ ), Protium apiculatum (de $0,65 \mathrm{~m}^{2} \cdot \mathrm{ha}^{-1}$ para $0,89 \mathrm{~m}^{2} \cdot \mathrm{ha}^{-1}, 37 \%$ ), Eschweilera odora (de $0,70 \mathrm{~m}^{2} \cdot \mathrm{ha}^{-1}$ para $0,91 \mathrm{~m}^{2} \cdot \mathrm{ha}^{-1}, 30 \%$ ) e Caryocar glabrum (de $0,70 \mathrm{~m}^{2} \cdot \mathrm{ha}^{-1}$ para $\left.0,88 \mathrm{~m}^{2} \cdot \mathrm{ha}^{-1}, 25,7 \%\right)$.

A Figura 8 mostra a distribuição da área basal por classe de diâmetro considerando três períodos 1983, 1995 e 2003. Pode-se observar que, na área onde não ocorreram intervenções, houve poucas alterações na área basal entre as classes diamétricas ao longo de 20 anos. Apenas as classes acima de $65 \mathrm{~cm}$ de DAP apresentaram maior movimento, uma vez que a mortalidade natural e a mudança de classe de alguns indivíduos ao longo do período de acompanhamento, provocam alterações na distribuição da área basal nestas classes. 


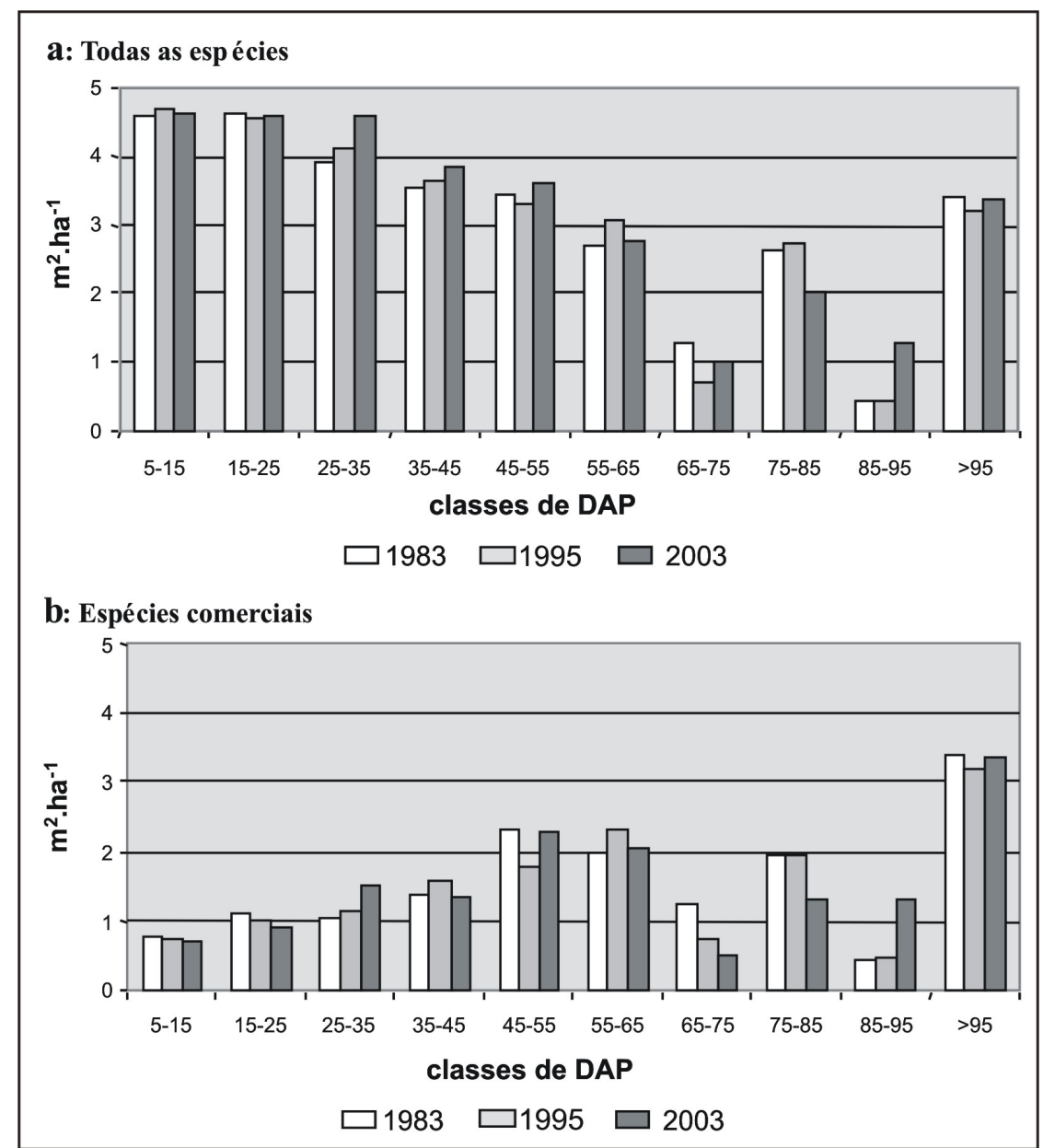

Figura 8 - Distribuição da área basal por classe diamétrica no tratamento T0, considerando todas as árvores (a) e somente árvores de espécies com valor comercial (b), em uma amostra de 1,5ha na Floresta Nacional do Tapajós, em 3 períodos de medição: 1983, 1995 e 2003

\subsubsection{Volume}

O comportamento do volume, ao longo do período de acompanhamento, seguiu a mesma tendência da área basal. Entre o primeiro e o segundo ano de medição ocorreram reduções devidas, principalmente, a extração de madeira ocorrida em 1982. O tratamento que sofreu a maior redução no volume total, em termos percentuais, foi o T4 com 35\% seguido do T1 com 29\%, T2 com 25,6\% e T3 com 22,8\%. Em relação ao volume comercial os valores foram T4 com 49\%, T2 com 41,2\%, T1 com 40,2\% e T3 com 34\%. 
Nos dois levantamentos seguintes à exploração (1987 e 1989) houve aumento progressivo do volume total e comercial em todos os tratamentos. Em 1995, um ano após a aplicação do tratamento silvicultural, ocorreu redução do volume na área do T3 (9\%) e T4 (15,6\%), onde o desbaste foi realizado nas intensidades de $30 \%$ e $50 \%$, respectivamente. No tratamento $\mathrm{T} 2$, cuja intensidade do desbaste foi $20 \%$, e no $\mathrm{T} 1$, onde o mesmo não foi realizado, o volume total e comercial continuou a crescer (Tabela 3 e Figura 9).

No final dos 22 anos de acompanhamento, o volume total do tratamento T2 representou 98,4\% do original, seguido do T1 com 88,9\%, T3 com 75,4\% e T4 com $59 \%$. Para as espécies comerciais madeireiras o tratamento que melhor recuperou o volume original foi o T3 com 80,4\%, seguido do T2 com 79,8\%, T1 com 75,2\% e T4 com 55,8\% (Tabela 3 e Figura 9).

Tabela 3 Volume total e volume das espécies comerciais em cada tratamento e a cada ano de medição, em uma amostra de 10,25ha na Floresta Nacional do Tapajós, considerando todas as árvores com $\mathrm{DAP} \geq 20,0 \mathrm{~cm}$

\begin{tabular}{|c|c|c|c|c|c|c|c|c|c|c|}
\hline \multirow[t]{2}{*}{$\overline{\text { Anos }}$} & \multicolumn{5}{|c|}{ Volume total $\left(\mathrm{m}^{3} \cdot \mathrm{ha}^{-1}\right)$} & \multicolumn{5}{|c|}{ Volume das espécies comerciais $\left(\mathrm{m}^{3} \cdot \mathrm{ha}^{-1}\right)$} \\
\hline & TO & T1 & T2 & T3 & T4 & T0 & T1 & T2 & T3 & T4 \\
\hline 1981 (1 AE) & & 304,50 & 293,48 & 256,99 & 247,38 & & 163,23 & 177,81 & 153,45 & 154,07 \\
\hline 1983 (1 DE) & 286,47 & 216,11 & 218,23 & 198,38 & 160,78 & 184,04 & 97,66 & 104,54 & 101,66 & 78,92 \\
\hline 1987 (5 DE) & 297,35 & 221,57 & 237,01 & 205,14 & 169,59 & 190,32 & 106,65 & 111,24 & 101,44 & 80,14 \\
\hline 1989 (7 DE) & 293,92 & 237,88 & 246,43 & 213,88 & 182,13 & 186,16 & 112,62 & 116,35 & 104,40 & 83,31 \\
\hline 1995 (13DE 1DT) & 284,93 & 259,00 & 264,29 & 194,90 & 153,65 & 176,68 & 119,16 & 126,74 & 109,49 & 77,83 \\
\hline 2003 (21DE 9DT) & 300,52 & 270,71 & 288,75 & 193,85 & 145,75 & 182,03 & 122,8 & 141,88 & 123,44 & 85,98 \\
\hline
\end{tabular}




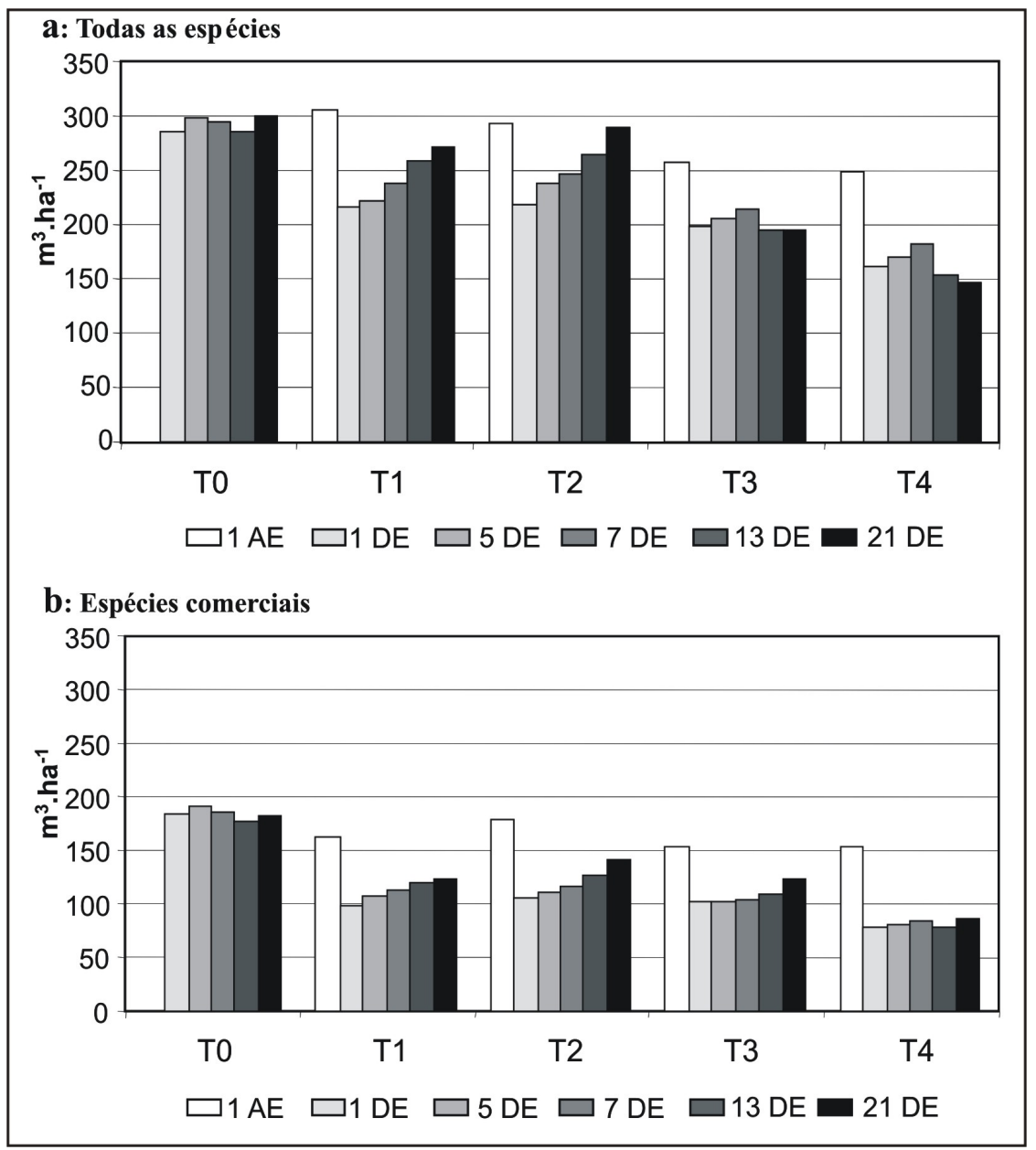

Figura 9 - Volume para todas as espécies (a) e para as espécies comerciais (b) em cada tratamento e a cada ano de medição, em uma amostra de 10,25ha na Floresta Nacional dos Tapajós, considerando árvores com DAP $\geq 20,0 \mathrm{~cm}$. AE: número de anos antes da exploração DE: número de anos após a exploração

\subsection{Discussão}

Alterações na estrutura das florestas estão diretamente relacionadas com a intensidade das intervenções e com os métodos utilizados. Quanto maior o grau de abertura no dossel, ou seja, quanto mais intenso o tratamento, maior a redução em abundância, área basal e volume dos indivíduos.

A redução no número de árvores e área basal, devido a colheita de madeira, ocorreu tanto nas espécies que foram extraídas como naquelas que, mesmo não estando 
na relação de espécies a retirar, perderam árvores em conseqüência dos danos ocasionados pelas atividades de derruba e arraste das árvores exploradas.

O tratamento que sofreu maior redução em abundância e dominância em conseqüência da exploração foi o T4 com diminuição de $16 \%$ do número de árvores e $27,5 \%$ da área basal. $\mathrm{O}$ menos afetado foi o $\mathrm{T} 2$ com $9,3 \%$ do número e $19,4 \%$ da área basal.

Em outro experimento, localizado em Paragominas - PA, onde foi realizada a extração de madeira, Silva (2004) obteve redução de 25\% no número de indivíduos na área explorada convencionalmente e $21 \%$ na área com exploração de impacto reduzido. Carvalho (1992), observou que a extração de madeira, realizada na Floresta Nacional do Tapajós reduziu em média $12,6 \%$ do número de árvores e $25 \%$ da área basal.

Neste experimento, a capacidade de resiliência da floresta mostrou-se mais eficiente para a recuperação da abundância, quando comparada à área basal. Cinco anos após a colheita de madeira, todos os tratamentos apresentaram número de árvores superior ao encontrado antes da intervenção, inclusive para as espécies de valor comercial.

Comparando-se o primeiro levantamento (antes das intervenções) com o último (21 anos após a exploração) observou-se que a distribuição da dominância entre as classes diamétricas foi alterada. A recuperação da área basal ocorreu de forma mais efetiva nas primeiras classes diamétricas $(5-45 \mathrm{~cm})$. Esse fato era esperado, uma vez que essas classes não foram alvos da extração de madeira, embora tenham sido reduzidas em conseqüência dos danos provocados pela exploração e devido aos desbastes 12 anos depois. $\mathrm{O}$ aumento da dominância nas classes iniciais também foi proporcionado pela entrada de novos indivíduos na comunidade, principalmente de espécies pioneiras, em função da maior disponibilidade de luz, devido as aberturas no dossel (Figura 10).

Os tratamentos T3 e T4, que tiveram sua área basal reduzida pelos desbastes em $30 \%$ e $50 \%$, respectivamente, obtiveram o maior aumento em número de árvores.ha ${ }^{-1}$ ao final do período, ultrapassando o valor original em aproximadamente $20 \%$. Todavia, em relação a área basal tiveram recuperação inferior aos demais tratamentos, apresentando 
valores maiores que os originais somente nas classes inferiores a $25 \mathrm{~cm}$ de DAP (Figura 10).
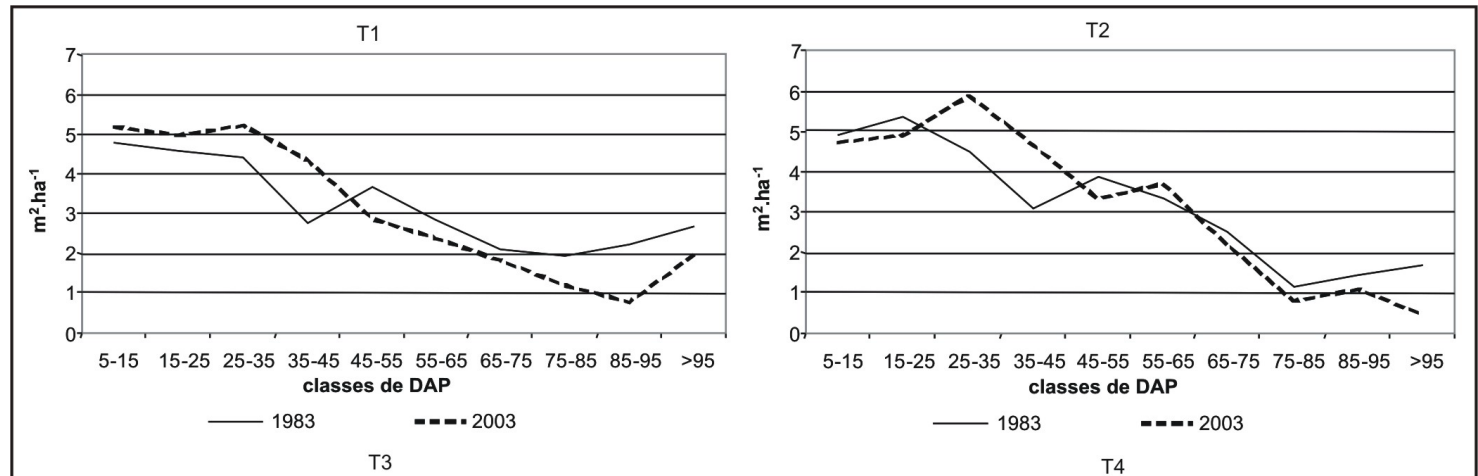

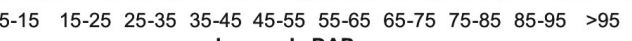
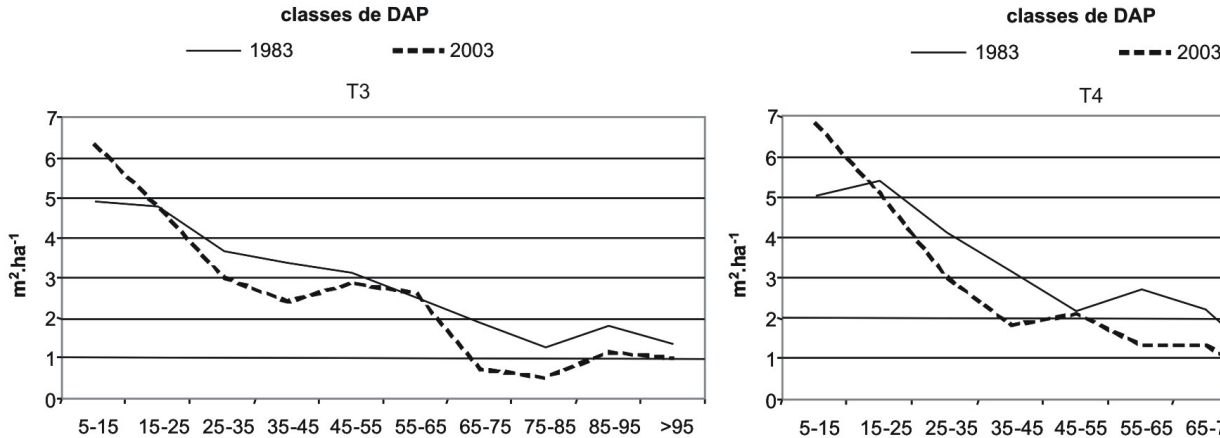

T4

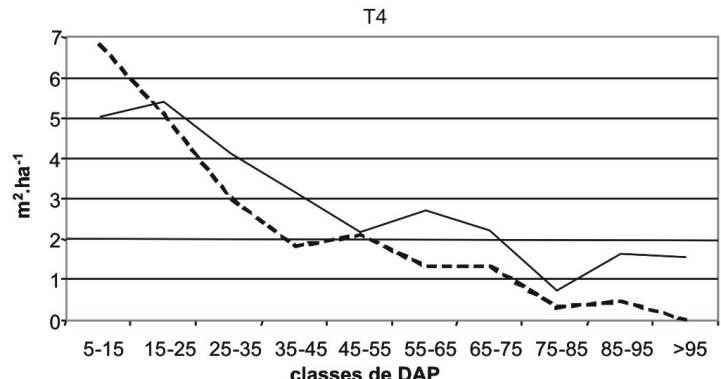

1983

$=-2003$

$-1983$

$=-=2003$

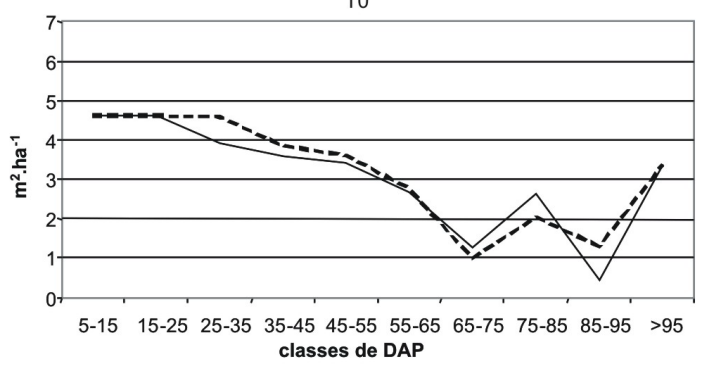

$1983 \quad-=-2003$

Figura 10 - Distribuição da área basal por classe de diâmetro em cada tratamento em dois períodos de medição: antes da exploração (1981) e 21 anos após a exploração (2003), em uma amostra de 10,25ha na Floresta Nacional dos Tapajós

Nas classes acima de $45 \mathrm{~cm}$ de diâmetro, nenhum dos tratamentos alcançou a área basal presente antes da extração de madeira. A maior taxa de recuperação foi obtida no tratamento T2 (82\%), seguida do T3 com 74\%, T1 com 71\% e T4 com 50\% (Figura 10). Com relação a área basal das espécies de valor comercial madeireiro as taxas de recuperação foram um pouco menores, variando de $70 \%$ a $89,5 \%$, sendo o tratamento T3 o que apresentou o maior valor. 
No Suriname, em floresta explorada e logo depois submetida ao desbaste, onde todas as árvores com DAP maior que $20 \mathrm{~cm}$ foram aneladas e envenenadas, a recuperação da área basal, 28 anos após as intervenções, foi em torno de 87\% (De Graaf et al. 1999). Em outro experimento localizado no $\mathrm{Km} \mathrm{67,} \mathrm{na} \mathrm{Floresta} \mathrm{Nacional} \mathrm{do}$ Tapajós, Silva et al. (1995) observaram que 13 anos após a exploração, sem nenhuma intervenção posterior, a floresta apresentou área basal em torno de $76 \%$ da área não explorada.

O efeito das intervenções, neste experimento, seguiu um mesmo padrão em todos os tratamentos. A abertura do dossel causada pela exploração favoreceu o aumento da abundância e dominância de espécies pioneiras, colonizadoras de áreas abertas, tais como Cecropia sciadophylla, Bixa arborea, Cecropia leucoma, Sloanea froesii e Aegiphilla sp. Porém, a partir dos 13 anos após a exploração, a quantidade dessas espécies começou a reduzir devido ao fechamento do dossel, que aumentou a competição por luz, e em função do tempo de vida relativamente curto, característico desse grupo ecológico (Lieberman et al., 1985). Os desbastes, aplicados para redução da área basal das espécies indesejáveis nos tratamentos T2, T3 e T4, promoveram nova abertura no dossel, 12 anos após a exploração. A intensidade dos tratamentos T2 (aproximadamente 20\% de redução efetiva da AB) e T3 (aproximadamente 30\% de redução efetiva da $\mathrm{AB}$ ) favoreceram várias espécies de valor comercial tais como Jacaranda copaia, Laetia procera, Cordia bicolor, Cordia alliodora, Sclerolobium chrysophyllum, Schyzolobium amazonicum, Virola melinonii, Tachigali myrmecophyla, Licaria canella e Couratari oblongifolia, que aumentaram bastante sua participação em número de árvores e área basal no povoamento. O tratamento T4, de redução mais intensa da área basal (aproximadamente 50\%), além de favorecer as espécies comercias citadas acima, também provocou grandes aumentos na densidade de espécies pioneiras sem valor comercial conhecido tais como Bixa arborea, Sterculia pilosa e Inga sp.

O aumento na densidade de espécies comerciais devido aos tratamentos silviculturais, também foram observados por Zanetti (2002), que analisou o efeito de 4 tratamentos (exploração convencional, exploração+refinamento, apenas refinamento e 
testemunha) em uma floresta tropical no Paraguai, durante o período de 5 anos após a intervenção e concluiu que todos os tratamentos, exceto a testemunha, provocaram alterações na estrutura da floresta sendo exploração+refinamento a intervenção que provocou a maior redução na área basal e a que mostrou melhores resultados em termos de estímulo a regeneração natural e aumento da participação das espécies comerciais no povoamento.

Por outro lado, grandes reduções na área basal e conseqüentemente grandes aberturas no dossel podem gerar efeitos negativos. Plumptre (1996) constatou que tratamentos pesados com arboricida aplicados na Reserva Florestal de Budongo, em Uganda foram correlacionados positivamente com espécies colonizadoras indesejáveis, as mesmas que foram envenenadas como parte dos tratamentos. O mesmo autor afirma ainda que 50 anos de regeneração não foram suficientes para que a floresta recuperasse a área basal reduzida pela exploração.

Dekker \& De Graaf (2003), estudando três níveis de exploração combinados com tratamentos de refinamento: (1) tratamento leve (exploração de $15 \mathrm{~m}^{3} \cdot \mathrm{ha}^{-1}$ ), (2) tratamento médio (exploração de $23 \mathrm{~m}^{3} \cdot \mathrm{ha}^{-1}+$ anelamento de árvores indesejáveis para redução da área basal para $18 \mathrm{~m}^{2} \cdot \mathrm{ha}^{-1}$ ) e (3) tratamento pesado (exploração de $46 \mathrm{~m}^{3} \cdot \mathrm{ha}^{-1}$ + anelamento de árvores indesejáveis para redução da área basal para $14 \mathrm{~m}^{2} \cdot \mathrm{ha}^{-1}$ ) durante 20 anos de acompanhamento, em uma floresta tropical no Suriname, concluíram que o tratamento médio foi o que apresentou a maior densidade de regeneração e que o tratamento pesado foi severo demais e não recomendável porque causou os maiores distúrbios na floresta, além de apresentar a menor recuperação da densidade.

Resultados semelhantes foram encontrados por Finegan e Camacho (1999) em uma floresta tropical na Costa Rica, sete anos após a aplicação de três regimes silviculturais pós-exploração: "explorar e deixar” (exploração de madeira sem nenhuma intervenção subseqüente), "refinamento" (anelamento de todas as espécies não comerciais com DAP $\geq 40 \mathrm{~cm}$ que estivessem competindo com uma árvore potencial, reservada para uma segunda colheita) e "Shelterwood" (corte de todas as árvores não comerciais com $\mathrm{DAP} \geq 10 \mathrm{~cm}$, cujas copas não faziam parte do dossel superior), onde 
tanto a densidade quanto a área basal tiveram aumentos acentuados nos anos que se seguiram à aplicação dos tratamentos, porém no refinamento, onde ocorreram as maiores alterações na estrutura da floresta (redução de 20\% do número de árvores e 26\% da área basal) a recuperação tem se mostrado mais lenta.

\subsection{Conclusão}

As intervenções realizadas na área dos tratamentos provocaram mudanças na estrutura original da floresta que ainda permanecem 21 anos após sua aplicação. De maneira geral, as principais alterações foram:

- Aumento na densidade em todos os tratamentos, principalmente nas classes de 5,0$20,0 \mathrm{~cm}$ de diâmetro, que tiveram um acréscimo de aproximadamente $15 \%$ no número de árvores por hectare.

- Redução na dominância, que tem apresentado lenta recuperação em todos os tratamentos, principalmente nas classes acima de $45 \mathrm{~cm}$ de diâmetro que foram as mais afetadas pela extração de madeira. Passados 21 anos da exploração, a área basal nessas classes ainda está, em média, 30\% abaixo do valor original.

- Muitas espécies pioneiras, que não faziam parte da estrutura inicial ou estavam presentes em baixa densidade, foram favorecidas pela abertura no dossel pósexploração e pós-desbaste e aumentaram sua densidade na comunidade, alterando o balanço entre os grupos ecológicos;

- Algumas espécies que eram abundantes antes da exploração, mas que sofreram grande redução durante a extração de madeira ainda se mantém em baixa densidade;

Comparando as taxas de recuperação da estrutura entre os tratamentos analisados conclui-se que:

- O sistema de manejo denominado "explorar e deixar", aplicado no tratamento T1, foi pouco eficiente na recuperação do número de árvores e área basal, extraídos da área durante a exploração. A ausência de uma nova intervenção, provavelmente elevou os 
níveis de competição entre as árvores remanscentes após o fechamento do dossel, dificultando o crescimento e a entrada de novas árvores na população.

- O tratamento T4 foi o que obteve o maior número de árvores.ha ${ }^{-1}$ no final do período, ultrapassando o valor original em $21 \%$ considerando todas as espécies e em $73 \%$ considerando somente as espécies de valor comercial. Todavia, em relação a área basal sua recuperação foi inferior aos demais tratamentos, atingindo somente $77 \%$ da área basal inicial considerando todas as espécies e 70\% considerando somente as espécies de valor comercial. Esses valores indicam que o desbaste de aproximadamente $50 \%$ da $\mathrm{AB}$, aplicado no $\mathrm{T} 4$, apesar de ter produzido o aumento no número de árvores comerciais (estoque para futuras colheitas), ainda está com os valores de área basal bastante inferiores aos originais, além disso, as grandes clareiras abertas após a aplicação do desbaste favoreceram a infestação de cipós e o aumento no número de espécies pioneiras colonizadoras de áreas abertas;

- O tratamento T2 foi o que apresentou as maiores taxas de recuperação em área basal (99,7\%) considerando todas as espécies e ficou em segundo lugar em relação a recuperação da área basal $(85,2 \%)$ das espécies de valor comercial. Porém é preciso considerar que o tratamento $\mathrm{T} 2$ sofreu as menores reduções em área basal durante a colheita de madeira, consequentemente, sua recuperação também foi mais rápida do que os demais.

- O T3 foi considerado o mais eficiente dentre os tratamentos analisados, pois favoreceu várias espécies comerciais importantes no mercado madeireiro, que aumentaram sua participação em número de árvores e área basal. No final do período de acompanhamento, o número de árvores comerciais foi $47 \%$ superior ao valor original e a taxa de recuperação da área basal deste grupo foi 89,5\% (a maior dentre os tratamentos testados). Esses valores indicam que o desbaste de aproximadamente $30 \%$ da área basal, aplicado no T3, teve efeito positivo na indução da regeneração natural e no crescimento de espécies de valor comercial madeireiro que poderão ser extraídas em futuras colheitas. 


\section{EFEITO DA EXPLORAÇÃO DE MADEIRA E TRATAMENTOS SILVICULTURAIS SOBRE A DINÂMICA DA VEGETAÇÃO EM 136ha DA FLORESTA NACIONAL DO TAPAJÓS, BELTERRA-PARÁ.}

\section{Resumo}

O objetivo deste trabalho foi analisar o efeito de quatro intensidades de redução da área basal, representadas pela exploração e desbastes sistemáticos, na dinâmica do extrato arbóreo, durante um período de 22 anos. O experimento se localiza na Floresta Nacional do Tapajós, município de Belterra, Pará, a altura do km 114 da Rodovia Santarém-Cuiabá. O delineamento estatístico utilizado foi Blocos ao Acaso com 4 repetições onde foram testados os seguintes tratamentos: T0: controle, representado pela floresta não explorada; T1: Abate de árvores comerciais com DAP $\geq 45 \mathrm{~cm}$, sem nenhuma intervenção posterior; T2: Abate de árvores comerciais DAP $\geq 55 \mathrm{~cm}+$ desbaste de espécies não comerciais para reduzir a área basal em $20 \%$ da original; T3: Abate de árvores comerciais DAP $\geq 55 \mathrm{~cm}+$ desbaste de espécies não comerciais para reduzir a área basal em $40 \%$ da original; T4: Abate de árvores comerciais DAP $\geq 55 \mathrm{~cm}+$ desbaste de espécies não comerciais para reduzir a área basal em $60 \%$ da original. Em cada tratamento foram instaladas ao acaso 12 parcelas permanentes $(\mathrm{PP})$ de $0,25 \mathrm{ha}$, onde foram medidas todas árvores com diâmetro $\geq$ 5,0cm. A exploração de madeira foi realizada em 1982 e os desbastes em 1994. As medições das PP foram realizadas em 1981, 1983, 1987, 1989, 1995 e 2003. Os resultados mostraram que as intervenções alteraram a dinâmica da floresta, elevando as taxas de mortalidade, estimulando o aumento no número de ingressos e a aceleração nas taxas de crescimento das árvores remanescentes. $\mathrm{O}$ tratamento $\mathrm{T} 4$ produziu as maiores taxas de 
ingressos e crescimento em diâmetro, porém, devido ao aumento na mortalidade, apresentou taxas negativas de crescimento em área basal e volume. $\mathrm{O}$ tratamento $\mathrm{T} 3$ foi considerado o mais adequado porque favoreceu elevadas taxas de recrutamento e crescimento em diâmetro, sem elevar em demasiado a mortalidade. Esse tratamento também mostrou as maiores taxas de incremento em $\mathrm{AB}$ e volume, no período após a aplicação do desbaste.

\section{Summary}

The objective of this work was to analyze the effect of four intensities of basal area reduction, represented by systematic logging and liberation thinning, on the dynamics of arboreal extract, over a period of 22 years. The experiment is located in the Tapajós National Forest, municipality of Belterra, Pará, at km 114 of the Santarém-Cuiabá Highway. The statistical delineation employed was Random Blocks with 4 repetitions, in which the following treatments were tested: T0: control, represented by unlogged forest; T1: Felling of commercial trees with $\mathrm{DBH} \geq 45 \mathrm{~cm}$, with no posterior intervention; T2: Felling of commercial trees $\mathrm{DBH} \geq 55 \mathrm{~cm}+$ thinning of non-commercial species to reduce the original basal area by $20 \%$; T3: Felling of commercial trees DBH $\geq 55 \mathrm{~cm}+$ thinning of non-commercial species to reduce the original basal area by $40 \%$; T4: Felling of commercial trees $\mathrm{DBH} \geq 55 \mathrm{~cm}+$ thinning of non-commercial species to reduce the original basal area by $60 \%$. In each treatment 120,25 ha permanent parcels (PP) were randomly installed, in which all trees with diameter $\geq 5,0 \mathrm{~cm}$ were measured. Logging was carried out in 1982 and the thinning treatments in 1994. The measurements of PP were carried in 1981, 1983, 1987, 1989, 1995 and 2003. The results showed that interventions alter forest dynamics, increasing mortality rates, stimulating an increase in the number of ingresses and acceleration in growth of remaining trees. Treatment T4 produced the highest rates of ingress and diameter growth; however, due to the mortality increase, it presented negative growth rates in basal area and volume. Treatment T3 was considered the most adequate treatment, because it favored high rates of recruitment and 
diameter growth, without excessively raising mortality. This treatment also showed the greatest increments in $\mathrm{AB}$ and volume, in the period after application of the thinnings.

\subsection{Introdução}

Do ponto de vista técnico, a produção de madeira em florestas tropicais, sob regime de rendimento sustentável, exige certo volume de informações, nas quais uma parte significativa se relaciona com o crescimento, rendimento e regeneração natural das espécies arbóreas, tanto aquelas de valor comercial, como as demais (Camacho \& Finegan, 1997).

Elevadas taxas de incremento e freqüente recrutamento constituem o primeiro indicativo de que a floresta possui características favoráveis ao manejo para produção de madeira (Finegan \& Camacho, 1999). Portanto, o conhecimento das taxas de crescimento, ingressos e mortalidade são de fundamental importância para o planejamento da produção e determinação dos ciclos de corte de florestas tropicais.

Segundo Chambers et al. (1998), o incremento em diâmetro em florestas tropicais é mais importante do que a idade para descrever a dinâmica, principalmente porque a idade é um parâmetro muito difícil de se medir com precisão, já que as árvores não apresentam anéis de crescimento anual definidos. As taxas de crescimento em diâmetro variam significativamente dentro e entre espécies, além de serem influenciadas pelo tamanho da árvore, estação do ano e condições climáticas (Ferri, 1979). Usualmente, as árvores de uma mesma família ou de uma mesma espécie botânica apresentam diferentes comportamentos sob diferentes condições. As diferenças no crescimento, tanto por espécie como em grupos ecológicos, ocorrem em função de importantes fatores como: disponibilidade de luz, fertilidade dos solos, regimes pluviométricos, grupos ecológicos predominantes, características genéticas da espécie, grau de sanidade das árvores e distúrbios na floresta, entre outros.

O estudo dos ingressos em florestas tropicais tem especial importância sob o ponto de vista silvicultural, porque determina em termos qualitativos e quantitativos, o quanto o sistema está sendo "alimentado" com a entrada, na população monitorada, de novos 
indivíduos das espécies alvo do manejo (Silva, 1989). Para manter a produção florestal, é necessário que uma quantidade adequada de regeneração de espécies de valor econômico entrem regularmente no sistema e que um número mínimo de árvores provenientes dessa regeneração sobreviva e cresça até o tamanho de corte a cada ciclo de colheita.

A mortalidade é um dos parâmetros mais complicados e que demanda maior custo para determinar. Taxas anuais de mortalidade devem ser provenientes de populações com várias centenas de indivíduos, acompanhados por longos períodos (pelo menos 10 anos), para compensar a irregularidade de eventos climáticos que interferem nos valores, tais como, períodos muito secos ou muito chuvosos, fenômeno el niño, etc. (De Graaf et al., 1999). Swaine et al. (1987) comentam que o padrão de mortalidade natural no tempo e no espaço, em florestas tropicais, é fortemente correlacionado com a longevidade máxima das árvores, distribuição nas classes de tamanho, abundância relativa das espécies e tamanho e quantidade de aberturas no dossel. A mortalidade pode ser causada por ventanias em tempestades, mas, freqüentemente, as árvores morrem em pé, como resultado da ação de fungos patogênicos, senescência natural, condições ambientais adversas, como grandes períodos de estiagem, ou ainda uma combinação destes fatores (Lieberman \& Lieberman, 1987).

$\mathrm{Na}$ busca por um sistema silvicultural adequado para as florestas tropicais uma importante consideração é o baixo incremento das espécies de valor comercial madeireiro após a primeira exploração. Isto se dá devido a relativa escassez, em número e volume, de árvores potenciais para a próxima colheita (árvores de espécies com valor comercial e diâmetro entre $30-45 \mathrm{~cm}$, ou mais) deixadas após a primeira exploração aliada ao lento crescimento das mesmas (De Graaf et al., 1999).

As taxas de crescimento podem ser aceleradas pelos tratamentos silviculturais, que basicamente envolvem dois tipos: i) Liberação ou desbaste seletivo, que consiste na remoção de indivíduos competidores, não desejáveis, cujas copas estejam competindo com por luz com as copas das árvores de espécies selecionadas para a próxima colheita; ou ii) Refinamento ou desbaste sistemático, que consiste na redução da área basal de 
espécies não desejáveis visando diminuir a competição no povoamento, de forma geral. Os tratamentos silviculturais, além de acelerar o crescimento das árvores remanescentes, inclusive nas menores classes de diâmetro, também aumentam as taxas de ingressos de novos indivíduos na comunidade e têm seus efeitos comprovados em vários experimentos nas florestas tropicais do mundo (Lamprecht, 1993).

O objetivo deste capítulo é analisar a dinâmica da vegetação de uma área de 136ha, localizada na Floresta Nacional do Tapajós, em 22 anos de monitoramento. O comportamento da floresta será analisado em relação as taxas de ingressos, mortalidade e crescimento após a exploração de madeira e após os diferentes tratamentos silviculturais aplicados na área, e será comparado com a floresta não explorada nem tratada. Procura-se especificamente responder as seguintes perguntas:

1. Como as diferentes intensidades de exploração e desbaste afetam o crescimento (diâmetro, área basal e volume), os ingressos e a mortalidade das árvores remanescentes?

2. Qual(is), dentre os tratamentos aplicados, é o mais adequado visando a produção sustentada de madeira, ou seja, produz as maiores taxas de crescimento os maiores ingressos e a menor mortalidade?

\subsection{Material e métodos}

A dinâmica da floresta foi analisada em termos de ingressos, mortalidade e crescimento. Foram considerados todos os indivíduos arbóreos com DAP $\geq 5,0 \mathrm{~cm}$, presentes em 41 parcelas permanentes de 50m x 50m distribuídas nas áreas dos seguintes tratamentos:

- Tratamento T0: Testemunha, área sem intervenção (6 parcelas, 1,5ha amostrado).

- Tratamento T1: Exploração de espécies comerciais madeireiras com DAP $\geq$ $45 \mathrm{~cm}$ (10 parcelas, 2,5ha amostrados) 
- Tratamento T2: Exploração de espécies comerciais madeireiras com DAP $\geq$ $55 \mathrm{~cm}+$ desbaste de espécies não comerciais totalizando $20 \%$ de redução da área basal original (7 parcelas, 1,75ha amostrados).

- Tratamento T3: Exploração de espécies comerciais madeireiras com DAP $\geq$ $55 \mathrm{~cm}+$ desbaste de espécies não comerciais totalizando aproximadamente $30 \%$ de redução da área basal original (12 parcelas, 3,0ha amostrados).

- Tratamento T4: Exploração de espécies comerciais madeireiras com DAP $\geq$ $55 \mathrm{~cm}+$ desbaste de espécies não comerciais totalizando aproximadamente $50 \%$ de redução da área basal original (6 parcelas - 1,5ha amostrado).

O método de instalação e medição das parcelas permanentes, assim como informações sobre a exploração e a aplicação dos tratamentos silviculturais, estão descritos no Capítulo I e II.

Um resumo das principais atividades realizadas na área encontra-se no Quadro 1

\begin{tabular}{|c|c|}
\hline Ano & Atividades Realizadas \\
\hline 1981 & $\begin{array}{l}\text { Instalação e primeira medição das parcelas permanentes (PP) na área a ser explorada (T1, T2, T3, } \\
\text { T4); }\end{array}$ \\
\hline 1982 & Exploração florestal na área experimental de 144ha, seguindo a prescrição dos tratamentos; \\
\hline 1983 & $\begin{array}{l}2^{\underline{0}} \text { Medição das PP na área explorada; } \\
\text { Instalação e primeira medição das PP na área testemunha (T0); }\end{array}$ \\
\hline 1987 & $\begin{array}{l}3^{\circ} \text { Medição das PP na área explorada; } \\
2^{\circ} \text { Medição das PP na área testemunha; }\end{array}$ \\
\hline 1989 & $\begin{array}{l}4^{\circ} \text { Medição das PP na área explorada; } \\
3^{\circ} \text { Medição das PP na área testemunha; }\end{array}$ \\
\hline 1994 & Aplicação dos tratamentos silviculturais (desbastes); \\
\hline 1995 & $\begin{array}{l}5^{\circ} \text { Medição das PP na área explorada; } \\
4^{\circ} \text { Medição das PP na área testemunha; }\end{array}$ \\
\hline 2003 & $\begin{array}{l}6^{\circ} \text { Medição das PP na área explorada; } \\
5^{\circ} \text { Medição das PP na área testemunha; }\end{array}$ \\
\hline
\end{tabular}

Quadro 1 Histórico das atividades realizadas em uma área experimental de 136ha na Floresta Nacional do Tapajós, km 114 da rodovia Santarém-Cuiabá, município de Belterra, PA

Ingressos ou recrutamento foram considerados como sendo o número de árvores que atingiram o diâmetro mínimo de $5,0 \mathrm{~cm}$, em cada medição, a partir da segunda. Esse valor foi dividido pelo número de anos do intervalo entre as medições para obter o número de ingressos.ha ${ }^{-1}$. ano ${ }^{-1}$. A partir desse valor foi calculada a percentagem anual de 
ingressos, pela relação entre o número de novos indivíduos em cada medição e o número de árvores presentes na medição anterior.

Mortalidade foi considerada como sendo o número de árvores com diâmetro $\geq$ $5,0 \mathrm{~cm}$ encontradas mortas em cada medição, a partir da segunda. No primeiro levantamento após a exploração, árvores colhidas e aquelas que morreram em conseqüência das atividades de extração foram incluídas no cálculo da mortalidade. O número de árvores registradas como mortas em cada medição foi dividido pelo número de anos do intervalo entre os levantamentos para obter o número de mortas.ha ${ }^{-1} \cdot$ ano $^{-1}$. A partir desse valor, assim como no caso dos ingressos, foi calculada a percentagem anual de mortalidade pela relação entre o número de árvores mortas em cada medição e o total de árvores presentes na medição anterior.

Os incrementos em diâmetro, área basal e volume foram calculados subtraindo o valor obtido na medição anterior do valor presente na medição atual e dividindo pelo número de anos do intervalo. No cálculo do crescimento em área basal e volume foi utilizado o incremento líquido, ou seja, foram incluídas as mudanças devidas ao ingresso e à mortalidade de árvores no período.

Para o estudo da variação entre os tratamentos, foi utilizada a análise de variância e teste Tukey para a comparação das médias, sempre que as pressuposições básicas de normalidade e homocedasticidade foram obedecidas. A verificação da normalidade dos dados foi realizada através do teste de Shapiro Wilks e a análise de variância através do Proc ANOVA, ambos com auxílio do programa estatístico "SAS-system (Statistical Analysis Systems)”. Quando não foi possível obedecer as pressuposições da análise, procedeu-se a transformação dos dados através do log.

\subsection{Resultados}

\subsubsection{Ingressos}

O tratamento que apresentou o maior número de ingressos, considerando os 22 anos do período de acompanhamento, foi o T4 com 42 árvores.ha ${ }^{-1} \cdot$ ano $^{-1}\left(3,7 \%\right.$ ano $\left.^{-1}\right)$ 
seguido do T3 com 36 árvores.ha ${ }^{-1}$.ano ${ }^{-1}\left(3,3 \%\right.$.ano $\left.{ }^{-1}\right)$, T1 com 25,6 árvores.ha ${ }^{-1}$.ano ${ }^{-1}$ $\left(2,3 \% \cdot\right.$ ano $\left.^{-1}\right)$ e T2 com 21 árvores.ha ${ }^{-1} \cdot$ ano $^{-1}\left(1,9 \% \cdot\right.$ ano $\left.^{-1}\right)$. A floresta testemunha (T0) apresentou média de 11 ingressos.ha ${ }^{-1}$.ano ${ }^{-1}\left(1,2 \%\right.$.ano $\left.{ }^{-1}\right)$ ao longo dos 20 anos de medição (Tabela 1).

Tabela 1 Ingressos em número de árvores.ha ${ }^{-1} \cdot$ ano $^{-1}$ (diâmetro $\geq 5,0 \mathrm{~cm}$ ) em cada tratamento e a cada período de medição em uma amostra de 10,25ha na Floresta Nacional do Tapajós (Km 114 da BR 163). O número entre parênteses $\left(\%\right.$.ano $\left.{ }^{-1}\right)$ indica a proporção de árvores que ingressaram no final de cada período, em relação ao número inicial de árvores presentes no período, divididos pelo número de anos do intervalo

\begin{tabular}{|c|c|c|c|c|c|c|}
\hline Tratamento & $\begin{array}{c}\text { 1AE-1 DE } \\
(1981-1983) \\
(2 \text { anos })\end{array}$ & $\begin{array}{c}1 \text { DE-5 DE } \\
(1983-1987) \\
(4 \text { anos })\end{array}$ & $\begin{array}{c}5 \text { DE-7 DE } \\
(1987-1989) \\
(2 \text { anos })\end{array}$ & $\begin{array}{c}7 \text { DE-13 DE } \\
(1989-1995) \\
(6 \text { anos) }\end{array}$ & $\begin{array}{c}13 \text { DE-21 DE } \\
(1995-2003) \\
(8 \text { anos })\end{array}$ & $\begin{array}{c}\text { 1AE-21DE } \\
(1981-2003) \\
(22 \text { anos })\end{array}$ \\
\hline T1 & $39,6^{\mathrm{a}}(3,5)$ & $85,4^{\mathrm{a}}(8,9)$ & $64,8^{\mathrm{a}}(5,3)$ & $21,4^{\mathrm{ab}}(1,7)$ & $15,0^{\mathrm{a}}(1,2)$ & $\mathbf{2 5 , 6 ^ { \mathrm { a } } ( 2 , 3 )}$ \\
\hline $\mathbf{T} 2$ & $33,5^{\mathrm{a}}(3,0)$ & $48,9^{\mathrm{ab}}(4,8)$ & $41,5^{\mathrm{ab}}(3,6)$ & $15,3^{\mathrm{b}}(1,3)$ & $20,0^{\mathrm{a}}(1,8)$ & $21,1^{a}(1,9)$ \\
\hline T3 & $40,9^{\mathrm{a}}(3,7)$ & $76,8^{\mathrm{a}}(8,0)$ & $59,0^{\mathrm{a}}(4,9)$ & $29,3^{\mathrm{a}}(2,3)$ & $43,3^{\mathrm{b}}(3,6)$ & $\mathbf{3 6}, \mathbf{1}^{\mathrm{b}}(3,3)$ \\
\hline T4 & $40,4^{\mathrm{a}}(3,5)$ & $89,5^{\mathrm{a}}(9,3)$ & $67,0^{\mathrm{a}}(5,4)$ & $27,8^{\mathrm{a}}(2,1)$ & $58,9^{\mathrm{c}}(4,9)$ & $41,9^{b}(3,7)$ \\
\hline & & $\begin{array}{c}1 \mathrm{M}-2 \mathrm{M} \\
(4 \text { anos })\end{array}$ & $\begin{array}{c}2 \mathrm{M}-3 \mathrm{M} \\
(2 \text { anos })\end{array}$ & $\begin{array}{c}3 \mathrm{M}-4 \mathrm{M} \\
(6 \text { anos })\end{array}$ & $\begin{array}{c}4 \mathrm{M}-5 \mathrm{M} \\
(8 \text { anos })\end{array}$ & $\begin{array}{l}1 \mathrm{M}-5 \mathrm{M} \\
(20 \text { anos })\end{array}$ \\
\hline T0 & - & $13,3^{\mathrm{b}}(1,3)$ & $19,7^{\mathrm{b}}(1,9)$ & $14,1^{\mathrm{b}}(1,3)$ & $11,5^{\mathrm{a}}(1,1)$ & $\mathbf{1 1}, \mathbf{1}^{\mathrm{a}}(1,2)$ \\
\hline $\mathbf{F}$ & $2,27^{\mathrm{ns}}$ & $4,53^{*}$ & $4,09^{*}$ & $7,18^{*}$ & $42,84^{*}$ & $9,25^{*}$ \\
\hline $\mathrm{CV}$ & 32,5 & 58,0 & 48,1 & 32,2 & 27,8 & 35,2 \\
\hline
\end{tabular}

F: valor do F na análise de variância $(\alpha=0,05)$; CV: coeficiente de variação experimental. Médias seguidas pela mesma letra na posição vertical não apresentam diferença significativa de acordo com o teste Tukey $(\alpha=0,05)$. 1AE: um ano antes da exploração; 1DE: um ano depois da exploração...Para área testemunha, 1M: primeira medição, 2M: segunda medição.....

Pode-se observar na Figura 1, que à medida que o processo de recuperação pósexploração da floresta avança e inicia-se o fechamento do dossel, as taxas médias de ingresso tendem a se aproximar dos valores encontrados na área não explorada. Em 987, cinco anos após a colheita de madeira, as taxas de ingresso do tratamento T2 já são estatisticamente iguais ao T0. Após treze anos (1995), o tratamento T1, apesar de ter sido explorado mais intensamente, também se iguala a área testemunha. Os tratamentos T3 e T4 permanecem com taxas estatisticamente maiores em função dos desbastes aplicados na intensidade de 30\% e 50\%, que provocaram nova abertura no dossel, criando espaço e condições de maior luminosidade para o estabelecimento de novos ingressantes. O tratamento T2, apesar de também ter sofrido redução da área basal 
durante os desbastes, a intensidade de $20 \%$ não foi suficiente para provocar o aumento significativo no número de ingressos.

As maiores taxas de ingresso, para todos os tratamentos onde houve a colheita de madeira, foram observadas no período entre um e cinco anos depois da exploração (1983-1987), como conseqüência da maior entrada de luz ocasionada pela abertura do dossel. Nos dois períodos seguintes (1987-1989 e 1989-1995) o número de ingressos diminuiu gradativamente, aproximando-se dos encontrados, no mesmo período, para a floresta sem intervenção (T0) (Tabela 1 e Figura 2a). A mesma tendência foi observada considerando somente os ingressos de espécies comerciais madeireiras (Figura 2b).

No período de 13 a 21 anos depois da exploração (1995-2003), a abertura no dossel, ocasionada pelos desbastes para redução da área

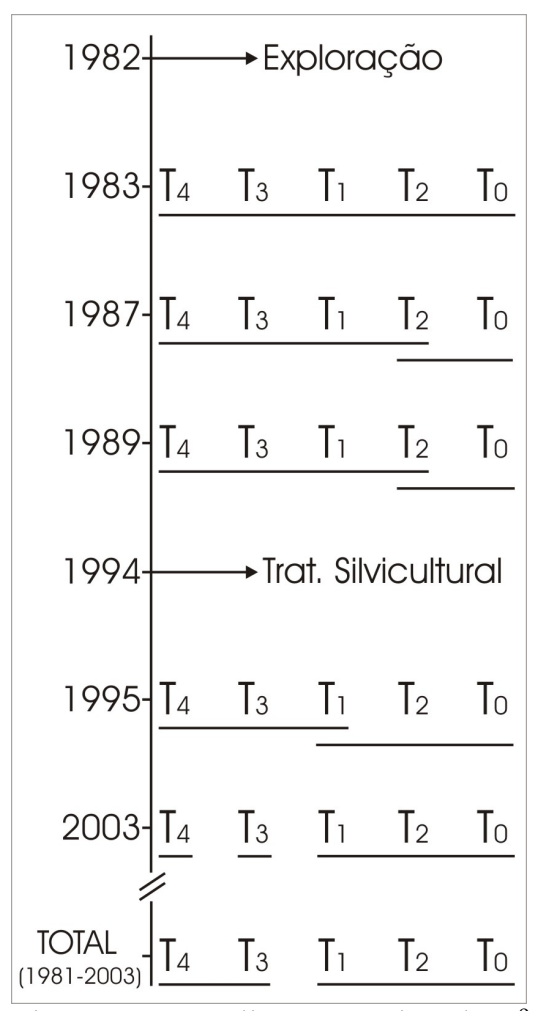

Figura 1 - Análise estatística do $\mathrm{n}^{\mathrm{o}}$ de ingressos.ha ${ }^{-1} \cdot$ ano $^{-1}$ a cada período de medição. Tratamentos seguidos pelo mesmo traço não apresentam $\neq$ significativa de acordo com o teste Tukey $(\alpha=0,05)$ basal, realizada no ano anterior (1994), favoreceu o aumento no número de ingressos nos tratamentos onde o mesmo foi aplicado (T2, T3 e T4). O efeito do desbaste na quantidade de ingressos variou conforme a intensidade de redução da área basal, sendo maior no tratamento T4 (50\% de redução) onde o número de ingressos aumentou em aproximadamente 112,0\% em relação ao período anterior. Para os tratamentos T3 (30\% de redução) e T2 (20\% de redução) esses valores foram $47,8 \%$ e $30,7 \%$, respectivamente (Figura 2a). Considerando somente as espécies de valor comercial, o aumento no número de ingressos.ha ${ }^{-1}$.ano ${ }^{-1}$, após os desbastes, foi $92 \%$ para o T4; 56,7\% para o T2 e 12,5\% para o T3 (Figura 2b). O Tratamento T1, onde não foi realizada nenhuma intervenção 
após a exploração, continuou reduzindo as taxas anuais de ingresso, equiparando-se ao tratamento T0 (Figuras 2a e 2b).

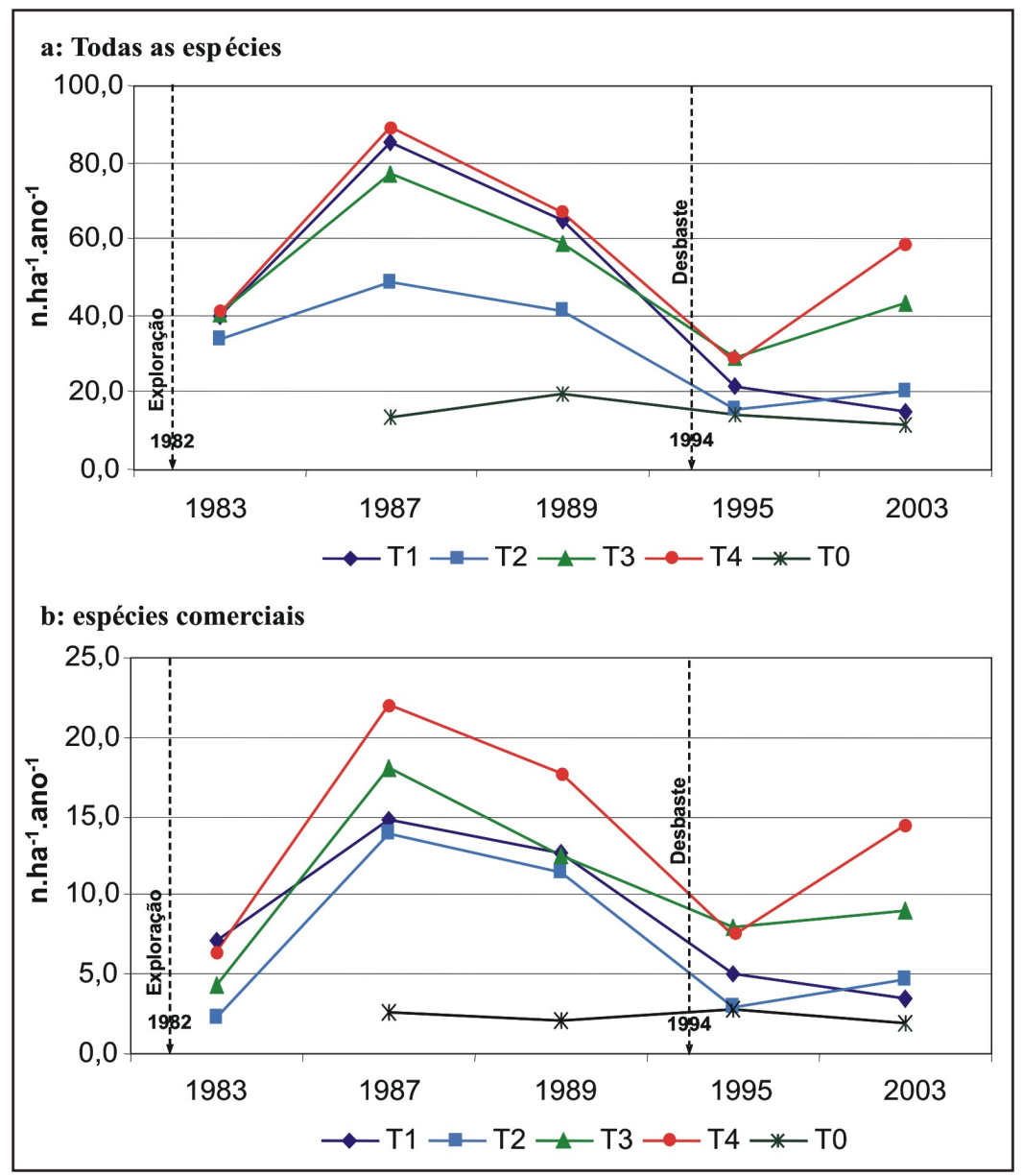

Figura 2 - Efeito das intervenções no número de ingressos (diâmetro $\geq$ $5,0 \mathrm{~cm})$ em cada tratamento e a cada período de medição em uma amostra de 10,25ha na Floresta Nacional do Tapajós (km 114 da BR 163)

As espécies pioneiras apresentaram os maiores valores percentuais de ingressos ao longo de todo o período de acompanhamento. Nos tratamentos em que houve colheita de madeira, o período 1983-1987 (1-5 anos após a exploração) mostrou as maiores taxas de ingressos nesse grupo ecológico, com valores variando entre $24 \%$ e $55 \%$, devido à abertura do dossel causada pelas atividades de extração. As espécies tolerantes à sombra 
mantiveram-se com taxas de $1 \%$ a $4 \%$ durante todo o período, com pouca variação ao longo do tempo (Figura 3).

A floresta testemunha também apresentou maior percentual de ingressos no grupo das pioneiras, principalmente nos dois primeiros períodos de acompanhamento. Esse fato se deve, provavelmente, à mortalidade natural de alguns indivíduos de grande porte (diâmetro $>50 \mathrm{~cm}$ ) das espécies Tachigali myrmecophyla e Iryanthera juruensis, que provocaram grandes aberturas no dossel, criando condições favoráveis ao estabelecimento de indivíduos nesse grupo ecológico.

O grupo das espécies comerciais também teve maior percentual de ingressos no período 1-5 anos depois da exploração, quando os valores variaram de $10 \%$ a $16 \%$. Nos demais períodos a taxa foi reduzida para 1 a $5 \%$ (Figura 3).

Considerando o período total de acompanhamento, o tratamento T4 destacou-se em termos de ingressos no grupo de espécies de valor comercial madeireiro, apresentando em torno de 11 novos indivíduos.ha ${ }^{-1}$.ano ${ }^{-1}$, que representa $5,8 \%$ ao ano do total de árvores de espécies comerciais presentes no primeiro levantamento. As espécies com maiores valores de ingressos nesse grupo foram: Jacaranda copaia, Licaria canela, Virola melinonii e Laetia procera. Para os demais tratamentos, os ingressos no grupo de valor comercial

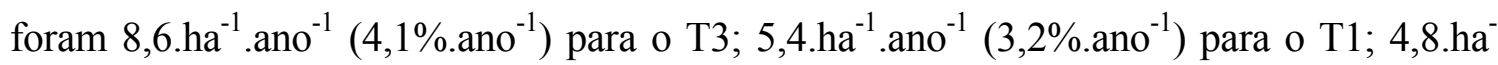

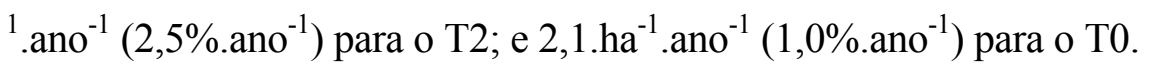

No Anexo P estão listadas as 12 espécies que mais contribuíram para o número total de ingressos em todos os tratamentos onde ocorreu a extração de madeira em três períodos de observação (1 ano antes da exploração a 5 anos depois; 5-13 anos após a exploração e 13-21 anos após a exploração). Nos três períodos observados, esse pequeno grupo representou mais de $40 \%$ do número total de ingressos. 

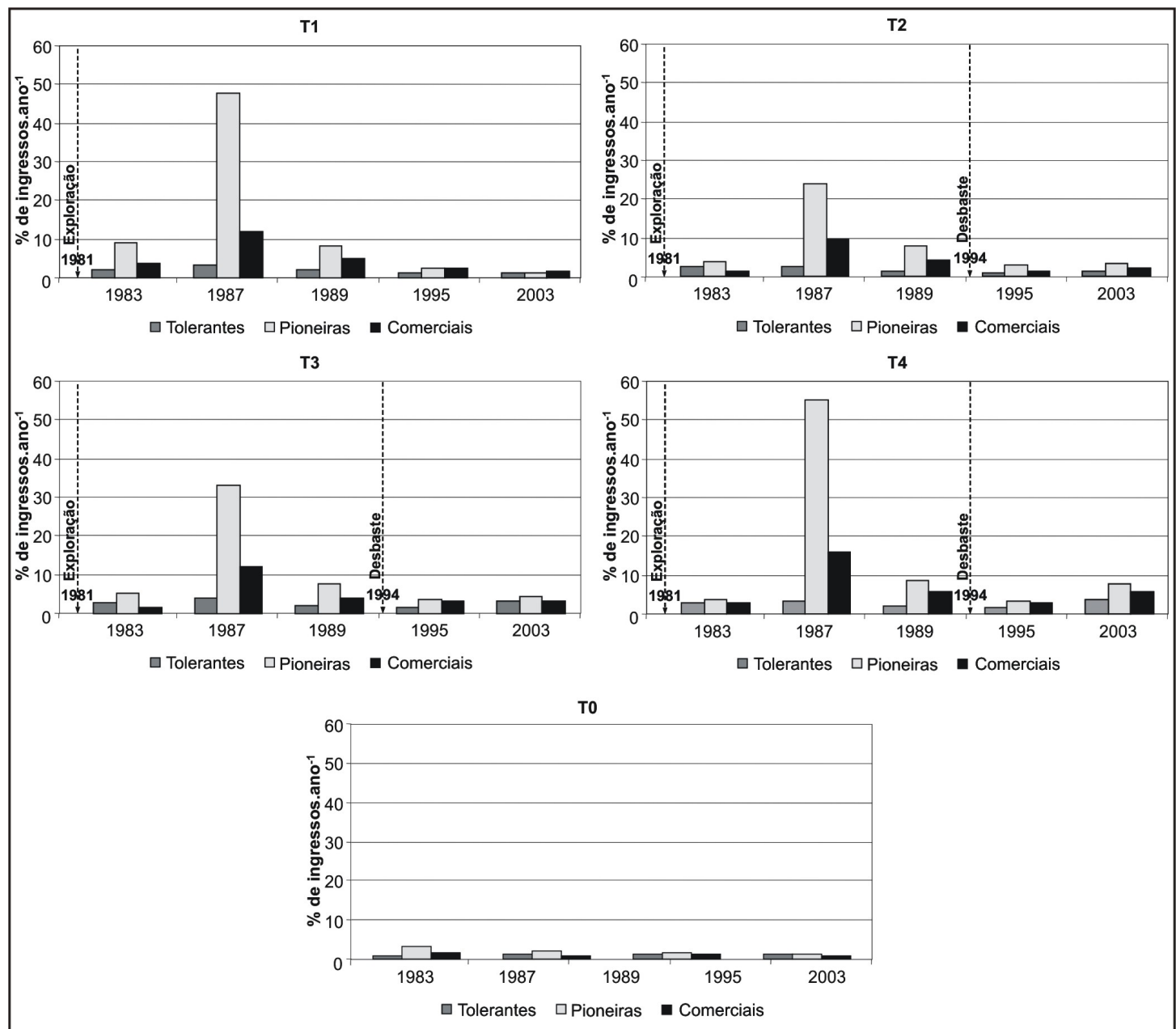

Figura 3 - Ingresso de árvores com diâmetro $\geq 5,0 \mathrm{~cm}$ em cada tratamento e a cada período de medição em uma amostra de 10,25ha na Floresta Nacional do Tapajós (km 114 da BR 163). Percentagem (\%) de ingressos refere-se ao número de novas árvores em relação as existentes na medição anterior

As espécies Inga sp., Protium apiculatum, Rinorea flavescens e o grupo das Sapotaceas (9 spp.) foram as que mais se destacaram em termos de número de novos indivíduos. $\mathrm{ha}^{-1}$. ano ${ }^{-1} \mathrm{em}$ todos os tratamentos, mantendo elevadas taxas de ingressos nos três períodos analisados. As pioneiras Cecropia leucoma e Cecropia sciadophylla tiveram altas taxas de ingressos apenas no primeiro período, beneficiadas pela abertura do dossel logo após a exploração, mas sua capacidade de recrutamento de novos indivíduos sofreu forte redução nos anos seguintes, em todos os tratamentos. Outras duas pioneiras Bixa arborea e Sloanea froesii tiveram o mesmo comportamento nos tratamentos T1 e T2, 
porém nos tratamentos $\mathrm{T} 3$ e $\mathrm{T} 4$, mantiveram elevadas taxas de ingresso durante todo o período, provavelmente por terem sido beneficiadas pela intensidade do desbaste, realizado nessas áreas (30\% e 50\% de redução da área basal, respectivamente) (Anexo P).

\subsubsection{Mortalidade}

Considerando a média geral dos 22 anos do período de acompanhamento, o tratamento que apresentou a maior mortalidade foi o T4 com 30,9 árvores.ha ${ }^{-1}$.ano ${ }^{-1}$

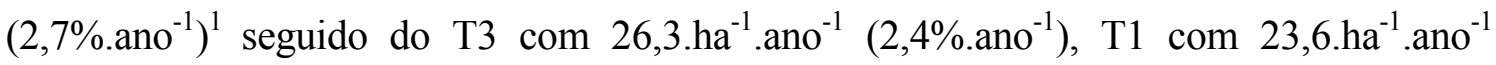
$\left(2,1 \% \cdot\right.$ ano $\left.^{-1}\right)$ e $\mathrm{T} 2$ com $20,1 \cdot$ ha $^{-1} \cdot$ ano $^{-1}\left(1,8 \% \cdot\right.$ ano $\left.^{-1}\right)$. Todavia, não foram encontradas diferenças significativas nas médias de mortalidade entre esses tratamentos. Diferenças estatísticas só foram detectadas em relação à floresta testemunha (T0), que apresentou média de 10,7 árvores mortas.ha ${ }^{-1}$.ano ${ }^{-1}\left(1,0 \%\right.$.ano $\left.{ }^{-1}\right)$ ao longo dos 20 anos de medição (Tabela 2).

Tabela 2 Mortalidade em número de árvores.ha ${ }^{-1} \cdot$ ano $^{-1}$ (diâmetro $\geq 5,0 \mathrm{~cm}$ ) em cada tratamento e a cada período de medição em uma amostra de 10,25ha na Floresta Nacional do Tapajós (km 114 da BR 163). O número entre parênteses $\left(\% . \mathrm{ano}^{-1}\right)$ indica a proporção de árvores que morreram no final de cada período, em relação ao número inicial de árvores presentes no período, dividido pelo número de anos do intervalo

\begin{tabular}{|c|c|c|c|c|c|c|}
\hline Tratamentos & $\begin{array}{c}\text { 1AE-1 DE } \\
(1981-1983) \\
(2 \text { anos })\end{array}$ & $\begin{array}{c}1 \text { DE-5 DE } \\
(1983-1987) \\
(4 \text { anos })\end{array}$ & $\begin{array}{c}5 \text { DE-7 DE } \\
(1987-1989) \\
(2 \text { anos })\end{array}$ & $\begin{array}{c}7 \text { DE-13 DE } \\
(1989-1995) \\
(6 \text { anos })\end{array}$ & $\begin{array}{c}13 \text { DE-21 DE } \\
(1995-2003) \\
(8 \text { anos })\end{array}$ & $\begin{array}{c}\text { 1AE-21DE } \\
(1981-2003) \\
(22 \text { anos) }\end{array}$ \\
\hline T1 & $122,2^{\mathrm{a}}(10,9)$ & $19,9^{\mathrm{a}}(2,1)$ & $35,6^{\mathrm{a}}(2,9)$ & $27,9^{\mathrm{a}}(2,3)$ & $24,1^{\mathrm{bc}}(1,9)$ & $\mathbf{2 3 , 6 ^ { \mathrm { a } } ( 2 , 1 )}$ \\
\hline $\mathbf{T} 2$ & $85,5^{\text {a }}(7,6)$ & $14,9^{\mathrm{a}}(1,5)$ & $24,6^{\mathrm{a}}(2,1)$ & $23,2^{\mathrm{a}}(2,0)$ & $19,6^{\mathrm{ab}}(1,7)$ & 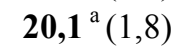 \\
\hline T3 & $110,0^{\mathrm{a}}(10,0)$ & $16,1^{\mathrm{a}}(1,7)$ & $27,4^{\mathrm{a}}(2,3)$ & $38,5^{\mathrm{b}}(3,0)$ & $30,2^{\mathrm{cd}}(2,5)$ & $\mathbf{2 6 , 3 ^ { \mathrm { a } }}(2,4)$ \\
\hline T4 & $131,0^{\mathrm{a}}(11,5)$ & $18,3^{\mathrm{a}}(1,9)$ & $31,7^{\mathrm{a}}(2,5)$ & $46,0^{\mathrm{b}}(3,5)$ & $37,0^{\mathrm{d}}(3,1)$ & $30,9^{\mathrm{a}}(2,7)$ \\
\hline T0 & - & $\begin{array}{c}1 \mathrm{M}-2 \mathrm{M} \\
(4 \text { anos }) \\
13,5^{\mathrm{a}}(1,3)\end{array}$ & $\begin{array}{c}2 \mathrm{M}-3 \mathrm{M} \\
(2 \text { anos }) \\
16,7^{\mathrm{a}}(1,6)\end{array}$ & $\begin{array}{c}3 \mathrm{M}-4 \mathrm{M} \\
(6 \text { anos }) \\
13,0^{\mathrm{a}}(1,2)\end{array}$ & $\begin{array}{c}4 \mathrm{M}-5 \mathrm{M} \\
(8 \text { anos }) \\
11,8^{\mathrm{a}}(1,1)\end{array}$ & 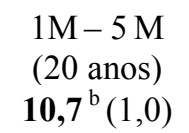 \\
\hline $\mathbf{F}$ & $2,30^{\mathrm{ns}}$ & $1,06^{\mathrm{ns}}$ & $2,61^{\mathrm{ns}}$ & $11,14^{*}$ & $19,39^{*}$ & $15,82^{*}$ \\
\hline $\mathrm{CV}$ & 44,6 & 40,2 & 42,8 & 32,7 & 22,1 & 35,5 \\
\hline
\end{tabular}

F: valor do F na análise de variância $(\alpha=0,05) ; \mathrm{CV}$ : coeficiente de variação experimental. Médias seguidas pela mesma letra na posição vertical não apresentam diferença significativa de acordo com o teste Tukey $(\alpha=0,05)$. $1 \mathrm{AE}$ : um ano antes da exploração; 1DE: um ano depois da exploração...Para área testemunha, 1M: primeira medição, 2M: segunda medição

\footnotetext{
${ }^{1}$ Percentagem anual do número de árvores presentes na primeira medição, em 1981.
} 
Como esperado, as maiores taxas de mortalidade foram observadas no período logo após a exploração em todos os tratamentos onde houve a colheita de madeira, estando incluídas as árvores extraídas e as que morreram em conseqüência dos danos ocasionados pelas atividades de derruba e arraste das toras (Figura 4a). O tratamento T4

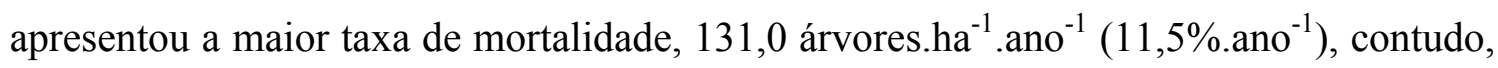
as diferenças entre as médias dos tratamentos, nesse período, não foram estatisticamente significativas (Tabela 2).

Nos dois períodos seguintes (1983-1987 e 1987-1989) que correspondem a 5 e 7 anos após a exploração, o número de indivíduos mortos diminuiu acentuadamente, igualando-se aos encontrados na floresta sem intervenção (T0) (Tabela 2 e Figura 4a). A mesma tendência foi observada considerando somente a mortalidade das espécies comerciais madeireiras (Figura 4b).

O tratamento silvicultural para redução da área basal realizado no final do período seguinte (1989-1995) provocou um aumento nas taxas de mortalidade dos tratamentos $\mathrm{T} 3$ e $\mathrm{T} 4$, que foram os de maior intensidade ( $30 \%$ e $50 \%$, respectivamente), o que fez com que as médias desses dois tratamentos fossem iguais entre si e estatisticamente superiores aos demais (T0, T1 e T2). Esse aumento ocorreu, provavelmente, devido à inclusão das árvores aneladas nos cálculos das taxas de mortalidade, ou seja, essa taxa não reflete somente a mortalidade natural da comunidade. A intensidade de redução da área basal aplicada no tratamento T2 (20\%), não foi suficiente para provocar o aumento significativo nas taxas de mortalidade (Tabela 2 e Figura 4a).

No último período de acompanhamento (1995-2003), as taxas de mortalidade diminuíram gradualmente em todos os tratamentos, porém as médias do T3 e T4 continuaram superiores às médias das demais áreas, como um reflexo dos desbastes, uma vez que muitas árvores aneladas demoram mais tempo para morrer (ver Capítulo II). 


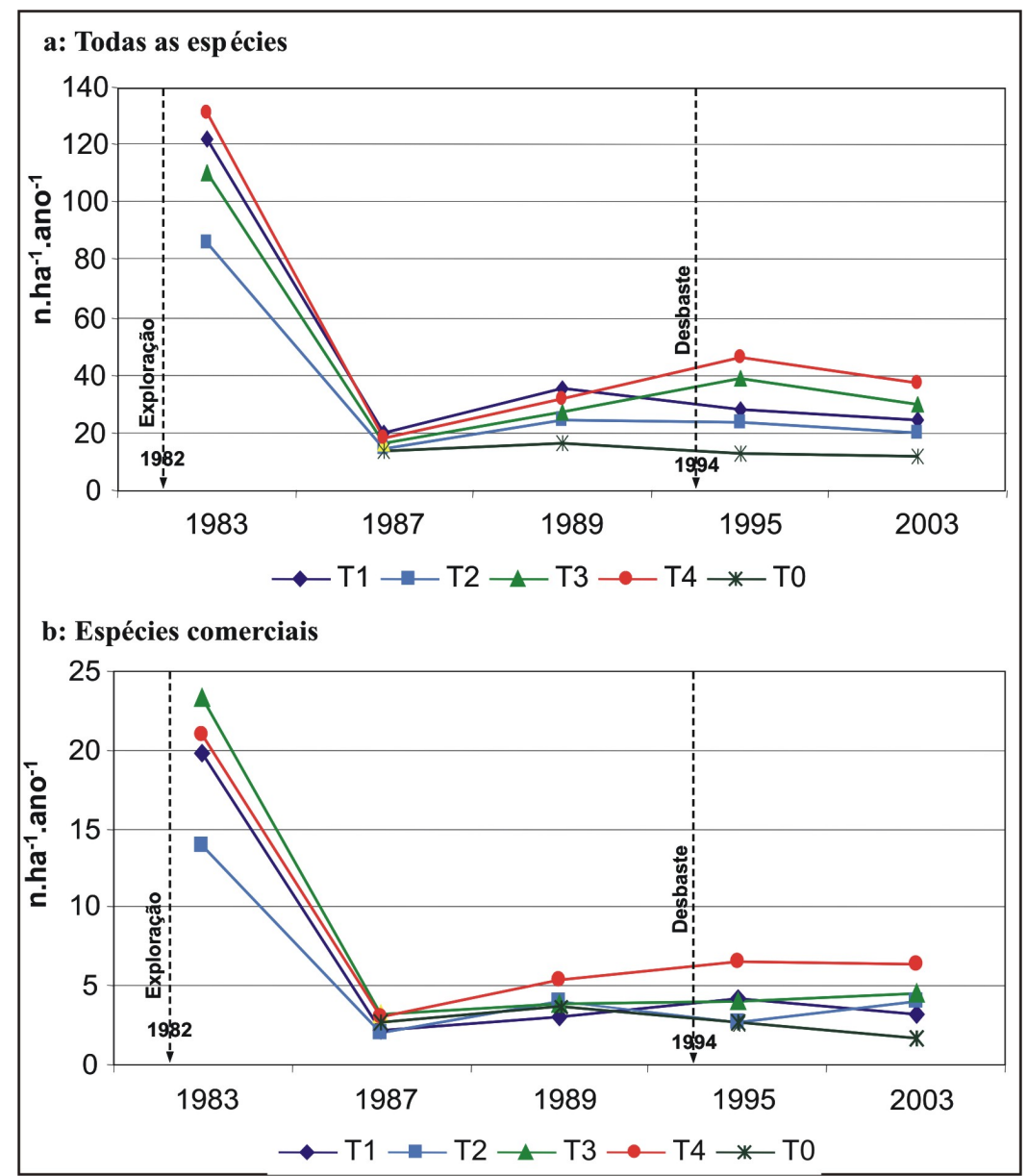

Figura 4 - Efeito das intervenções na mortalidade de árvores com diâmetro $\geq$ $5,0 \mathrm{~cm}$, em cada tratamento e a cada período de medição em uma amostra de 10,25ha na Floresta Nacional do Tapajós (km 114 da BR 163)

Com relação aos grupos ecológicos, observou-se que os percentuais de mortalidade das espécies tolerantes à sombra foram semelhantes aos das pioneiras em todos os tratamentos onde ocorreu a exploração e em todos os períodos de medição, exceto para T3 e T4, no período logo após a aplicação dos desbastes (1995), quando a mortalidade das pioneiras foi aproximadamente 2,5 vezes superior a das tolerantes devido ao anelamento de grande número de árvores de espécies desse grupo (Figura 5).

$\mathrm{Na}$ floresta testemunha observou-se maior percentual de mortalidade no grupo das pioneiras (Figura 5). Espécies como Cecropia leucoma, Cecropia sciadophylla, Pourouma longipendula, Jacaratia spinosa, Miconia sp. e Vismia japurensis, que eram 
representadas por um pequeno número de indivíduos, restritos as áreas de clareiras naturais, apresentaram elevadas taxas de mortalidade (em torno de $5 \%$ ao ano), provavelmente devido à competição por luz causada pelo crescimento das árvores e o conseqüente fechamento gradual das clareiras.

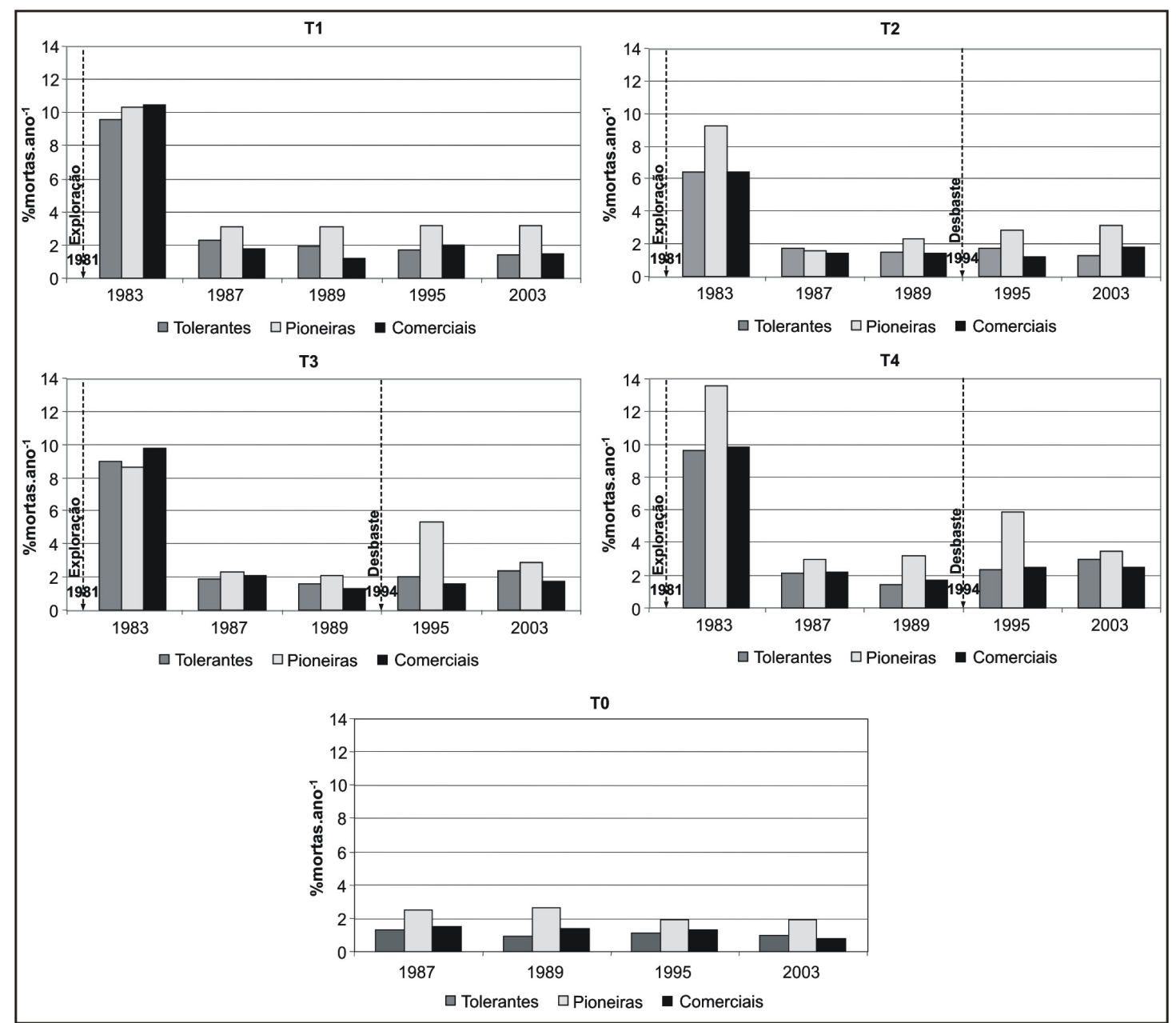

Figura 5 - Mortalidade de árvores (diâmetro $\geq 5,0 \mathrm{~cm}$ ) em cada tratamento e a cada período de medição em uma amostra de 10,25ha na Floresta Nacional do Tapajós (km 114 da BR 163). Percentagem (\%) de mortas refere-se ao número de indivíduos encontrados mortos na medição atual em relação ao total de árvores existentes na medição anterior

As espécies comerciais mostraram os maiores valores percentuais de mortalidade, no primeiro período, nos tratamentos onde ocorreu a exploração, como conseqüência da extração de grande número de árvores desse grupo. Nos tratamentos T1, T3 e T4 a taxa ficou em torno de $10 \%$ e no tratamento T2, aproximadamente $6 \%$. As principais espécies 
extraídas durante a exploração foram Carapa guianensis, Manilkara huberi, Lecythis lurida e Hymenaea courbaril (Anexo B) Nos demais períodos, a mortalidade das espécies comerciais ficou em torno de $2 \%$ nos tratamentos onde houve colheita de madeira e em torno de 1,25\% para a floresta testemunha (Figura 5).

No Anexo Q estão listadas as 15 espécies que apresentaram as maiores taxas de mortalidade em todos os tratamentos onde ocorreu a extração de madeira, em três períodos de observação ( 1 ano antes da exploração a 5 anos depois; 5-13 anos após a exploração e 13-21 anos após a exploração). Nos três períodos observados, esse pequeno grupo representou aproximadamente $50 \%$ do número total de árvores mortas.

As espécies Rinorea flavescens, Protium apiculatum, Inga sp., Rinorea guianensis e o grupo das Sapotaceas (9 spp.) foram as que apresentaram o maior número de árvores mortas.ha ${ }^{-1} \cdot$ ano $^{-1}$ em todos os tratamentos, mantendo elevadas taxas de mortalidade nos três períodos analisados. As pioneiras Jacaranda copaia, Cecropia leucoma e Cecropia sciadophylla tiveram alta mortalidade apenas no segundo período (5-13 anos após a exploração) devido à redução dos níveis de iluminação com o fechamento gradual do dossel (Anexo Q).

\subsubsection{Balanço dinâmico}

Considerando os 22 anos de acompanhamento, todos os tratamentos tiveram um balanço positivo, com o número de ingressos superior à mortalidade. As intervenções realizadas na floresta aumentaram a mortalidade, mas também estimularam o aumento dos ingressos, principalmente nos tratamentos $\mathrm{T} 3$ e $\mathrm{T} 4$ onde o número de novos indivíduos foi aproximadamente $37 \%$ e $36 \%$ superior ao número de árvores mortas, respectivamente (Figura 6a). Considerando somente as árvores de espécies comerciais, o número de ingressos foi o dobro do número de árvores mortas para o T3 e 2,4 vezes superior para o tratamento T4 (Figura 6b). 


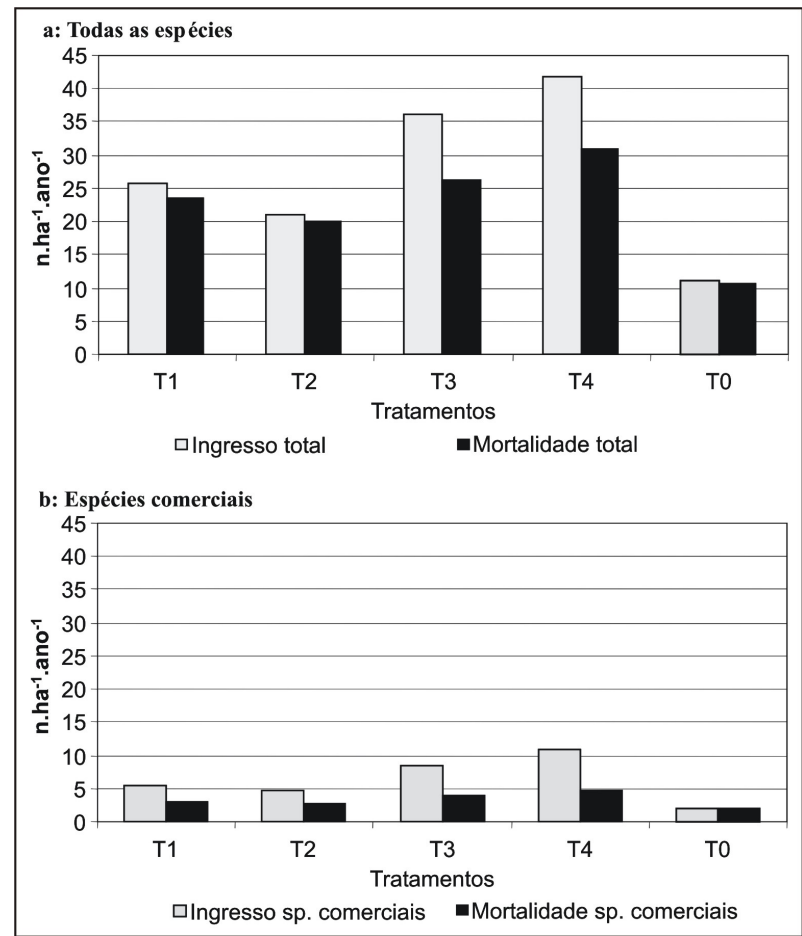

Figura 6 - Ingressos e mortalidade em n.ha ${ }^{-1} \cdot$ ano $^{-1}$ (diâmetro $\geq 5,0 \mathrm{~cm}$ ), em cada tratamento, no intervalo de 22 anos de acompanhamento em uma amostra de 10,25 ha na Floresta Nacional do Tapajós (km 114 da BR 163)

A Figura 7 mostra que os valores de ingressos e mortalidade tiveram comportamento semelhante entre os tratamentos onde ocorreu a colheita de madeira. Registrou-se elevadas taxas de mortalidade logo após a exploração e redução acentuada a partir do quinto ano. Em relação aos ingressos, verificou-se um comportamento inverso, com pequenas taxas logo após a colheita de madeira e aumento acentuado no quinto e sétimo ano. 
$\mathrm{Na}$ floresta sem intervenção as taxas de ingressos e mortalidade foram semelhantes em todos os períodos de acompanhamento, exceto no intervalo entre 1987-1989, quando os ingressos foram superiores à mortalidade em aproximadamente 15\% (Figura 7).

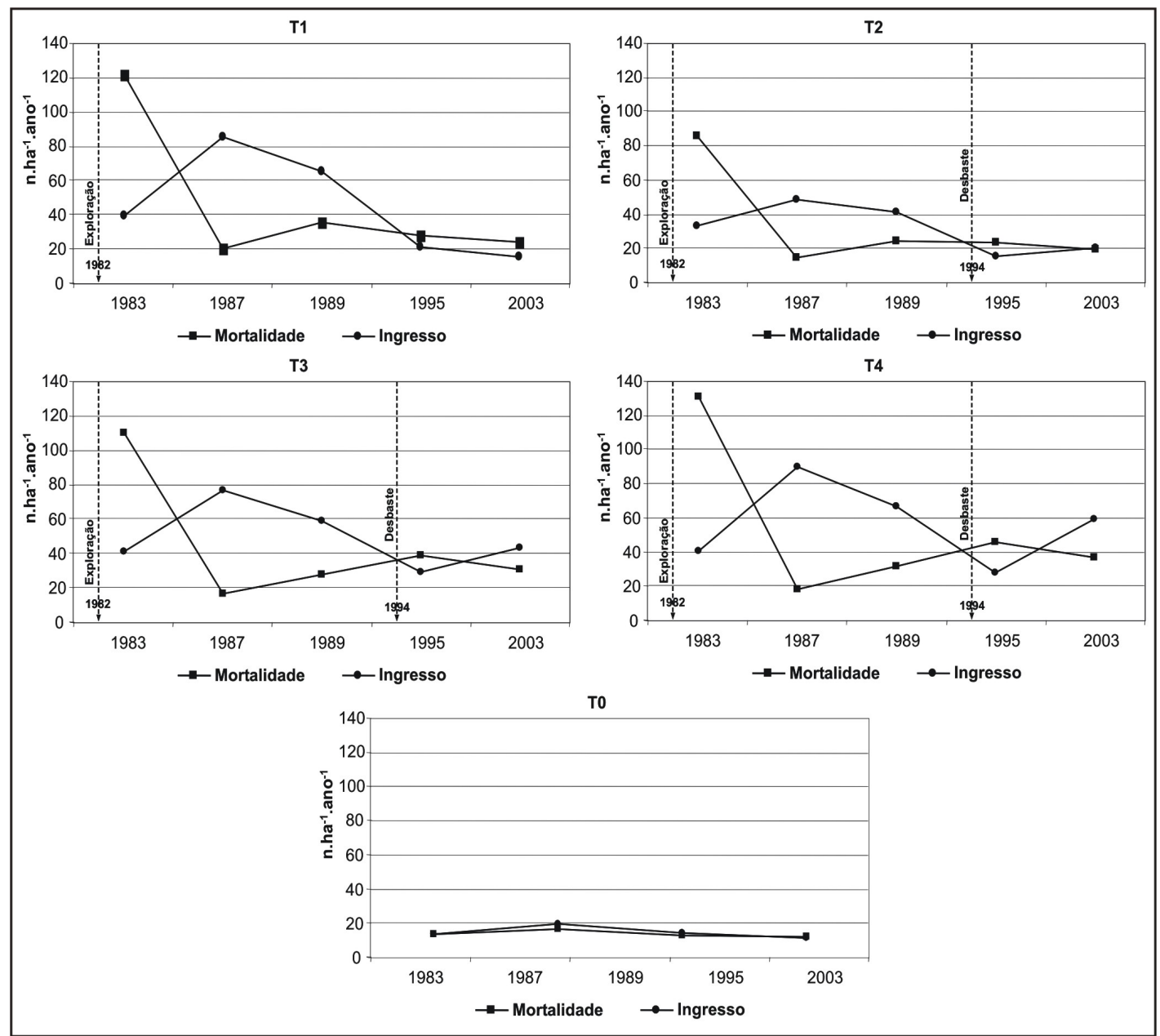

Figura 7 - Ingressos e mortalidade de árvores em n.ha ${ }^{-1}$.ano ${ }^{-1}$ (diâmetro $\geq 5,0 \mathrm{~cm}$ ) em cada tratamento e a cada período de medição em uma amostra de 10,25 ha na Floresta Nacional do Tapajós (km 114 da BR 163)

\subsubsection{Crescimento em diâmetro}

O incremento anual em diâmetro, considerando o período total de acompanhamento, diferiu significativamente entre os tratamentos analisados. A floresta não explorada (tratamento T0) apresentou média geral de $0,14 \mathrm{~cm} \cdot a^{-1} o^{-1}$, sendo esse valor estatisticamente 
inferior aos demais tratamentos. As médias do T3 $\left(0,23 \mathrm{~cm} \cdot \mathrm{ano}^{-1}\right)$ e T4 $\left(0,22 \mathrm{~cm} \cdot \mathrm{ano}^{-1}\right)$ foram iguais entre si e estatisticamente superiores a T1 $\left(0,19 \mathrm{~cm} \cdot\right.$ ano $\left.^{-1}\right)$ e T2 $\left(0,18 \mathrm{~cm} \cdot\right.$ ano $\left.^{-1}\right)$ (Tabela 3). Todavia algumas diferenças foram observadas nesse comportamento, quando se analisou períodos mais curtos, ou seja, os intervalos entre cada medição.

No primeiro período (antes da exploração a 1 ano depois) não houve diferença significativa entre as médias do incremento anual em diâmetro nos tratamentos em que ocorreu a colheita de madeira. Deve-se considerar que a área testemunha não foi medida antes da exploração, por isso não pôde ser comparada nesse período (Tabela 3).

O segundo e terceiro período (1-5 e 5-7 anos após a exploração) apresentaram comportamento semelhante, com as médias dos tratamentos T1, T3 e T4 estatisticamente iguais e superiores a T2 e T0. No quarto período (7-13 anos depois da exploração) todos os tratamentos onde houve a colheita de madeira tiveram incrementos estatisticamente iguais e a floresta testemunha apresentou crescimento inferior aos demais (Tabela 3).

Tabela 3 Incremento periódico anual em diâmetro $\left(\mathrm{cm} \cdot \mathrm{ano}^{-1}\right)$, por tratamento, a cada período de medição, considerando árvores com DAP $\geq 5,0 \mathrm{~cm}$, em uma amostra de 10,25 ha na Floresta Nacional do Tapajós (km 114 da BR 163)

\begin{tabular}{|c|c|c|c|c|c|c|}
\hline Tratamentos & $\begin{array}{c}\text { 1AE-1 DE } \\
(1981-1983) \\
(2 \text { anos }) \\
\end{array}$ & $\begin{array}{c}1 \text { DE-5 DE } \\
(1983-1987) \\
(4 \text { anos }) \\
\end{array}$ & $\begin{array}{c}5 \text { DE-7 DE } \\
(1987-1989) \\
(2 \text { anos }) \\
\end{array}$ & $\begin{array}{c}7 \text { DE-13 DE } \\
(1989-1995) \\
(6 \text { anos }) \\
\end{array}$ & $\begin{array}{c}13 \text { DE-21 DE } \\
(1995-2003) \\
(8 \text { anos }) \\
\end{array}$ & $\begin{array}{c}\text { 1AE-21DE } \\
(1981-2003) \\
(22 \text { anos })\end{array}$ \\
\hline T1 & $0,29^{\mathrm{a}}$ & $0,35^{a}$ & $0,37^{\mathrm{a}}$ & $0,22^{a}$ & $0,17^{\mathrm{a}}$ & $0,19^{a}$ \\
\hline $\mathbf{T} 2$ & $0,27^{\mathrm{a}}$ & $0,28^{b}$ & $0,24^{b}$ & $0,18^{\mathrm{a}}$ & $0,16^{\mathrm{a}}$ & $0,18^{a}$ \\
\hline T3 & $0,30^{\mathrm{a}}$ & $0,37^{\mathrm{a}}$ & $0,30^{\mathrm{a}}$ & $0,19^{\mathrm{a}}$ & $0,30^{\mathrm{b}}$ & $0,23^{b}$ \\
\hline T4 & $0,33^{a}$ & $0,35^{a}$ & $0,32^{\mathrm{a}}$ & $0,20^{\mathrm{a}}$ & $0,37^{\mathrm{c}}$ & $0,22^{b}$ \\
\hline T0 & - & $\begin{array}{c}1 \mathrm{M}-2 \mathrm{M} \\
(4 \text { anos }) \\
0,18^{\mathrm{b}}\end{array}$ & $\begin{array}{c}2 \mathrm{M}-3 \mathrm{M} \\
(2 \text { anos }) \\
0,13^{\mathrm{b}}\end{array}$ & $\begin{array}{c}3 \mathrm{M}-4 \mathrm{M} \\
(6 \text { anos }) \\
0,13^{\mathrm{b}}\end{array}$ & $\begin{array}{c}4 \mathrm{M}-5 \mathrm{M} \\
(8 \text { anos }) \\
0,12^{\mathrm{a}}\end{array}$ & $\begin{array}{c}1 \mathrm{M}-5 \mathrm{M} \\
(20 \text { anos }) \\
\mathbf{0 , 1 4}{ }^{\mathrm{c}}\end{array}$ \\
\hline $\mathbf{F}$ & $1,82^{\mathrm{ns}}$ & $7,33^{*}$ & $5,74^{*}$ & $5,95^{*}$ & $46,0^{*}$ & $6,82^{*}$ \\
\hline CV & 25,1 & 24,3 & 35,6 & 20,4 & 17,7 & 22,3 \\
\hline
\end{tabular}

F: valor do F na análise de variância $(\alpha=0,05)$; CV: coeficiente de variação experimental. Médias seguidas pela mesma letra na posição vertical não apresentam diferença significativa de acordo com o teste Tukey $(\alpha=0,05)$. $1 \mathrm{AE}$ : um ano antes da exploração; 1DE: um ano depois da exploração...Para área testemunha, 1M: primeira medição, 2M: segunda medição

O último período (13-21 anos depois da exploração) coincide com a aplicação dos tratamentos silviculturais, que foram realizados em 1994, doze anos após a exploração. O tratamento mais intenso $(\mathrm{T} 4=50 \%$ de redução da área basal) obteve o maior incremento 
em DAP (0,37 cm.ano $\left.{ }^{-1}\right)$, seguido do T3 (30\% de redução da AB) com incremento de $0,30 \mathrm{~cm} \cdot \mathrm{ano}^{-1}$. O tratamento $\mathrm{T} 2(20 \%$ de redução da $\mathrm{AB})$ não apresentou diferença significativa do tratamento $\mathrm{T} 1$, onde não foi aplicado o refinamento, nem da floresta testemunha (tratamento T0) onde não houve qualquer intervenção (Tabela 3).

Os valores de incremento periódico anual em diâmetro para cada tratamento, nos cinco períodos de medição, presentes na Tabela 3, foram plotados em um gráfico para visualizar o efeito das intervenções realizadas na floresta sob o crescimento das árvores, ao longo do tempo. A Figura 8 mostra claramente que o efeito positivo da abertura do dossel, promovida pela colheita de madeira, na liberação da competição nas árvores remanescentes, começa a diminuir a partir de 1987, 5 anos após a exploração, quando todos os tratamentos apresentaram redução nas taxas de crescimento, exceto o T1, onde a intensidade de exploração foi maior e o crescimento manteve-se elevado até 1989, 7 anos após a intervenção (Figura 8a). Considerando o crescimento somente das espécies de valor comercial madeireiro, a redução no crescimento ainda é mais acentuada e com igual comportamento em todos os tratamentos (Figura 8b).

No período 1995-2003, observou-se nova aceleração no crescimento das árvores nos tratamentos T3 e T4 como resultado do desbaste que reduziu a área basal, e conseqüentemente a competição entre a árvores remanescentes. A intensidade de redução da área basal aplicada no tratamento T2 (20\%) não foi suficiente para promover o aumento das taxas de crescimento, que continuaram diminuindo, igualando-se ao tratamento T1, onde nenhuma intervenção pós-exploração foi realizada. O efeito positivo do desbaste, nos tratamentos T3 e T4, permaneceu por 8 anos (1995-2003), embora o intervalo entre as duas medições tenha sido muito extenso para determinar com maior precisão sua real duração (Figuras 8a e 8b). Novas medições em intervalos mais curtos seriam necessárias para estimar esse efeito.

Em nível de espécies, as taxas de incremento variaram de acordo com o grau de tolerância à sombra. As espécies pioneiras apresentaram as maiores taxas de crescimento em todos os tratamentos, com valores médios em torno de $0,35 \mathrm{~cm} . \mathrm{ano}^{-1}$, que representam aproximadamente o dobro da média obtida pelas tolerantes $\left(0,17 \mathrm{~cm}^{-a n o}{ }^{-1}\right)$ (Tabela 4$)$. 


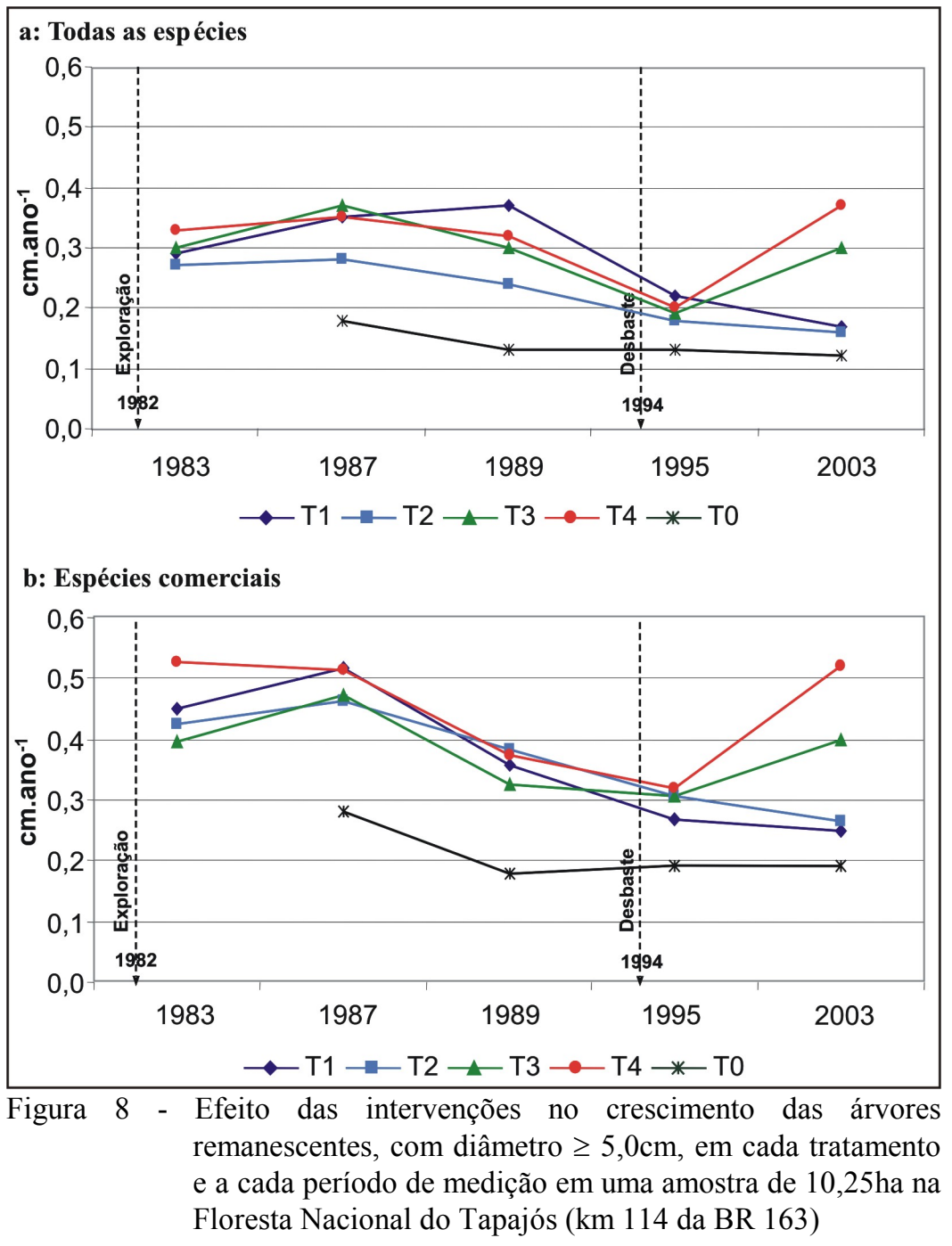

Algumas espécies pioneiras como Cecropia sciadophylla, Pourouma longipendula, Tachigali myrmecophyla, Sclerolobium chrysophyllum, Bixa arborea e Didymopanax morototoni tiveram incrementos em diâmetro acima de $1,0 \mathrm{~cm} . \mathrm{ano}^{-1}$, principalmente durante o período imediatamente após as aberturas do dossel, realizadas pela exploração e pelos tratamentos silviculturais. Por outro lado, algumas espécies tolerantes, como Talisia longifolia, Sagotia racemosa, Guarea kunthiana, Theobroma speciosum e Rinorea flavescens, abundantemente presentes no sub-bosque de todos os tratamentos, tiveram incrementos menores que $0,1 \mathrm{~cm}$. ano $^{-1}$.

As espécies comerciais mostraram elevadas taxas de crescimento nos tratamentos onde houve colheita de madeira (T1, T2, T3 e T4) com média de $0,34 \mathrm{~cm} \cdot \mathrm{ano}^{-1}$ (Tabela 4). 
As pioneiras Parkia multijuga, Schyzolobium amazonicum, Sclerolobium chrysophyllum, Tachigali myrmecophyla, Symphonia globulifera e Jacaranda copaia e as tolerantes Virola melinonii, Carapa guianensis, Hymenaea courbaril e Trattinickia rhoifolia, foram as espécies de valor comercial madeireiro com maiores taxas de crescimento nestas áreas.

Tabela 4 Incremento anual em diâmetro por grupo de espécies (diâmetro $\geq 5,0 \mathrm{~cm}$ ) e por tratamento, considerando o período total de acompanhamento em uma amostra de 10,25 ha na Floresta Nacional do Tapajós (km 114 da BR 163)

\begin{tabular}{|c|c|c|c|c|c|c|c|c|c|c|}
\hline \multirow{2}{*}{$\begin{array}{c}\text { Grupos de } \\
\text { espécies }\end{array}$} & \multicolumn{2}{|c|}{ T1 } & \multicolumn{2}{|c|}{$\mathbf{T 2}$} & \multicolumn{2}{|c|}{ T3 } & \multicolumn{2}{|c|}{ T4 } & \multicolumn{2}{|c|}{ T0 } \\
\hline & cm.ano $^{-1}$ & $\mathbf{n}$ & cm.ano $^{-1}$ & $\mathbf{n}$ & cm.ano $^{-1}$ & $\mathbf{n}$ & cm.ano $^{-1}$ & $\mathbf{n}$ & cm.ano $^{-1}$ & $\mathbf{n}$ \\
\hline Tolerantes & 0,16 & $\begin{array}{c}117 \\
3\end{array}$ & 0,15 & 932 & 0,21 & 1118 & 0,20 & 502 & 0,12 & 965 \\
\hline Pioneiras & 0,40 & 160 & 0,39 & 129 & 0,36 & 191 & 0,34 & 68 & 0,26 & 181 \\
\hline Comerciais & 0,35 & 228 & 0,33 & 211 & 0,35 & 307 & 0,34 & 116 & 0,21 & 235 \\
\hline Total & 0,19 & $\begin{array}{c}133 \\
3\end{array}$ & 0,18 & 1061 & 0,23 & 1309 & 0,22 & 570 & 0,14 & 1146 \\
\hline
\end{tabular}

n: número de árvores (em pé e completas), consideradas para o cálculo de cada média.

Os incrementos anuais em diâmetro, considerando o período total de acompanhamento, para as 30 espécies mais abundantes, presentes em todos os tratamentos, estão no Anexo R. A maioria destas 30 espécies apresentou médias de incremento semelhantes entre os tratamentos onde houve exploração de madeira e valores mais baixos na floresta testemunha. Porém, algumas espécies destacaram-se com taxas de crescimento mais elevadas em alguns tratamentos como, por exemplo, Guarea sp., Guatteria poeppigiana e Casearia favitensis no tratamento T3, Eugenia lambertiana e Licaria canella no T4 e Sclerolobium chrysophyllum no T2. A média de crescimento anual das espécies mais abundantes $(\mathrm{T} 1=0,17 ; \mathrm{T} 2=0,16 ; \mathrm{T} 3=0,21 ; \mathrm{T} 4=0,19 ; \mathrm{T} 0=0,13)$ foi ligeiramente inferior à obtida para o total de espécies presentes em cada um dos cinco tratamentos. Uma razão para isso é que nesse grupo de 30 espécies estão presentes somente 4 pioneiras e um grande número de tolerantes de sub-bosque com baixas taxas de crescimento, o que provocou a redução das médias.

Os valores de incremento, para cada tratamento, foram plotados em um gráfico por classe de diâmetro, para verificar a influência das intervenções nas taxas de crescimento de árvores em diferentes dimensões (Figura 9). Foram determinados três períodos consecutivos: i) Um ano antes da exploração a 5 anos depois; ii) Cinco a treze anos depois 
da exploração e iii) 13-21 anos após a exploração e nove anos após a aplicação dos desbastes.

Pode-se observar que a colheita de madeira teve um efeito positivo sobre as taxas de crescimento em todas as classes diamétricas e em todos os tratamentos no primeiro período (até 5 anos após a exploração), principalmente nas árvores acima de $35 \mathrm{~cm}$ de diâmetro, que cresceram em média: $0,50 \mathrm{~cm} \cdot \mathrm{ano}^{-1}$ no $\mathrm{T} 1 ; 0,55 \mathrm{~cm} \cdot \mathrm{ano}^{-1}$ no $\mathrm{T} 2 ; 0,45 \mathrm{~cm} \cdot \mathrm{ano}^{-1}$ no $\mathrm{T} 3$; e $0,49 \mathrm{~cm}^{-a n o}{ }^{-1}$ no T4. O segundo e terceiro períodos tiveram comportamento diferenciado entre os tratamentos. No T1, onde não ocorreu nenhuma intervenção após a exploração as taxas de incremento diminuíram ao longo do tempo, principalmente nas menores classes (até $25 \mathrm{~cm}$ de DAP). Uma exceção a esse padrão, foi a classe $85-95 \mathrm{~cm}$ que mostrou aumento no crescimento entre o segundo e terceiro período. Esse aumento foi devido à mudança de classe de diâmetro das espécies pioneiras Sloanea froesii, Parkia gigantocarpa, Enterolobium maximum e Anacardium giganteum, que vinham mostrando elevadas taxas de incremento e que nos dois períodos anteriores estavam na classe $75-85 \mathrm{~cm}$ (Figura 9).

No T2, o desbaste na intensidade de $20 \%$ de redução da área basal, aplicado pouco antes do início do último período, não teve efeito sobre as taxas de crescimento, que mantiveram-se próximas às encontradas no período 5-13 anos após a exploração, nas classes diamétricas até $75 \mathrm{~cm}$. Para as árvores maiores que $75 \mathrm{~cm}$, observou-se redução acentuada no incremento entre o segundo e terceiro período (Figura 9).

Nos tratamentos T3 e T4, os desbastes aplicados na intensidade de $30 \%$ e $50 \%$ de redução da área basal favoreceram o aumento nas taxas de crescimento no último período em relação ao período anterior, em todas as classes diamétricas, inclusive nas árvores menores (DAP $<25 \mathrm{~cm}$ ). As taxas de crescimento que estavam em torno de $0,20 \mathrm{~cm} . \mathrm{ano}^{-1}$, 13 anos após a exploração, subiram para aproximadamente $0,30 \mathrm{~cm} \cdot a^{-1}(58 \%)$ no tratamento T3 e para $0,37 \mathrm{~cm}^{-a_{n}}{ }^{-1}(85 \%)$ no tratamento T4. As classes mais beneficiadas foram $55-65 \mathrm{~cm}$ no $\mathrm{T} 3$ e $15-25 \mathrm{~cm}$ e $35-45 \mathrm{~cm}$ no $\mathrm{T} 4$, onde o incremento do terceiro período superou o obtido logo após a exploração (Figura 9). 

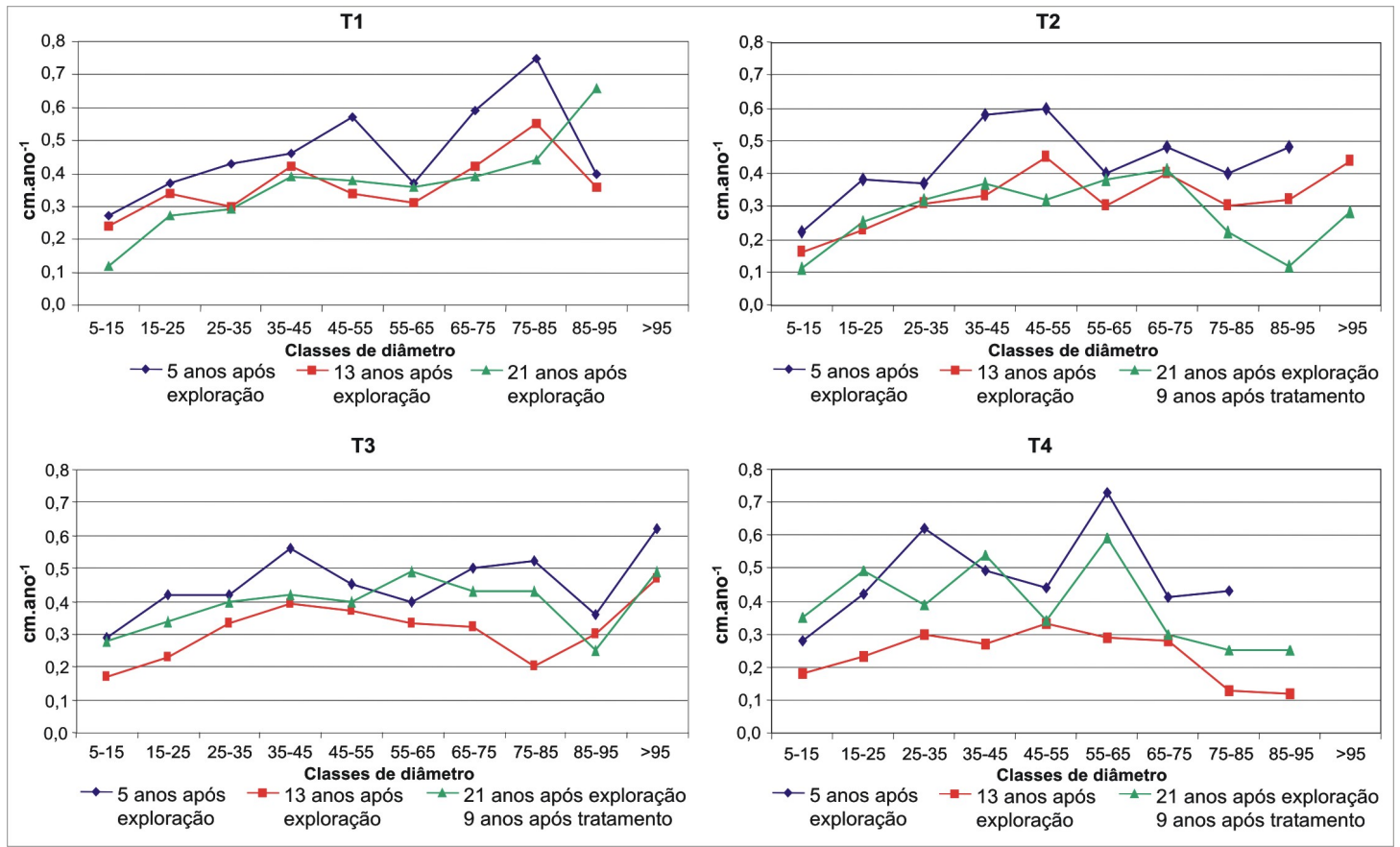

Figura 9 - Incremento anual em diâmetro (DAP $\geq 5,0 \mathrm{~cm}$ ) por classe diamétrica, em cada tratamento e em três períodos de medição, em uma amostra de 10,25 ha na Floresta Nacional do Tapajós (km 114 da BR 163)

\subsubsection{Incremento em área basal}

$\mathrm{O}$ incremento anual líquido na área basal total, isto é, considerando tanto o recrutamento quanto a mortalidade, no período de 1983 a 2003 (1 ano após a exploração até a última medição), diferiu significativamente entre os tratamentos, sendo as médias do T1 e T2 iguais e estatisticamente superiores aos demais. Considerando somente as espécies de valor comercial, as médias dos tratamentos T1, T2 e T3 foram iguais e superiores a T4 e T0 (Tabela 5).

Para verificar a influência das intervenções realizadas na floresta sobre as taxas de crescimento em área basal, os valores de incremento por tratamento foram plotados em um gráfico considerando três períodos consecutivos (1983-1989, 1989-1995 e 1995-2003). O primeiro período corresponde aos seis primeiros anos após a exploração e observou-se o efeito positivo da abertura do dossel nas taxas de crescimento. Os tratamentos com os maiores incrementos em área basal foram o $\mathrm{T} 1 \mathrm{e} \mathrm{T} 4$, ambos com $0,70 \mathrm{~m}^{2} \cdot \mathrm{ha}^{-1}$.ano ${ }^{-1}$ (Figura 
10a). Considerando somente as espécies de valor comercial madeireiro, se destacaram o T1 com $0,25 \mathrm{~m}^{2} \cdot \mathrm{ha}^{-1} \cdot$ ano $^{-1}$ e o T2 com $0,21 \mathrm{~m}^{2} \cdot \mathrm{ha}^{-1} \cdot$ ano $^{-1}$ (Figura 10b).

Tabela 5 Incremento periódico anual em área basal por tratamento, no período 1983-2003

(20 anos), considerando árvores com diâmetro $\geq 5,0 \mathrm{~cm}$. Floresta Nacional do Tapajós (km 114 da BR 163)

\begin{tabular}{|c|c|c|}
\hline Tratamentos & Todas as espécies $\left(\mathrm{m}^{2} \cdot \mathrm{ha}^{-1} \cdot \mathrm{ano}^{-1}\right)$ & Espécies comerciais $\left(\mathrm{m}^{2} \cdot \mathrm{ha}^{-1} \cdot\right.$ ano $\left.^{-1}\right)$ \\
\hline $\mathrm{T} 1$ & $0,32^{\mathrm{a}}$ & $0,12^{a}$ \\
\hline T2 & $0,30^{\mathrm{a}}$ & $0,16^{\mathrm{a}}$ \\
\hline $\mathrm{T} 3$ & $0,10^{\mathrm{b}}$ & $0,13^{\mathrm{a}}$ \\
\hline $\mathrm{T} 4$ & $0,07^{\mathrm{b}}$ & $0,08^{\mathrm{b}}$ \\
\hline T0 & $0,06^{\mathrm{b}}$ & $-0,02^{b}$ \\
\hline
\end{tabular}

No segundo período, que vai de 6 a 12 anos após a exploração (1989-1995), houve uma redução acentuada nas taxas de crescimento em área basal. Além disso, verificou-se efeito dos desbastes aplicados em 1994, um ano antes do final do período avaliado. Os tratamentos T3 e T4, desbastados na intensidade de 30\% e 50\% de redução da área basal, mostraram incrementos negativos devidos, em parte, à elevada mortalidade causada pelo anelamento. A floresta testemunha também mostrou incremento negativo, principalmente devido à mortalidade natural de 3 árvores de grande porte das espécies Pouteria bilocularis, Trattinickia rhoifolia e Swartzia brachyrachis, com diâmetros de 99,9cm; $79,3 \mathrm{~cm}$ e $56,4 \mathrm{~cm}$, respectivamente (Figura 10a e 10b)

No terceiro período, que vai de 1 a 9 anos após os desbastes (1995-2003), pôde-se observar o efeito positivo de sua aplicação nas taxas de crescimento das espécies de valor comercial. O tratamento $\mathrm{T} 2$, desbastado na intensidade mais leve (20\%), teve o seu incremento em área basal aumentado em $10,5 \%$ em relação ao período anterior. O tratamento T3, onde foi usada intensidade intermediária (30\%), mostrou o melhor desempenho com aumento na taxa de incremento em $80 \%$. O T4, de maior intensidade (50\% de redução da $\mathrm{AB})$, voltou a apresentar taxa de crescimento semelhante à observada logo após a exploração, passando do decrescimento de $-0,06 \mathrm{~m}^{2} \cdot$ ha $^{-1} \cdot$ ano $^{-1}$, observado no segundo período, para $0,14 \mathrm{~m}^{2} \cdot \mathrm{ha}^{-1} \cdot \mathrm{ano}^{-1}$. O tratamento T1, onde não foi realizado desbaste, 
continuou diminuindo seu incremento em área basal, que passou de $0,10 \mathrm{~m}^{2} \cdot \mathrm{ha}^{-1}$.ano ${ }^{-1}$ para $0,04 \mathrm{~m}^{2} \cdot$ ha $^{-1} \cdot$ ano $^{-1}$ (Figura 10b).

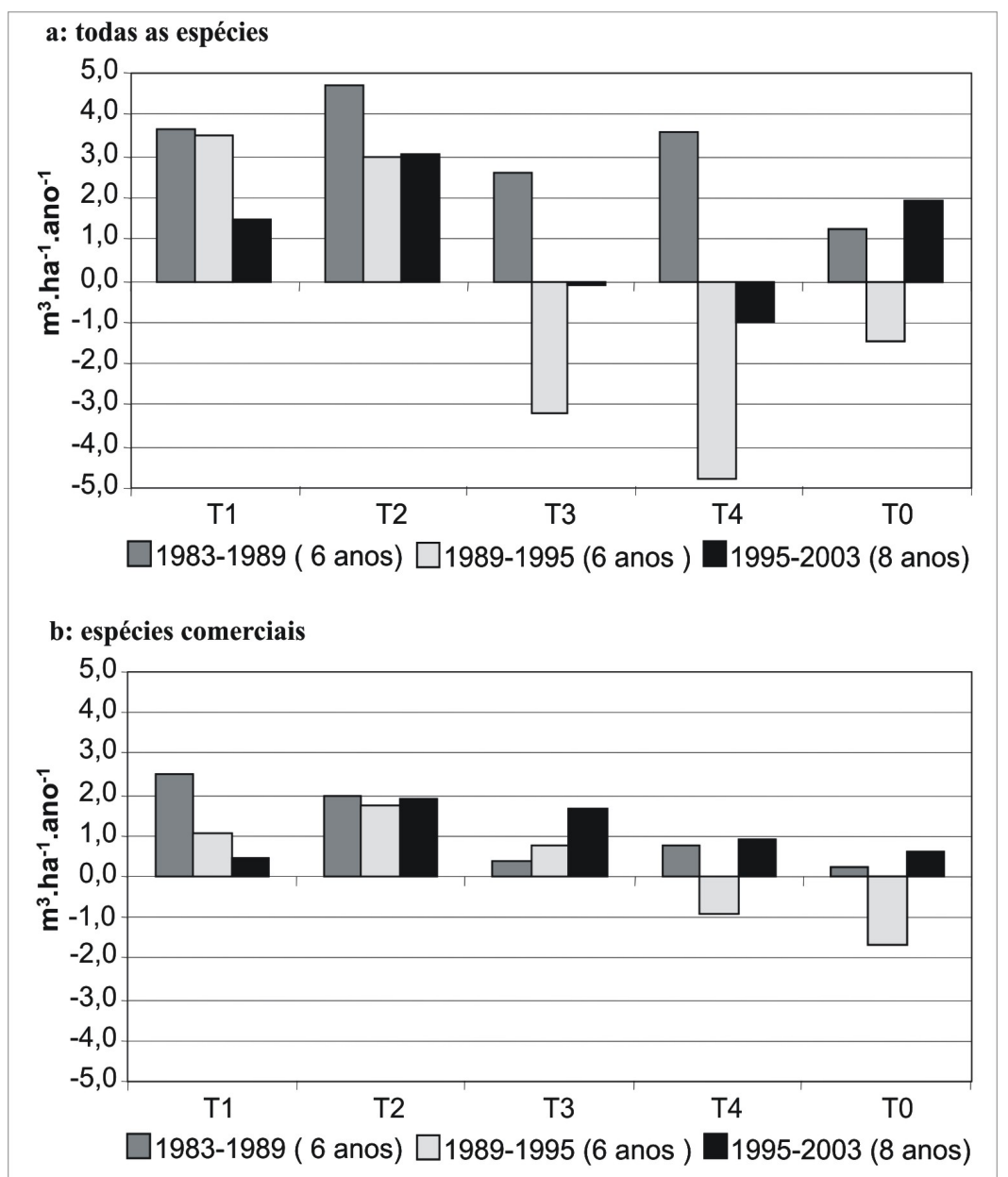

Figura 10 - Incremento periódico anual em área basal, considerando árvores com DAP $\geq 5,0 \mathrm{~cm}$, por tratamento, em três períodos consecutivos: 1983-1989 (seis primeiros anos após a exploração); 1989-1995 (6 a 12 anos após a exploração) e 19952003 (1 a 9 anos após os desbastes). Floresta Nacional do Tapajós (km 114 da BR 163)

\subsubsection{Incremento em volume}

As taxas de incremento em volume, considerando o período de 20 anos (1983-2003), apresentaram comportamento semelhante ao observado para a área basal. Porém é preciso considerar que, apesar do volume ser calculado em função da $\mathrm{AB}$, o limite de diâmetro 
usado para o cálculo do volume é $20,0 \mathrm{~cm}$, enquanto que para a $\mathrm{AB}$, foram consideradas todas as árvores a partir de 5,0cm de DAP.

$\mathrm{O}$ tratamento $\mathrm{T} 2$ apresentou o maior valor de incremento $3,5 \mathrm{~m}^{3} \cdot \mathrm{ha}^{-1}$.ano ${ }^{-1}$, porém não foram detectadas diferenças significativas em relação à média obtida para o $\mathrm{T} 1\left(2,7 \mathrm{~m}^{3}\right.$.ha ${ }^{-}$ ${ }^{1}$.ano $\left.{ }^{-1}\right)$. Considerando o incremento em volume somente das espécies de valor comercial madeireiro, os tratamentos T1, T2 e T3 foram iguais entre si e superiores ao T4 e T0 (Tabela 6).

Tabela 6 Incremento periódico anual em volume por tratamento, no período 1983-2003 (20 anos), considerando árvores com DAP $\geq 20,0 \mathrm{~cm}$. Floresta Nacional do Tapajós (km 114 da BR 163)

\begin{tabular}{ccc}
\hline Tratamentos & Todas as espécies $\left(\mathbf{m}^{3} \cdot \mathbf{h a}^{-1} \cdot \mathbf{a n o}^{-1}\right)$ Espécies comerciais $\left(\mathbf{m}^{3} \cdot \mathbf{h a}^{-1} \cdot \mathbf{a n o}^{-1}\right)$ \\
\hline T1 & $2,7^{\mathrm{a}}$ & $1,3^{\mathrm{a}}$ \\
T2 & $3,5^{\mathrm{a}}$ & $1,9^{\mathrm{a}}$ \\
T3 & $-0,2^{\mathrm{b}}$ & $1,0^{\mathrm{a}}$ \\
T4 & $-0,8^{\mathrm{b}}$ & $0,3^{\mathrm{b}}$ \\
T0 & $0,7^{\mathrm{b}}$ & $-0,2^{\mathrm{b}}$ \\
\hline
\end{tabular}

Médias seguidas pela mesma letra na posição vertical não apresentam diferença significativa de acordo com o teste Tukey $(\alpha=0,05)$.

Assim como observado para a área basal, as taxas de incremento em volume variaram bastante entre os três períodos analisados (1983-1989, 1989-1995 e 1995-2003). No primeiro período, logo após a exploração, foram encontrados os maiores valores, com destaque para o tratamento T2 que apresentou $4,7 \mathrm{~m}^{3} \cdot \mathrm{ha}^{-1}$.ano ${ }^{-1}$ considerando todas as espécies e para o tratamento $\mathrm{T} 1 \mathrm{com} 2,5 \mathrm{~m}^{3} \cdot \mathrm{ha}^{-1} \cdot \mathrm{ano}^{-1}$, considerando somente as espécies comerciais madeireiras. No segundo período (1989-1995), foram encontrados incrementos negativos nos tratamentos T3 e T4 como conseqüência dos desbastes aplicados nessas duas áreas. Incrementos negativos, devido à mortalidade natural de árvores de grande porte, também foram observados nesse período na floresta testemunha (Figura 11a).

No terceiro período, o efeito positivo do desbaste pôde ser sentido entre as árvores de espécies com valor comercial madeireiro, nos tratamentos onde o mesmo foi aplicado (T2, T3 e T4). O tratamento T2 passou de $1,7 \mathrm{~m}^{3} \cdot \mathrm{ha}^{-1} \cdot$ ano $^{-1}$ para $1,9 \mathrm{~m}^{3} \cdot \mathrm{ha}^{-1}$.ano ${ }^{-1}(11,8 \%$ de aumento), o T3 passou de $0,8 \mathrm{~m}^{3} \cdot \mathrm{ha}^{-1} \cdot$ ano $^{-1}$ para $1,7 \mathrm{~m}^{3} \cdot \mathrm{ha}^{-1} \cdot$ ano $^{-1}(112,5 \%$ de aumento) e o 
T4 passou do incremento negativo de $-0,09 \mathrm{~m}^{3} \cdot \mathrm{ha}^{-1} \cdot$ ano $^{-1}$ para $0,09 \mathrm{~m}^{3} \cdot \mathrm{ha}^{-1} \cdot$ ano $^{-1}$ (Figura 11b).
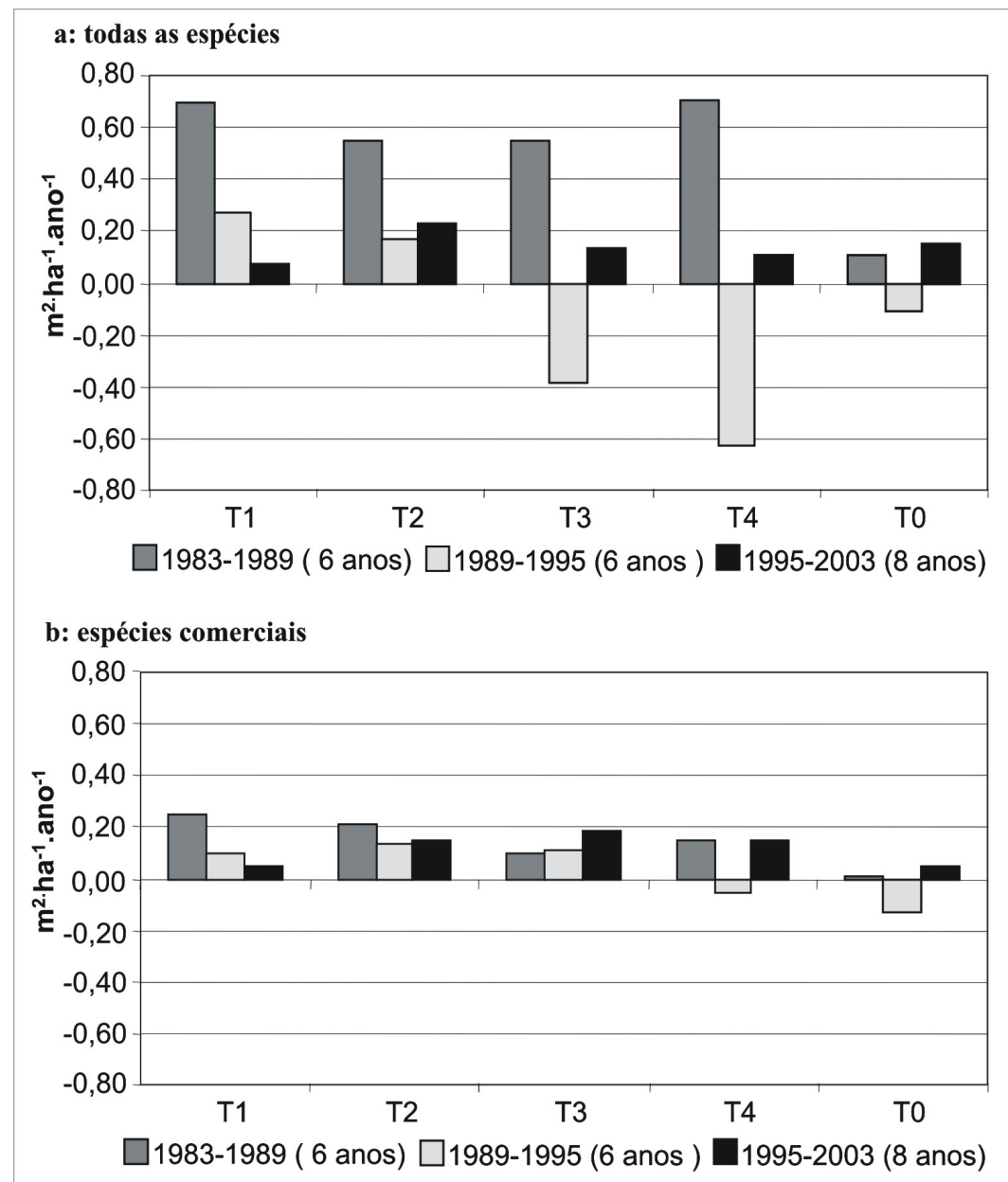

Figura 11 - Incremento periódico anual em volume por tratamento, considerando árvores com DAP $\geq 20,0 \mathrm{~cm}$, em três períodos consecutivos: 1983-1989 (seis primeiros anos após a exploração); 1989-1995 (6 a 12 anos após a exploração) e 1995-2003 (1 a 9 anos após os desbastes). Floresta Nacional do Tapajós (km 114 da BR 163) 


\subsection{Discussão}

\subsubsection{Ingressos}

A média anual de ingressos de árvores com diâmetro $\geq 5,0 \mathrm{~cm}$, considerando os 22 anos de acompanhamento, ficou em torno de 3,5\%.ano ${ }^{-1}$ para os tratamentos considerados mais intensos (T3 e T4: exploração de árvores com diâmetro $\geq 55,0 \mathrm{~cm}$ e desbastes na intensidade de $30 \%$ e $50 \%$ de redução da área basal, respectivamente), em torno de 2,0\%.ano ${ }^{-1}$ para os tratamentos considerados menos intensos (T1: exploração de árvores com diâmetro $\geq 45,0 \mathrm{~cm}$ e T2: exploração de árvores com diâmetro $\geq 55,0 \mathrm{~cm}$ e desbastes na intensidade de $20 \%$ de redução da área basal) e 1,2\%.ano ${ }^{-1}$ para a floresta testemunha (T0). Os valores obtidos neste estudo, para os tratamentos considerados menos intensos e para a floresta testemunha, são similares aos encontrados por Lieberman \& Lieberman (1987) para uma floresta primária na Costa Rica $\left(1,8 \%\right.$. ano $\left.^{-1}\right)$, por Silva (2004), em Paragominas, sete anos após a exploração $\left(2,3 \%\right.$.ano ${ }^{-1}$ a $2,5 \%$.ano $\left.{ }^{-1}\right)$, por Manokaran e Kochummen (1987) para floresta sem intervenção na Malásia $\left(1,5 \%\right.$.ano $\left.{ }^{-1}\right)$ e por Gomide (1997) em floresta primária na região do Jarí $\left(1,5 \%\right.$.ano $\left.{ }^{-1}\right)$.

A taxa de ingressos de 3,5\% ano $^{-1}$ obtida nos tratamentos considerados mais intensos (T3 e T4) foram semelhantes às encontradas por Higuchi et al. (1997) em áreas exploradas e submetidas a desbastes na intensidade de $25 \%$ a $75 \%$ de redução da área basal na região de Manaus (2,9\%.ano ${ }^{-1}$ a 4,2\%.ano $\left.{ }^{-1}\right)$ e por Silva et al. (1995), 11 anos após uma exploração pesada $\left(75 \mathrm{~m}^{3} \cdot \mathrm{ha}^{-1}\right)$, porém sem intervenção posterior, na Floresta Nacional do Tapajós $\left(3,1 \%\right.$.ano $\left.{ }^{-1}\right)$.

As condições favoráveis de luminosidade, ocasionadas pela abertura do dossel, logo após a exploração, contribuíram para o aumento dos ingressos, cuja maior taxa (em torno de $9 \%$.ano ${ }^{-1}$ ) foi obtida no período 1983-1987 (1 a 5 anos depois a exploração); após esse período, o fechamento gradual do dossel fez com que as taxas médias de ingresso diminuíssem até se aproximar dos valores encontrados na área não explorada (em torno de 1,5\%.ano ${ }^{-1}$ ). Treze anos após a colheita de madeira, as taxas de ingresso da área explorada não diferiram estatisticamente dos valores obtidos para a floresta testemunha. Semelhante 
comportamento foi observado por Costa et al. (2002) para uma área de 64ha na Flona Tapajós, que obtiveram taxa de ingresso de 13,6\%.ano ${ }^{-1}$, quatro anos após a exploração, caindo para 4,6\%.ano ${ }^{-1}$ aos 6 anos e estabilizando em torno de $2 \%$.ano ${ }^{-1}$ até o fím dos 18 anos de acompanhamento pós-exploração.

Os desbastes, realizados em 1994, através do anelamento de espécies sem valor comercial conhecido, ocasionaram nova abertura no dossel e favoreceram novo aumento no número de ingressos no período 1995-2003. Os desbastes mais intensos (30\% e 50\% de redução da área basal) aumentaram em 48\% e 112\%, respectivamente, o número de novos indivíduos em relação ao período anterior (1989-1995). Considerando somente as espécies de valor comercial, estes valores foram 12,5\% e 92\%. Esses dados comprovam a importância dos tratamentos silviculturais como estimuladores do ingresso de novos indivíduos em florestas tropicais. Fato este, já comentado e comprovado por diversos autores como, por exemplo, Dubois (1978), De Graaf (1986), Hutchinson (1987), Lamprecht (1990), Negreros-Castillo \& Mize (1993), Howard et al. (1996), Kuusipalo et al. (1996), Higuchi et al. (1997), Fredericksen (1998), Finegan et al. (1999), Pariona et al. (2001), Zaneti (2002), Kammesheidt et al. (2003), Dekker \& De Graaf (2003).

\subsubsection{Mortalidade}

A média anual de mortalidade, nos 22 anos de acompanhamento, ficou em torno de $2,5 \%$ ano $^{-1}$ para os tratamentos onde ocorreu exploração e desbastes (T2, T3 e T4), aproximadamente $2 \%$.ano ${ }^{-1}$ onde só ocorreu a exploração (T1) e $1 \%$.ano ${ }^{-1}$ na floresta sem intervenção (T0). Esses valores são semelhantes aos encontrados por Silva et al. (1995) em outra área explorada sem intervenção posterior, na Floresta Nacional do Tapajós, que obtiveram taxa de mortalidade de $2,2 \%$.ano ${ }^{-1}$ no período de 11 anos após a exploração e por Silva (2004) em Paragominas, onde a mortalidade média anual, sete anos após a exploração, foi de $1,82 \%$ no tratamento testemunha, $1,40 \%$ na exploração de impacto reduzido e 2,38\% no tratamento exploração convencional. Sist \& Nguyen-Thé (2002) relataram taxas médias anuais de mortalidade após exploração de cerca de 2,6\% na 
Indonésia e Higuchi et al. (1997) obtiveram valores variando de 1,6\% a 2,2\% na Amazônia Central.

As maiores taxas de mortalidade foram observadas no período logo após a exploração (1981-1983), com valores em torno de 10\%.ano ${ }^{-1}$. Essa taxa elevada se deve, além da mortalidade natural, à ocasionada pela extração das árvores comerciais e pelos danos às árvores remanescentes, devidos à derruba e ao arraste das toras. Lopes (1993) comenta que a taxa de mortalidade de árvores em decorrência da exploração madeireira é muito alta no período logo após a extração, e é causada principalmente pela derrubada e pelos danos resultantes das operações. Segundo Sist \& Nguyen-Thé (2002) a tendência é que a mortalidade seja reduzida nos anos seguintes à exploração, declinando para taxas normais após 10 anos (Jonkers, 1982; De Graaf, 1986).

Neste estudo, as taxas de mortalidade reduziram acentuadamente cinco anos após a exploração, ficando em torno de 1,8\%.ano ${ }^{-1}$. Esse valor foi similar aos encontrados por Swaine et al. (1987) em revisão de 18 áreas de floresta tropical, em condições naturais de distúrbio, cujas taxas estavam entre $1 \%$ e $2 \%$, variando de acordo com o local e o período entre as medições. Silva (1989) também encontrou declínio acentuado nas taxas de mortalidade, quatro anos após a exploração, em área semelhante na Flona Tapajós e Higuchi et al. (1997) verificaram a mesma tendência em uma floresta manejada experimentalmente em Manaus - AM, onde houve redução das taxas de mortalidade de $17 \%$.ano $^{-1}$ logo após a exploração, para cerca de $1,6 \%$.ano ${ }^{-1}$, após cinco anos.

O tratamento silvicultural para redução da área basal provocou um novo aumento nas taxas de mortalidade no período 1989-1995. Porém, esse aumento só foi verificado nos tratamentos $\mathrm{T} 3$ e $\mathrm{T} 4$, onde o desbaste foi realizado nas intensidades de $30 \%$ e $50 \%$ de redução da área basal, cujas taxas aumentaram para 3,0\%.ano ${ }^{-1}$ e 3,5\%.ano ${ }^{-1}$, respectivamente, 1 ano após a aplicação. Esse aumento provavelmente ocorreu devido a dois fatores: a inclusão das árvores aneladas nos cálculos das taxas de mortalidade; e os danos às árvores remanescentes, causados pela queda de galhos grossos ou mesmo da árvore anelada, inteira, ainda que Durrieu de Madron (1994) afirme que, em um experimento realizado em Paracou na Guiana Francesa, a queda gradual de árvores 
aneladas e/ou envenenadas causou menos danos à vegetação do entorno do que a queda de árvores vivas nas parcelas-testemunha. Esse autor também sugere que o aumento na mortalidade, quatro anos após a aplicação do tratamento, pode ter sido causado pela mortalidade de espécies pioneiras de vida curta.

Na última medição, 9 anos após a aplicação do tratamento, as taxas de mortalidade do T3 e T4 tiveram uma pequena redução para $2,5 \%$.ano ${ }^{-1}$ e $3,1 \%$.ano ${ }^{-1}$, respectivamente, porém ainda se encontram muito superiores às observadas na floresta testemunha (em torno de $1 \%$.ano ${ }^{-1}$ ), provavelmente porque algumas árvores aneladas pelo tratamento demoram muito tempo para morrer (ver Capítulo II).

Em outros experimentos com aplicação de tratamentos silviculturais, consultados na literatura, foi observada a mesma tendência de aumento da mortalidade logo após a intervenção e retorno aos níveis encontrados na área testemunha em intervalos variados de tempo, de acordo com a intensidade e o método aplicado.

Em Sarawak, na Malásia, parcelas submetidas ao desbaste de liberação apresentaram taxas de mortalidade de 14,3\%.ano ${ }^{-1}$, dois anos após a aplicação, e no período 13-14 anos após a intervenção, reduziram-se para 3,3\%.ano ${ }^{-1}$, valor equivalente ao apresentado pela floresta testemunha $\left(3,9 \%\right.$.ano $\left.{ }^{-1}\right)$ (Kammesheidt et al., 2003).

De Graaf et al. (1999), analisando vários experimentos com aplicação de tratamentos silviculturais no Suriname, observaram que a mortalidade foi bastante alta no período 3-5 anos após a aplicação do refinamento, devido aos danos provocados pela queda das árvores mortas, porém após o quinto ano, as taxas voltaram aos valores regulares, próximas as encontradas na área testemunha. Finegan \& Camacho (1999) comentam que, em um experimento realizado na Costa Rica, a mortalidade aos cinco anos após o tratamento de refinamento $\left(3,6 \%\right.$.ano $\left.{ }^{-1}\right)$ foi maior do que nas parcelas-testemunha $\left(1,97 \%\right.$.ano $\left.{ }^{-1}\right)$, porém essa diferença não foi estatisticamente significativa.

No presente estudo, o longo intervalo entre as duas medições pós-tratamento silvicultural (8 anos) e o curto tempo de acompanhamento após a aplicação, dificultou a determinação do período necessário para que as taxas de mortalidade retornem aos níveis 
apresentados pelas parcelas-controle. Novas medições do experimento, em intervalos mais curtos, serão necessárias para responder esta questão.

\subsubsection{Balanço entre ingresso e mortalidade}

O balanço entre os ingressos e a mortalidade varia de acordo com o ciclo de crescimento da floresta, após distúrbios naturais ou provocados pelo homem. Nas clareiras o recrutamento costuma ser maior que a mortalidade. Durante a fase de construção, o recrutamento e a mortalidade tendem a caminhar para um equilíbrio por um período relativamente curto, quando então a mortalidade excede os ingressos, e na fase madura, as duas taxas costumam permanecer em balanço até que um novo distúrbio provoque o reinício do processo (Uhl, 1982; Whitmore, 1984).

Neste estudo, a taxa de mortalidade só foi superior a de ingressos nos períodos logo após a exploração e logo após a aplicação do tratamento silvicultural. Porém, essas intervenções abriram clareiras na floresta e estimularam o aumento dos ingressos, principalmente nos tratamentos $\mathrm{T} 3$ e $\mathrm{T} 4$, onde o número de novos indivíduos muito superior ao número de árvores mortas.

Considerando o período total, todos os tratamentos tiveram um balanço positivo, com o número de ingressos superior a mortalidade. A maioria das espécies também apresentou maiores taxas de ingresso que mortalidade nas áreas exploradas, enquanto que na floresta testemunha, uma grande proporção de espécies mostrou igualdade entre estas taxas. De maneira geral, segundo Witmore (1984), em florestas sem interferência humana, as diferenças entre as taxas de ingressos e mortalidade são pequenas. Swaine et al. (1987) complementam, afirmando que existe um balanço dinâmico em florestas naturais, onde as árvores mortas são continuamente substituídas por novos recrutas. Diversos autores, tais como Uhl (1982), Lieberman \& Lieberman (1987), Manokaran e Kochummen (1987), Silva (1989), Carvalho (1992), Silva et al. (1995), Costa et al. (2002) entre outros, apresentaram dados experimentais confirmando essa tendência. 


\subsubsection{Crescimentos em diâmetro}

A taxa média de incremento diamétrico das árvores nas florestas tropicais varia por diversos fatores, porém, raramente é superior a 1,0 cm.ano ${ }^{-1}$ (Schmidt, 1987). Geralmente, a taxa de crescimento em diâmetro de espécies com valor comercial madeireiro nas florestas tropicais, varia entre 0,1 e 0,5 cm.ano ${ }^{-1}$ (Silva, 1989; Silva et al., 1995).

No presente estudo, considerando o período total de acompanhamento, a floresta não explorada (tratamento T0) apresentou média geral de $0,14 \mathrm{~cm} \cdot \mathrm{ano}^{-1}$. As médias do T3 $\left(0,23 \mathrm{~cm} \cdot \mathrm{ano}^{-1}\right)$ e $\mathrm{T} 4\left(0,22 \mathrm{~cm} \cdot \mathrm{ano}^{-1}\right)$ foram iguais entre si e estatisticamente superiores a T1 $\left(0,19 \mathrm{~cm} \cdot \mathrm{ano}^{-1}\right)$ e T2 $\left(0,18 \mathrm{~cm} \cdot \mathrm{ano}^{-1}\right)$.

Segundo Silva (1989), comparações entre taxas de crescimento em diferentes florestas tropicais são muito imprecisas porque diversos fatores, tais como, condições ambientais (solo, precipitação, altitude), intensidade de exploração, tratamentos silviculturais, espécies dominantes, tempo transcorrido após a última intervenção, entre outros, exercem importante influência sobre as taxas de incremento. Apesar de concordar com o autor citado, alguns estudos foram selecionados da literatura visando ilustrar a grande variabilidade do crescimento em diâmetro em diferentes situações.

Silva et al. (1995) encontraram taxa de crescimento de 0,3cm.ano ${ }^{-1}, 13$ anos após a exploração em uma área de 64ha na Floresta Nacional do Tapajós. Em Sarawak, onde foi aplicado o Sistema Malaio Modificado, Bryan (1981) verificou que nas florestas exploradas sem tratamentos silviculturais, o incremento diamétrico de todas as árvores foi de $0,6 \mathrm{~cm} \cdot a^{-1}$, enquanto que nas florestas que sofreram extração de madeira comercial e desbaste, o crescimento diamétrico foi de $0,7 \mathrm{~cm} . \mathrm{ano}^{-1}$. De Graaf (1986) no Suriname, encontrou $0,4 \mathrm{~cm} . \mathrm{ano}^{-1}$, nove anos após a exploração e Silva (2004) encontrou taxas em torno de $0,5 \mathrm{~cm}$. ano $^{-1}$ para exploração de impacto reduzido e $0,3 \mathrm{~cm}$. ano $^{-1}$ para exploração convencional, em Paragominas-PA, sete anos após a exploração de madeira.

Florestas sem intervenção humana, por outro lado, costumam apresentar taxas de crescimento inferiores às obtidas em povoamentos explorados. Silva et al. (2002) estudando o crescimento em floresta sem intervenção, em região próxima a Manaus, 
obtiveram 0,16cm.ano ${ }^{-1}$ para 272 árvores monitoradas. Veillon (1985) encontrou taxa de $0,2 \mathrm{~cm} \cdot \mathrm{ano}^{-1}$ para florestas da Venezuela e Hutchinson (1987) obteve $0,3 \mathrm{~cm} . \mathrm{ano}^{-1} \mathrm{em}$ Sarawak.

A colheita de madeira teve um efeito positivo na aceleração do crescimento em diâmetro, uma vez que provocou a abertura do dossel e diminuição da competição entre as árvores remanescentes. Porém, esse efeito começou a diminuir cinco anos após a exploração nos tratamentos onde o limite mínimo de corte foi $55 \mathrm{~cm}$ de diâmetro $(\mathrm{T} 2, \mathrm{~T} 3 \mathrm{e}$ T4) e aos sete anos após a intervenção onde o limite de corte foi $45 \mathrm{~cm}$ (T1). Após esse período, as taxas de crescimento aproximaram-se das encontradas para a floresta sem intervenção (T0).

A mesma tendência foi observada em outro experimento realizado na Flona Tapajós, onde as taxas de incremento em diâmetro reduziram acentuadamente 3 a 4 anos após a exploração (Silva, 1989; Silva et al., 1995). Similares resultados também foram descritos por Bryan (1981) em Sarawak, por De Graaf (1986) no Suriname e por Kammesheidt et al. (2003) na Malásia.

Os desbastes, aplicados em 1994, na intensidade de 30\% (T3) e 50\% (T4) de redução da área basal, promoveram nova aceleração no incremento em diâmetro, aumentando em torno de $58 \%$ as taxas de crescimento no tratamento $\mathrm{T} 3$ e em $85 \%$ no tratamento $\mathrm{T} 4$, sendo o seu efeito sentido em todas as classes diamétricas. A intensidade de $20 \%$ de redução da área basal (T2) não teve efeito sobre as taxas de crescimento, que se mantiveram próximas às encontradas na floresta testemunha.

Em floresta explorada e submetida a três diferentes regimes de tratamento silvicultural na Costa Rica, os valores do incremento em diâmetro, para árvores de espécies comerciais, dobraram nos três períodos anuais após a aplicação do tratamento de refinamento, em relação aos períodos antes da aplicação. As parcelas tratadas também apresentaram incremento em diâmetro significativamente maior do que as parcelascontrole, considerando o conjunto de todas as espécies, e separadamente as espécies comerciais e as potencias (Finegan \& Camacho, 1999). Em outro estudo realizado em Sarawak na Malásia, Kammesheidt et al. (2003) observaram que o incremento em diâmetro 
nas parcelas submetidas ao desbaste de liberação $\left(0,9\right.$ a $1,2 \mathrm{~cm} \cdot$ ano $\left.^{-1}\right)$ foi estatisticamente maior do que o obtido nas parcelas-controle $\left(0,3\right.$ a $\left.0,8 \mathrm{~cm} \cdot \mathrm{ano}^{-1}\right)$, em todas as classes de diâmetro, e que o efeito positivo do desbaste sobre as taxas de crescimento durou até aproximadamente 8-9 anos após a sua aplicação. Em floresta próxima a Manaus, Higushi et al. (1997) obtiveram incremento variando de $0,25 \mathrm{~cm} \cdot \mathrm{ano}^{-1}$ a $0,28 \mathrm{~cm} \cdot \mathrm{ano}^{-1}$ nas parcelas onde foi realizada a redução da área basal, através de anelamento de espécies indesejáveis, e em torno $0,15 \mathrm{~cm} . \mathrm{ano}^{-1}$ nas parcelas-testemunha. Na região de Mapane, no Suriname, o incremento em diâmetro das árvores de espécies comerciais foi em torno de $0,71 \mathrm{~cm} . \mathrm{ano}^{-1}$, entre o primeiro e o sexto ano após a aplicação do refinamento que reduziu em torno de $60 \%$ a área basal total, caindo para $0,39 \mathrm{~cm} \cdot \mathrm{ano}^{-1}$ no período entre o sexto e o vigésimo ano após a aplicação (De Graaf et al., 1999). Ainda no mesmo experimento, De Graaf (1986) e Jonkers (1987) observaram que após a realização do refinamento, o incremento médio anual em diâmetro das árvores comerciais com DAP acima de $5 \mathrm{~cm}$ aumentou entre $4 \%$ a $42 \%$.

Os valores obtidos no presente estudo, assim como os encontrados na literatura, mostram que o incremento em diâmetro é positivamente influenciado pelo tratamento silvicultural e, ainda que sua duração seja variada, 4-5 anos nas Filipinas (Weidelt, 1996), 8-9 anos na Malásia (Kammesheidt et al., 2003), em torno de 10 anos na península Malaia (Wyatt-Smith, 1995) e no Suriname (De Graaf et al., 1999), os tratamentos silviculturais são importantes aceleradores do crescimento, reduzindo os ciclos de corte e melhorando a qualidade do povoamento, uma vez que eliminam árvores mal formadas e reduzem a densidade de árvores de espécies com baixo ou nenhum valor comercial conhecido.

\subsubsection{Crescimento em área basal e volume}

Os incrementos em área basal e volume foram altamente influenciados pelas taxas de mortalidade, e considerando o período 1983-2003 (1 ano após a exploração até o último levantamento), o tratamento que apresentou as melhores taxas, no grupo das espécies de valor comercial, foi o T2 com $0,16 \mathrm{~m}^{2} \cdot \mathrm{ha}^{-1} \cdot \mathrm{ano}^{-1}$ e $1,9 \mathrm{~m}^{3} \cdot \mathrm{ha}^{-1} \cdot \mathrm{ano}^{-1}$, uma vez que a 
intensidade de redução da área basal foi bastante leve $(20 \%)$ e não provocou aumentos significativos nas taxas de mortalidade.

Todavia, analisando período a período, observou-se o efeito positivo dos desbastes sobre as taxas de crescimento em área basal e volume, principalmente entre as espécies de valor comercial, no período que vai de um a nove anos após sua aplicação. O tratamento T2, desbastado na intensidade mais leve (20\%), aumentou 10,5\% seu incremento em área basal e 11,8\% em volume, em relação ao período anterior. O tratamento T3, onde foi usada intensidade intermediária (30\%), mostrou o melhor desempenho, aumentando seu incremento em área basal e volume em $80 \%$ e $112 \%$, respectivamente. O tratamento T4, que no período anterior vinha apresentando taxas negativas de crescimento em área basal ($0,06 \mathrm{~m}^{2} \cdot \mathrm{ha}^{-1} \cdot$ ano $\left.^{-1}\right)$ e em volume $\left(-0,09 \mathrm{~m}^{3} \cdot \mathrm{ha}^{-1} \cdot\right.$ ano $\left.^{-1}\right)$, aumentou suas taxas para $0,14 \mathrm{~m}^{2} \cdot \mathrm{ha}^{-}$ ${ }^{1}$.ano ${ }^{-1}$ e $0,09 \mathrm{~m}^{3} \cdot \mathrm{ha}^{-1} \cdot$ ano $^{-1}$.

No Suriname, com o emprego do Sistema Silvicultural CELOS, o incremento em área basal nas áreas manejadas com uso de tratamentos silviculturais foi de $0,6 \mathrm{~m}^{2} \cdot \mathrm{ha}^{-1}$ (De Graaf, 1986). Em um experimento realizado pelo Instituto Nacional de Pesquisas da Amazônia (INPA), foram testadas diferentes intensidades de redução da área basal da floresta, em 4 tratamentos distintos: (i) sem remoção de área basal (testemunha), (ii) remoção de $25 \%$ de área basal, (iii) remoção de 50\% de área basal e (iv) remoção de 75\% de área basal. O incremento em área basal e volume das espécies "espécies listadas" (comerciais com DAP acima de $10 \mathrm{~cm}$ ) nesses estudos foi, para a testemunha, $0,07 \mathrm{~m}^{2} \cdot \mathrm{ha}^{-}$ ${ }^{1}$.ano ${ }^{-1}$ e $0,96 \mathrm{~m}^{3} \cdot \mathrm{ha}^{-1}$.ano ${ }^{-1}$; com remoção de $25 \%$ de área basal, $0,16 \mathrm{~m}^{2} \cdot \mathrm{ha}^{-1}$.ano ${ }^{-1} \mathrm{e}$

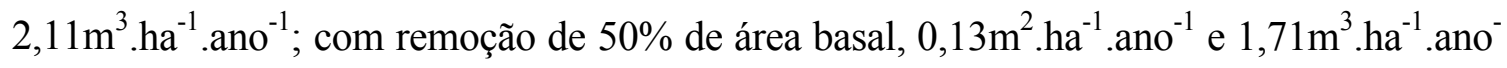
${ }^{1}$; e com remoção de $75 \%$ de área basal, $0,10 \mathrm{~m}^{2} \cdot \mathrm{ha}^{-1}$.ano ${ }^{-1}$ e $1,58 \mathrm{~m}^{3} \cdot \mathrm{ha}^{-1}$.ano ${ }^{-1}$ (Higuchi et al., 1997).

As intensidades de desbaste que mais se destacaram, em termos de incremento em área basal e volume, no estudo realizado pelo INPA foram $25 \%$ e $50 \%$ de remoção da área basal (Higuchi et al., 1997). No presente estudo, onde foram testados níveis semelhantes de redução da área basal, embora o método de aplicação tenha sido diferenciado, os tratamentos onde foram obtidos os maiores incrementos para o conjunto de espécies com 
valor comercial madeireiro, oito anos após a aplicação, foram T2 (20\% de redução da AB) com $0,14 \mathrm{~m}^{2} \cdot \mathrm{ha}^{-1} \cdot$ ano $^{-1}$ e $1,9 \mathrm{~m}^{3} \cdot \mathrm{ha}^{-1} \cdot \mathrm{ano}^{-1}$ e T3 (30\% de redução da $\left.\mathrm{AB}\right)$, com $0,18 \mathrm{~m}^{2}$.ha${ }^{1}$.ano ${ }^{-1}$ e $1,7 \mathrm{~m}^{3} \cdot$ ha $^{-1} \cdot$ ano $^{-1}$.

\subsection{Conclusão}

- A exploração de madeira e os desbastes para redução da área basal causaram grandes alterações na dinâmica da floresta, elevando as taxas de mortalidade, estimulando o aumento no número de ingressos e a aceleração nas taxas crescimento das árvores remanescentes;

- A influência das intervenções teve duração variável. O efeito da exploração sobre a dinâmica da floresta, durou em torno de cinco anos. Após esse período, as taxas de ingressos, mortalidade e crescimento foram reduzidas, aproximando-se das observadas na floresta testemunha. Em relação aos desbastes, a ausência de medições regulares nas parcelas permanentes, após sua aplicação, tornou imprecisa a estimativa do tempo em que o efeito dessa intervenção vai permanecer;

- O balanço positivo, obtido em todos os tratamentos no período monitorado, comprova que o aumento da mortalidade foi compensado pelo aumento no número de ingressos, principalmente entre as espécies de valor comercial, o que valorizou a floresta em termos de potencial madeireiro para a próxima colheita.

Comparando os tratamentos em relação a todos os parâmetros da dinâmica da floresta analisados, conclui-se que:

- O tratamento T1 (exploração de árvores com diâmetro $\geq 45,0 \mathrm{~cm}$ sem intervenção posterior) apresentou elevadas taxas de ingresso e crescimento, apenas nos primeiros anos após a exploração. Com o passar do tempo, o fechamento gradual do dossel, provavelmente elevou os níveis de competição entre as árvores remanescentes e 
provocou a redução nestas taxas que tornaram-se semelhantes as observadas na floresta testemunha;

- A intensidade de redução da área basal, utilizada no tratamento T2 (Exploração de espécies comerciais madeireiras com DAP $\geq 55 \mathrm{~cm}+$ desbaste de espécies não comerciais totalizando aproximadamente $20 \%$ de redução da área basal original) praticamente não teve efeito sobre as taxas de ingressos, mortalidade e crescimento que, assim como no tratamento T1, apresentaram redução gradual e constante ao longo do período pós-exploração em quase todos os parâmetros analisados;

- A redução de $50 \%$ da área basal utilizada no tratamento T4 (Exploração de espécies comerciais madeireiras com DAP $\geq 55 \mathrm{~cm}+$ desbaste de espécies não comerciais totalizando aproximadamente $50 \%$ de redução da área basal original), apesar de ter produzido as maiores taxas de recrutamento e crescimento em diâmetro, foi considerada muito intensa, uma vez que o aumento da mortalidade nas maiores classes de diâmetro não foi compensado pelo aumento dos ingressos em termos de área basal e volume, o que fez com que esse tratamento apresentasse taxas negativas de crescimento nestas variáveis, mesmo no grupo das espécies comerciais madeireiras.

- O tratamento T3 (exploração de árvores com diâmetro $\geq 55,0 \mathrm{~cm}$ e desbastes na intensidade de aproximadamente $30 \%$ de redução da área basal) foi considerado o mais adequado por favorecer elevadas taxas de recrutamento e crescimento em diâmetro, área basal e volume, sem elevar em demasiado a mortalidade. Estes parâmetros são bons indicativos preliminares de que a integridade da floresta está sendo mantida no contexto do aproveitamento para exploração madeireira. 


\section{CONCLUSÕES GERAIS}

Algumas conclusões gerais e recomendações podem ser feitas em relação aos tratamentos testados, considerando as análises realizadas na riqueza florística, diversidade de espécies, estrutura da floresta, ingressos de novos indivíduos, mortalidade e taxas de crescimento.

- O sistema de manejo denominado "explorar e deixar", aplicado no tratamento T1, pode levar a ciclos de corte maiores do que os demais tratamentos testados. $\mathrm{O}$ efeito positivo da abertura do dossel, promovida pela colheita de madeira, na liberação da competição entre as árvores remanescentes, começou a diminuir 7 anos após a exploração, quando as taxas de ingresso e de crescimento em diâmetro, área basal e volume apresentaram redução acentuada, aproximando-se dos baixos valores observados para a floresta testemunha. A ausência de uma nova intervenção que promovesse novas aberturas no dossel e reduzisse os níveis de competição tornou o sistema pouco eficiente na recuperação do número de árvores e área basal, extraídos da área durante a exploração. Desse modo, a extração de madeira sem intervenção posterior, embora seja um sistema muito utilizado por empresas madeireiras na região amazônica, não é recomendado para produção em ciclos de corte regulares;

- O sistema silvicultural utilizado no tratamento T2 (Exploração de espécies comerciais madeireiras com DAP $\geq 55 \mathrm{~cm}+$ desbaste de espécies não comerciais totalizando $20 \%$ de redução da área basal original), favoreceu o ingresso de algumas espécies de valor comercial madeireiro e gerou pequeno aumento na riqueza florística da comunidade. Todavia a intensidade de $20 \%$ de redução da área basal não foi suficiente para 
promover o aumento das taxas de crescimento em diâmetro e ingressos que, nos últimos períodos, foram estatisticamente iguais a floresta testemunha. $\mathrm{O}$ tratamento $\mathrm{T} 2$ mostrou também fraco desempenho na aceleração dos incrementos em área basal e volume que, após o desbaste, aumentaram apenas em torno de $10 \%$ em relação ao período anterior à aplicação;

- O tratamento T3 (Exploração de espécies comerciais madeireiras com DAP $\geq 55 \mathrm{~cm}+$ desbaste de espécies não comerciais totalizando aproximadamente $30 \%$ de redução da área basal original) induziu ao maior aumento na riqueza florística e favoreceu várias espécies de valor comercial madeireiro que aumentaram sua participação na abundância e área basal no povoamento. Esse tratamento também mostrou a maior taxa de recuperação da área basal comercial, subtraída pela exploração (aproximadamente 90\%) e as maiores taxas de incremento em área basal e volume, no grupo das espécies comerciais, após a aplicação do desbaste. Todavia, uma maneira de melhorar a eficiência do sistema, seria reduzir para aproximadamente 5 anos o intervalo de tempo entre a extração de madeira e a aplicação do refinamento, visando manter elevadas as taxas de crescimento e ingressos, e repetir sua aplicação assim que for detectada, através do monitoramento contínuo, a diminuição acentuada nesses valores;

- A abertura no dossel promovida pelo tratamento T4 (Exploração de espécies comerciais madeireiras com DAP $\geq 55 \mathrm{~cm}+$ desbaste de espécies não comerciais totalizando aproximadamente $40 \%$ de redução da área basal original) favoreceu o maior aumento no número de árvores.ha ${ }^{-1}$ no final do período e produziu as maiores taxas de recrutamento e crescimento em diâmetro. Todavia, em relação a área basal e volume sua recuperação foi inferior aos demais tratamentos, apresentando incrementos negativos, mesmo no grupo de espécies de valor comercial. O tratamento T4 também provocou os maiores distúrbios na floresta. A abertura de grandes clareiras provocou a infestação de cipós em algumas áreas e o aumento na densidade de espécies pioneiras colonizadoras de áreas abertas. 


\section{ANEXOS}


Anexo A. Listagem de todas as espécies encontradas em 10,25ha de área amostral na Floresta Nacional do Tapajós, Rodovia Santarám-Cuiabá, Km 114

\begin{tabular}{|c|c|}
\hline \multirow{2}{*}{\multicolumn{2}{|c|}{$\begin{array}{l}\text { Família/Nome botânico } \\
\text { ANACARDIACEAE }\end{array}$}} \\
\hline & \\
\hline $\begin{array}{l}\text { Anacardium giganteum Loud.ex Steud } \\
\text { Astronium gracile Engel } \\
\text { Astronium lecointei Ducke } \\
\text { Astronium sp. } \\
\text { Tapirira guianensis Aubl. }\end{array}$ & $\begin{array}{l}\text { Caju-açú } \\
\text { Aroeira } \\
\text { Muiracatiara } \\
\text { Muiracatiara-rajada } \\
\text { Tatapiririca }\end{array}$ \\
\hline $\begin{array}{l}\text { ANNONACEAE } \\
\text { Annona ambotay Aubl. } \\
\text { Annona montana Macfad. } \\
\text { Duguetia echinophora } \text { R.E. Fr. } \\
\text { Guatteria ovalifolia } \text { R.E. Fr. } \\
\text { Guatteria poeppigianaMart. Mart. } \\
\text { Guateria } \text { sp. } \\
\text { Xylopia benthamiana } \\
\text { Ni ni }\end{array}$ & $\begin{array}{l}\text { Envira-taia } \\
\text { Araticum } \\
\text { Envira-surucucu } \\
\text { Envira-cana } \\
\text { Envira-preta } \\
\text { Envira-vermelha } \\
\text { Envira-amarela } \\
\text { Annonaceae }\end{array}$ \\
\hline $\begin{array}{l}\text { APOCYNACEAE } \\
\text { Ambelania grandiflora Huber } \\
\text { Ambelania sp. } \\
\text { Aspidosperma duckei Huber } \\
\text { Aspidosperma rigidum Rusby } \\
\text { Aspidosperma desmanthum Benth. ex Müll. Arg. } \\
\text { Geissospermum sericeum (Sagot) Benth. \& Hook.f. } \\
\text { Himatanthus sucuuba (Spruce ex Müll.Arg.) Woodson } \\
\text { Malouetia } \text { sp. }\end{array}$ & $\begin{array}{l}\text { Culhão-de-bode } \\
\text { Pepino-da-mata } \\
\text { Bucheira } \\
\text { Carapanauba } \\
\text { Araracanga } \\
\text { Quinarana } \\
\text { Sucuuba } \\
\text { Cumai }\end{array}$ \\
\hline $\begin{array}{l}\text { ARALIACEAE } \\
\text { Didymopanax morototoni (Aubl.) Decne \& Planch } \\
\text { BIGNONIACEAE }\end{array}$ & Morototó \\
\hline $\begin{array}{l}\text { Jacaranda copaia (Aubl.) D.Don } \\
\text { Tabebuia impetiginosa (Mart. ex DC.) Standl. } \\
\text { Tabebuia serratifolia (Vahl) Nichols. } \\
\text { Tabebuia insignis (Miq.) Sandw. }\end{array}$ & $\begin{array}{l}\text { Parapara } \\
\text { Pau-d'arco-roxo } \\
\text { Pau-d'arco-amarelo } \\
\text { Pau-d'arco }\end{array}$ \\
\hline $\begin{array}{l}\text { BIXACEAE } \\
\text { Bixa arborea Huber } \\
\text { BOMBACACEAE }\end{array}$ & Urucu-da-mata \\
\hline $\begin{array}{l}\text { Bombax globosum Aubl. } \\
\text { Bombax paraensis Ducke }\end{array}$ & $\begin{array}{l}\text { Munguba } \\
\text { Mamorana }\end{array}$ \\
\hline
\end{tabular}


Anexo A. Listagem de todas as espécies encontradas em 10,25ha de área amostral na Floresta Nacional do Tapajós, Rodovia Santarám-Cuiabá, Km 114

\begin{tabular}{|c|c|}
\hline Família/Nome botânico & Nome vulgar \\
\hline Bombax sp. & Munguba-da-terra-firme \\
\hline Ceiba pentandra (L.) Gaertn. & Sumaúma \\
\hline Quararibea guianensis Aubl. & Inajarana \\
\hline \multicolumn{2}{|l|}{ BORAGINACEAE } \\
\hline Cordia alliodora (Ruiz \& Pavon) Oken & Uruazeiro \\
\hline Cordia bicolor DC. & Freijo-branco \\
\hline Cordia goeldiana Huber. & Freijo-cinza \\
\hline \multicolumn{2}{|l|}{ BURSERACEAE } \\
\hline Protium spruceanum Huber. & Breu-manga \\
\hline Protium opacum Swart & Breu-preto \\
\hline Protium subserratum (Engl.) Engl. & Breu-vermelho \\
\hline Protium sagotianum Marchand & Breu-branco \\
\hline Protium apiculatum Swart & Breu \\
\hline Trattinickia rhoifolia Willd. & Breu-sucuruba \\
\hline \multicolumn{2}{|l|}{ CARICACEAE } \\
\hline Jacaratia spinosa (Aubl.) A. DC. & Mamui \\
\hline \multicolumn{2}{|l|}{ CARYOCARACEAE } \\
\hline Caryocar glabrum (Aubl.) Pers. & Piquiarana \\
\hline Caryocar villosum (Aubl.) Pers. & Piquia \\
\hline \multicolumn{2}{|l|}{ CELASTRACEAE } \\
\hline Goupia glabra Aubl. & Cupiuba \\
\hline Maytenus pruinosa Reissek & Chichua \\
\hline \multicolumn{2}{|l|}{ CHRYSOBALANACEAE } \\
\hline Licania heteromorpha Benth. & Macucu \\
\hline Licania sp. & Caripé \\
\hline Parinarium barbatum & Caraiperana \\
\hline Couepia bracteosa Benth. & Pajura-da-mata \\
\hline \multicolumn{2}{|l|}{ COMBRETACEAE } \\
\hline Terminalia amazonica (J.F.Gmel) Exell. & Cuiarana \\
\hline \multicolumn{2}{|l|}{ CONNARACEAE } \\
\hline Connarus sp. & Cunário \\
\hline \multicolumn{2}{|l|}{ EBENACEAE } \\
\hline Diospyros sp. & Caqui \\
\hline \multicolumn{2}{|l|}{ ELAEOCARPACEAE } \\
\hline Sloanea froesii C.E.Sm. & Urucurana \\
\hline \multicolumn{2}{|l|}{ EUPHORBIACEAE } \\
\hline Drypetes variabilis Uittien & Maparana \\
\hline Glycidendron amazonicum Ducke & Mirindiba-doce \\
\hline Hevea sp. & Seringueira \\
\hline Joannesia heveoides Ducke & Castanha-de-arara \\
\hline Mabea sp. & Taquari \\
\hline Sagotia racemosa Baill. & Arataciu \\
\hline
\end{tabular}


Anexo A. Listagem de todas as espécies encontradas em 10,25ha de área amostral na Floresta Nacional do Tapajós, Rodovia Santarám-Cuiabá, Km 114

\begin{tabular}{|c|c|}
\hline Família/Nome botânico & Nome vulgar \\
\hline Sapium marmieri Huber R. & Murupita \\
\hline Phyllanthus nobilis (L.f.) Müll.Arg. & Aquiqui \\
\hline \multicolumn{2}{|l|}{ FABACEAE } \\
\hline Alexa grandiflora Ducke & Melancieira \\
\hline Apuleia molaris Spruce et. Benth & Amarelão \\
\hline Cassia leiandra Benth & Fava-mari-mari \\
\hline Copaifera multijuga Hayne & Copaíba \\
\hline Crudia sp. & Jutairana \\
\hline Dialium guianense (Aubl.) Sandwith & Pororoqueira \\
\hline Dinizia excelsa Ducke & Angelim-vermelho \\
\hline Diplotropis purpurea (Rich.) Amshoff & Sucupira-preta \\
\hline Dipteryx odorata (Aubl.) Willd. & Cumaru \\
\hline Enterolobium maximum Ducke & Fava-bolacha \\
\hline Enterolobium schomburgkii (Benth.) Benth. & Fava-da-rosca \\
\hline Enterolobium sp. & Fava-timbaúba \\
\hline Eperua schomburgkiana Benth. & Muirapiranga \\
\hline Eperua bijuga Benth. & Cocão \\
\hline Hymenaea courbaril L. & Jutai-açú \\
\hline Hymenaea parvifolia Huber & Jutai-mirim \\
\hline Hymenolobium excelsum Ducke & Angelim-da-mata \\
\hline Inga alba (Sw.) Willd. & Inga-xixica \\
\hline Inga heterophylla Willd. & Inga-xixi-vermelho \\
\hline Inga sp. & Ingá \\
\hline Ormosia discolor Spruce ex Benth. & Tento-folha-grauda \\
\hline Ormosia flava (Ducke) Rudd & Tento-folha-miuda \\
\hline Ormosia sp. & Tento \\
\hline Parkia pendula (Willd.)Walp. & Fava-bolota \\
\hline Parkia gigantocarpa Ducke & Fava-barriguda \\
\hline Parkia multijuga Benth. & Fava-arara-tucupi \\
\hline Parkia sp. & Muirarema \\
\hline Peltogyne paradoxa Ducke & Coataquicaua \\
\hline Piptadenia suaveolens Miq. & Faveira-folha-fina \\
\hline Pithecellobium racemosum Ducke & Angelim-rajado \\
\hline Pithecellobium cauliflorum Mart. & Ingarana \\
\hline Pithecellobium scandens Ducke & Fava \\
\hline Platymiscium filipes Benth. & Macacauba \\
\hline Pterocarpus amazonicus (Benth.) Amshoff & Mututi \\
\hline Pterocarpus rohrii Vahl & Mututi-da-terra-firme \\
\hline Schyzolobium amazonicum (Huber) Ducke & Parica \\
\hline Sclerolobium chrysophyllum Poepp. & Taxi-vermelho \\
\hline Sclerolobium guianensis Benth. & Taxi-branco \\
\hline Sclerolobium sp. & Taxi \\
\hline
\end{tabular}


Anexo A. Listagem de todas as espécies encontradas em 10,25ha de área amostral na Floresta Nacional do Tapajós, Rodovia Santarám-Cuiabá, Km 114

\begin{tabular}{|c|c|}
\hline Família/Nome botânico & Nome vulgar \\
\hline Stryphnodendron barbatimam Mart. & Barbatimão \\
\hline Stryphnodendron pulcherrimum (Willd.) Hochr. & Fava-barbatimão \\
\hline Swartzia acuminata Willd. ex Vogel & Pitaíca \\
\hline Swartzia corrugata Benth. & Coração-de-negro \\
\hline Swartzia stipulifera Harms & Gombeira \\
\hline Swartzia brachyrachis Harms & Paraputaca \\
\hline Tachigali myrmecophila (Ducke) Ducke & Taxi-preto-folha-graúda \\
\hline Tachigali sp. & Taxi-preto-folha-miúda \\
\hline Taralea oppositifolia Aublet & Cumarurana \\
\hline Vatairea sericea (Ducke)Ducke & Fava-amargosa \\
\hline Dimorphandra gardneriana Tul. & Fava-mapuchiqui \\
\hline Poecilanthe effusa (Huber)Ducke & Amarelinho \\
\hline Abarema sp. & Fava-saboeiro \\
\hline \multicolumn{2}{|l|}{ FLACOURTIACEAE } \\
\hline Casearia javitensis Kunth & Caneleira \\
\hline Laetia procera (Poepp.) Eich. & Pau-jacare \\
\hline Lindackeria paraensis Kuhlm. & Farinha-seca \\
\hline Homalium sp. & Sardinheira \\
\hline \multicolumn{2}{|l|}{ GUTTIFERAE } \\
\hline Calophyllum brasiliense Cambess. & Jacareuba \\
\hline Caraipa $\mathrm{sp}$ & Tamaquaré \\
\hline Rheedia acuminata (Ruiz \& Pav.) P1.\& Tr. & Bacuri-da-mata \\
\hline Symphonia globulifera L.f. & Anani \\
\hline Vismia cayennensis (Jacq.) Pers. & Lacre-branco \\
\hline Vismia japurensis Reichardt & Lacre-vermelho \\
\hline Vismia sp. & Lacre \\
\hline \multicolumn{2}{|l|}{ HUMIRIACEAE } \\
\hline Endopleura uchi (Huber) Cuatrec. & Uxi-liso \\
\hline Endopleura sp. & Uxi \\
\hline Saccoglottis amazonica Mart. & Uxirana \\
\hline Saccoglottis sp. & Achuá \\
\hline Ni ni & Humiriaceae \\
\hline \multicolumn{2}{|l|}{ ICACINACEAE } \\
\hline Emmotum fagifolium Ham. & Cumarui \\
\hline \multicolumn{2}{|l|}{ LACISTEMACEAE } \\
\hline Lacistema aggregatum (Bergius) Rusby & Mata-calado \\
\hline \multicolumn{2}{|l|}{ LAURACEAE } \\
\hline Aniba canelilla (Kunth) Mez & Preciosa \\
\hline Aniba duckei Kostermans & Pau-rosa \\
\hline Aniba sp. & Aniba \\
\hline Licaria cannella (Meisn.) Kosterm & Louro-preto \\
\hline Licaria armeniaca (Nees) Kosterm. & Louro-pimenta \\
\hline
\end{tabular}


Anexo A. Listagem de todas as espécies encontradas em 10,25ha de área amostral na Floresta Nacional do Tapajós, Rodovia Santarám-Cuiabá, Km 114

\begin{tabular}{|c|c|}
\hline Família/Nome botânico & Nome vulgar \\
\hline Mezilaurus itauba (Meissn.) Taub. & Itauba \\
\hline Mezilaurus lindaviana Schw. \& Mez. & Itauba-abacate \\
\hline Mezilaurus sp. & Itauba-amarela \\
\hline Ocotea canaliculata (Rich.) Mez & Louro-branco \\
\hline Ocotea rubra Mez & Louro-vermelho \\
\hline NI ni & Louro \\
\hline \multicolumn{2}{|l|}{ LECYTHIDACEAE } \\
\hline Bertholletia excelsa Bonpl. & Castanha-do-para \\
\hline Cariniana sp. & Cariniana \\
\hline Couratari oblongifolia Ducke \& Knuth & Tauari \\
\hline Eschweilera amara (Aubl.) $\mathrm{Ndz}$ & Matamata-vermelho \\
\hline Eschweilera amazonica R.Knuth & Matamata-ci \\
\hline Eschweilera blanchetiana (O.Berg) Miers & Matamata-preto \\
\hline Eschweilera odora (Poepp.) Miers. & Matamata-branco \\
\hline Eschweilera sp. & Matamata \\
\hline Gustavia augusta $\mathrm{L}$. & Jeniparana \\
\hline Holopyxidium jarana Huber ex Ducke & Jarana \\
\hline Lecythis usitata Miers & Castanha-sapucaia \\
\hline \multicolumn{2}{|l|}{ MALPIGHIACEAE } \\
\hline Byrsonima crispa A.Juss. & Muruci-da-mata \\
\hline \multicolumn{2}{|l|}{ MELASTOMATACEAE } \\
\hline Mouriria plasschaerti Pulle. & Muirauba \\
\hline Miconia guianensis (Aubl.) Cogn. & Canela-de-veado \\
\hline Miconia sp. & Papaterra \\
\hline Bellucia sp. & Muuba \\
\hline Ni ni & Passarinheira \\
\hline \multicolumn{2}{|l|}{ MELIACEAE } \\
\hline Carapa guianensis Aubl. & Andiroba \\
\hline Cedrela huberi Ducke & Cedro-branco \\
\hline Cedrela odorata $\mathrm{L}$. & Cedro-vermelho \\
\hline Guarea kunthiana A.Juss. & Andirobarana \\
\hline Guarea sp. & Jatauba \\
\hline Trichilia lecointei Ducke & Pracuuba-da-terra-firme \\
\hline Trichilia $\mathrm{sp}$. & Thichilia \\
\hline \multicolumn{2}{|l|}{ MONIMIACEAE } \\
\hline Siparuna decipiens (Tul.) A.DC. & Capitiu \\
\hline \multicolumn{2}{|l|}{ MORACEAE } \\
\hline Bagassa guianensis Aubl. & Tatajuba \\
\hline Brosimum obovata $\mathrm{L}$. & Murure \\
\hline Brosimum guianensis (Aubl.) Huber & Amapa-amargoso \\
\hline Brosimum parinarioides Ducke & Amapa-doce \\
\hline Brosimum lactescens (S.Moore) C.C.Berg & Amapai \\
\hline
\end{tabular}


Anexo A. Listagem de todas as espécies encontradas em 10,25ha de área amostral na Floresta Nacional do Tapajós, Rodovia Santarám-Cuiabá, Km 114

\begin{tabular}{|c|c|}
\hline Família/Nome botânico & Nome vulgar \\
\hline Brosimum discolor Schott & Muirapinima \\
\hline Castilla ulei Warb. & Caucho \\
\hline Cecropia leucoma Miq. & Embauba-branca \\
\hline Cecropia sciadophylla Mart. & Embauba-vermelha \\
\hline Cecropia sp. & Embauba \\
\hline Clarisia racemosa Ruiz \& Pavon & Guariuba \\
\hline Ficus anthelminthica Rich. ex DC. & Caxinguba \\
\hline Helicostylis pedunculata Benoist & Muiratinga-folha-peluda \\
\hline Lacmellea aculeata (Ducke) Monach. & Pau-de-colher \\
\hline Maquira sclerophylla (Ducke) CC Berg. & Muiratinga-folha-lisa \\
\hline Pourouma longipendula Ducke & Embaubarana \\
\hline Pourouma cecropiaefolia Mart. & Mapati \\
\hline Pourouma paraensis Huber. & Mapatirana \\
\hline Sahagunia racemifera Huber. & Janita \\
\hline Perebea guianensis Aubl. & Muiratinga \\
\hline Perebea mollis (Poepp. \& Endl.) Huber & Pama \\
\hline \multicolumn{2}{|l|}{ MYRISTICACEAE } \\
\hline Iryanthera juruensis Warb. & Ucuubarana \\
\hline Virola melinonii (Benoist) Smith & Ucuuba-da-terra-firme \\
\hline Virola cuspidata (Spruce ex Bentham) Warburg & Ucuuba-vermelha \\
\hline Virola divergens Ducke & Ucuuba-folha-peluda \\
\hline Virola sp. & Ucuuba-folha-fina \\
\hline \multicolumn{2}{|l|}{ MYRTACEAE } \\
\hline Myrcia cf. m paivae & Goiabarana \\
\hline Eugenia lambertiana DC. & Goiabinha \\
\hline Eugenia patrisii Vahl & Araçarana \\
\hline Eugenia paraensis O. Berg & Araça-da-mata \\
\hline Eugenia sp. & Eugenia \\
\hline NI ni & Murta \\
\hline \multicolumn{2}{|l|}{ NYCTAGINACEAE } \\
\hline Neea $\mathrm{sp}$ & João-mole \\
\hline \multicolumn{2}{|l|}{ OCHANACEAE } \\
\hline Ouratea cf. aquatica & Pau-de-cobra \\
\hline \multicolumn{2}{|l|}{ OLACACEAE } \\
\hline Minquartia guianensis Aubl. & Acariquara \\
\hline \multicolumn{2}{|l|}{ OPILIACEAE } \\
\hline Agonandra sp. & Marfim-preto \\
\hline \multicolumn{2}{|l|}{ POLYGONACEAE } \\
\hline Coccoloba latifólia Lam. & Tabocão \\
\hline PROTEACEAE & \\
\hline Roupala sp. & Faeira \\
\hline
\end{tabular}


Anexo A. Listagem de todas as espécies encontradas em 10,25ha de área amostral na Floresta Nacional do Tapajós, Rodovia Santarám-Cuiabá, Km 114

\begin{tabular}{|c|c|}
\hline Família/Nome botânico & Nome vulgar \\
\hline \multicolumn{2}{|l|}{ QUINACEAE } \\
\hline Lacunaria jenmani (Oliv.) Ducke & Papo-de-mutum \\
\hline \multicolumn{2}{|l|}{ RUBIACEAE } \\
\hline Capirona huberiana Ducke & Escorrega-macaco \\
\hline Chimarrhis turbinata DC. & Pau-de-remo \\
\hline Coussarea paniculata (Vahl) Standl. & Caferana \\
\hline Duroia macrophylla Huber & Cabeca-de-urubu \\
\hline Duroia sprucei Rusby & Purui \\
\hline Randia armata (Sw.) DC. & Limorana \\
\hline \multicolumn{2}{|l|}{ RUTACEAE } \\
\hline Fagara pentandra Aubl. & Tamanqueira-da-terra-firme \\
\hline \multicolumn{2}{|l|}{ SAPINDACEAE } \\
\hline Talisia longifolia (Bth.)Radlk. & Pitomba \\
\hline \multicolumn{2}{|l|}{ SAPOTACEAE } \\
\hline Manilkara huberi (Ducke) A.Chev. & Maçaranduba \\
\hline Manilkara paraensis (Huber) Standl. & Maparajuba \\
\hline Micropholis venulosa (Mart. \& Eichler) Pierre & Rosadinho \\
\hline Pouteria bilocularis (H.Winkl.) Baehni & Abiu-casca-grossa \\
\hline Pouteria guianensis Aubl. & Abiurana vermelha \\
\hline Pouteria sp. & Abiu-cutiti \\
\hline Ni ni & Abiu \\
\hline \multicolumn{2}{|l|}{ SIMARUBACEAE } \\
\hline Simaba cedron Planch. & Pau-para-tudo \\
\hline Simarouba amara Aubl. & Marupa \\
\hline \multicolumn{2}{|l|}{ SOLANACEAE } \\
\hline Solanum rugosum Dunal & Cajussara \\
\hline \multicolumn{2}{|l|}{ STERCULIACEAE } \\
\hline Sterculia pilosa Ducke ex Engl. & Axixa \\
\hline Theobroma speciosum Willd. ex Spreng. & Cacau-da-mata \\
\hline Theobroma subincanum Mart. & Cupui \\
\hline \multicolumn{2}{|l|}{ THEOPHRASTACEAE } \\
\hline Clavija lancifolia Desf. & Marapuama \\
\hline \multicolumn{2}{|l|}{ TILIACEAE } \\
\hline Apeiba albiflora Ducke & Pente-de-macaco \\
\hline Luehea speciosa Willd. & Açoita-cavalo \\
\hline \multicolumn{2}{|l|}{ VERBENACEAE } \\
\hline Aegiphilla sp. & Tamanqueira \\
\hline Vitex triflora Vahl. & Tarumã \\
\hline \multicolumn{2}{|l|}{ VIOLACEAE } \\
\hline Rinorea flavescens (Aubl.) Kuntze & Canela-de-jacamim \\
\hline Rinorea guianensis Aubl. & Acariquarana \\
\hline Rinorea macrocarpa (C. Mart. ex Eichler) Kuntze & Canela-de-velho \\
\hline
\end{tabular}


Anexo A. Listagem de todas as espécies encontradas em 10,25ha de área amostral na Floresta Nacional do Tapajós, Rodovia Santarám-Cuiabá, Km 114

Família/Nome botânico

Paypayrola grandiflora Tul.

VOCHYSIACEAE

Erisma uncinatum Warm.

Qualea sp.

Vochysia máxima Ducke

Vochysia surinamensis Stafleu
Nome vulgar

Paparola

Quarubarana

Mandioqueira

Quaruba-verdadeira

Quaruba-rosa 
Anexo B. Listagem das espécies extraídas durante a exploração de madeira, na área de cada tratamento, na Floresta Nacional do Tapajós (Km 144 da BR 163)

\begin{tabular}{|c|c|c|c|c|c|c|c|c|c|}
\hline \multirow[b]{2}{*}{ Nome científico } & \multirow{2}{*}{ Nome Vulgar } & \multicolumn{2}{|c|}{ T1 } & \multicolumn{2}{|c|}{ T2 } & \multicolumn{2}{|c|}{ T3 } & \multicolumn{2}{|c|}{ T4 } \\
\hline & & n.ha ${ }^{-1}$ & $\mathrm{~m}^{2} \cdot \mathrm{ha}^{-1}$ & n.ha ${ }^{-1}$ & $\mathrm{~m}^{2} \cdot h \mathrm{ha}^{-1}$ & n.ha ${ }^{-1}$ & $\mathrm{~m}^{2} \cdot h \mathrm{~h}^{-1}$ & n.ha $\mathrm{h}^{-1}$ & $\mathrm{~m}^{2} \cdot h \mathrm{ha}^{-1}$ \\
\hline Carapa guianensis & Andiroba & 4,8 & 1,3 & 2,3 & 0,6 & 1,0 & 0,2 & 2,0 & 0,6 \\
\hline Manilkara huberi & Maçaranduba & 2,0 & 0,7 & 1,1 & 0,2 & 2,3 & 1,0 & 2,0 & 1,0 \\
\hline Holopyxidium jarana & Jarana & 2,4 & 0,57 & 2,9 & 1,1 & 1,0 & 0,5 & 1,3 & 0,4 \\
\hline Hymenaea courbaril & Jutai-acu & 0,8 & 0,56 & 0,6 & 0,1 & 0,3 & 0,2 & - & - \\
\hline Didymopanax morototoni & Morototo & 0,4 & 0,16 & 0,6 & 0,2 & - & - & 0,7 & 0,2 \\
\hline Bertholletia excelsa & Castanha-do-para & 0,4 & 0,22 & 1,2 & 1,6 & - & - & 1,3 & 0,8 \\
\hline Vatairea sericea & Fava-amargosa & 0,4 & 0,1 & 0,6 & 0,3 & - & - & - & - \\
\hline Tabebuia serratifolia & Pau-d'arco-amarelo & - & - & 0,6 & 0,2 & 0,3 & 0,1 & - & - \\
\hline Goupia glabra & Cupiuba & - & - & - & - & 1,0 & 0,5 & 2,0 & 1,1 \\
\hline Cordia bicolor & Freijo-branco & - & - & - & - & 0,3 & 0,1 & 0,7 & 0,2 \\
\hline Trattinickia rhoifolia & Breu-sucuruba & 0,4 & 0,16 & - & - & - & - & - & - \\
\hline Caryocar glabrum & Piquiarana & 0,4 & 0,28 & - & - & - & - & - & - \\
\hline Bagassa guianensis & Tatajuba & 0,8 & 0,4 & - & - & - & - & - & - \\
\hline Pouteria bilocularis & Abiu-casca-grossa & 0,4 & 0,1 & - & - & - & - & - & - \\
\hline Astronium gracile & Aroeira & - & - & 0,6 & 0,4 & - & - & - & - \\
\hline Caryocar villosum & Piquia & - & - & 0,6 & 0,3 & - & - & - & - \\
\hline Swartzia stipulifera & Gombeira & - & - & 0,6 & 0,2 & - & - & - & - \\
\hline Ocotea rubra & Louro-vermelho & - & - & - & - & 0,3 & 0,1 & - & - \\
\hline Hymenaea parvifolia & Jutai-mirim & - & - & - & - & 0,3 & 0,1 & - & - \\
\hline Jacaranda copaia & Parapara & - & - & - & - & 0,3 & 0,1 & - & - \\
\hline Simaruba amara & Marupa & - & - & - & - & 0,3 & 0,2 & - & - \\
\hline Licaria canella & Louro-preto & - & - & - & - & - & - & 0,7 & 0,2 \\
\hline Hymenolobium excelsum & Angelim-da-mata & - & - & - & - & - & - & 0,7 & 0,4 \\
\hline
\end{tabular}

Estimativa baseada na análise das parcelas permanentes medidas antes e após a exploração 
Anexo C. Efetividade da anelagem com envenenamento, por espécie, aplicado na Floresta Nacional do Tapajós (Km 114 da BR 163)

\begin{tabular}{|c|c|c|c|c|c|}
\hline \multirow{2}{*}{ Família } & \multirow{2}{*}{ Espécies aneladas } & \multirow{2}{*}{ Nome Vulgar } & \multirow{2}{*}{\multicolumn{2}{|c|}{$\begin{array}{l}\mathrm{N}^{\mathrm{o}} \quad \text { Mortal } \\
\text { árv. tot. } \mathrm{N}^{\mathrm{o}} \text { mort. }\end{array}$}} & \multirow{2}{*}{$\begin{array}{c}\text { idade } \\
\%\end{array}$} \\
\hline & & & & & \\
\hline LEGUMINOSAE & Inga sp. & Ingá & 106 & 105 & 99,1 \\
\hline SAPOTACEAE & Pouteria sp. & Abiu & 103 & 82 & 79,6 \\
\hline VIOLACEAE & Rinorea guianensis & Acariquarana & 98 & 82 & 83,7 \\
\hline MORACEAE & Cecropia sciadophylla & Embaúba & 96 & 96 & 100 \\
\hline NYCTAGINACEAE & Neea sp. & João-mole & 41 & 16 & 39,0 \\
\hline APOCYNACEAE & Geissospermum senceum & Quinarana & 37 & 6 & 16,2 \\
\hline MORACEAE & Cecropia leucoma & Embaúba-branca & 36 & 32 & 88,9 \\
\hline LECYTHIDACEAE & Eschweilera blanchetiana & Matamatá-preto & 25 & 22 & 88,0 \\
\hline LECYTHIDACEAE & Eschweilera odora & Matamata-branco & 21 & 16 & 76,2 \\
\hline ANNONACEAE & Guatteria poeppigiana & Envira-preta & 15 & 12 & 80 \\
\hline CARICACEAE & Jacaratia spinosa & Mamui & 14 & 14 & 100 \\
\hline VIOLACEAE & Rinorea flavescens & Canela-de-jacamim & 13 & 10 & 76,9 \\
\hline VERBENACEAE & Aegiphilla sp. & Tamanqueiro & 11 & 10 & 90,9 \\
\hline MORACEAE & Sahagunia racemifera & Janita & 10 & 6 & 60 \\
\hline MORACEAE & Perebea mollis & Pama & 8 & 8 & 100 \\
\hline LEGUMINOSAE & Sclerolobium chrysophyllum & Taxi-vermelho & 8 & 8 & 100 \\
\hline ANNONACEAE & Duguetia echinophora & Envira-surucucu & 8 & 7 & 87,5 \\
\hline LECYTHIDACEAE & Eschweilera amara & Matamatá-vermelho & 8 & 7 & 87,5 \\
\hline APOCYNACEAE & Aspidosperma rigidum & Carapanauba & 8 & 1 & 12,5 \\
\hline BIXACEAE & Bixa arbórea & Urubu-da-mata & 7 & 7 & 100 \\
\hline CLUSIACEAE & Caraipa $\mathrm{sp}$. & Tamaquaré & 7 & 6 & 85,7 \\
\hline ELAEOCARPACEAE & Sloanea froesii & Urucurana & 7 & 5 & 71,4 \\
\hline EUPHORBIACEAE & Sagotia racemosa & Arataciu & 7 & 4 & 57,1 \\
\hline MELIACEAE & Guarea kunthiana & Andirobarana & 6 & 6 & 100 \\
\hline CHRYSOBALANACEAE & Licania sp. & Caraipé & 6 & 6 & 100 \\
\hline MYRISTICACEAE & Virola melinonii & Ucuuba-da-terra-firme & 6 & 6 & 100 \\
\hline MORACEAE & Maquira sclerophylla & Muiratinga-folha-lisa & 6 & 5 & 83,3 \\
\hline MYRTACEAE & Myrcia cf, m paivae & Goiabarana & 6 & 5 & 83,3 \\
\hline MORACEAE & Perebea guianensis & Muiratinga & 6 & 5 & 83,3 \\
\hline RUBIACEAE & Chimarrhis turbinata & Pau-de-remo & 6 & 2 & 33,3 \\
\hline BOMBACACEAE & Quararibea guianensis & Inajarana & 5 & 5 & 100 \\
\hline HUMIRIACEAE & Saccoglottis sp. & Achuá & 5 & 5 & 100 \\
\hline STERCULIACEAE & Theobroma speciosum & Cacau-da-mata & 5 & 5 & 100 \\
\hline EBENACEAE & Diospyros sp. & Caqui & 5 & 3 & 60 \\
\hline FLACOURTIACEAE & Casearia favitensis & Caneleira & 5 & 2 & 40 \\
\hline THEOPHRASTACEAE & Clavija lancifolia & Marapuama & 4 & 4 & 100 \\
\hline LEGUMINOSAE & Enterolobium maximum & Fava-bolacha & 4 & 4 & 100 \\
\hline LECYTHIDACEAE & Eschweilera amazonica & Matamatá-cí & 4 & 4 & 100 \\
\hline MELIACEAE & Guarea sp. & Jataúba & 4 & 4 & 100 \\
\hline LEGUMINOSAE & Inga heterophylla & Inga-xixi-vermelho & 4 & 4 & 100 \\
\hline BURSERACEAE & Protium apiculatum & Breu & 4 & 4 & 100 \\
\hline MYRISTICACEAE & Iryanthera juruensis & Ucuubarana & 4 & 3 & 75,0 \\
\hline QUIINACEAE & Lacunaria jenmani & Papo-de-mutum & 4 & 3 & 75,0 \\
\hline LEGUMINOSAE & Ormosia sp. & Tento & 4 & 3 & 75,0 \\
\hline
\end{tabular}


Anexo C. Efetividade da anelagem com envenenamento, por espécie, aplicado na Floresta Nacional do Tapajós (Km 114 da BR 163)

\begin{tabular}{|c|c|c|c|c|c|}
\hline \multirow{2}{*}{ Família } & \multirow{2}{*}{ Espécies aneladas } & \multirow{2}{*}{ Nome Vulgar } & \multirow{2}{*}{$\begin{array}{c}\mathrm{N}^{0} \\
\text { árv.tot. }\end{array}$} & \multicolumn{2}{|c|}{ Mortalidade } \\
\hline & & & & $\mathrm{N}^{\mathrm{o}}$ mort. & $\%$ \\
\hline RUBIACEAE & Duroia sprucei & Purui & 3 & 3 & 100 \\
\hline FLACOURTIACEAE & Lindackeria paraensis & Farinha-seca & 3 & 3 & 100 \\
\hline MELASTOMATACEAE & Miconia sp. & Papaterra & 3 & 3 & 100 \\
\hline MORACEAE & Porouma longipendula & Embaubarana & 3 & 3 & 100 \\
\hline LEGUMINOSAE & Swartzia acuminata & Pitaíca & 3 & 3 & 100 \\
\hline TILIACEAE & Apeiba albiflora & Pente-de-macaco & 3 & 2 & 66,7 \\
\hline MORACEAE & Brosimum guianensis & Amapa-amargoso & 3 & 2 & 66,7 \\
\hline RUBIACEAE & Duroia macrophylla & Cabeca-de-urubu & 3 & 2 & 66,7 \\
\hline VERBENACEAE & Vitex triflora & Taruma & 3 & 2 & 66,7 \\
\hline MYRTACEAE & Eugenia lambertiana & Goiaba & 3 & 1 & 33,3 \\
\hline MORACEAE & Lacmellia sculenta & Pau-de-colher & 3 & 0 & 0 \\
\hline RUBIACEAE & Coussarea paniculata & Caferana & 2 & 2 & 100 \\
\hline SAPOTACEAE & Micropholis venulosa & Rosadinho & 2 & 2 & 100 \\
\hline NI & Ni ni & ni & 2 & 2 & 100 \\
\hline VIOLACEAE & Paypayrola grandiflora & Paparola & 2 & 2 & 100 \\
\hline LEGUMINOSAE & Pterocarpus amazonicus & Mututi & 2 & 2 & 100 \\
\hline STERCULIACEAE & Sterculia pilosa & Axixa & 2 & 2 & 100 \\
\hline LEGUMINOSAE & Piptadenia suaveolens & faveira-folha-fina & 2 & 1 & 50 \\
\hline LEGUMINOSAE & Stryphnodendron barbatim & Barbatimao & 2 & 1 & 50 \\
\hline SAPINDACEAE & Talisia longifolia & Pitomba & 2 & 1 & 50 \\
\hline MELIACEAE & Trichilia lecointei & Pracuuba-da-terra-firme & 2 & 1 & 50 \\
\hline COMBRETACEAE & Terminalia amazonica & Cuiarana & 2 & 0 & 0 \\
\hline MORACEAE & Brosimum lactescens & Amapai & 1 & 1 & 100 \\
\hline MORACEAE & Brosimum obovata & Murure & 1 & 1 & 100 \\
\hline MALPIGHIACEAE & Byrsonima crispa & Muruci-da-mata & 1 & 1 & 100 \\
\hline MORACEAE & Clarisia racemosa & Guariuba & 1 & 1 & 100 \\
\hline MYRTACEAE & Eugenia sp. & Goiabinha & 1 & 1 & 100 \\
\hline ANNONACEAE & Guatteria sp. & Envira & 1 & 1 & 100 \\
\hline CHRYSOBALANACEAE & Licania heteromorpha & Macucu & 1 & 1 & 100 \\
\hline TILIACEAE & Luehea speciosa & Acoita-cavalo & 1 & 1 & 100 \\
\hline APOCYNACEAE & Malouetia sp. & Cumai & 1 & 1 & 100 \\
\hline CELASTRACEAE & Maytenus pruinosa & Chichua & 1 & 1 & 100 \\
\hline LAURACEAE & Mezilaurus lindaviana & Itauba-abacate & 1 & 1 & 100 \\
\hline LAURACEAE & Ocotea sp. & Louro & 1 & 1 & 100 \\
\hline MONIMIACEAE & Siparuna decipiens & Capitiu & 1 & 1 & 100 \\
\hline LEGUMINOSAE & Swartzia brachyrachis & Paraputaca & 1 & 1 & 100 \\
\hline MYRISTICACEAE & Virola cuspidata & Ucuuba-vermelha & 1 & 1 & 100 \\
\hline MYRISTICACEAE & Virola divergens & Ucuuba-folha-peluda & 1 & 1 & 100 \\
\hline ANNONACEAE & Guatteria ovalifolia & Envira-cana & 1 & 0 & 0 \\
\hline MELASTOMATACEAE & Mouriria plasschaerti & Muirauba & 1 & 0 & 0 \\
\hline MYRTACEAE & Myrcia sp. & Murta & 1 & 0 & 0 \\
\hline EUPHORBIACEAE & Phyllanthus nobilis & Aquiqui & 1 & 0 & 0 \\
\hline SAPOTACEAE & Pouteria bilocularis & Abiu-casca-grossa & 1 & 0 & 0 \\
\hline ANNONACEAE & Xylopia benthamiana & Envira-amarela & 1 & 0 & 0 \\
\hline $\begin{array}{r}\text { Total } \\
\end{array}$ & --- & --- & 874 & 706 & 80,8 \\
\hline
\end{tabular}


Anexo D. Valores do teste de normalidade de Shapiro Wilks e do teste F da análise de variância, obtidos para o número de árvores total e número de árvores de espécies comerciais, em cada tratamento e a cada ano de medição, na Floresta Nacional do Tapajós (Km 114 da BR 163)

\begin{tabular}{|c|c|c|c|c|c|c|}
\hline \multirow{2}{*}{ Tratamentos } & \multirow{2}{*}{$\begin{array}{l}1 \text { ano antes } \\
\text { exploração }\end{array}$} & \multicolumn{5}{|c|}{ Anos após a exploração } \\
\hline & & 1 & 5 & 7 & 13 & 21 \\
\hline \multicolumn{7}{|c|}{$\mathrm{N}^{0}$ árvores.ha $^{-1}$ (todas as espécies) } \\
\hline $\mathrm{T} 1$ & $1122,4^{\mathrm{a}}$ & $957,2^{\mathrm{a}}$ & $1219,2^{\mathrm{a}}$ & $1227,6^{\mathrm{a}}$ & $1238,8^{\mathrm{a}}$ & $1166,4^{\mathrm{a}}$ \\
\hline $\mathrm{T} 2$ & $1121,1^{\mathrm{a}}$ & $1017,1^{\mathrm{a}}$ & $1153,1^{\mathrm{a}}$ & $1186,9^{\mathrm{a}}$ & $1140,0^{\mathrm{a}}$ & $1143,4^{\mathrm{a}}$ \\
\hline $\mathrm{T} 3$ & $1097,0^{\text {a }}$ & $958,7^{\mathrm{a}}$ & $1201,3^{\mathrm{a}}$ & $1264,7^{\mathrm{a}}$ & $1209,7^{\mathrm{a}}$ & $1314,0^{\mathrm{b}}$ \\
\hline $\mathrm{T} 4$ & $1138,7^{\mathrm{a}}$ & $957,3^{\mathrm{a}}$ & $1242,0^{\mathrm{a}}$ & $1312,7^{\mathrm{a}}$ & $1203,3^{\mathrm{a}}$ & $1378,7^{b}$ \\
\hline \multicolumn{7}{|c|}{ Teste de Normalidade } \\
\hline W & 0,98 & 0,95 & 0,94 & 0,93 & 0,97 & 0,97 \\
\hline $\operatorname{Pr}>W$ & 0,91 & 0,17 & 0,05 & 0,05 & 0,42 & 0,60 \\
\hline \multicolumn{7}{|c|}{ Análise de variância } \\
\hline $\mathrm{F}$ & 0,66 & 0,25 & 0,63 & 1,34 & 1,27 & 11,02 \\
\hline $\operatorname{Pr}>\mathrm{F}$ & 0,59 & 0,86 & 0,60 & 0,28 & 0,30 & $<0,0001$ \\
\hline \multicolumn{7}{|c|}{ № árvores.ha ${ }^{-1}$ (espécies com valor comercial) } \\
\hline $\mathrm{T} 1$ & $168,4^{\mathrm{a}}$ & $142,8^{\mathrm{a}}$ & $193,2^{\mathrm{a}}$ & $212,4^{\mathrm{a}}$ & $217,6^{\mathrm{a}}$ & $220,0^{\mathrm{a}}$ \\
\hline $\mathrm{T} 2$ & $194,8^{\mathrm{a}}$ & $169,7^{\mathrm{a}}$ & $218,2^{\mathrm{a}}$ & $233,1^{\mathrm{a}}$ & $234,2^{\mathrm{a}}$ & $240,0^{\mathrm{ab}}$ \\
\hline $\mathrm{T} 3$ & $213,0^{\mathrm{a}}$ & $174,7^{\mathrm{a}}$ & $234,0^{\mathrm{a}}$ & $251,3^{\mathrm{a}}$ & $275,7^{\mathrm{a}}$ & $314,0^{b c}$ \\
\hline $\mathrm{T} 4$ & $193,3^{\mathrm{a}}$ & $162,7^{\mathrm{a}}$ & $238,7^{\mathrm{a}}$ & $263,4^{\mathrm{a}}$ & $268,7^{\mathrm{a}}$ & $333,3^{\mathrm{c}}$ \\
\hline \multicolumn{7}{|c|}{ Teste de Normalidade } \\
\hline W & 0,94 & 0,95 & 0,98 & 0,96 & 0,94 & 0,87 \\
\hline $\operatorname{Pr}>W$ & 0,06 & 0,13 & 0,75 & 0,23 & 0,07 & 0,25 \\
\hline \multicolumn{7}{|c|}{ Análise de variância } \\
\hline $\mathrm{F}$ & 2,13 & 1,19 & 0,80 & 0,71 & 1,59 & 6,32 \\
\hline $\operatorname{Pr}>\mathrm{F}$ & 0,12 & 0,33 & 0,51 & 0,56 & 0,21 & 0,0021 \\
\hline
\end{tabular}

As médias de número de árvores comerciais para os anos 5, 7 e 21 após a exploração foram transformadas através do $\log$ para obter a normalidade dos valores; $\mathrm{Pr}>\mathrm{W}$ Valores de probabilidade acima de 0,05 , aceita-se a normalidade dos dados; $\operatorname{Pr}>$ F Valores de probabilidade acima de 0,05 são considerados não significativos, ou seja, aceita-se a hipótese nula; médias seguidas pela mesma letra na posição vertical não apresentam diferenças estatísticas significativas. 
Anexo E. Listagem das 40 espécies mais abundantes $\left(\mathrm{n}^{0}\right.$ de árvores.ha $\left.{ }^{-1}\right)$ no tratamento $\mathrm{T} 1$ (2,5 ha), considerando árvores com DAP $\geq 5,0 \mathrm{~cm}$. Floresta Nacional do Tapajós ( $\mathrm{km} 114$ da BR 163)

\begin{tabular}{|c|c|c|c|c|c|c|c|}
\hline \multirow{2}{*}{ Espécies } & \multirow{2}{*}{ GR } & \multirow{2}{*}{$\begin{array}{l}1 \text { ano antes } \\
\text { explor. }\end{array}$} & \multicolumn{5}{|c|}{ Anos após a exploração } \\
\hline & & & 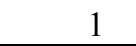 & 5 & 7 & 13 & 21 \\
\hline Bixa arborea & PP & 6,0 & 9,6 & 36,8 & 44,8 & 43,2 & 38,4 \\
\hline Carapa guianensis & $\mathrm{CT}$ & 12,8 & 6,8 & 6,8 & 7,2 & 7,2 & 7,2 \\
\hline Casearia favitensis & NT & 16,0 & 12,0 & 11,6 & 11,6 & 12,4 & 11,2 \\
\hline Cecropia leucoma & NP & 0,8 & 0,8 & 30,0 & 26,0 & 13,2 & 7,6 \\
\hline Cecropia sciadophylla & NP & - & - & 54,0 & 53,2 & 43,2 & 31,6 \\
\hline Cordia alliodora & $\mathrm{CP}$ & 3,2 & 3,6 & 7,6 & 8,8 & 9,6 & 8,4 \\
\hline Cordia bicolor & $\mathrm{CP}$ & 1,2 & 2,4 & 8,4 & 10,0 & 8,8 & 8,0 \\
\hline Couratari oblongifolia & $\mathrm{CT}$ & 12,0 & 11,6 & 11,6 & 11,6 & 11,6 & 11,6 \\
\hline Duguetia echinophora & NT & 58,0 & 44,8 & 42,8 & 42,4 & 39,2 & 37,2 \\
\hline Duroia sprucei & NT & 10,0 & 9,2 & 8,0 & 7,6 & 7,6 & 7,6 \\
\hline Eperua bifuga & NT & 10,0 & 9,6 & 9,6 & 9,2 & 8,8 & 7,6 \\
\hline Eschweilera amazônica & NT & 16,0 & 15,2 & 15,2 & 16,0 & 16,0 & 16,8 \\
\hline Eschweilera blanchetian & NT & 30,8 & 23,2 & 22,8 & 22,4 & 21,6 & 22,8 \\
\hline Eschweilera odora & NT & 20,0 & 19,6 & 20,4 & 20,4 & 18,0 & 18,4 \\
\hline Eugenia lambertiana & NT & 14,8 & 11,6 & 12,0 & 12,8 & 13,2 & 14,0 \\
\hline Geissospermum senceum & NT & 8,4 & 7,2 & 7,6 & 8,4 & 8,8 & 8,8 \\
\hline Guarea kunthiana & PT & 38,0 & 31,6 & 31,6 & 30,8 & 27,6 & 23,2 \\
\hline Guarea sp. & NT & 8,8 & 6,8 & 7,2 & 6,8 & 6,4 & 5,2 \\
\hline Guatteria poeppigiana & PT & 16,0 & 11,6 & 16,8 & 18,8 & 17,2 & 15,6 \\
\hline Inga sp.(10 esp.) & NP & 35,2 & 30,8 & 81,6 & 104,4 & 111,2 & 89,2 \\
\hline Jacaranda copaia & $\mathrm{CP}$ & - & 0,8 & 28,0 & 31,6 & 27,2 & 21,6 \\
\hline Lauraceae (9 esp.) & PT & 29,6 & 24,8 & 27,2 & 27,6 & 31,2 & 27,2 \\
\hline Licaria canella & $\mathrm{CT}$ & 12,4 & 9,6 & 8,8 & 10,4 & 10,8 & 13,6 \\
\hline Minquartia guianensis & $\mathrm{CT}$ & 10,4 & 9,2 & 9,2 & 9,6 & 8,8 & 8,4 \\
\hline Neea sp. & NT & 24,4 & 21,2 & 22,8 & 22,4 & 22,4 & 23,2 \\
\hline Paypayrola grandiflora & NT & 10,4 & 6,4 & 6,8 & 6,8 & 6,8 & 6,0 \\
\hline Perebea guianensis & PT & 20,8 & 15,2 & 16,0 & 16,0 & 14,8 & 14,8 \\
\hline Pouteria bilocularis & $\mathrm{CT}$ & 6,4 & 6,4 & 6,4 & 6,8 & 6,8 & 6,8 \\
\hline Protium apiculatum & PT & 55,2 & 46,4 & 50,8 & 54,8 & 56,4 & 63,6 \\
\hline Rinorea flavescens & NT & 148,0 & 128,8 & 124,4 & 118,0 & 108,4 & 98,4 \\
\hline Rinorea guianensis & NT & 68,0 & 59,2 & 55,2 & 52,8 & 51,2 & 48,0 \\
\hline Sagotia racemosa & NT & 19,6 & 16,4 & 16,0 & 14,4 & 15,6 & 16,0 \\
\hline Sahagunia racemifera & NT & 7,2 & 6,8 & 7,2 & 6,8 & 6,8 & 6,8 \\
\hline Sapotaceae (9 esp.) & NT & 75,2 & 63,6 & 67,2 & 66,8 & 66,0 & 68,0 \\
\hline Sclerolobium chrysophyllum & $\mathrm{CP}$ & 17,2 & 16,0 & 20,4 & 20,8 & 22,4 & 21,6 \\
\hline Sloanea froesii & NP & 10,4 & 14,0 & 18,0 & 18,4 & 12,8 & 9,6 \\
\hline Sterculia pilosa & PP & 7,2 & 7,6 & 8,0 & 8,4 & 8,4 & 9,2 \\
\hline Talisia longifolia & NT & 14,0 & 13,6 & 14,8 & 16,0 & 16,0 & 17,6 \\
\hline Trichilia sp. & NT & 8,4 & 6,8 & 6,4 & 6,4 & 6,0 & 6,0 \\
\hline Virola melinonii & $\mathrm{CT}$ & 6,8 & 6,8 & 8,0 & 8,0 & 9,6 & 10,8 \\
\hline \multirow[t]{2}{*}{ Total (40 espécies) } & \multirow[t]{2}{*}{-} & 869,6 & 747,6 & 964,0 & 996,0 & 953,2 & 887,6 \\
\hline & & $(77,5 \%)$ & $(78,1 \%)$ & $(79,1 \%)$ & $(81,1 \%)$ & $(76,9 \%)$ & $(76,1 \%)$ \\
\hline \multirow[t]{2}{*}{ Demais espécies } & \multirow[t]{2}{*}{-} & 252,8 & 209,6 & 255,2 & 231,6 & 285,6 & 278,8 \\
\hline & & $(22,5 \%)$ & $(21,9 \%)$ & $(20,9 \%)$ & $(18,9 \%)$ & $(23,1 \%)$ & $(23,9 \%)$ \\
\hline Total Geral & - & 1122,4 & 957,2 & 1219,2 & 1227,6 & 1238,8 & 1166,4 \\
\hline
\end{tabular}

CT: comercial tolerante, CP: comercial pioneira, PT: potencial tolerante, PP: potencial pioneira, NT: não comercial tolerante, NP: não comercial pioneira 
Anexo F. Listagem das 40 espécies mais abundantes ( $\mathrm{n}^{0}$ de árvores.ha $\left.{ }^{-1}\right)$ no tratamento T2 (1,75 ha), considerando árvores com DAP $\geq 5,0 \mathrm{~cm}$. Floresta Nacional do Tapajós $(\mathrm{km} 114$ da BR 163)

\begin{tabular}{|c|c|c|c|c|c|c|c|}
\hline \multirow{2}{*}{ Espécies } & \multirow{2}{*}{ GR } & \multirow{2}{*}{$\begin{array}{l}1 \text { ano antes } \\
\text { explor. }\end{array}$} & \multicolumn{5}{|c|}{ Anos após a exploração } \\
\hline & & & 1 & 5 & 7 & 13 & 21 \\
\hline Bixa arborea & $\mathrm{PP}$ & 0,6 & 0,6 & 10,9 & 14,3 & 12,6 & 12,6 \\
\hline Carapa guianensis & $\mathrm{CT}$ & 13,7 & 10,3 & 9,7 & 8,6 & 8,6 & 8,6 \\
\hline Casearia favitensis & NT & 8,0 & 7,4 & 9,1 & 8,6 & 7,4 & 7,4 \\
\hline Cecropia leucoma & NP & - & 0,6 & 8,0 & 9,7 & 6,9 & 2,9 \\
\hline Cecropia sciadophylla & NP & 0,6 & 0,6 & 11,4 & 12,0 & 10,9 & 9,7 \\
\hline Cordia bicolor & $\mathrm{CP}$ & 6,3 & 6,3 & 9,1 & 11,4 & 11,4 & 10,3 \\
\hline Couratari oblongifolia & $\mathrm{CT}$ & 12,0 & 12,6 & 13,1 & 13,7 & 14,3 & 13,7 \\
\hline Duguetia echinophora & NT & 20,0 & 21,1 & 21,7 & 22,9 & 16,0 & 18,3 \\
\hline Eschweilera amazonica & NT & 10,9 & 11,4 & 12,0 & 12,0 & 11,4 & 10,3 \\
\hline Eschweilera blanchetiana & NT & 28,0 & 23,4 & 22,9 & 22,3 & 21,1 & 20,6 \\
\hline Eschweilera odora & NT & 26,9 & 25,1 & 24,6 & 24,6 & 22,9 & 22,9 \\
\hline Eugenia lambertiana & NT & 6,9 & 5,7 & 8,6 & 8,6 & 9,7 & 8,6 \\
\hline Geissospermum senceum & NT & 11,4 & 10,3 & 10,3 & 10,3 & 10,3 & 11,4 \\
\hline Guarea kunthiana & PT & 38,9 & 32,6 & 32,0 & 29,7 & 27,4 & 23,4 \\
\hline Guarea sp. & NT & 12,6 & 12,6 & 13,7 & 12,6 & 12,0 & 12,0 \\
\hline Guatteria poeppigiana & PT & 16,0 & 16,0 & 17,7 & 16,6 & 16,0 & 18,3 \\
\hline Inga sp.(10 esp.) & NP & 49,7 & 45,1 & 61,7 & 69,7 & 74,3 & 74,9 \\
\hline Jacaranda copaia & $\mathrm{CP}$ & 2,9 & 3,4 & 38,3 & 45,1 & 42,9 & 33,7 \\
\hline Laetia procera & $\mathrm{CP}$ & 1,7 & 1,7 & 4,6 & 9,7 & 11,4 & 13,7 \\
\hline Lauraceae (9 esp.) & PT & 27,4 & 22,3 & 22,9 & 23,4 & 20,6 & 20,0 \\
\hline Licaria canella & $\mathrm{CT}$ & 12,6 & 10,9 & 10,3 & 9,7 & 8,6 & 10,9 \\
\hline Manilkara huberi & $\mathrm{CT}$ & 6,9 & 5,7 & 6,9 & 7,4 & 6,9 & 6,3 \\
\hline Minquartia guiane & $\mathrm{CT}$ & 21,7 & 20,6 & 20,6 & 20,6 & 20,0 & 18,9 \\
\hline Neea sp. & NT & 29,7 & 23,4 & 25,7 & 24,6 & 21,7 & 20,6 \\
\hline Paypayrola grandiflora & NT & 9,7 & 7,4 & 8,6 & 7,4 & 6,9 & 6,9 \\
\hline Perebea guianensis & PT & 21,7 & 17,1 & 17,7 & 17,7 & 16,0 & 15,4 \\
\hline Pouteria bilocularis & $\mathrm{CT}$ & 6,9 & 6,9 & 7,4 & 7,4 & 7,4 & 7,4 \\
\hline Protium apiculatum & PT & 68,0 & 63,4 & 65,7 & 67,4 & 66,3 & 69,1 \\
\hline Rinorea flave. & NT & 147,4 & 150,3 & 153,1 & 149,7 & 142,9 & 141,1 \\
\hline Rinorea guianensis & NT & 60,0 & 57,1 & 58,3 & 55,4 & 52,0 & 51,4 \\
\hline Sagotia racemosa & NT & 13,7 & 9,1 & 9,7 & 10,3 & 10,3 & 10,3 \\
\hline Sahagunia racemifera & NT & 10,9 & 10,3 & 8,6 & 8,6 & 8,0 & 8,0 \\
\hline Sapotaceae (9 esp.) & NT & 77,7 & 72,6 & 73,7 & 74,9 & 69,1 & 68,0 \\
\hline Sclerolobium chrysophyllum & $\mathrm{CP}$ & 8,0 & 6,3 & 8,0 & 9,1 & 9,1 & 9,1 \\
\hline Sloanea froesii & NP & 6,9 & 8,0 & 20,3 & 12,6 & 12,0 & 13,1 \\
\hline Sterculia pilosa & PP & 6,9 & 6,3 & 7,4 & 8,0 & 8,6 & 9,7 \\
\hline Tachigalia $\mathrm{sp}$. & PP & 10,9 & 8,6 & 11,4 & 12,0 & 10,9 & 9,1 \\
\hline Talisia longifólia & NT & 17,1 & 14,3 & 16,0 & 16,6 & 17,7 & 17,7 \\
\hline Theobroma speciosum & NT & 10,3 & 8,6 & 8,6 & 9,1 & 8,6 & 9,1 \\
\hline Virola melinonii & $\mathrm{CT}$ & 9,1 & 8,0 & 8,0 & 8,0 & 7,4 & 10,3 \\
\hline Total (40 espécies) & - & $\begin{array}{r}850,3 \\
(75,8 \%)\end{array}$ & $\begin{array}{r}784,0 \\
(77,1 \%)\end{array}$ & $\begin{array}{r}908,3 \\
(78,8 \%)\end{array}$ & $\begin{array}{r}922,3 \\
(77,7 \%)\end{array}$ & $\begin{array}{r}878,3 \\
(77,0 \%)\end{array}$ & $\begin{array}{r}865,7 \\
(75,7 \%)\end{array}$ \\
\hline & & 270,8 & 233,1 & 244,8 & 264,6 & 261,7 & 277,7 \\
\hline Dentilas esp & - & $(24,2 \%)$ & $(22,9 \%)$ & $(21,2 \%)$ & $(22,3 \%)$ & $(23,0 \%)$ & $(24,3 \%)$ \\
\hline Total Geral & - & 1121,1 & 1017,1 & 1153,1 & 1186,9 & 1140,0 & 1143,4 \\
\hline
\end{tabular}

CT: comercial tolerante, CP: comercial pioneira, PT: potencial tolerante, PP: potencial pioneira, NT: não comercial tolerante, NP: não comercial pioneira 
Anexo G. Listagem das 40 espécies mais abundantes $\left(\mathrm{n}^{\mathrm{o}}\right.$ de árvores.ha $\left.{ }^{-1}\right)$ no tratamento T3 (3,0 ha), considerando árvores com DAP $\geq 5,0 \mathrm{~cm}$. Floresta Nacional do Tapajós $(\mathrm{km} 114$ da BR 163)

\begin{tabular}{|c|c|c|c|c|c|c|c|}
\hline \multirow{2}{*}{ Espécies } & \multirow{2}{*}{ GR } & \multirow{2}{*}{$\begin{array}{l}1 \text { ano antes } \\
\text { explor. }\end{array}$} & \multicolumn{5}{|c|}{ Anos após a exploração } \\
\hline & & & 1 & 5 & 7 & 13 & 21 \\
\hline Carapa guianensis & CT & 15,7 & 13,7 & 15,0 & 14,0 & 14,7 & 14,3 \\
\hline Cесropia lеисота & NP & 1,0 & 1,7 & 22,7 & 24,0 & 8,7 & 5,3 \\
\hline Cecropia sciadophylla & NP & 0,0 & 0,0 & 22,7 & 27,3 & 5,7 & 3,0 \\
\hline Cordia alliodora & $\mathrm{CP}$ & 9,3 & 8,7 & 11,3 & 12,0 & 13,7 & 13,0 \\
\hline Cordia bicolor & $\mathrm{CP}$ & 4,0 & 3,0 & 7,3 & 10,3 & 10,3 & 10,3 \\
\hline Couratari oblongifolia & $\mathrm{CT}$ & 11,7 & 10,3 & 10,0 & 10,3 & 12,0 & 16,0 \\
\hline Duguetia echinophora & NT & 50,7 & 44,3 & 49,3 & 48,0 & 43,7 & 50,7 \\
\hline Eschweilera blanchetiana & NT & 22,0 & 18,7 & 19,7 & 19,7 & 17,3 & 16,3 \\
\hline Eschweilera odora & NT & 22,7 & 22,7 & 23,7 & 22,7 & 22,3 & 21,0 \\
\hline Eugenia lambertiana & NT & 20,3 & 19,7 & 20,0 & 21,7 & 21,0 & 23,7 \\
\hline Geissospermum sencet & NT & 10,7 & 9,7 & 11,0 & 12,0 & 12,3 & 16,3 \\
\hline Guarea kunthiana & PT & 21,0 & 17,3 & 16,7 & 16,7 & 15,7 & 17,7 \\
\hline Guarea sp. & NT & 9,0 & 7,7 & 8,7 & 9,0 & 10,0 & 10,0 \\
\hline Guatteria poeppigiana & PT & 17,7 & 15,0 & 17,7 & 16,7 & 14,7 & 16,7 \\
\hline Inga sp. (10 esp.) & NP & 73,7 & 70,7 & 109,0 & 127,7 & 116,0 & 137,7 \\
\hline Jacaranda copaia & $\mathrm{CP}$ & 2,3 & 2,3 & 36,3 & 39,3 & 41,3 & 37,3 \\
\hline Lacunaria jenmani & NT & 9,3 & 7,0 & 8,0 & 7,7 & 8,3 & 7,7 \\
\hline Laetia procera & $\mathrm{CP}$ & 0,7 & 0,3 & 8,0 & 12,7 & 13,3 & 13,7 \\
\hline e (9 esp.) & $\mathrm{PT}$ & 37,7 & 31,3 & 34,0 & 34,3 & 30,7 & 29,7 \\
\hline Licania sp. & NT & 7,3 & 7,3 & 9,7 & 9,7 & 9,3 & 5,7 \\
\hline Licaria canella & $\mathrm{CT}$ & 16,3 & 12,3 & 13,7 & 15,0 & 19,7 & 25,3 \\
\hline Maquira sclerophylla & PT & 9,7 & 9,0 & 8,7 & 8,3 & 9,3 & 11,3 \\
\hline Neea sp. & NT & 52,0 & 48,3 & 51,3 & 52,0 & 48,7 & 51,3 \\
\hline Paypayrola grandiflora & NT & 13,0 & 10,0 & 10,7 & 10,3 & 10,0 & 9,0 \\
\hline Perebea guianensis & PT & 25,3 & 18,7 & 20,7 & 20,7 & 21,3 & 25,7 \\
\hline Pithec & $\mathrm{CP}$ & 7,0 & 7,3 & 8,7 & 8,7 & 8,3 & 8,7 \\
\hline Pouteria biloc & CT & 15,0 & 13,7 & 13,7 & 3,7 & 14,3 & 14,3 \\
\hline Protium apiculatum & PT & 68,0 & 57,3 & 67,3 & 71,7 & 78,0 & 105,3 \\
\hline Quar & NT & 8,3 & 7,3 & 9,3 & 9,3 & 9,3 & 10,0 \\
\hline Rinorea flavescens & NT & 25,0 & 23,3 & 26,7 & 26,0 & 28,7 & 31,0 \\
\hline Rinorea guianensis & NT & 62,7 & 56,0 & 54,0 & 51,3 & 47,0 & 28,3 \\
\hline Sagotia racemosa & NT & 12,3 & 10,7 & 11,7 & 11,7 & 11,0 & 16,0 \\
\hline Sapotaceae (9 esp.) & NT & 79,7 & 72,7 & 75,3 & 75,3 & 65,3 & 55,3 \\
\hline Sclerolobium chryso & $\mathrm{CP}$ & 10,7 & 10,7 & 12,3 & 12,7 & 12,3 & 13,0 \\
\hline Sloan & NP & 7,7 & 7,0 & 12,0 & 15,0 & 14,3 & 12,7 \\
\hline Ster & PI & 7,7 & 7,0 & 10,0 & 10,3 & 10,3 & 11,7 \\
\hline Tachigalia sp. & PP & 6,7 & 7,0 & 11,0 & 14,7 & 12,3 & 10,7 \\
\hline Talisia longifolia & NT & 17,0 & 13,3 & 14,3 & 14,7 & 16,0 & 20,0 \\
\hline Theobroma speciosum & NT & 11,3 & 11,0 & 12,0 & 12,0 & 12,0 & 11,3 \\
\hline Virola melinonii & $\mathrm{CT}$ & 12,0 & 8,0 & 9,0 & 9,7 & 10,3 & 14,7 \\
\hline Total (40 espécies) & - & $\begin{array}{r}814,0 \\
(74,2 \%)\end{array}$ & $\begin{array}{r}722,0 \\
(75,3 \%)\end{array}$ & $\begin{array}{r}913,0 \\
(76,0 \%)\end{array}$ & $\begin{array}{r}948,7 \\
(75 \%)\end{array}$ & $\begin{array}{r}899,6 \\
(74,4 \%)\end{array}$ & $\begin{array}{r}951,7 \\
(72,4 \%)\end{array}$ \\
\hline Demais espécies & - & 283,0 & 236,7 & 288,3 & 316,0 & 310,1 & $\begin{array}{r}362,3 \\
27, \%\end{array}$ \\
\hline Total Geral & - & $\begin{array}{r}(25,8 \%) \\
1097,0\end{array}$ & $\begin{array}{l}4,7 \%) \\
958,7\end{array}$ & $\begin{array}{r}(24,0 \%) \\
1201,3\end{array}$ & $\begin{array}{c}(25,0 \%) \\
1264,7\end{array}$ & $\begin{array}{r}25,6 \%) \\
1209,7\end{array}$ & $\begin{array}{l}(27,6 \%) \\
1314,0\end{array}$ \\
\hline
\end{tabular}

CT: comercial tolerante, $\mathrm{CP}$ : comercial pioneira, PT: potencial tolerante, PP: potencial pioneira, NT: não comercial tolerante, NP: não comercial pioneira. 
Anexo H. Listagem das 40 espécies mais abundantes $\left(\mathrm{n}^{0}\right.$ de árvores.ha $\left.{ }^{-1}\right)$ no tratamento $\mathrm{T} 4(1,5 \mathrm{ha})$, considerando árvores com DAP $\geq 5,0 \mathrm{~cm}$. Floresta Nacional do Tapajós $(\mathrm{km} 114$ da BR 163)

\begin{tabular}{|c|c|c|c|c|c|c|c|}
\hline \multirow{2}{*}{ Espécies } & \multirow{2}{*}{ GR } & \multirow{2}{*}{$\begin{array}{l}1 \text { ano antes } \\
\text { explor. }\end{array}$} & \multicolumn{5}{|c|}{ Anos após a exploração } \\
\hline & & & 1 & 5 & 7 & 13 & 21 \\
\hline Aegiphylla sp. & NP & 0,0 & 0,0 & 12,7 & 17,3 & 15,3 & 8,0 \\
\hline Bixa arborea & PP & 6,0 & 4,7 & 8,7 & 9,3 & 12,7 & 23,3 \\
\hline Carapa guianensis & $\mathrm{CT}$ & 16,0 & 13,3 & 13,3 & 14,0 & 15,3 & 18,0 \\
\hline Casearia favitensis & NT & 9,3 & 10,7 & 10,7 & 11,3 & 11,3 & 14,0 \\
\hline Cecropia leucoma & NP & 1,3 & 2,7 & 38,0 & 36,7 & 14,7 & 8,0 \\
\hline Cecropia sciadophylla & NP & 0,0 & 0,7 & 40,7 & 44,7 & 4,7 & 2,0 \\
\hline Codia alliodora & $\mathrm{CT}$ & 4,0 & 4,0 & 8,7 & 9,3 & 8,7 & 12,7 \\
\hline Cordia bicolor & $\mathrm{CP}$ & 12,7 & 7,3 & 10,7 & 13,3 & 12,7 & 17,3 \\
\hline Couratari oblongifolia & CT & 14,7 & 12,0 & 11,3 & 11,3 & 12,7 & 14,0 \\
\hline Coussarea paniculata & NT & 13,3 & 9,3 & 10,0 & 9,3 & 9,3 & 6,7 \\
\hline Duguetia echinophora & NT & 29,3 & 29,3 & 31,3 & 31,3 & 28,7 & 28,7 \\
\hline Eschweilera amazonica & NT & 13,3 & 10,0 & 10,0 & 12,0 & 10,7 & 9,3 \\
\hline Eschweilera blanchetiana & NT & 22,0 & 18,0 & 17,3 & 18,0 & 18,7 & 18,7 \\
\hline Eschweilera odora & NT & 26,0 & 22,7 & 22,7 & 24,0 & 23,3 & 19,3 \\
\hline Eugenia lambertiana & NT & 12,0 & 10,0 & 12,0 & 13,3 & 14,0 & 13,3 \\
\hline Guarea kunthiana & PT & 29,3 & 28,0 & 28,7 & 29,3 & 24,0 & 21,3 \\
\hline Guarea sp. & NT & 10,7 & 9,3 & 10,0 & 10,7 & 9,3 & 8,0 \\
\hline Guatteria poeppigiana & $\mathrm{PT}$ & 21,3 & 14,7 & 13,3 & 15,3 & 14,0 & 15,3 \\
\hline Inga sp. (10 esp.) & NP & 60,7 & 43,3 & 98,0 & 113,3 & 100,0 & 180,7 \\
\hline Iryanthera juruensis & CT & 8,7 & 8,7 & 8,0 & 8,0 & 7,3 & 6,7 \\
\hline Jacaranda copaia & $\mathrm{CP}$ & 0,0 & 0,0 & 41,3 & 54,7 & 58,0 & 52,0 \\
\hline Laetia procera & $\mathrm{CP}$ & 0,7 & 0,7 & 7,3 & 12,0 & 18,0 & 19,3 \\
\hline Lauraceae (9 esp.) & $\mathrm{PT}$ & 28,0 & 24,7 & 29,3 & 29,3 & 30,7 & 31,3 \\
\hline Licaria canella & CT & 18,7 & 18,7 & 18,0 & 18,7 & 16,7 & 20,7 \\
\hline Minquartia guianensis & $\mathrm{CT}$ & 9,3 & 8,7 & 8,0 & 8,7 & 7,3 & 7,3 \\
\hline Neea sp. & NT & 34,0 & 30,7 & 31,3 & 28,7 & 26,0 & 30,0 \\
\hline Perebea guianensis & $\mathrm{PT}$ & 22,0 & 17,3 & 19,3 & 18,7 & 17,3 & 18,0 \\
\hline Protium apiculatum & $\mathrm{PT}$ & 83,3 & 63,3 & 64,7 & 65,3 & 73,3 & 84,0 \\
\hline Quararibea guianensis & NT & 10,0 & 9,3 & 12,0 & 12,7 & 12,7 & 16,7 \\
\hline Rinorea flavescens & NT & 119,3 & 106,0 & 112,0 & 114,7 & 114,7 & 111,3 \\
\hline Rinorea guianensis & NT & 60,7 & 52,0 & 53,3 & 50,7 & 42,7 & 38,7 \\
\hline Sagotia racemosa & NT & 13,3 & 12,0 & 11,3 & 12,0 & 12,0 & 14,0 \\
\hline Sapotaceae (9 esp.) & NT & 76,7 & 65,3 & 66,7 & 68,0 & 56,0 & 54,0 \\
\hline Sclerolobium chrysophyllum & $\mathrm{CP}$ & 10,0 & 8,7 & 8,7 & 9,3 & 6,7 & 14,0 \\
\hline Sloan & $\mathrm{NI}$ & 8,0 & 9,3 & 21,3 & 28,0 & 28,7 & 23,3 \\
\hline Sterculia pilosa & PP & 7,3 & 8,0 & 8,0 & 7,3 & 9,3 & 13,3 \\
\hline Tachigalia myrmecophyla & $\mathrm{CP}$ & 1,3 & 0,7 & 2,7 & 3,3 & 10,7 & 16,7 \\
\hline Talisia longifolia & NT & 11,3 & 10,0 & 9,3 & 8,7 & 7,3 & 12,7 \\
\hline Theobroma speciosum & NT & 8,0 & 8,0 & 8,0 & 9,3 & 10,7 & 14,7 \\
\hline Virola melinonii & $\mathrm{CT}$ & 8,0 & 7,3 & 7,3 & 7,3 & 7,3 & 19,3 \\
\hline Total (40 espécies) & - & $\begin{array}{r}840,7 \\
(73,8 \%)\end{array}$ & $\begin{array}{r}719,3 \\
(75,1 \%)\end{array}$ & $\begin{array}{r}956,0 \\
(77,0 \%)\end{array}$ & $\begin{array}{r}1019,3 \\
(77,6 \%)\end{array}$ & $\begin{array}{r}933,4 \\
(77,6 \%)\end{array}$ & $\begin{array}{r}1056,7 \\
(76,6 \%)\end{array}$ \\
\hline Demais espécies & - & 298,1 & 238,0 & 286,0 & 293,4 & 270,0 & 322,0 \\
\hline & & & & $\% \%)$ & $(22,4 \%)$ & $(22,4 \%)$ & $(23,4 \%)$ \\
\hline Total Geral & - & 1138,7 & 957,3 & 1242,0 & 1312,7 & 1203,3 & 13 \\
\hline
\end{tabular}

CT: comercial tolerante, CP: comercial pioneira, PT: potencial tolerante, PP: potencial pioneira, NT: não comercial tolerante, NP: não comercial pioneira 
Anexo I. Listagem das 40 espécies mais abundantes $\left(\mathrm{n}^{0}\right.$ de árvores.ha $\left.{ }^{-1}\right)$ no tratamento T0 (1,75 ha), considerando árvores com DAP $\geq 5,0 \mathrm{~cm}$. Floresta Nacional do Tapajós $(\mathrm{km} 114$ da BR 163)

\begin{tabular}{|c|c|c|c|c|c|c|}
\hline \multirow{2}{*}{ Espécies } & \multirow{2}{*}{ GR } & \multicolumn{5}{|c|}{ Anos de medição } \\
\hline & & 1983 & 1987 & 1989 & 1995 & 2003 \\
\hline Rinorea guianensis & NT & 86,0 & 86,0 & 85,3 & 84,7 & 86,0 \\
\hline Protium apiculatum & PT & 68,7 & 70,0 & 72,0 & 75,3 & 81,3 \\
\hline Duguetia echinophora & NT & 66,7 & 68,0 & 69,3 & 72,7 & 72,0 \\
\hline Sapotaceae (9 esp.) & NT & 59,3 & 58,7 & 59,3 & 58,7 & 56,7 \\
\hline Inga sp. (10 esp.) & NP & 46,0 & 48,0 & 48,0 & 46,0 & 44,0 \\
\hline Eperua bifuga & NT & 35,3 & 34,0 & 34,7 & 31,3 & 30,0 \\
\hline Eschweilera blanchetiana & NT & 29,3 & 29,3 & 30,0 & 27,3 & 28,7 \\
\hline Eschweilera odora & NT & 28,7 & 28,7 & 28,0 & 29,3 & 28,7 \\
\hline Sclerolobium chrysophyllum & $\mathrm{CP}$ & 22,7 & 26,7 & 26,7 & 26,0 & 23,3 \\
\hline Lauraceae (9 esp.) & PT & 22,7 & 20,7 & 22,0 & 21,3 & 20,7 \\
\hline Perebea guianensis & PT & 22,7 & 23,3 & 23,3 & 24,0 & 24,0 \\
\hline Guarea kunthiana & PT & 20,7 & 19,3 & 20,0 & 24,0 & 25,3 \\
\hline Eugenia lambertiana & NT & 19,3 & 18,7 & 19,3 & 19,3 & 17,3 \\
\hline Neea $\mathrm{sp}$ & NT & 18,7 & 20,0 & 20,0 & 21,3 & 20,0 \\
\hline Guatteria poeppigiana & PT & 17,3 & 16,0 & 16,0 & 15,3 & 14,7 \\
\hline Sloanea froesii & NP & 17,3 & 19,3 & 18,7 & 16,7 & 14,7 \\
\hline Manilkara huberi & $\mathrm{CT}$ & 14,7 & 14,7 & 14,7 & 13,3 & 13,3 \\
\hline Carapa guianensis & $\mathrm{CT}$ & 14,0 & 14,0 & 13,3 & 12,7 & 12,0 \\
\hline Sterculia pilosa & PP & 14,0 & 12,7 & 13,3 & 14,0 & 14,0 \\
\hline Couratari oblongifolia & CT & 12,7 & 12,0 & 12,7 & 12,7 & 11,3 \\
\hline Licaria canella & CT & 12,0 & 10,0 & 10,0 & 9,3 & 9,3 \\
\hline Talisia longifolia & NT & 11,3 & 11,3 & 10,7 & 11,3 & 11,3 \\
\hline Minquartia guianensis & CT & 10,7 & 11,3 & 10,0 & 12,7 & 12,7 \\
\hline Rinorea flavescens & NT & 10,7 & 12,0 & 14,0 & 15,3 & 17,3 \\
\hline Theobroma speciosum & NT & 10,0 & 9,3 & 9,3 & 9,3 & 8,0 \\
\hline Eschweilera amara & NT & 9,3 & 10,0 & 10,0 & 9,3 & 9,3 \\
\hline Casearia favitensis & NT & 9,3 & 10,0 & 9,3 & 8,7 & 9,3 \\
\hline Mezilaurus lindaviana & CT & 8,7 & 8,7 & 8,7 & 8,7 & 10,0 \\
\hline Holopyxidium jarana & $\mathrm{CT}$ & 8,7 & 8,7 & 8,7 & 8,7 & 8,0 \\
\hline Iryanthera juruensis & CT & 8,7 & 8,0 & 8,0 & 8,7 & 8,7 \\
\hline Geissospermum senceum & NT & 8,0 & 8,0 & 8,0 & 8,0 & 8,0 \\
\hline Ormosia sp. & PP & 7,3 & 7,3 & 6,0 & 6,0 & 6,7 \\
\hline Eschweilera amazonica & NT & 7,3 & 7,3 & 8,7 & 10,0 & 10,7 \\
\hline Sagotia racemosa & NT & 7,3 & 7,3 & 6,7 & 8,7 & 9,3 \\
\hline Paypayrola grandiflora & NT & 7,3 & 7,3 & 7,3 & 8,7 & 8,7 \\
\hline Pouteria bilocularis & $\mathrm{CT}$ & 6,7 & 6,7 & 6,7 & 6,7 & 6,7 \\
\hline Lacunaria jenmani & NT & 6,7 & 6,7 & 8,0 & 7,3 & 8,0 \\
\hline Cordia alliodora & $\mathrm{CP}$ & 5,3 & 6,0 & 6,0 & 7,3 & 8,7 \\
\hline Vismia cayennensis & NP & 5,3 & 8,0 & 10,7 & 9,3 & 8,0 \\
\hline Hymenaea courbaril & CT & 5,3 & 6,0 & 6,0 & 6,0 & 6,0 \\
\hline Total (40 espécies) & & $\begin{array}{r}802,7 \\
(76,0 \%)\end{array}$ & $\begin{array}{r}810,0 \\
(976,7 \%)\end{array}$ & $\begin{array}{r}819,3 \\
(77,2 \%)\end{array}$ & $\begin{array}{r}826,0 \\
(77,3 \%)\end{array}$ & $\begin{array}{r}822,7 \\
(77,2 \%)\end{array}$ \\
\hline Demais esnécie & & 254,0 & 246,0 & 242,7 & 242,7 & 243,3 \\
\hline Dema1s especies & & $(24,0 \%)$ & $(23,35 \%)$ & $(22,8 \%)$ & $(22,7 \%)$ & $(22,8 \%)$ \\
\hline Total Geral & & 1056,7 & 1056,0 & 1062,0 & 1068,7 & 1066,0 \\
\hline
\end{tabular}

CT: comercial tolerante, CP: comercial pioneira, PT: potencial tolerante, PP: potencial pioneira, NT: não comercial tolerante, NP: não comercial pioneira 
Anexo J. Valores do teste de normalidade de Shapiro Wilks e do teste F da análise de variância, obtidos para o área basal total e área basal de espécies comerciais, em cada tratamento e a cada ano de medição, na Floresta Nacional do Tapajós (Km 114 da BR 163)

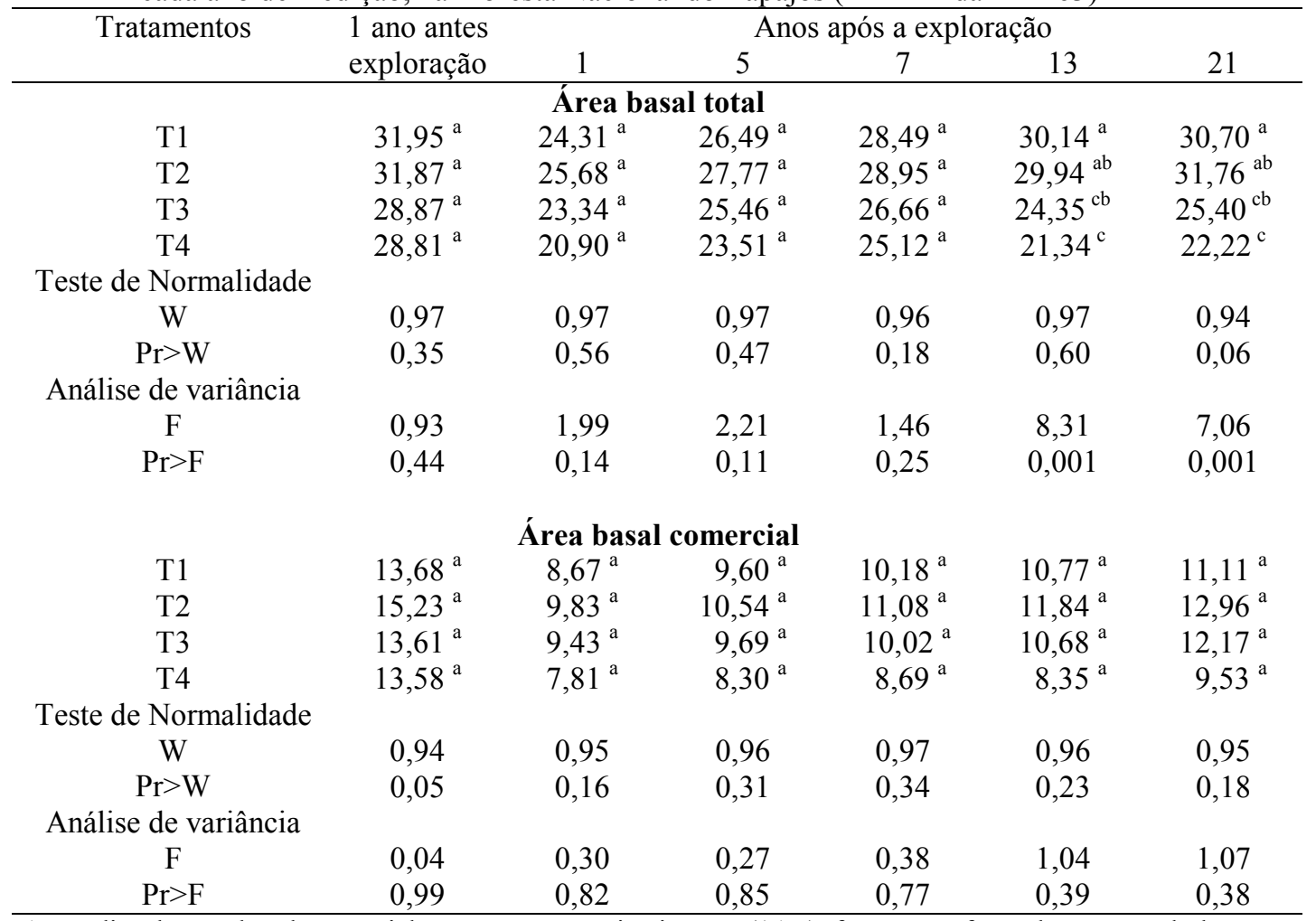

As médias de área basal comercial, exceto para o primeiro ano (1 $\mathrm{AE}$ ), foram transformadas através do log para obter a normalidade dos valores; $\operatorname{Pr}>\mathrm{W}$ : Valores de probabilidade acima de 0,05 , aceita-se a normalidade dos dados; Pr $>\mathrm{F}$ : Valores de probabilidade acima de 0,05 são considerados não significativos, ou seja, aceita-se a hipótese nula; médias seguidas pela mesma letra na posição vertical não apresentam diferenças estatísticas significativas. 
Anexo K. Listagem das 40 espécies dominantes $\left(\mathrm{m}^{2} \cdot \mathrm{ha}^{-1}\right)$ no tratamento $\mathrm{T} 1$ (2,5ha), considerando árvores com DAP $\geq 5,0 \mathrm{~cm}$. Floresta Nacional do Tapajós (km 114 da BR 163)

\begin{tabular}{|c|c|c|c|c|c|c|c|}
\hline \multirow{2}{*}{ Espécies } & \multirow{2}{*}{ GR } & \multirow{2}{*}{$\begin{array}{l}1 \text { ano antes } \\
\text { explor. }\end{array}$} & \multicolumn{5}{|c|}{ Anos após a exploração } \\
\hline & & & 1 & 5 & 7 & 13 & 21 \\
\hline Anacardium giganteum & $\mathrm{CP}$ & 0,15 & 0,16 & 0,18 & 0,20 & 0,23 & 0,28 \\
\hline Apeiba albiflora & PP & 0,29 & 0,28 & 0,31 & 0,32 & 0,35 & 0,33 \\
\hline Bixa arborea & PP & 0,25 & 0,20 & 0,37 & 0,47 & 0,64 & 0,66 \\
\hline Brosimum lactescens & PT & 0,30 & 0,23 & 0,24 & 0,25 & 0,17 & 0,19 \\
\hline Carapa guianensis & $\mathrm{CT}$ & 1,73 & 0,34 & 0,39 & 0,42 & 0,43 & 0,48 \\
\hline Cecropia leucoma & NP & 0,01 & 0,02 & 0,19 & 0,30 & 0,35 & 0,32 \\
\hline Cecropia sciadophylla & NP & 0,00 & 0,00 & 0,56 & 1,22 & 2,17 & 2,40 \\
\hline Couratari oblongifolia & $\mathrm{CT}$ & 0,96 & 0,95 & 1,02 & 1,06 & 1,10 & 0,91 \\
\hline Duguetia echinophora & NT & 0,53 & 0,42 & 0,40 & 0,40 & 0,36 & 0,36 \\
\hline Enterolobium maximum & $\mathrm{CP}$ & 0,30 & 0,32 & 0,37 & 0,39 & 0,45 & 0,52 \\
\hline Enterolobium schomburgkii & $\mathrm{CP}$ & 0,24 & 0,24 & 0,26 & 0,27 & 0,28 & 0,29 \\
\hline Eschweilera amazônica & NT & 0,30 & 0,27 & 0,20 & 0,28 & 0,30 & 0,33 \\
\hline Eschweilera blanchetiana & NT & 0,78 & 0,72 & 0,80 & 0,81 & 0,82 & 0,87 \\
\hline Eschweilera odora & NT & 0,24 & 0,24 & 0,26 & 0,26 & 0,27 & 0,28 \\
\hline Geissospermum senceum & NT & 0,67 & 0,47 & 0,51 & 0,52 & 0,54 & 0,56 \\
\hline Guarea kunthiana & PT & 0,40 & 0,35 & 0,38 & 0,39 & 0,35 & 0,33 \\
\hline Guatteria poeppigiana & PT & 0,37 & 0,30 & 0,30 & 0,32 & 0,34 & 0,25 \\
\hline Holopyxidium jarana & $\mathrm{CT}$ & 1,09 & 0,22 & 0,23 & 0,24 & 0,24 & 0,26 \\
\hline Inga sp. (10 esp.) & NP & 0,65 & 0,62 & 0,84 & 1,11 & 1,50 & 1,62 \\
\hline Iryanthera juruensis & $\mathrm{CT}$ & 0,89 & 0,79 & 0,82 & 0,84 & 0,86 & 0,58 \\
\hline Jacaranda copaia & $\mathrm{CP}$ & 0,00 & 0,00 & 0,15 & 0,20 & 0,28 & 0,40 \\
\hline Lauraceae (9 esp.) & PT & 0,60 & 0,51 & 0,50 & 0,46 & 0,50 & 0,52 \\
\hline Licaria canella & $\mathrm{CT}$ & 0,27 & 0,25 & 0,26 & 0,25 & 0,27 & 0,32 \\
\hline Manilkara huberi & $\mathrm{CT}$ & 0,98 & 0,27 & 0,30 & 0,33 & 0,39 & 0,46 \\
\hline Mezilaurus lindaviana & $\mathrm{CT}$ & 0,21 & 0,20 & 0,21 & 0,21 & 0,22 & 0,22 \\
\hline Minquartia guianensis & $\mathrm{CT}$ & 1,13 & 1,11 & 1,17 & 1,21 & 1,27 & 1,15 \\
\hline Neea $\mathrm{sp}$ & NT & 0,42 & 0,43 & 0,48 & 0,50 & 0,49 & 0,42 \\
\hline Parkia gigantocarpa & $\mathrm{CP}$ & 0,37 & 0,39 & 0,44 & 0,48 & 0,27 & 0,36 \\
\hline Parkia multijuga & $\mathrm{CP}$ & 0,16 & 0,18 & 0,21 & 0,23 & 0,28 & 0,35 \\
\hline Pouteria bilocularis & $\mathrm{CT}$ & 0,81 & 0,73 & 0,76 & 0,79 & 0,82 & 0,88 \\
\hline Protium apiculatum & PT & 0,67 & 0,63 & 0,65 & 0,67 & 0,68 & 0,72 \\
\hline Protium spruceanum & PT & 0,33 & 0,22 & 0,23 & 0,23 & 0,24 & 0,19 \\
\hline Rinorea flavescens & NT & 0,64 & 0,58 & 0,58 & 0,56 & 0,52 & 0,50 \\
\hline Rinorea guianensis & NT & 1,75 & 1,49 & 1,46 & 1,45 & 1,48 & 1,46 \\
\hline Sapotaceae (9 esp.) & NT & 1,90 & 1,67 & 1,80 & 1,86 & 1,98 & 2,06 \\
\hline Sclerolobium chrysophyllum & $\mathrm{CP}$ & 0,62 & 0,67 & 0,80 & 0,85 & 0,78 & 0,77 \\
\hline Sloanea froesii & NP & 0,34 & 0,37 & 0,45 & 0,48 & 0,49 & 0,52 \\
\hline Swartzia acuminata & NT & 0,75 & 0,79 & 0,89 & 0,93 & 0,59 & 0,70 \\
\hline Tachigalia myrmecophyla & $\mathrm{CP}$ & 0,04 & 0,04 & 0,08 & 0,11 & 0,21 & 0,34 \\
\hline Virola melinonii & $\mathrm{CT}$ & 0,27 & 0,20 & 0,24 & 0,26 & 0,32 & 0,39 \\
\hline Total (40 espécies) & - & $\begin{array}{r}22,4 \\
(70,1 \%)\end{array}$ & $\begin{array}{r}17,9 \\
(73,4 \%)\end{array}$ & $\begin{array}{r}20,2 \\
(76,4 \%)\end{array}$ & $\begin{array}{r}22,1 \\
(77,6 \%)\end{array}$ & $\begin{array}{r}23,8 \\
(78,9 \%)\end{array}$ & $\begin{array}{r}24,5 \\
(79,9 \%)\end{array}$ \\
\hline Demais espécies & - & $\begin{array}{r}9,6 \\
(29,9 \%)\end{array}$ & $\begin{array}{r}6,5 \\
(26,6 \%)\end{array}$ & $\begin{array}{r}6,2 \\
(23,6 \%)\end{array}$ & $\begin{array}{r}6,4 \\
(22,4 \%)\end{array}$ & $\begin{array}{r}6,4 \\
(21,1 \%)\end{array}$ & $\begin{array}{r}6,2 \\
(20,1 \%)\end{array}$ \\
\hline Total Geral & - & 31,95 & 24,31 & 26,49 & 28,49 & 30,14 & 30,7 \\
\hline
\end{tabular}


Anexo L. Listagem das 40 espécies dominantes $\left(\mathrm{m}^{2} \cdot \mathrm{ha}^{-1}\right)$ no tratamento T2 (1,75 ha), considerando árvores com DAP $\geq 5,0 \mathrm{~cm}$. Floresta Nacional do Tapajós (km 114 da BR 163)

\begin{tabular}{|c|c|c|c|c|c|c|c|}
\hline \multirow{2}{*}{ Espécies } & \multirow{2}{*}{ GR } & \multirow{2}{*}{$\begin{array}{l}1 \text { ano antes } \\
\text { explor. }\end{array}$} & \multicolumn{5}{|c|}{ Anos após a exploração } \\
\hline & & & 1 & 5 & 7 & 13 & 21 \\
\hline Apeiba albiflora & PP & 0,17 & 0,18 & 0,20 & 0,20 & 0,21 & 0,23 \\
\hline Apuleia molaris & $\mathrm{CP}$ & 0,28 & 0,27 & 0,28 & 0,28 & 0,29 & 0,29 \\
\hline Brosimum obovata & PT & 0,47 & 0,49 & 0,53 & 0,57 & 0,60 & 0,66 \\
\hline Carapa guianensis & $\mathrm{CT}$ & 1,53 & 0,83 & 0,91 & 0,73 & 0,81 & 0,91 \\
\hline Cecropia sciadophylla & NP & 0,06 & 0,06 & 0,14 & 0,28 & 0,60 & 0,94 \\
\hline Chimarrhis turbinata & NT & 0,34 & 0,35 & 0,37 & 0,37 & 0,26 & 0,28 \\
\hline Cordia bicolor & $\mathrm{CP}$ & 0,17 & 0,19 & 0,23 & 0,27 & 0,28 & 0,30 \\
\hline Couratari oblongifolia & $\mathrm{CT}$ & 1,08 & 1,12 & 1,17 & 1,23 & 1,28 & 1,33 \\
\hline Crudia sp. & $\mathrm{PT}$ & 0,16 & 0,17 & 0,17 & 0,18 & 0,19 & 0,20 \\
\hline Eperua schomburgkiana & CT & 0,19 & 0,22 & 0,26 & 0,28 & 0,35 & 0,36 \\
\hline Eschweilera amara & NT & 0,68 & 0,71 & 0,76 & 0,80 & 0,62 & 0,55 \\
\hline Eschweilera blanchetiana & NT & 0,44 & 0,45 & 0,50 & 0,51 & 0,52 & 0,55 \\
\hline Eschweilera odora & NT & 0,49 & 0,49 & 0,53 & 0,53 & 0,51 & 0,54 \\
\hline Geissospermum senceum & NT & 1,17 & 1,07 & 1,13 & 1,15 & 1,18 & 1,15 \\
\hline Guarea kunthiana & PT & 0,59 & 0,52 & 0,54 & 0,52 & 0,52 & 0,54 \\
\hline Guarea sp & NT & 0,20 & 0,20 & 0,22 & 0,19 & 0,19 & 0,17 \\
\hline Guatteria poeppigiana & $\mathrm{PT}$ & 0,31 & 0,29 & 0,34 & 0,35 & 0,35 & 0,37 \\
\hline Holopyxidium jarana & CT & 1,29 & 0,17 & 0,19 & 0,19 & 0,20 & 0,21 \\
\hline Hymenaea courbaril & CT & 0,29 & 0,15 & 0,17 & 0,18 & 0,21 & 0,25 \\
\hline Inga sp. (10 esp.) & NP & 0,76 & 0,69 & 0,92 & 1,09 & 1,22 & 1,08 \\
\hline Iryanthera juruensis & CT & 0,42 & 0,40 & 0,29 & 0,29 & 0,13 & 0,14 \\
\hline Jacaranda copaia & $\mathrm{CP}$ & 0,17 & 0,19 & 0,39 & 0,51 & 0,73 & 0,78 \\
\hline Lauraceae (9 esp.) & PT & 0,55 & 0,45 & 0,49 & 0,53 & 0,59 & 0,66 \\
\hline Licaria canella & $\mathrm{CT}$ & 0,32 & 0,32 & 0,20 & 0,21 & 0,18 & 0,22 \\
\hline Manilkara huberi & CT & 0,55 & 0,32 & 0,36 & 0,38 & 0,42 & 0,48 \\
\hline Maquira sclerophylla & PT & 0,38 & 0,29 & 0,32 & 0,34 & 0,36 & 0,38 \\
\hline Mezilaurus itauba & $\mathrm{CT}$ & 0,23 & 0,23 & 0,24 & 0,25 & 0,25 & 0,27 \\
\hline Minquartia guianensis & $\mathrm{CT}$ & 2,23 & 2,24 & 2,39 & 2,46 & 2,58 & 2,73 \\
\hline Neea $\mathrm{sp}$ & NT & 0,37 & 0,31 & 0,30 & 0,26 & 0,24 & 0,23 \\
\hline Parkia gigantocarpa & $\mathrm{CP}$ & 0,13 & 0,16 & 0,21 & 0,25 & 0,36 & 0,54 \\
\hline Piptadenia suaveolens & PP & 0,21 & 0,22 & 0,23 & 0,24 & 0,27 & 0,33 \\
\hline Pouteria bilocularis & CT & 0,45 & 0,47 & 0,50 & 0,52 & 0,40 & 0,44 \\
\hline Protium apiculatum & PT & 0,99 & 1,05 & 1,16 & 1,24 & 1,32 & 1,44 \\
\hline Rinorea flavescens & NT & 0,65 & 0,67 & 0,70 & 0,71 & 0,68 & 0,68 \\
\hline Rinorea guianensis & NT & 1,51 & 1,49 & 1,49 & 1,45 & 1,34 & 1,41 \\
\hline Sapotaceae (9 esp.) & NT & 1,82 & 1,82 & 1,94 & 1,87 & 1,71 & 1,82 \\
\hline Sclerolobium chrysophyllum & $\mathrm{CP}$ & 0,49 & 0,33 & 0,49 & 0,61 & 0,94 & 0,87 \\
\hline Stryphnodendron barbatimam & NT & 0,21 & 0,19 & 0,20 & 0,22 & 0,23 & 0,25 \\
\hline Swartzia acuminata & NT & 0,22 & 0,21 & 0,25 & 0,27 & 0,27 & 0,01 \\
\hline Virola melinonii & CT & 0,44 & 0,44 & 0,24 & 0,26 & 0,26 & 0,33 \\
\hline Total (40 espécies) & - & $\begin{array}{r}23,0 \\
(72,1 \%)\end{array}$ & $\begin{array}{r}20,4 \\
(79,5 \%)\end{array}$ & $\begin{array}{r}22,0 \\
(79,1 \%)\end{array}$ & $\begin{array}{r}22,7 \\
(78,6 \%)\end{array}$ & $\begin{array}{r}23,6 \\
(78,9 \%)\end{array}$ & $\begin{array}{r}24,9 \\
(78,4 \%)\end{array}$ \\
\hline Demais espécies & - & $\begin{array}{r}8,9 \\
(27,9 \%)\end{array}$ & $\begin{array}{r}5,3 \\
(20,5 \%)\end{array}$ & $\begin{array}{r}5,8 \\
(20,9 \%)\end{array}$ & $\begin{array}{r}6,2 \\
(21,4 \%)\end{array}$ & $\begin{array}{r}6,3 \\
(21.1 \%)\end{array}$ & $\begin{array}{r}6,9 \\
(21,6 \%)\end{array}$ \\
\hline Total Geral & - & 31,87 & 25,68 & 27,77 & 28,95 & 29,94 & 31,76 \\
\hline
\end{tabular}


Anexo M. Listagem das 40 espécies dominantes $\left(\mathrm{m}^{2} \cdot \mathrm{ha}^{-1}\right)$ no tratamento $\mathrm{T} 3$ (3,0 ha), considerando árvores com DAP $\geq 5,0 \mathrm{~cm}$. Floresta Nacional do Tapajós (km 114 da BR 163)

\begin{tabular}{|c|c|c|c|c|c|c|c|}
\hline \multirow{2}{*}{ Espécies } & \multirow{2}{*}{ GR } & \multirow{2}{*}{$\begin{array}{c}1 \text { ano antes } \\
\text { explor. }\end{array}$} & \multicolumn{5}{|c|}{ Anos após a exploração } \\
\hline & & & 1 & 5 & 7 & 13 & 21 \\
\hline Apeiba albiflora & $\mathrm{PP}$ & 0,22 & 0,21 & 0,23 & 0,25 & 0,27 & 0,21 \\
\hline Brosimum lactescens & PT & 0,37 & 0,15 & 0,31 & 0,32 & 0,36 & 0,22 \\
\hline Brosimum obovata & PT & 0,35 & 0,15 & 0,16 & 0,17 & 0,18 & 0,21 \\
\hline Brosimum parinarioides & $\mathrm{CT}$ & 0,31 & 0,31 & 0,23 & 0,23 & 0,24 & 0,27 \\
\hline Carapa guianensis & $\mathrm{CT}$ & 0,86 & 0,50 & 0,56 & 0,59 & 0,68 & 0,84 \\
\hline Ceiba pentandra & $\mathrm{CP}$ & 0,30 & 0,30 & 0,32 & 0,32 & 0,35 & 0,39 \\
\hline Clarisia racemosa & PT & 0,24 & 0,16 & 0,17 & 0,17 & 0,18 & 0,20 \\
\hline Cordia alliodora & $\mathrm{CP}$ & 0,16 & 0,16 & 0,18 & 0,16 & 0,18 & 0,21 \\
\hline Couratari oblongifolia & $\mathrm{CT}$ & 1,13 & 1,03 & 1,06 & 1,09 & 1,16 & 1,22 \\
\hline Duguetia echinophora & NT & 0,27 & 0,22 & 0,26 & 0,26 & 0,22 & 0,24 \\
\hline Eschweilera blanchetiana & NT & 0,41 & 0,35 & 0,41 & 0,43 & 0,36 & 0,24 \\
\hline Eschweilera odora & NT & 0,29 & 0,30 & 0,34 & 0,33 & 0,36 & 0,21 \\
\hline Eugenia lambertiana & NT & 0,17 & 0,16 & 0,16 & 0,17 & 0,14 & 0,16 \\
\hline Geissospermum senceum & NT & 0,57 & 0,50 & 0,55 & 0,57 & 0,60 & 0,57 \\
\hline Guarea kunthiana & PT & 0,19 & 0,17 & 0,16 & 0,17 & 0,15 & 0,18 \\
\hline Guatteria poeppigiana & PT & 0,53 & 0,46 & 0,46 & 0,42 & 0,41 & 0,43 \\
\hline Holopyxidium jarana & CT & 0,65 & 0,19 & 0,21 & 0,19 & 0,20 & 0,22 \\
\hline Inga sp. (10 esp.) & NP & 1,12 & 1,14 & 1,42 & 1,68 & 0,85 & 1,37 \\
\hline Jacaranda copaia & $\mathrm{CP}$ & 0,20 & 0,05 & 0,24 & 0,31 & 0,47 & 0,84 \\
\hline Lauraceae (9 esp.) & PT & 0,53 & 0,53 & 0,52 & 0,56 & 0,53 & 0,56 \\
\hline Licaria canella & $\mathrm{CT}$ & 0,20 & 0,17 & 0,17 & 0,19 & 0,21 & 0,27 \\
\hline Manilkara huberi & $\mathrm{CT}$ & 1,31 & 0,33 & 0,31 & 0,32 & 0,37 & 0,44 \\
\hline Manilkara paraensis & $\mathrm{CT}$ & 0,58 & 0,58 & 0,61 & 0,62 & 0,65 & 0,70 \\
\hline Maquira sclerophylla & PT & 0,23 & 0,16 & 0,28 & 0,29 & 0,33 & 0,42 \\
\hline Mezilaurus itauba & $\mathrm{CT}$ & 0,29 & 0,30 & 0,31 & 0,31 & 0,34 & 0,35 \\
\hline Minquartia guianensis & $\mathrm{CT}$ & 0,73 & 0,68 & 0,72 & 0,72 & 0,75 & 0,81 \\
\hline Neea sp & NT & 0,65 & 0,59 & 0,64 & 0,65 & 0,62 & 0,60 \\
\hline Perebea guianensis & PT & 0,20 & 0,15 & 0,18 & 0,18 & 0,18 & 0,23 \\
\hline Piptadenia suaveolens & $\mathrm{PP}$ & 0,26 & 0,20 & 0,23 & 0,25 & 0,07 & 0,12 \\
\hline Pouteria bilocularis & $\mathrm{CT}$ & 1,14 & 1,02 & 1,01 & 1,04 & 1,10 & 1,27 \\
\hline Protium apiculatum & PT & 0,94 & 0,84 & 1,00 & 1,06 & 1,13 & 1,45 \\
\hline Rinorea guianensis & NT & 1,28 & 1,11 & 1,11 & 1,08 & 0,89 & 0,33 \\
\hline Saccoglottis sp & NT & 0,19 & 0,19 & 0,20 & 0,21 & 0,13 & 0,06 \\
\hline Sahagunia racemifera & NT & 0,19 & 0,19 & 0,21 & 0,22 & 0,23 & 0,19 \\
\hline Sapotaceae (9 esp.) & NT & 2,71 & 2,48 & 2,48 & 2,29 & 1,54 & 0,68 \\
\hline Sclerolobium chrysophyllum & $\mathrm{CP}$ & 0,63 & 0,69 & 0,73 & 0,78 & 0,52 & 0,55 \\
\hline Swartzia corrugata & PT & 0,16 & 0,17 & 0,19 & 0,20 & 0,22 & 0,22 \\
\hline Tachigalia myrmecophyla & $\mathrm{CP}$ & 0,26 & 0,27 & 0,15 & 0,17 & 0,23 & 0,15 \\
\hline Trattinickia rhoifolia & CT & 0,14 & 0,11 & 0,13 & 0,14 & 0,18 & 0,23 \\
\hline Virola melinonii & $\mathrm{CT}$ & 0,58 & 0,44 & 0,42 & 0,45 & 0,49 & 0,49 \\
\hline Total (40 espécies) & - & $\begin{array}{r}21,50 \\
(74,5 \%)\end{array}$ & $\begin{array}{r}17,72 \\
(75,9 \%)\end{array}$ & $\begin{array}{r}19,00 \\
(74,6 \%)\end{array}$ & $\begin{array}{r}19,55 \\
(73,3 \%)\end{array}$ & $\begin{array}{r}18,07 \\
(74,2 \%)\end{array}$ & $\begin{array}{r}18,33 \\
(72,2 \%)\end{array}$ \\
\hline Demais espécies & - & $\begin{array}{r}7,4 \\
(25,5 \%)\end{array}$ & $\begin{array}{r}5,6 \\
(24,1 \%)\end{array}$ & $\begin{array}{r}6,5 \\
(25,4 \%)\end{array}$ & $\begin{array}{r}7,1 \\
(26,7 \%)\end{array}$ & $\begin{array}{r}6,3 \\
(25,8 \%)\end{array}$ & $\begin{array}{r}7,1 \\
(27,8 \%)\end{array}$ \\
\hline Total Geral & - & 28,87 & 23,34 & 25,46 & 26,66 & 24,35 & 25,4 \\
\hline
\end{tabular}


Anexo N. Listagem das 40 espécies dominantes $\left(\mathrm{m}^{2} \cdot \mathrm{ha}^{-1}\right)$ no tratamento T4 (1,5 ha), considerando árvores com DAP $\geq 5,0 \mathrm{~cm}$. Floresta Nacional do Tapajós (km 114 da BR 163)

\begin{tabular}{|c|c|c|c|c|c|c|c|}
\hline \multirow{2}{*}{ Espécies } & \multirow{2}{*}{ GR } & \multirow{2}{*}{$\begin{array}{l}1 \text { ano antes } \\
\text { explor. }\end{array}$} & \multicolumn{5}{|c|}{ Anos após a exploração } \\
\hline & & & 1 & 5 & 7 & 13 & 21 \\
\hline Aegiphilla sp & NP & 0,00 & 0,00 & 0,07 & 0,14 & 0,21 & 0,28 \\
\hline Apeiba albiflora & PP & 0,28 & 0,26 & 0,29 & 0,30 & 0,13 & 0,09 \\
\hline Bixa arborea & PP & 0,26 & 0,27 & 0,30 & 0,28 & 0,09 & 0,36 \\
\hline Bombax sp & $\mathrm{CP}$ & 0,28 & 0,28 & 0,30 & 0,30 & 0,31 & 0,32 \\
\hline Carapa guianensis & CT & 1,22 & 0,55 & 0,63 & 0,67 & 0,75 & 0,82 \\
\hline Castilla ulei & $\mathrm{PT}$ & 0,30 & 0,31 & 0,36 & 0,36 & 0,39 & 0,48 \\
\hline Cecropia leucoma & NP & 0,10 & 0,11 & 0,27 & 0,43 & 0,18 & 0,26 \\
\hline Cecropia sciadophylla & NP & 0,00 & 0,00 & 0,54 & 1,03 & 0,11 & 0,13 \\
\hline Cordia bicolor & $\mathrm{CP}$ & 0,74 & 0,37 & 0,42 & 0,45 & 0,50 & 0,67 \\
\hline Cordia goeldiana & $\mathrm{CP}$ & 0,25 & 0,25 & 0,26 & 0,26 & 0,23 & 0,24 \\
\hline Couratari oblongifolia & CT & 1,06 & 1,05 & 0,60 & 0,62 & 0,61 & 0,60 \\
\hline Duguetia echinophora & NT & 0,21 & 0,20 & 0,22 & 0,23 & 0,18 & 0,13 \\
\hline Eschweilera amara & NT & 0,19 & 0,20 & 0,13 & 0,14 & 0,11 & 0,09 \\
\hline Eschweilera amazonica & NT & 0,35 & 0,21 & 0,23 & 0,24 & 0,23 & 0,17 \\
\hline Eschweilera blanchetiana & NT & 0,41 & 0,34 & 0,37 & 0,38 & 0,30 & 0,21 \\
\hline Eschweilera odora & NT & 0,33 & 0,24 & 0,28 & 0,29 & 0,30 & 0,18 \\
\hline Geissospermum senceum & NT & 0,75 & 0,68 & 0,71 & 0,72 & 0,73 & 0,75 \\
\hline Guarea kunthiana & PT & 0,19 & 0,20 & 0,20 & 0,20 & 0,15 & 0,12 \\
\hline Guatteria poeppigiana & $\mathrm{PT}$ & 0,43 & 0,39 & 0,46 & 0,51 & 0,57 & 0,18 \\
\hline Hymenaea parvifolia & $\mathrm{CT}$ & 0,13 & 0,14 & 0,17 & 0,18 & 0,21 & 0,29 \\
\hline Inga sp. (10 esp.) & NP & 1,04 & 0,58 & 0,83 & 1,03 & 0,73 & 2,00 \\
\hline Iryanthera juruensis & CT & 1,04 & 1,07 & 1,06 & 0,93 & 0,98 & 0,51 \\
\hline Jacaranda copaia & $\mathrm{CP}$ & 0,00 & 0,00 & 0,20 & 0,31 & 0,56 & 1,12 \\
\hline Lauraceae (9 esp.) & $\mathrm{PT}$ & 0,50 & 0,42 & 0,45 & 0,47 & 0,49 & 0,39 \\
\hline Licaria canella & CT & 0,60 & 0,48 & 0,54 & 0,58 & 0,67 & 0,50 \\
\hline Manilkara huberi & CT & 1,40 & 0,26 & 0,29 & 0,30 & 0,32 & 0,42 \\
\hline Maquira sclerophylla & $\mathrm{PT}$ & 0,21 & 0,22 & 0,25 & 0,26 & 0,17 & 0,04 \\
\hline Minquartia guianensis & $\mathrm{CT}$ & 0,85 & 0,79 & 0,80 & 0,81 & 0,74 & 0,67 \\
\hline Neea sp & NT & 0,33 & 0,32 & 0,34 & 0,33 & 0,28 & 0,32 \\
\hline Parkia gigantocarpa & $\mathrm{CP}$ & 0,10 & 0,11 & 0,14 & 0,14 & 0,16 & 0,22 \\
\hline Perebea guianensis & $\mathrm{PT}$ & 0,19 & 0,17 & 0,19 & 0,16 & 0,24 & 0,13 \\
\hline Pouteria bilocularis & CT & 0,32 & 0,32 & 0,30 & 0,31 & 0,31 & 0,35 \\
\hline Protium apiculatum & PT & 1,07 & 0,94 & 1,09 & 1,14 & 1,26 & 1,44 \\
\hline Rheedia acuminata & PT & 0,11 & 0,12 & 0,12 & 0,13 & 0,15 & 0,17 \\
\hline Rinorea flavescens & NT & 0,55 & 0,52 & 0,58 & 0,59 & 0,58 & 0,58 \\
\hline Rinorea guianensis & NT & 1,49 & 1,32 & 1,31 & 1,23 & 0,95 & 0,40 \\
\hline Sapotaceae (9 esp.) & NT & 1,78 & 1,63 & 1,71 & 1,75 & 1,37 & 0,88 \\
\hline Schyzolobium amazonicum & $\mathrm{CP}$ & 0,22 & 0,24 & 0,40 & 0,45 & 0,18 & 0,44 \\
\hline Sclerolobium chrysophyllum & $\mathrm{CP}$ & 0,28 & 0,36 & 0,51 & 0,56 & 0,04 & 0,15 \\
\hline Virola melinonii & CT & 0,34 & 0,30 & 0,23 & 0,23 & 0,06 & 0,12 \\
\hline Total (40 espécies) & - & 19,9 & 16,2 & 18,1 & 19,4 & 16,5 & 17,2 \\
\hline & & $(69,0 \%)$ & $(77,6 \%)$ & $(77,1 \%)$ & $(77,3 \%)$ & $7,4 \%)$ & $7,5 \%)$ \\
\hline Demais espécies & - & $\begin{array}{r}8,9 \\
0\end{array}$ & $\begin{array}{r}4,7 \\
4 \%\end{array}$ & $\begin{array}{r}5,4 \\
9 \%)\end{array}$ & $\begin{array}{r}5,7 \\
(227 \%)\end{array}$ & $\begin{array}{r}4,8 \\
(226 \%)\end{array}$ & $\begin{array}{r}5,0 \\
(22,5 \%)\end{array}$ \\
\hline Total Geral & - & 28,8 & 20,9 & 23,5 & 25,1 & 21,3 & 22,2 \\
\hline
\end{tabular}

CT: comercial tolerante, CP: comercial pioneira, PT: potencial tolerante, PP: potencial pioneira, NT: não comercial tolerante, NP: não comercial pioneira 
Anexo O. Listagem das 40 espécies dominantes $\left(\mathrm{m}^{2} \cdot \mathrm{ha}^{-1}\right)$ no tratamento T0 (1,5 ha), considerando árvores com DAP $\geq 5,0 \mathrm{~cm}$. Floresta Nacional do Tapajós (km 114 da BR 163)

\begin{tabular}{|c|c|c|c|c|c|c|}
\hline \multirow{2}{*}{ Espécies } & \multirow{2}{*}{ GR } & \multicolumn{5}{|c|}{ Anos de medição } \\
\hline & & 1983 & 1987 & 1989 & 1995 & 2003 \\
\hline Apeiba albiflora & PP & 0,40 & 0,41 & 0,41 & 0,30 & 0,31 \\
\hline Aspidosperma rigidum & NT & 0,23 & 0,26 & 0,28 & 0,28 & 0,35 \\
\hline Astronium gracile & $\mathrm{CT}$ & 0,55 & 0,58 & 0,58 & 0,61 & 0,69 \\
\hline Bertholletia excelsa & $\mathrm{CP}$ & 0,30 & 0,33 & 0,34 & 0,38 & 0,42 \\
\hline Carapa guianensis & $\mathrm{CT}$ & 0,81 & 0,88 & 0,90 & 0,97 & 0,82 \\
\hline Caryocar glabrum & $\mathrm{CP}$ & 0,70 & 0,74 & 0,76 & 0,81 & 0,88 \\
\hline Chimarrhis turbinata & NT & 0,20 & 0,22 & 0,23 & 0,26 & 0,31 \\
\hline Couratari oblongifolia & $\mathrm{CT}$ & 1,07 & 1,04 & 1,07 & 1,11 & 0,97 \\
\hline Duguetia echinophora & NT & 0,64 & 0,68 & 0,71 & 0,75 & 0,77 \\
\hline Endopleura uchi & $\mathrm{CT}$ & 0,39 & 0,41 & 0,42 & 0,46 & 0,51 \\
\hline Eperua bifuga & NT & 0,23 & 0,21 & 0,22 & 0,18 & 0,19 \\
\hline Eschweilera blanchetiana & NT & 0,44 & 0,46 & 0,48 & 0,41 & 0,46 \\
\hline Eschweilera odora & NT & 0,70 & 0,74 & 0,77 & 0,84 & 0,91 \\
\hline Geissospermum senceum & NT & 0,47 & 0,50 & 0,51 & 0,52 & 0,55 \\
\hline Goupia glabra & $\mathrm{CP}$ & 0,14 & 0,18 & 0,18 & 0,20 & 0,21 \\
\hline Guatteria poeppigiana & PT & 0,34 & 0,32 & 0,34 & 0,39 & 0,44 \\
\hline Hevea $\mathrm{sp}$ & PP & 0,21 & 0,23 & 0,10 & 0,11 & 0,12 \\
\hline Holopyxidium jarana & $\mathrm{CT}$ & 0,85 & 0,86 & 0,87 & 0,83 & 0,68 \\
\hline Hymenaea courbaril & $\mathrm{CT}$ & 0,59 & 0,62 & 0,63 & 0,65 & 0,68 \\
\hline Inga sp. (10 esp.) & NP & 0,50 & 0,60 & 0,66 & 0,72 & 0,84 \\
\hline Iryanthera juruensis & $\mathrm{CT}$ & 0,81 & 0,83 & 0,83 & 0,85 & 0,87 \\
\hline Lauraceae (9 esp.) & PT & 0,65 & 0,67 & 0,69 & 0,70 & 0,70 \\
\hline Lecythis usitata & $\mathrm{CT}$ & 0,67 & 0,67 & 0,74 & 0,75 & 0,75 \\
\hline Manilkara huberi & $\mathrm{CT}$ & 2,52 & 2,64 & 2,69 & 2,69 & 2,85 \\
\hline Maquira sclerophylla & PT & 0,28 & 0,29 & 0,30 & 0,17 & 0,18 \\
\hline Mezilaurus lindaviana & $\mathrm{CT}$ & 0,22 & 0,23 & 0,23 & 0,21 & 0,22 \\
\hline Minquartia guianensis & $\mathrm{CT}$ & 0,37 & 0,42 & 0,42 & 0,45 & 0,48 \\
\hline Neea sp & NT & 0,33 & 0,35 & 0,36 & 0,38 & 0,29 \\
\hline Ormosia sp & PP & 0,23 & 0,22 & 0,22 & 0,24 & 0,28 \\
\hline Perebea guianensis & PT & 0,16 & 0,18 & 0,18 & 0,20 & 0,22 \\
\hline Pouteria bilocularis & $\mathrm{CT}$ & 0,94 & 0,96 & 0,97 & 0,47 & 0,49 \\
\hline Protium apiculatum & PT & 0,65 & 0,69 & 0,71 & 0,79 & 0,89 \\
\hline Protium spruceanum & PT & 0,34 & 0,34 & 0,34 & 0,34 & 0,34 \\
\hline Rinorea guianensis & NT & 1,66 & 1,73 & 1,75 & 1,74 & 1,86 \\
\hline Sapotaceae (9 esp.) & NT & 1,74 & 1,83 & 1,88 & 1,89 & 1,97 \\
\hline Sclerolobium chrysophyllum & $\mathrm{CP}$ & 1,24 & 1,43 & 1,53 & 1,32 & 1,46 \\
\hline Sloanea froesii & NP & 0,18 & 0,19 & 0,19 & 0,20 & 0,19 \\
\hline Stryphnodendron barbatimam & NT & 0,19 & 0,19 & 0,19 & 0,20 & 0,20 \\
\hline Tabebuia impetiginosa & $\mathrm{CP}$ & 0,61 & 0,63 & 0,63 & 0,64 & 0,65 \\
\hline Tachigalia myrmecophyla & $\mathrm{CP}$ & 0,69 & 0,42 & 0,14 & 0,18 & 0,11 \\
\hline Total (40 espécies) & - & 24,2 & 25,1 & & 25,2 & 26,1 \\
\hline & & $(79,4 \%)$ & $(80,2 \%)$ & $(81,6 \%)$ & $(82,5 \%)$ & $(82,3 \%)$ \\
\hline Demais espécies & - & 6,3 & 6,2 & 5,7 & 5,3 & 5,6 \\
\hline Total Geral & & $(20,6 \%)$ & $(19,8 \%)$ & $(18,4 \%)$ & $(17,5 \%)$ & $(17,7 \%)$ \\
\hline otal Geral & - & 30,5 & 31,3 & 31,2 & 30,5 & 31,7 \\
\hline
\end{tabular}

CT: comercial tolerante, CP: comercial pioneira, PT: potencial tolerante, PP: potencial pioneira, NT: não comercial tolerante, NP: não comercial pioneira 


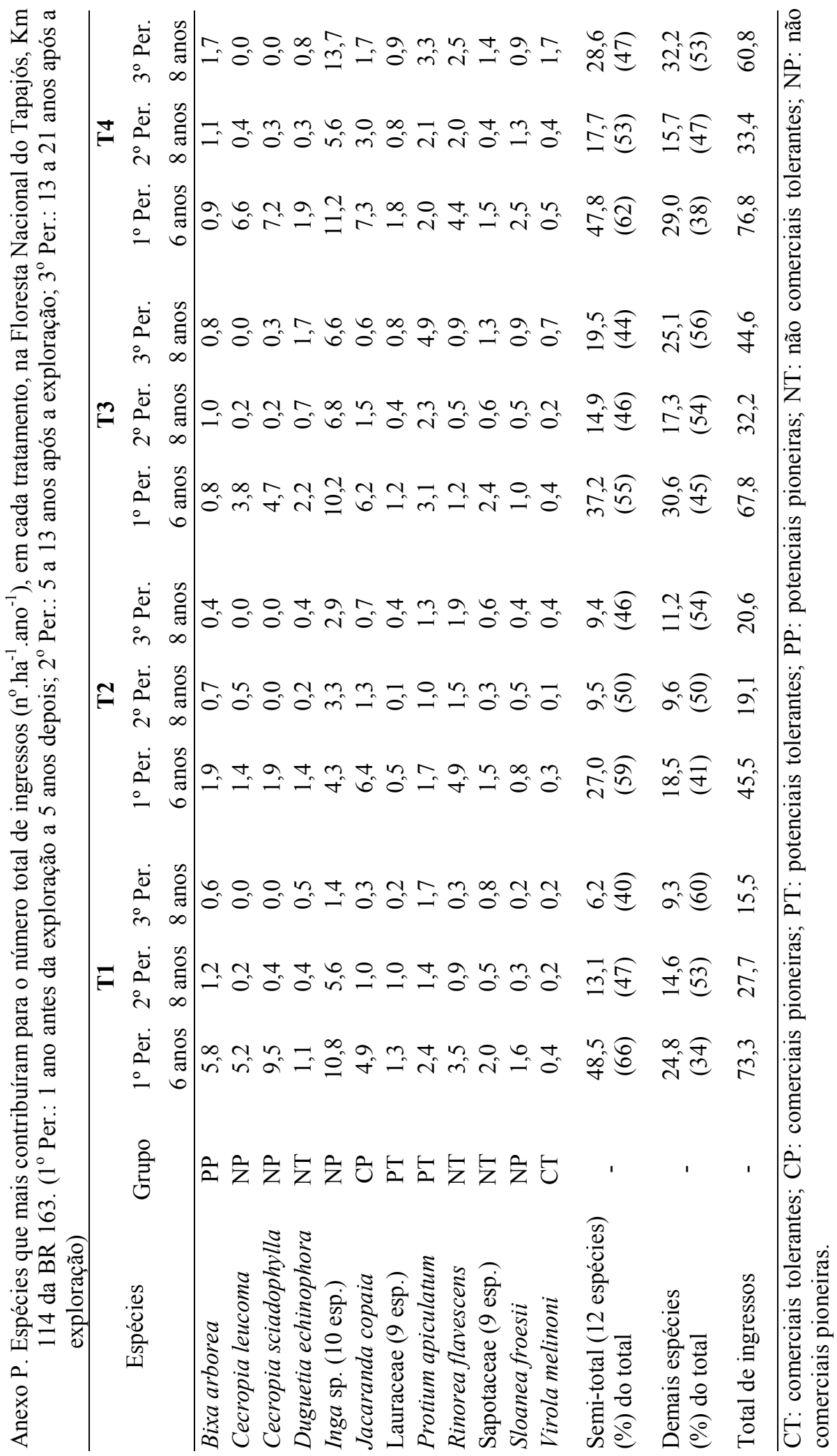




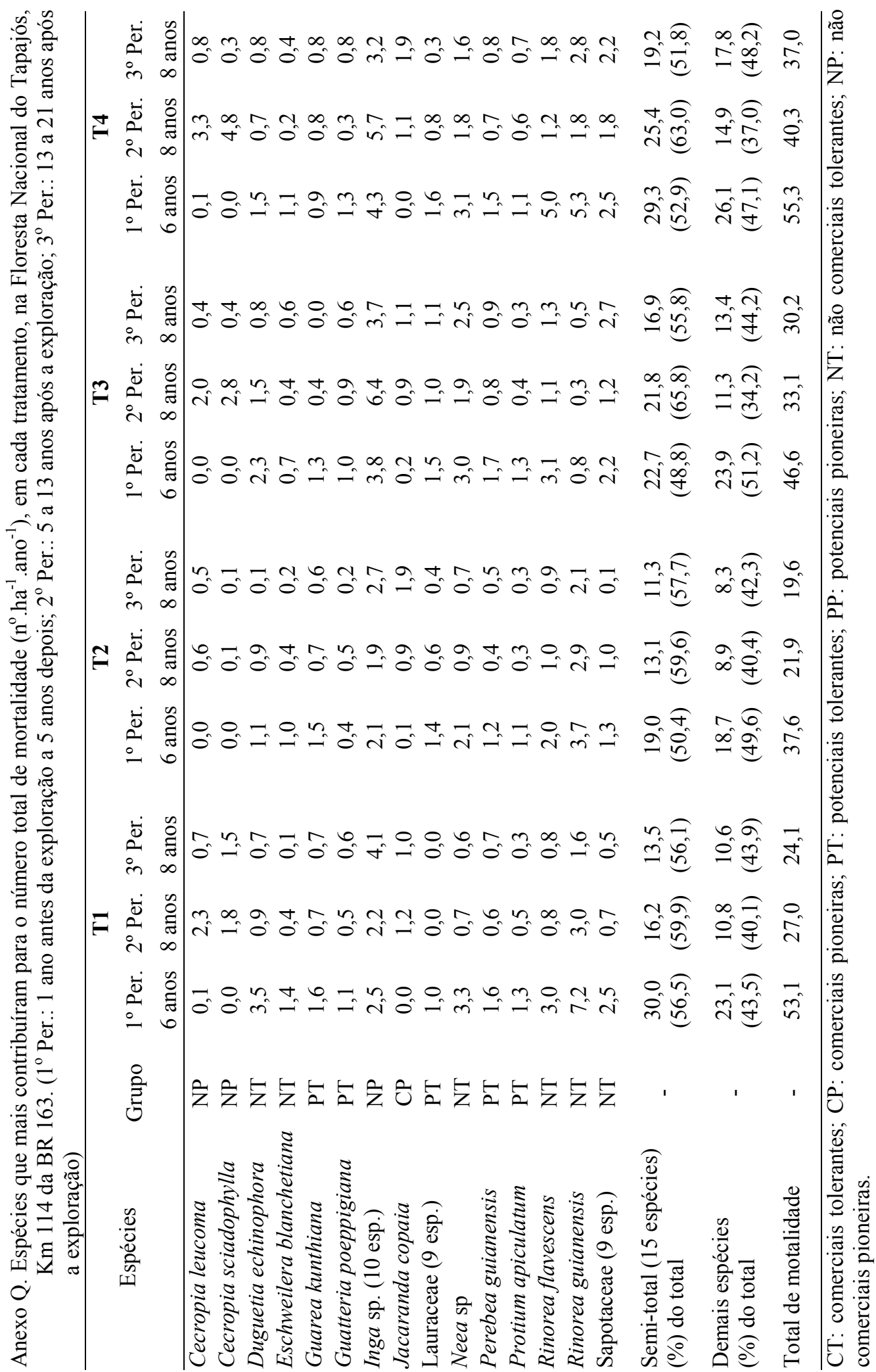


Anexo R. Incrementos em diâmetro $\left(\mathrm{cm} \cdot \mathrm{ano}^{-1}\right)$, considerando o período total de acompanhamento, para as 30 espécies mais abundantes, presentes em todos os tratamentos em uma área de 10,25ha na Floresta Nacional do Tapajós (Km114 da BR 163)

\begin{tabular}{|c|c|c|c|c|c|c|c|c|c|c|c|}
\hline \multirow{2}{*}{ Espécie } & \multirow{2}{*}{ GR } & \multicolumn{2}{|l|}{$\mathrm{T} 1$} & \multicolumn{2}{|l|}{$\mathrm{T} 2$} & \multicolumn{2}{|l|}{ T3 } & \multicolumn{2}{|l|}{ T4 } & \multicolumn{2}{|l|}{ T0 } \\
\hline & & $\mathrm{cm}^{\mathrm{ano}} \mathrm{-}^{-1}$ & $\mathrm{n}$ & $\mathrm{cm}_{\mathrm{ano}}{ }^{-1}$ & $\mathrm{n}$ & $\mathrm{cm} \cdot \mathrm{ano}^{-1}$ & $\mathrm{n}$ & $\mathrm{cm}^{\mathrm{ano}} \mathrm{o}^{-1}$ & $\mathrm{n}$ & $\mathrm{cm} \cdot \mathrm{ano}^{-1}$ & $\mathrm{n}$ \\
\hline Carapa guianensis & CT & 0,31 & 13 & 0,42 & 14 & 0,41 & 28 & 0,43 & 14 & 0,28 & 15 \\
\hline Casearia favitensis & NT & 0,14 & 15 & 0,19 & 7 & 0,25 & 6 & 0,15 & 8 & 0,10 & 11 \\
\hline Couratari oblongifolia & CT & 0,26 & 18 & 0,20 & 16 & 0,26 & 17 & 0,18 & 11 & 0,11 & 16 \\
\hline Duguetia echinophora & NT & 0,10 & 56 & 0,04 & 11 & 0,09 & 56 & 0,09 & 14 & 0,09 & 69 \\
\hline Eschweilera blanchetiana & NT & 0,16 & 42 & 0,15 & 29 & 0,20 & 25 & 0,18 & 14 & 0,11 & 37 \\
\hline Eschweilera odora & NT & 0,14 & 27 & 0,11 & 33 & 0,14 & 34 & 0,13 & 16 & 0,13 & 38 \\
\hline Eugenia lambertiana & NT & 0,12 & 17 & 0,07 & 6 & 0,14 & 26 & 0,20 & 6 & 0,11 & 18 \\
\hline Geissospermum senceum & NT & 0,19 & 14 & 0,16 & 15 & 0,19 & 22 & 0,21 & 5 & 0,11 & 10 \\
\hline Guarea kunthiana & $\mathrm{PT}$ & 0,08 & 41 & 0,12 & 29 & 0,09 & 24 & 0,14 & 17 & 0,03 & 21 \\
\hline Guarea sp. & NT & 0,13 & 7 & 0,13 & 10 & 0,27 & 10 & 0,10 & 5 & 0,04 & 4 \\
\hline Guatteria poeppigiana & $\mathrm{PT}$ & 0,18 & 11 & 0,29 & 16 & 0,37 & 16 & 0,20 & 6 & 0,21 & 17 \\
\hline Inga sp.(10 esp.) & $\mathrm{NP}$ & 0,35 & 27 & 0,32 & 27 & 0,25 & 44 & 0,29 & 13 & 0,26 & 42 \\
\hline Lauraceae (9 esp.) & $\mathrm{PT}$ & 0,25 & 31 & 0,26 & 23 & 0,26 & 44 & 0,21 & 12 & 0,16 & 23 \\
\hline Licaria canella & $\mathrm{CT}$ & 0,30 & 13 & 0,27 & 11 & 0,22 & 25 & 0,37 & 10 & 0,12 & 10 \\
\hline Minquartia guiane & $\mathrm{CT}$ & 0,23 & 16 & 0,23 & 32 & 0,30 & 15 & 0,16 & 7 & 0,16 & 13 \\
\hline Neea sp. & NT & 0,15 & 30 & 0,11 & 22 & 0,16 & 69 & 0,18 & 22 & 0,11 & 20 \\
\hline Paypayrola grandiflora & NT & 0,10 & 13 & 0,08 & 7 & 0,14 & 12 & 0,16 & 1 & 0,07 & 11 \\
\hline Perebea guianensis & $\mathrm{PT}$ & 0,13 & 19 & 0,14 & 19 & 0,15 & 38 & 0,17 & 8 & 0,10 & 26 \\
\hline Pouteria bilocularis & $\mathrm{CT}$ & 0,22 & 13 & 0,22 & 10 & 0,29 & 34 & 0,23 & 4 & 0,13 & 7 \\
\hline Protium apiculatum & $\mathrm{PT}$ & 0,24 & 58 & 0,21 & 73 & 0,28 & 92 & 0,31 & 47 & 0,16 & 78 \\
\hline Rinorea flavescens & NT & 0,06 & 152 & 0,06 & 138 & 0,11 & 34 & 0,10 & 61 & 0,08 & 12 \\
\hline Rinorea guianensis & NT & 0,14 & 101 & 0,12 & 68 & 0,17 & 52 & 0,18 & 18 & 0,11 & 102 \\
\hline Sagotia racemosa & NT & 0,08 & 27 & 0,08 & 15 & 0,10 & 16 & 0,10 & 12 & 0,06 & 9 \\
\hline Sapotaceae (9 esp.) & NT & 0,18 & 111 & 0,13 & 84 & 0,15 & 75 & 0,19 & 43 & 0,11 & 77 \\
\hline Sclerolobium chrysophyllum & $\mathrm{CP}$ & 0,56 & 22 & 1,10 & 9 & 0,77 & 14 & 0,66 & 2 & 0,56 & 24 \\
\hline Sloanea froesii & $\mathrm{NP}$ & 0,23 & 12 & 0,14 & 7 & 0,21 & 10 & 0,16 & 7 & 0,08 & 19 \\
\hline Sterculia pilosa & $\mathrm{PP}$ & 0,19 & 11 & 0,26 & 6 & 0,25 & 11 & 0,22 & 5 & 0,06 & 10 \\
\hline Talisia longifolia & NT & 0,10 & 14 & 0,04 & 13 & 0,10 & 20 & 0,05 & 6 & 0,06 & 11 \\
\hline Theobroma specios & NT & 0,07 & 11 & 0,03 & 9 & 0,07 & 15 & 0,10 & 8 & 0,03 & 9 \\
\hline Virola melinonii & CT & 0,44 & 14 & 0,43 & 10 & 0,41 & 15 & 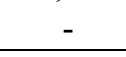 & - & 0,30 & 2 \\
\hline
\end{tabular}




\section{REFERÊNCIAS BIBLIOGRÁFICAS}

BARRETO, P.; AMARAL, P.; VIDAL, E.; UHL, C. Costs and benefits of forest management for timber production in eastern Amazonia. Forest Ecology and Management, v.108, p.9-26, 1998.

BARROS, A. C.; VERÍSSIMO, A. A expansão da atividade madeireira na Amazônia: impactos e perspectivas para o desenvolvimento do setor florestal na Pará. Belém: IMAZON, 1996. 168p.

BROWER, J. E.; ZAR, J. H. Field and laboratory methods for general ecology. Iowa: Wm.C. Brown, 1977. 194p.

BRUENIG, E. The tropical rainforest as ecosystem. Plant Research and Development, n.24, p.15-30, 1986.

BRYAN, M.B. Studies of timber growth and mortality in the mixed dipterocarp forest in Sarawak. Rome: FAO, 1981. 38p. (Field Document,11).

BUDOWSKI, G. Distribuition of tropical american rain forest species in the light of successional processes. Turrialba, v.15, n.1, p.40-42, 1965.

CAMACHO, M.; FINEGAN, B. Efectos del aprovechamiento forestal y el tratamiento silvicultural en un bosque húmedo del norest de Costa Rica: el crecimiento diamétrico con énfasis en el rodal comercial Turrialba, Costa Rica: CATIE.Colección Manejo Diversificado de Bosques Naturales, 1997. 54p. (Serie técnica. Informe técnico, 295)

CARVALHO, J.O.P. de. Estrutura de matas altas sem babaçu na Floresta Nacional do Tapajós. In: SILVA, J. N.M.; CARVALHO, J.O.P. de; YARED, J.A.G. (Ed.) A silvicultura na Amazônia Oriental: contribuições do projeto Embrapa/DFID. Belém: Embrapa Amazônia Oriental/DFID, 2001. p.277-290.

CARVALHO, J.O.P. de. Structure and dynamics of a logged over Brazilian Amazonian rain forest. Oxford, 1992. 215 p. Thesis (Ph.D.) - University of Oxford. 
CARVAlHO, J. O. P. de; SILVA, J. N. M; LOPES, J. do C.A.; COSTA, H. B. da. Manejo de florestas naturais do trópico úmido com referência especial à Floresta Nacional do Tapajós no Estado do Pará. Belém: EMBRAPA-CPATU, 1984. 14p. (Documento, 26).

CHAMBERS, J.Q.; HIGUCHI, N.; SCHIMEL, J.P. Ancient trees in Amazônia. Nature, v.391, p.135-136, 1998.

CLARK, D. B. The role of disturbance in the regeneration of neotropical moist forests. In: BAWA, K.S.; HADLEY, M. (Ed.). Reproductive ecology of tropical forest plants. Paris: UNESCO, 1990. p.291-315.

COSTA, D. H. M.; CARVAlHO, J. O. P. de; SILVA, J. N. M. Dinâmica da composição florística após a colheita de madeira em uma área de terra firme na Floresta Nacional do Tapajós. Revista de Ciências Agrárias, n.38, p.67-90, 2002.

COSTA, D.H.M.; SILVA, S.M.A. da; SILVA, J.N.M. Efetividade e custo do desbaste com aplicação de arboricida em floresta natural na região do Tapajós, Pará e Jarí, Amapá. In: SILVA, J.N.M.; CARVALHO, J.O.P. de; YARED, J.A.G. (Ed.) A silvicultura na Amazônia Oriental: contribuições do projeto Embrapa/DFID. Belém: Embrapa Amazônia Oriental/DFID, 2001. p.277-290.

DE GRAAF, N.R. de. A silvicultural system for natural regeneration of tropical rain forest in Suriname. Wageningen: Agricultural University, 1986. 250 p.

DE GRAAF, N.R.; POELS, R.L.H.; van ROMPAEY, R.S.A.R. Effect of silvicultural treatments on growth and mortality of rainforest in Surinam over long periods. Forest ecology and management. v.124, p.123-135, 1999.

DEKKER, M.; de GRAAF, N. R. Pioneer and climax tree regeneration following selective logging with silviculture in Suriname. Forest Ecology and Management, v.172, p.183$190,2003$.

DELGADO, D.; FINEGAN, B.; ZAMORA, N.; MEIR, P. Efectos del aprovechamiento forestal y el tratamiento silvicultural en un bosque húmedo del noreste de Costa Rica: câmbios en la riqueza y composición de la vegetación. Turrialba, Costa Rica: CATIE. Colección Manejo Diversificado de Bosques Naturales, 1997. 55p. (Serie técnica. Informe técnico, 298)

DENSLOW, J. S. Disturbance and diversity in tropical rain forests: The density effect. Ecological Applications, n.5, p.962-968, 1995.

DUBOIS, J.L.C. Silvicultural research in the Amazon. Rome: FAO, 1971. 53p. (Technical Report, 3).

DUBOIS, J.L.C. Preliminary Forest management guidelines for the National Forest of Tapajós. Belém: IBDF/PRODEPF, 1976. 24p. 
DUBOIS, J.C.L. Tratamentos silvicultuais. Belém: s. ed., 1978. 22p.

DURRIEU de MADRON, L. Mortalité des arbres en forêt primaire de Guyane Française. Bois et Forêts des Tropiques, v.293, n.1, p.43-57, 1994.

EMBRAPA. Diagnóstico dos projetos de manejo florestal no Estado do Pará - Fase Paragominas. Belém: EMBRAPA-CPATU, 1997. 133p. (Documento, 106).

FOOD AND AGRICULTURE ORGANIZATION OF THE UNITED NATIONS. Global forest resources assessment 2000. Rome, 2001. 479p. (FAO Forestry Paper, 140).

FELFILI, J. A.; VENTUROLI, F.Tópicos em análise de vegetação. Brasília. Comunicações Técnicas Florestais, v.2, n.1, p.24, 2000.

FERRI, M.G. Fisiologia vegetal. 2.ed. São Paulo: Editora Pedagógica, 1979, v.2. 401p.

LEAL FILHO, N. Dinâmica inicial de regeneração natural de florestas exploradas na Amazônia brasileira. São Paulo, 2000. 157p. Tese (Doutorado) - Instituto de Biociências, Universidade de São Paulo.

FINEGAN, B.; CAMACHO, M. Stand dynamics in a logged and silviculturally treated Costa Rican rain forest, 1988-1996. Forest Ecology and Management, v.121, p.177$189,1999$.

FINEGAN, B.; CAMACHO, M.; ZAMORA, N. Diameter increment patterns among 106 tree species in a logged and silviculturally treated Costa Rican rain forest. Forest Ecology and Management, v.121, p.159-176, 1999.

FREDERICKSEN, T.S. Limitations of low-intensity selective logging for sustainable tropical forestry. Commonwealth Forestry Review, v.77, n.4, p.262-266, 1998.

GARCIA, A. Influência de diferentes níveis de exploração florestal em uma floresta tropical na região de Marabá, PA. Piracicaba, 1990, 201p. Dissertação (Mestrado) - Escola Superior de Agricultura "Luiz de Queiróz". Universidade de São Paulo

GERWING, J.; JOHNS, J.; VIDAL, E. Reducing waste during logging and log processing towards forest conservation in Eastern Amazon. Unassylva, v.47, n.187, p.17-25, 1996.

GOMIDE, G.L.A. Estrutura e dinâmica de crescimento de floresta tropical primária e secundária no Estado do Amapá. Curitiba, 1997, 169p. Dissertação (Mestrado) Universidade Federal do Paraná.

GRIMM, A. M. The El Niño impact on the summer monsoon in Brazil: regional processes versus remote influences. Journal of Climate, v.16, n.2, p.263-280, 2003. 
HENDRISON, J. Damage-controlled logging in tropical rain forests in Suriname. Wageningen: Agricultural University, 1990. 204p.

HIGUCHI, N.; SANTOS, J. dos; RIBEIRO, R. J.; FREITAS, J.V. de; VIEIRA, G.; COIC, A.; MINETTE, L. J. Crescimento e incremento de uma floresta amazônica de terra firme manejada experimentalmente. Manaus: INPA/DFID, 1997, p.87-132 (Relatório Final do Projeto Bionte).

HIGUCHI, N.; SANTOS, J. dos; RIBEIRO, R. J.; SILVA, R. P.; ROCHA, R. M. Sustentabilidade na produção de madeira dura tropical. Revista Silvicultura, n.83 p.3237,2000 .

HOLDSWORTH, A. R.; UHL, C. Fire in Amazonian selectively logged rain forest and the potential for fire reduction. Ecological Applications, v.7, p.713-725, 1997.

HOLMES, T. P.; BLATE, G. M.; ZWEEDE, J. C.; PEREIRA-JUNIOR, R.; BARRETO, P.; BOLTZ, F. Custos e benefícios financeiros da exploração de impacto reduzido em comparação à exploração florestal convencional na Amazônia oriental. Belém: Fundação Floresta Tropical, 2002. 69p.

HOSOKAWA, R.T. Manejo sustentado de florestas naturais: aspectos econômicos, ecológicos e sociais. In: CONGRESO NACIONAL SOBRE ESSÊNCIAS NATIVAS, Campos do Jordão, 1982. Anais. São Paulo: Silvicultura em São Paulo, 1982. p.14651472.

HOWARD, A. F.; RICE, R. E.; GULLISON, R. E. Retornos financieros e impactos ambientales simulados de cuatro prescripciones silviculturales alternativas aplicadas en el tropico americano: caso de estudio del bosque chimanes, Bolivia: Proyecto BOLFOR, 1996. 24p. (Documento Técnico, 33)

HUTCHINSON, I.D. Improvement thinning in natural forests: aspects and institutionalization. In: MERGEN, F.; VINCENT, J.R. (Ed.). Natural management of tropical moist forests, silvicultural and management prospects of sustained utilization. New Haven: Yale University. School of Forestry and Environment Studies, 1987. p.113-133.

HUTCHINSON, I.D. Points o departure for silviculture in humid tropical forest. Commonwealth Forestry Review, v.67, n.3, p.223-230, 1998.

INSTITUTO BRASILEIRO DO MEIO AMBIENTE E DOS RECURSOS NATURAIS RENOVÁVEIS. Avaliação dos planos de manejo florestal sustentável da Amazônia. Brasília: IBAMA, 2001. 125p. 
JARDIM, F.C. da S. Comportamento da regeneração natural de espécies arbóreas em diferentes intensidades de desbaste por anelamento, na região de Manaus-AM. Viçosa, 1995. 169p. Tese (Doutorado) - Universidade Federal de Viçosa.

JARDIM, F.C. da S.; SILVA, G.A.P. da. Análise da variação estrutural da floresta equatorial úmida da estação experimental de silvicultura tropical do Instituto Nacional de pesquisa da Amazônia - INPA, Manaus (AM). Revista de Ciências Agrárias, n.39, p.25-54, 2003.

JARDIM, F. C. S.; SANTOS, J.; COIC, A. Efeitos do anelamento de espécies indesejáveis sobre a regeneração natural de espécies comerciais. In: ATELIER SUR L`AMÉNAGMENT ET LA CONSERVATION DE L`ECOSYSTÉME FOESTIER TROPICAL HUMIDE, Cayenne, 1990. Anais. Cayenne: Actes Cayenne, 1990. p.25-32.

JESUS, R.M de. Manejo florestal: impactos ecológicos de diferentes níveis de remoção e os impactos em sua sustentabilidade. Campinas, 2001. 247p. Tese (Doutorado) Universidade Estadual de Campinas.

JOHNS, A. D. Effects of selective timber extraction on rain forest structure and composition and some consequences for frugivores and folivores. Biotropica. v.20, n.1, p.31-37, 1988.

JOHNS, J. S.; BARRETO, P.; UHL, C. Os danos da exploração de madeira com e sem planejamento na Amazônia Oriental. Belém: IMAZON, 1998. 40p. (Série Amazônia, 16)

JOHNS, J.; BARRETO, P.; UHL, C. Logging damage during planned and unplanned logging operations in the eastern Amazon. Forest Ecology and Management, v.89, p.59-77, 1996.

JONKERS, W.B.J. Options for silviculture and management of the mixed dipterocarp forest Sarawak. Roma: FAO, 1982. 1v. (Working Paper, v.11)

JONKERS, W.B.J. Vegetation structure logging damage and silviculture in tropical rain forest in Suriname. Wageningen: Agricultural University, 1987. 172p.

KAMMESHEIDT, L. Effects of selective logging on the diversity of tree species in a tropical moist deciduous forest in Venezuela. Natural Resources and Development. $\mathrm{v}$ 45/46, p.103-123, 1997.

KAMMESHEIDT, L; LEZAMA, A.T.; FRANCO, W.; PLONCZAK, M. History of logging and silvicultural treatments in the western Venezuelan plain forests and the prospect for sustainable forest management. Forest Ecology and Management, v.148, p.1-20, 2001. 
KAMMESHEIDT, L.; DAGANG, A. A.; SCHWARZWALLER, W.; WEIDELT, H. Growth patterns of dipterocarps in treated and untreated plots. Forest Ecology and Management, v.174, p.437-445, 2003.

KUUSIPALO, J.; JAFARSIDIK, Y.; ADJERS, G.; TUOMELA, K. Population dynamics of tree seedlings in a mixed dipterocarp rainforest before and after logging and crown liberation. Forest Ecology and Management, v.81, p.85-94, 1996.

KUUSIPALO, J.; HADENGGANAN, S.; ADJERS, G.; PORKAS, A.; SAGALA, S. Effect of gap liberation on the performance and growth of dipterocarp trees in a logged-over rainforest. Forest Ecology and Management, v.92, p.209-219, 1997.

LAMPRECHT, H. Silvicultura em los trópicos. Rossdorf, Alemania: Deustsche Gesellschaft fur Technische Zusammenarbeit (GTZ), 1990. 335p.

LAMPRECHT, H. Silviculture in the tropical natural forest: In: PANCEL'S, L. (Ed.). Tropical Forestry Handbook. Berlin: Springer-Verlag, 1993. p.728-810.

LIEBERMAN, D.; LIEBERMAN, M. Forest tree growth and dynamics at La Selva, Costa Rica (1969-1982). Journal of Tropical Ecology, v.3, p.347-358, 1987.

LIEBERMAN, D.; LIEBERMAN, M.; HARTSHORN, G.; PERALTA, R. Growth rate and age size relationships of lowland tropical wet forest tree in Costa Rica. Journal of Tropical Ecology, v.1, p.97-109, 1985.

LOPES, J.C.A. Demografia e flutuações temporais da regeneração natural após uma exploração florestal: Flona Tapajós/PA. Piracicaba, 1993. 133p. Dissertação (Mestrado) - Escola Superior de Agricultura "Luiz de Queiróz”, Universidade de São Paulo.

LUDWIG, J. A.; REYNOLDS, J. F. Statistical ecology: a primer on methods and computing. New York: John Wiley, 1988.337p.

MAGNUSSON, W. E.; LIMA, O. P. de; REIS, F. Q.; HIGUCHI, N.; RAMOS, J. F. Logging activity and tree regeneration in a Amazonian forest. Forest Ecology and Management, v.113, p.67-74, 1999.

MAGURRAN, A. Ecological diversity and its measurement. New Jersey: Princeton University Press, 1988. 179p.

MANOKARAN, N.; KOCHUMMEN, K. M. Recruitment, growth and mortality of tree species in a lowland dipterocarp forest in Peninsular Malaysia. Journal of Tropical Ecology, v.3, p.315-330, 1987. 
MCINTOSH, R. P. An index of diversity and the relation of certain concepts to diversity. Ecology, v.48, p.392-404, 1967.

NEGREROS-CASTILLO, P.; MIZE, C. Effects of partial overstory removal on the natural regeneration of tropical forest in Quintana Roo, México. Forest Ecology and Management, v.58, p.259-272, 1993.

NICHOLSON, D. I.; HENRY, N.B.; RUDDER, J. Stand changes in north Queensland rainforest. Proceedings of the Ecological Society of Australia, v.15, p.61-80, 1988.

OFUSU-ASIEDU. El intercambio de experiencias y situación del conocimiento sobre la ordenación forestal sostenible de los bosques tropicales húmidos In: WORLD FORESTRY CONGRESS, 11; Antalya, TO, 1997. Proceedings. CD-ROM, vol 6, p.247267.

OKALI, D.U.U.; OLA-ADAMS, B.A. Tree population changes in treated rain forest at Omo Forest Reserve, south-western Nigeria. Journal of Tropical Ecology, v.3, p.291-313, 1987.

OLIVEIRA, L. C. de. Dinâmica de crescimento e regeneração natural de uma floresta secundária no Estado do Pará. Belém, 1995. 136p. Dissertação (Mestrado). Universidade Federal do Pará.

PARIONA, W.; FREDERICKSEN, T.; LICONA, J. C. Comparación de tres tratamientos para el mejoramiento de rodales en dos tipos de bosque bolivianos. Bolivia: Proyecto BOLFOR, 2001. 16p. (Documento Técnico, 102).

PIELOU, E.C. Ecological diversity. New York: John Wiley, 1975. 165p.

PINARD, M. A.; PUTZ, F. E. Retaining forest biomass by reducing logging damage. Biotropica, v.28, p.278-295, 1996.

PITT, J. Relatório ao governo do Brasil sobre aplicação de métodos silviculturais a algumas florestas da Amazônia. Belém: SUDAM, 1969. p.151-153.

PLUMPTRE, A. J. Changes following 60 years of selective timber harvesting in the Budongo Forest Reserve, Uganda. Forest Ecology and Management, v.89, p.101-113, 1996.

QUIROS, D.; FINEGAN, B. Manejo sustentable de um bosque natural tropical em Costa Rica: definición de um plan operacional y resultados de su aplicación. Turrialba, Costa Rica: Centro Agronómico Tropical de Investigación y Enseñanza. Programa Manejo Integrado de Recursos Naturales, 1994. 26p. (Serie técnica. Informe técnico, 225). 
SALATI, E.; SANTOS, A. A.; LOVEJOY, T. E.; KLABIN, I. Porque salvar a Amazônia. Manaus: INPA, 1998. 114p.

SANDEL, M. P.; CARVALHO, J. O. P. de. Anelagem de árvores como tratamento silvicultural em florestas naturais da Amazônia Brasileira. Revista de Ciências Agrárias, n.33, p.9-32, 2000.

SCHMIDT, R.C. Tropical rain forest management: a status report. Unasylva. v.39, n.2, p.2$17,1987$.

SILVA, E. J. V. Dinâmica de florestas manejadas e sob exploração convencional na Amazônia oriental. São Carlos, 2004. 148p. Tese (Doutorado) - Escola de Engenharia de São Carlos, Universidade de São Paulo.

SILVA, J.N.M. The behaviour of the tropical rain forest of the Brazilian Amazon after logging. Oxford, 1989. 302p.Thesis (Ph.D.) - University of Oxford.

SILVA, J.N.M., LOPES, J. do C.A. Inventario florestal continuo em florestas tropicais: a metodologia utilizada pela EMBRAPA-CPATU na Amazônia brasileira. Belém: EMBRAPA-CPATU, 1984. 36p. (Documento, 33).

SILVA, J.N.M., ARAÚJO, S.M. Equação de volume para árvores de menor diâmetro na Floresta Nacional do Tapajós. Boletim de Pesquisa Florestal v.8/9, p.16-25, 1984.

SILVA, J.N.M., UHL, C. A atividade madeireira como uma alternativa viável para a utilização sustentada dos recursos florestais na Amazônia brasileira. In: SEMINÁRIO INTERNACIONAL SOBRE MEIO AMBIENTE, POBREZA E DESENVOLVIMENTO DA AMAZÔNIA, 1, Belém, 1992. Anais. Belém: PRODEPA, 1992. p.257-262.

SILVA, J.N.M; CARVALHO, J. O. P. de; LOPES, J. do C. A. Inventário florestal de uma área experimental na Floresta Nacional do Tapajós. Boletim de Pesquisa Florestal v.10/11, p.38-110, 1985.

SILVA, J.N.M.; CARVALHO, J.O.P. de; LOPES, J. do C.A.; CARVALHO, M.S.P. de. Equação de volume para a Floresta Nacional do Tapajós. Boletim de Pesquisa Florestal, v.8/9, p.50-63, 1984.

SILVA, J.N.M.; CARVALHO, J. O. P. de; LOPES, J. do C. A.; ALMEIDA, B. F. de; COSTA, D. H. M.; OLIVEIRA, L. C. de; VANCLAY, J. K; SKOVSGAARD, J. P. Growth and yield of a tropical rain forest of the Brazilian Amazon 13 years after logging. Forest Ecology and Management v.71, p.267-274, 1995.

SILVA, R.P. da; SANTOS, J. dos; TRIBUZY, E.S.; CHAMBERS, J.Q.; NAKAMURA, S.; HIGUCHI, N. Diameter increment and growth patterns for individual tree growing in Central Amazon, Brazil. Forest Ecology and Management, v.166, p.295-301, 2002. 
SILVA, S.M.A. da; SILVA, J.N.M.; BAIMA, A.M.V.; LOBATO, N.M.; THOMPSON, I.S.; COSTA-FILHO, P.P. Impacto da exploração madeireira em floresta de terra firme no Município de Moju, Estado do Pará. In: SILVA, J.N.M.; CARVALHO, J.O.P. de; YARED, J.A.G. A silvicultura na Amazônia Oriental: contribuições do projeto Embrapa/DFID. Belém: Embrapa Amazônia Oriental/DFID, 2001. p.309-323.

SIST, P.; ABDURACHMAN. Liberation thinnings in logged-over forests. In: BERTAULT, J.G.; KADIR, K. (Ed.). Silvicultural research in a lowland mixed dipterocap forest of East kalimantan: the contribution of STREK project. Montpellier: CIRAD-foret. 1998, cap.9, p.171-180.

SIST, P.; NGUYEN-THÉ. Logging damage and the subsequent dynamics of a dipterocarp forest in East Kalimantan (1990-1996). Forest Ecology and Management, v.165, p.85$103,2002$.

SMERALDI, R.; VERÍSSIMO, A. Acertando o alvo: consumo de madeira no mercado interno brasileiro e promoção da certificação florestal. São Paulo: Amigos da terra/IMAZON/IMAFLORA, 1999. 42p.

STONE, S. Growth of timber industry in eastern Amazon: economic trends and implication for policy. New York, 1997. 232p. Thesis (Ph.D.) - Cornell University.

SWAINE, M.D.; LIEBERMAN, D.; PUTZ, F.E. The dynamics of tree population in tropical forest: a review. Journal of Tropical Ecology, n.3, p.359-366, 1987.

UHL, C. Tree dynamics in a species rich tierra firme forest in Amazonia Venezuelana. Acta Cientifica Venezolana, v.33, p.72-77, 1982.

UHL. C., VIEIRA, I.C.G. Ecological impacts of selective logging in the Brazilian Amazon: a case study from the Paragominas region of the State of Para. Biotropica, v.21, n.2, p.98-106, 1989.

VEILLON, J. P. El crescimiento de algunos bosques naturales de Venezuela en relacion con parametros del meio ambiente. Revista Forestal Venezolana, v.29, p.1-22, 1985.

VELOSO H.P.; RANGEL FILHO, A.L.R.; LIMA, J.C.A. Classificação da vegetação brasileira a um sistema universal. Rio de Janeiro: Fundação Instituto Brasileiro de Geografia e Estatística - IBGE, 1991.123p.

VERÍSSIMO, A.; LIMA, E.; LENTINI, M. Pólos madeireiros do Estado do Pará. Belém: Imazon, 2002. 72p.

VERÍSSIMO, A.; BARRETO, P.; MATTOS, M.; TARIFA, R.; UHL, C. Logging and prospects for sustainable forest management in an old Amazonian frontier: the case of Paragominas. Forest Ecology and Management, n.55, p.169-199, 1992. 
VERÍSSIMO, A.; UHL, C.; MATTOS, M.; BRANDINO, Z.; VIEIRA, I. Impactos sociais, econômicos e ecológicos da exploração seletiva de madeira numa região de fronteira na Amazônia Oriental: o caso de Tailândia. In. BARROS, A.C.; VERÍSSIMO, A. (Ed.). A expansão da atividade madeireira na Amazônia: impactos e perspectivas para o desenvolvimento do setor florestal na Pará. Belém: IMAZON, 1996. p.8-44.

VIDAL, E.; BARRETO, P.; JOHNS, J.; GERWING, J.; UHL, C. Vine management for reduced-impacts logging in Eastern Amazon. Forest Ecology and Management, v.98, p.105-114, 1997.

VIEIRA, G.; HOSOKAWA, R. T. Composição florística da vegetação da regeneração natural 1 ano após diferentes níveis de exploração de uma floresta tropical úmida. Acta Amazônica, v.19, p.401-413, 1989.

WAGNER, U. Efectos del manejo mederero sobre la florística y la estructura de bosques húmedos de Costa Rica. In: SIMPOSIO INTERNACIONAL "POSIBILIDADES DE MANEJO FORESTAL SOSTENIBLE EN AMÉRICA TROPICAL”. Santa Cruz de la Sierra, 1997. Anais. Bolívia: Proyecto de Manejo Forestal Sostenible (BOLFOR), 1997. p.1-8.

WEIDELT, H.J. Sustainable management of dipterocarp forests: opportunities and constraints. In: SCHULTE, A.; SCHONE, D. (Ed.). Dipterocarp forest ecosystems: towards sustainable management. Singapore: World Scientific, 1996. p.249-273.

WHITMORE, T. C. Tropical rain forest of the far east. 2.ed. Oxford-England: Oxford Clarendon Press, 1984, 352p.

WHITTAKER, R. H. Dominance and diversity land plant communities. Numerical relations of sciences express the importance of competition in community function and evolution. Science, v.147, p.250-260, 1965.

WYATT-SMITH, J. Manual of malayan silviculture for inland forests, 2 ed.. Kuala Lumpur, Malaysia: Forest Research Institute Malaysia, 1995. 35p. (Malayan Forest Record, 23)

YARED, J.A.G. A atividade florestal na Amazônia: diagnostico e perspectivas: Palestra// SEMINÁRIO FUTURO ECONÔMICO DA AMAZÔNIA, Belém: s. ed.,1990.

ZANETTI, E.A. Comparision of different silvicultural treatments in subtropical lowland forests in east Paraguai - Case study in Golondrina Forests, 2002. de $<$ http://www.google. com.br/servicos/teses $>$. 